Universidad Nacional de La Plata

Facultad de Ciencias Naturales y Museo

\title{
LA CRIANZA EN DISPUTA: \\ MEDICALIZACIÓN DEL CUIDADO INFANTIL EN LA \\ ARGENTINA, ENTRE 1890 Y 1930
}

Autora: Mgtr. María Adelaida Colangelo

Directora: Dra. Liliana E. Tamagno. 
A Diego

A mispadres 


\section{AGRADECIMIENTOS}

Muchos -¡demasiados!- años pasaron desde el comienzo de esta tesis, a lo largo de los cuales investigación, vida cotidiana, trabajo, afectos, viajes, encuentros, se fueron entrelazando inextricablemente, como suele suceder cuando, a pesar de las múltiples dificultades, seguimos apasionados por la profesión que elegimos. A lo largo de todo este tiempo y especialmente durante la solitaria etapa de la escritura final, fueron muchas las personas que aportaron conocimientos, bibliografía, ayuda técnica pero, por sobre todo, el ánimo necesario para poder llegar a este momento. Para ellas van, entonces, mis sinceros y desordenados agradecimientos...

A mi directora de tesis, Liliana Tamagno.

A los médicos pediatras con quienes he dialogado en diferentes espacios académicos y científicos, agradezco la apertura brindada para el intercambio de ideas y el haberme aportado una nueva mirada sobre su profesión. Muy especialmente al Doctor Marcos Cusminky, in memoriam, por la generosidad y el optimismo con que alentó mis primeras investigaciones vinculadas a la crianza infantil y su entusiasmo inagotable a la hora de reflexionar críticamente sobre la medicina y sus vínculos con las ciencias humanas y sociales.

A las madres, conocidas o anónimas, que han compartido conmigo las experiencias de crianza de sus hijos, por provocarme nuevas preguntas y ayudarme a ver la complejidad de un proceso tan poco "natural".

A mis compañeros de la Cátedra de Antropología Social II de la Facultad de Trabajo Social, por el aliento en esta última etapa del doctorado y el placer del trabajo docente compartido.

A mis compañeros de Equipo Técnico de la Secretaría de Niñez, por el apoyo incondicional a mis proyectos académicos y, sobre todo, por el maravilloso sentido del humor con el que, sabiamente, acompañan la tarea cotidiana.

A Andrea Szulc, con quien he compartido tantos diálogos sobre la antropología y la niñez, por la generosidad con que apuesta a la conformación de espacios de investigación sanos y respetuosos, pero también por la linda amistad que hemos construido a partir del trabajo conjunto.

A Viviana Maggio, por ayudarme a ver que terminar esta tesis era posible. 
A mis amigas queridas, de aquí y de allá: Olga, Bibi, Adriana, Mariana, Euge Li, Michele, Mónica, Adri Villalón, por todo lo compartido a lo largo de este tiempo y la amistad indestructible. Especialmente, en este momento de la escritura, a los aportes invalorables de Bibi, con su pericia en la traducción al inglés, y de Olga, por su paciente ayuda en el ordenamiento de mis listas bibliográficas.

A Darinca, por su cálida compañía durante tantas horas frente a la computadora y la alegría compartida ante los primeros rayos del sol invernal entrando en mi escritorio.

A mis padres, como siempre, por el afecto inconmovible y los mil modos en que contribuyeron a la concreción de esta tesis.

A Diego, por la complicidad y el cariño cotidianos, y por la felicidad de construir proyectos juntos. 


\section{ÍNDICE}

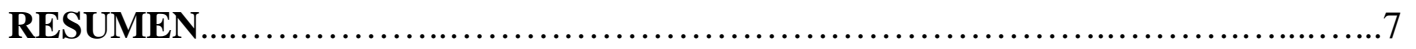

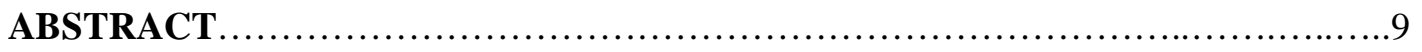

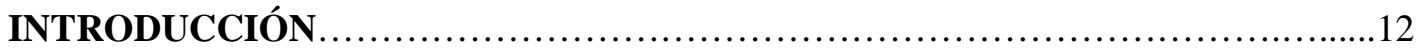

1. Pasado y presente en las prácticas de crianza: interrogantes y recorridos de la investigación............................................................ 12

2. Consideraciones metodológicas: desafíos y posibilidades del trabajo antropológico en archivos......................................... 18

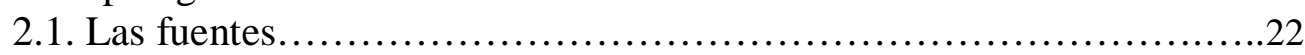

2.2. El trabajo con las fuentes......................................25

3. Itinerarios conceptuales y estructura de la tesis............................28

\section{CAPÍTULO 1- PEDIATRÍA Y PUERICULTURA: CONSTITUCIÓN DE}

UNA “MEDICINA DEL NIÑO". .36

1. 1. El cuidado del "capital humano de la nación": salud infantil y cuestión social.

1. 2. La pediatría: el proceso de construcción de una especialidad profesional.......45

1.2.1. El estudio de "un sujeto completamente nuevo".....................49

1.2.2. La institucionalización de la pediatría.............................54

1.3. La puericultura o la "ciencia de criar niños"..............................59

1.4. Los médicos de niños: modos y espacios de ejercicio profesional.............65

1.4.1. La construcción de un perfil profesional..........................65

1.4.2. Los espacios de ejercicio profesional...............................70

CAPÍTULO 2- MALEABILIDAD Y EVOLUCIÓN: LA NIÑEZ CONSTRUIDA POR

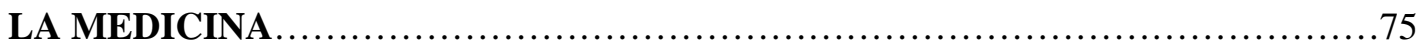

2. 1. Crecimiento y desarrollo: la especificidad de la niñez como etapa de la vida..................................................78

2.1.1 - Los patrones de crecimiento como expresión de la salud individual y colectiva............................................ 85

2. 2. Las etapas de la infancia............................................93

2.2.1. La primera infancia como objeto de estudio............................96 
2.2.2. El recién nacido y el lactante: las características del niño de primera

infancia.

2. 3. La definición de una "naturaleza" infantil.

CAPÍTULO 3- EL “ARTE DE CRIAR NIÑOS”: LA PEDAGOGÍA MÉDICA DE LA

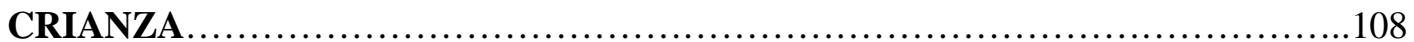

3.1. El discurso médico sobre la crianza: la "cruzada de la razón contra la ignorancia" ........................................................... 112

3.2. La pedagogía médica de la crianza....................................118

3.2.1. Seguimiento, consejos, visitas: el papel de las instituciones

especializadas en la primera infancia.................................122

3.2.2. Los consejos escritos: cartilla, manuales y revistas de divulgación...128

3.3. Condición femenina y maternidad en el discurso médico sobre la crianza......136

3.3.1. La instrucción de la "joven madre"................................141

3.3.2. Preparando a la "madre del futuro". ...............................146

3. 4. Un método para criar............................................... 150

3.4.1. Racionalidad, regularidad, equilibrio: principios médicos

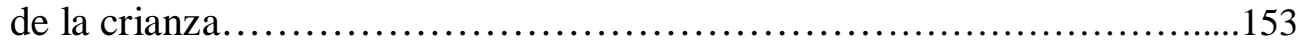

3.4.2. Cuidado infantil y categorías morales...........................159

3.5. Salud y vigor: las finalidades de una crianza higiénica.....................161

3.6. Los resultados de la medicalización: transformaciones y resistencias..........165

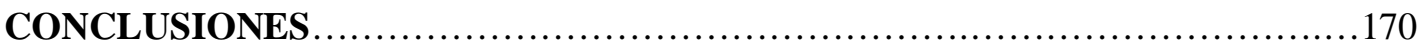

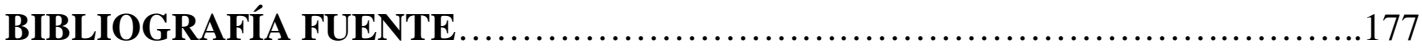

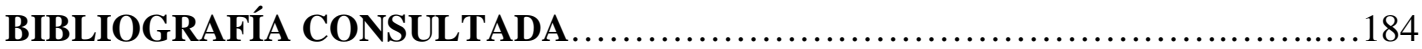

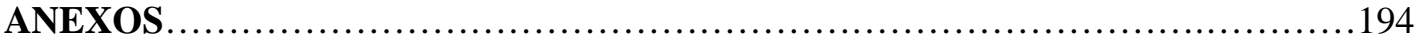




\section{RESUMEN}

En esta tesis se analiza el proceso de medicalización de la crianza infantil en la Argentina, en el periodo histórico que se extiende entre 1890 y 1930. A través de la exploración antropológica de un conjunto de fuentes documentales (textos escritos por médicos de la época, tanto destinadas a un publico especializado como a la divulgación entre un público lego) se procura comprender y mostrar el modo en que el cuidado y formación cotidianos de los niños, sobre todo durante la llamada "primera infancia", se tornaron en nuestro país incumbencia de la ciencia médica. Esto ha implicado considerar las disputas -aún inacabadas- con otras ideas y prácticas existentes sobre la crianza y la niñez, que dicho proceso conllevó.

Se comienza estudiando la constitución de una especialidad médica centrada en el niño: la pediatría y, vinculada a ella, la puericultura. Este proceso de especialización profesional se produjo a través de la puesta en práctica de estrategias de legitimación, tanto al interior del campo médico como hacia el exterior del mismo, mediante su relación con el Estado y disputas con los saberes populares, religiosos y familiares sobre la crianza infantil. Asimismo, implicó la construcción de un principio de clasificación que distinguió entre los cuerpos y las enfermedades de los adultos y los de los niños, dando lugar simultáneamente a la definición de un objeto específico de intervención y a la constitución de un grupo de profesionales especializados en su abordaje.

En un segundo momento, se indaga en la construcción particular que de la niñez realiza la pediatría. Pudo verse que en la búsqueda de peculiaridades que permitieran distinguir la niñez de otras etapas de la vida la pediatría y la puericultura hicieron de las nociones de crecimiento y de desarrollo las bases de su teoría y su práctica. Consideradas como las funciones esenciales de la vida de un niño, como el modo en que se manifiesta la "naturaleza infantil", esas nociones implicaron una visión de la infancia como estado transicional, incompleto y maleable. Constituyeron, asimismo, la base de una subdivisión de la infancia en sub-etapas, concentrándose las preocupaciones de la medicina en una de ellas, la llamada "primera infancia”, que se extiende aproximadamente durantes los dos primeros años de vida, encarnada por la figura del bebé. 
Luego, se explora el proyecto pedagógico de la puericultura mediante el cual la medicina pretende imponer determinadas prácticas de crianza, consideradas racionales y científicas. Las estrategias educativas puestas en juego por los médicos de la época estudiada fueron múltiples y tuvieron como destinatarias a mujeres madres pertenecientes a diferentes sectores sociales. Fueron presentadas por pediatras e higienistas en términos de un método científicamente fundado, a partir del cual se definieron minuciosamente el orden y la duración de todas las operaciones de cuidado del niño. La enunciación de estas reglas de la "buena crianza" estuvo atravesada por categorías morales y valores asociados a la maternidad.

Finalmente, a modo de balance, se exponen las posibles transformaciones y/o resistencias que las prescripciones médicas pueden haber provocado en la población en el periodo histórico estudiado. Se destaca que dichos procesos, lejos de manifestarse de manera monolítica, unidireccional o definitiva, fueron intrínsecamente conflictivos, diversos, atravesados por negociaciones, resignificaciones, tensiones, entre actores situados en posiciones asimétricas.

A partir del desarrollo realizado, se concluye en la necesidad de pensar la crianza como una arena de disputas -más que como un conjunto de prácticas y representaciones único y estable- y a la medicalización como un proceso complejo, tenso e inacabado. Asimismo, se pone de manifiesto el modo en que la preocupación por la crianza ilumina las actuales relaciones entre adultos y niños y da cuenta el lugar de éste en las sociedades occidentales. 


\begin{abstract}
This doctoral thesis deals with medicalization of the child rearing in Argentina, from 1890 to 1930 . By means of an anthropological research of a set of documental sources (textbooks written by physicians of that time -those aimed at an especialized audience as well as those to the general audience) seeking to understand and show how daily children care and education, especially during the "early childhood" in our country became a concern of medical science. This has led to consider the disputes -still under debate- with other ideas and practices on child rearing and childhood.

The investigation begins studying the constitution of a medical specialty focused on the child, the pediatrics and one of its links, the childcare. It was found that the process of professional expertise occurred through the implementation of legitimacy strategies, both within and out of the medical field, through the relationship with the State and the disputes with popular, religious and familiar knowledge about child rearing. It also involved the construction of a principle of classification to distinguish between bodies and diseases of adults and those of children, while leading to the definition of a specific intervention object and the establishment of a group of specialized professionals to its approach.

In the second place, it was analyzed the singular construction of the childhood by pediatrics, mainly focused on the concepts of "growth" and "development". It was observed that, to distinguish childhood from other life stages, growth and development constituted the fundamental notions on which the theory and practice in pediatrics and childcare were founded. These terms -understood as the essentials functions of the child's life, as the way in which "childhood nature" is expressed-, implied a vision on childhood as a transitional, incomplete and malleable state. Likewise, they constituted the basis for the childhood stages, being medicine concerning in the so-called "early childhood", during the first two years of life, embodied by the baby.

The study also explores the pedagogical project of childcare, by which medicine tried to impose certain childcare practices regarded as rational and scientific. In this regard, there were multiple instructional strategies brought into play
\end{abstract}


by the doctors of the time, aimed at women / mothers from different social sectors. They were introduced by pediatricians and hygienists in terms of a scientifically founded method, from which the order and duration of the child care activities were carefully defined. The enunciation of these rules of "good child rearing" was linked to moral categories and values associated with motherhood. Finally, this research inquires about possible changes and/or resistances that medical prescriptions may have caused to the population. It is noted that these processes, rather than monolithic, unidirectional or definitive, are variable and conflicting and are traversed by negotiations, re-significations, and tensions between actors located in asymmetrical positions. It is concluded that it is necessary to think about child rearing as an arena of dispute -rather than as a set of unique and constant practices and representations-; and medicalization as a complex, tense and unfinished process. 
“As representações da criança poderiam constituir um excelente teste projetivo do sistema de valores e de aspirações de uma sociedade. Elas caracterizam tanto aqueles que as expressam, e sobretudo aqueles que as criam, quanto aqueles que são designados.” (Marie-José Chombart de Lauwe, Um outro mundo: a infância). 


\title{
INTRODUCCIÓN
}

\section{Pasado y presente en las prácticas de crianza: interrogantes y recorridos de la investigación.}

\begin{abstract}
"[Cuando tengo dudas sobre la crianza consulto] al pediatra. Sobre el nene: al pediatra. ;A nadie, a nadie! Todos opinan, pero yo: al pediatra. No, no, viste, opinar: todos, al principio te vuelven loca. Porque cuando es bebé, todos: 'no, que tiene esto, que tiene lo otro', 'que tiene lo otro'. No, yo por eso desde que nació dije: no, sólo al pediatra. Escucho todo [...] a la abuela, a mi mamá, ¿no? Escucho a todos, pero... al pediatra, la última opinión sobre el gordo, es la del médico. [...]. Peor el primer año, viste, que es dificil. Los primeros meses. "(Mariela, 26 años, profesional, con un hijo de un año).
\end{abstract}

"El control mensual [con el pediatra] es importante para saber cómo va creciendo, como un parámetro para ver si soy buena madre, qué sé yo... si la estoy cuidando bien, si la alimento bien. [...] Es como que necesito el apoyo, que me diga: 'bueno, está todo bien"'. (Valeria, 26 años, estudiante universitaria, con una hija de 9 meses).

Relatos como el de Mariela o Valeria, con su carga de angustia e incertidumbre, fueron sucediéndose a lo largo de una investigación sobre pautas de crianza realizada en la ciudad de La Plata entre 1994 y 1996, comenzando a instalar algunos de los interrogantes que motivaron este trabajo de tesis.

A lo largo de esos dos años entrevisté a sesenta mujeres madres de hijos menores de cuatro años, pertenecientes a diferentes sectores socioculturales de la ciudad y sus alrededores. ${ }^{1}$ Las preguntas que suscitaron los testimonios más extensos

\footnotetext{
${ }^{1}$ Se trabajó en cuatro grupos: 1) mujeres de una comunidad toba asentada en las afueras de la ciudad; 2) migrantes bolivianas, en su mayoría quechuaparlantes, instaladas en la zona urbana o en las quintas de la zona rural del Gran La Plata, 3) sectores de clase media, en su mayoría, profesionales o estudiantes universitarias; 4) pobladores de una villa miseria, sin una adscripción étnica reconocida. Se realizaron entrevistas semi-estructuradas a quince integrantes de cada grupo. Recupero aquí los
} 
y más movilizaron emocionalmente a las entrevistadas fueron las que indagaban en las fuentes de información y aprendizaje sobre la crianza infantil, las personas que participaban en la crianza de sus hijos y a las que se recurría en caso de necesitar ayuda a lo largo de ese proceso. Al hablar de crianza, se incluían tanto los aspectos ligados al cuidado corporal cotidiano del niño, como los aspectos emocionales y la enseñanza de comportamientos esperados para la edad.

En la comparación de los testimonios de madres de clase media con los de madres de sectores populares, dos cuestiones me llamaron la atención: los relatos de la preocupación, inseguridad y cierta soledad cargada de responsabilidad, vivida por las primeras durante los primeros meses de vida de sus hijos, sobre todo si eran primerizas, y el lugar que ocupaba el médico pediatra en estas circunstancias, como consejero y garante de que la crianza se estaba llevando a cabo correctamente. Estos aspectos, por el contrario, no solían estar tan presentes en los relatos de las madres de sectores populares, quienes vinculaban al médico más bien con el diagnóstico y tratamiento de enfermedades y a las instituciones de salud con la prevención mediante la inmunización, aun cuando afirmaran que "hay que llevar a los chicos al control".

Las mujeres de sectores populares, en general, aun cuando fueran muy jóvenes, referían el aprendizaje de la crianza a una experiencia que había comenzado desde niñas, en el cuidado cotidiano de hermanos o sobrinos, o aun en su trabajo como empleadas domésticas en casas donde había niños. Por el contrario, la mayoría de las madres de clase media se habían enfrentado por primera vez con el cuidado de un bebé en el momento de tener su primer hijo. La proximidad generacional con sus hermanos generalmente no había permitido participar en su crianza y la residencia restringida a la pareja conyugal excluía la posibilidad de tomar parte en la atención cotidiana de los sobrinos. Además, la crianza de los hijos era vista como un ámbito de incumbencia exclusivo de la pareja parental y, si bien aparecía el acompañamiento de la madre o la suegra, la responsabilidad por el bienestar del niño era atribuida sólo a los padres y, más especialmente, a la madre. Era aquí donde la figura del pediatra aparecía como voz autorizada, en su carácter de "experto en niños", tanto para enseñar algunas de las operaciones rutinarias que requería la atención del recién

datos de los dos últimos grupos; la consideración de la variable étnica dio lugar a otros estudios. (Colangelo, 1996). 
nacido $^{2}$, como para establecer si el niño crecía bien y transmitir pautas de comportamiento.

Una mirada más profunda, al avanzar la investigación, permitió una lectura menos lineal, poniendo de manifiesto que, si bien el pediatra era reconocido como el especialista en niños, al que se atribuía "la última palabra" en materia de crianza, dado su conocimiento validado científicamente, a medida que el niño iba creciendo y, sobre todo, a partir del segundo hijo, las madres de clases media también incorporaban otros saberes, transmitidos por madres, suegras, hermanas o amigas, y legitimados por la experiencia. Esos otros conocimientos sobre el niño y la crianza coexistían con el saber médico, aunque desde un lugar subordinado, y las madres no eran pasivas ni acríticas en la construcción de un saber propio sobre el cuidado infantil. Pero, si bien algunas de ellas seleccionaban y combinaban conocimientos teóricos y prácticos de diferentes fuentes, produciendo una síntesis particular basada en su propia experiencia de maternidad, estas construcciones no contradecían los principios establecidos por la medicina -más bien, eran reelaboraciones, adaptaciones de ellos- y, ante situaciones críticas, se recurría sin dudar al médico para que orientara sobre los pasos a seguir o dirimiera entre diferentes alternativas.

Así, las narraciones de las mujeres entrevistadas me mostraron que, más allá de la variedad de fuentes de aprendizaje sobre la crianza consideradas, por lo menos para los sectores medios urbanos la crianza de un niño durante sus primeros años parece constituir algo demasiado complejo como para permanecer únicamente en la esfera de los cuidados familiares, pasando a requerir de la guía y supervisión de especialistas. Son los médicos pediatras quienes ocupan ese lugar de expertos, aunque sin haber desplazado totalmente a otros saberes, populares y familiares, que fundan su legitimidad en la experiencia.

El trabajo de análisis y extrañamiento sobre esa perspectiva, naturalizada en los grupos sociales a los cuales también pertenezco, fue suscitándome una serie de interrogantes que dieron lugar a la presente investigación: ¿en qué momento y de qué manera la crianza de un niño se ha vuelto algo demasiado riesgoso como para estar a cargo de las madres y las familias (por lo menos para ciertos sectores sociales) y ha

\footnotetext{
${ }^{2}$ Por ejemplo, una de las entrevistadas relataba emocionada que fue el pediatra quien fue a su casa a enseñarle a bañar a su bebé.
} 
pasado a requerir el acompañamiento y el control de profesionales especializados? ¿Qué procesos hicieron posible que las mujeres percibieran que cuidar y educar a un niño durante sus primeros años sea algo tan complejo y trascendente que no puede quedar sólo en sus manos y las de los adultos próximos? ¿Qué representaciones sobre la niñez sostienen la necesidad de que su cuidado sea guiado por profesionales especializados? ¿De qué manera la medicina construyó y legitimó su lugar de saber experto acerca de la crianza infantil? ¿En qué medida esto resultó de la disputa, aún inacabada, con otras ideas y prácticas sobre la crianza y la niñez? ¿Qué relaciones estableció con esos otros saberes -religiosos, tradicionales, familiares- existentes sobre la crianza infantil?

A partir de esas preguntas, decidí abordar como tema de investigación el proceso de medicalización de la crianza en Argentina, es decir, el modo en que el cuidado y formación cotidianos de los niños, sobre todo durante la llamada "primera infancia" (entre el nacimiento y los dos años), se tornaron en nuestro país incumbencia de la ciencia médica. Dar cuenta de ello requirió analizar y comprender cuándo y cómo se construyó, tanto al interior del campo científico como de la sociedad en general, la creencia en la legitimidad de la medicina para intervenir sobre numerosas conductas privadas referentes a la atención y educación cotidianas de los niños pequeños, reforzándose no sólo sobre la enfermedad, sino también sobre la salud. Esto implicó considerar las disputas -aún inacabadas- con otras ideas y prácticas existentes sobre la crianza y la niñez, que dicho proceso conllevó.

A su vez, esta indagación hizo necesario problematizar la niñez o la infancia ${ }^{3}$ como una categoría socialmente construida, explorando el modo en que, al menos en parte, ha sido producida, definida, caracterizada por una disciplina científica -la medicina- y, al mismo tiempo, ha constituido la base para la constitución y desarrollo de una especialidad médica - la pediatría.

\footnotetext{
3 Tal como lo plantea Giberti (1997), las categorías "infancia" y "niñez" no resultan totalmente equivalentes, tal como se desprende de su etimología: mientras el sentido de la primera se adhiere a orígenes o fundamentos de algo que está aun inacabado (el infans el es que aun no habla), la segunda remitiría a un estadio histórico dentro del desarrollo de los humanos, sin caracterizarla por la ausencia de características o capacidades. Si bien, por estas connotaciones prefiero el uso de "niñez", en este trabajo también aparece con frecuencia "infancia", dado que el término es utilizado como equivalente en gran parte de la bibliografía consultada (sobre todo aquella en lengua portuguesa, donde no existe un equivalente de "niñez") y además está presente en el discurso nativo.
} 
Los objetivos así propuestos me llevaron a historizar la cuestión y rastrear la medicalización del cuidado infantil en prácticas y representaciones del pasado. Para ello, decidí centrar la investigación en el periodo que se extendió entre 1890 y 1930, momento histórico en que la niñez se habría constituido y consolidado como un campo de conocimientos e intervenciones específicas, así como también de articulaciones y disputas entre diferentes disciplinas científicas, entre las cuales se encuentra la medicina. En efecto, hacia fines del siglo XIX, en nuestro país, ciertos aspectos o sectores de la niñez comienzan a ser conceptualizados en términos de "problemas sociales" que, bajo la forma de la mortalidad, pero también del abandono o la delincuencia infantiles, adquieren el carácter de problemas públicos. En torno al modo de definirla, de clasificarla y de proponer acciones sobre ella irán desplegándose, a lo largo de las primeras décadas del siglo $\mathrm{XX}$, tanto discursos científicos como políticas públicas, que ya aparecen consolidados en la década de 1930. También la medicina va estableciendo y consolidando su lugar hegemónico en el abordaje de la enfermedad, pero también de la salud y de los diferentes aspectos de la vida, en un contexto en que establece nuevas relaciones con el Estado y la sociedad en general. De esta manera, si bien la delimitación del periodo histórico a explorar no escapa a la arbitrariedad de todo recorte temporal artificial, busca anclar su referencia en procesos sociales de la época.

Al respecto, cabe aclarar que el proceso que comienza hacia 1890 no podría haberse dado sin los antecedentes de cambios en las costumbres vinculadas a la higiene y al cuidado infantil iniciados en épocas previas, tal como señalan Di Liscia (2005) y Cowen (2000). ${ }^{4}$ Sin embargo, si bien la crianza de los niños ya desde el siglo XVIII constituye en Europa el objeto de numerosas obras filosóficas, pedagógicas, médicas, entre las que se destaca el Emilio de Rousseau, es más tarde cuando la formación de niños sanos se torna eje de políticas públicas y de saberes especializados, vinculados a la preocupación por la gestión de la población, proceso que en América comienza a fines del siglo XIX.

Tampoco el periodo histórico seleccionado puede ser considerado homogéneo en sus procesos. Autoras como Nari (1996; 2004) y Di Liscia (op.cit.), entre otros, encuentran diferencias entre las características del proceso de

\footnotetext{
${ }^{4}$ Según esos autores, los periódicos, como el Semanario de Agricultura, Industria y Comercio, y los manuales de uso hogareño fueron los primeros recursos que los médicos utilizaron desde comienzos del siglo XIX para divulgar principios higiénicos entre las familias.
} 
medicalización en general y de las políticas de maternidad del periodo previo a la Primera Guerra Mundial y aquellas que se configuran a comienzos de la década de 1920. En líneas generales, en el primer momento (1890 -1920), comienza a ser desplegado desde el Estado un conjunto de discursos y prácticas higiénicas en relación con la maternidad y la crianza, en relación con un problema definido en términos de la alta mortalidad infantil. En el segundo momento, las mencionadas autoras identifican una preocupación poblacional centrada en el descenso de la tasa de natalidad, un avance de la institucionalización estatal en la atención de la salud materna e infantil y una progresiva profesionalización de los recursos humanos a ella vinculados, sobre todo los femeninos (visitadoras de higiene y parteras).

Dado el recorte temporal propuesto, la indagación cuyos avances aquí se presentan se basa en la exploración antropológica de un conjunto de fuentes bibliográficas y documentales, especialmente textos escritos por médicos en la Argentina entre 1890 y 1930. Dichas fuentes, como se verá más adelante, incluyen tanto obras eruditas, destinadas a un público especializado, como obras de divulgación, orientadas a un público lego con la finalidad de vulgarizar los principios científicos de la crianza infantil.

No obstante, si esta investigación tiene su foco en un período histórico pasado, ancla sus interrogantes en el presente, dado que ha sido a partir de una serie de aspectos vinculados a la crianza contemporánea, a su percepción desde las mujeres madres, que se fue delineando la necesidad de indagar en representaciones y prácticas de otras épocas (Colangelo, 2009). En este sentido, se espera que el análisis que aquí se presenta contribuya a entender la singularidad de los procesos sociales de construcción de un modo de ver y llevar a cabo la crianza de los niños que ha pasado a ser considerado - por lo menos desde los saberes hegemónicos- como obvio y universal para, de esta manera, aportar a su desnaturalización. 


\section{Consideraciones metodológicas: desafíos y posibilidades del trabajo antropológico en archivos.}

"Since, quite literally, we can't go back, where is 'the field'?" (Das Chene, "Locating the past", 1997).

En los comienzos de este trabajo, la delimitación de un objeto de estudio situado en gran parte en el pasado y su necesario abordaje mediante el análisis de documentos escritos, me suscitaron una serie de dudas acerca del tipo de investigación que me encontraba realizando. ¿Qué había de antropológico en este tipo de trabajo? ¿No se trataría de un trabajo de historiador? En todo caso, ¿seguía siendo antropóloga cuando, en lugar de alegrarme por el logro de una buena entrevista o por el contacto con un informante clave, me emocionaba ante el hallazgo de alguna ficha amarillenta oculta entre otras, en el fichero de un archivo o cuando veía aparecer al empleado de una biblioteca con una pila de libros polvorientos y desarmados?

A partir de esos interrogantes, se hizo necesario reflexionar acerca de las particularidades del quehacer antropológico cuando éste está orientado a analizar las prácticas y representaciones de un grupo social en el pasado a través de material de archivo. Más específicamente, ello llevó a evaluar las posibilidades de considerar un momento histórico pasado en término de mi campo, es decir, como un espacio social apropiado para realizar etnografía.

En efecto, el lugar que la definición del campo y el trabajo de campo han ocupado en la constitución de la antropología como disciplina (Stocking, 1983; 1991), así como la impronta y a la vez los límites que esos cánones clásicos han significado en la definición de nuevos objetos y abordajes etnográficos (Gupta y Ferguson, 1997; Passaro, 1997), generan dudas acerca del carácter antropológico de un trabajo realizado en archivos ${ }^{5}$. La combinación de un espacio geográfico delimitado y distante con la experiencia de una relación cara a cara con el "otro" a

\footnotetext{
${ }^{5}$ El trabajo de campo, tal como lo plantea metafóricamente Stocking (1991), puede ser considerado el ritual central de la "tribu antropológica" y el tema de una considerable elaboración mítica, que tiene en Malinowski su "héroe civilizador". A partir de la publicación de Los Argonautas del Pacífico Occidental (Malinowski, 1922), la imagen del investigador solitario viviendo durante un tiempo prolongado en una pequeña comunidad aislada, distante geográfica y culturalmente de su propia sociedad, se cristalizó en el sentido común profesional y de alguna manera aún permanece como cualidad distintiva del trabajo antropológico, más allá de transformaciones acontecidas en los objetos de estudio y en los abordajes teóricos.
} 
través de la observación participante, que el estereotipo de trabajo de campo de ese canon clásico presupone, se torna una limitación a la hora de pensar un estudio antropológico situado en otro momento histórico. ${ }^{6}$ Los estudios antropológicos que investigan el pasado vuelven problemático el encuentro localizado y cara a cara con el otro, y cuando el objeto no se sitúa en un lugar geográfico delimitado sino en un período de tiempo al que no es posible regresar físicamente, uno no puede dejar de preguntarse, como lo hace Das Chene (1997): “where is the field"?

Sin embargo, partiendo de que la distancia y la otredad no son datos situados geográficamente ni definidos a priori y abstractamente, sino teóricamente construidos en el proceso de producción de conocimiento, es posible pensar en el archivo como el modo de construcción y de acceso a un campo particular, en el que el encuentro con los "nativos" -en este caso, médicos de fines del XIX y comienzos del XX en Argentina- se realiza a través de los textos por ellos producidos considerados "documentos"- y está atravesado por las relaciones con otros "nativos" -archivistas, bibliotecarios- que facilitan o restringen su acceso. Así, como una caja dentro de otra caja, vinculadas por el valor otorgado a la palabra escrita y a su conservación en nuestra sociedad ${ }^{7}$, el tema pudo ser abordado antropológicamente a través de un trabajo de campo, aunque éste se apartara del modelo clásico.

Los archivos pueden ser considerados artefactos culturales de nuestra sociedad que abarcan el pasado y el presente (Cohn, 1980). A efectos de la investigación, sin embargo, es necesario distinguir entre el análisis antropológico de los archivos como fenómenos culturales y el trabajo de campo en archivos. Esta última opción es el caso del presente estudio.

El trabajo de campo se centró en los archivos de dos grandes bibliotecas públicas con acervos generales: Biblioteca Nacional y Biblioteca Pública de la Universidad Nacional de La Plata, y de dos bibliotecas especializadas en obras de

\footnotetext{
${ }^{6}$ Gupta y Ferguson (1997) analizan tres supuestos que resultan de esa construcción clásica del campo y que terminaron limitando la construcción de conocimiento antropológico: 1) una radical separación entre "field" y "home" y la consiguiente creación de una jerarquía de pureza de lugares de campo que valoriza como más puros a los más distantes, 2) la valorización de ciertos tipos de conocimiento y de temas con la consiguiente exclusión de otros, 3) la construcción de de un sujeto antropológico normativo, un "self" antropológico en contraste con el cual el antropólogo sitúa al "Otro".

${ }^{7} \mathrm{Al}$ respecto, resulta pertinente la observación de los Comaroffs en cuanto a que el etnógrafo no puede contentarse con los cánones establecidos de evidencia documental, porque estos también son parte de la cultura del modernismo global. "Moreover, - afirman- we have to operate with a working theory not merely of the social world, but also of the role of inscriptions of various kinds in the making of ideology and argument." (Comaroff y Comaroff, citado en Das Chene 1997, p.77).
} 
medicina: Biblioteca de la Academia de Medicina y Biblioteca de la Sociedad Argentina de Pediatría. El trabajo comenzó en las primeras, con una búsqueda general, y continuó con la consulta de material específico ya seleccionado, en las segundas.

La Biblioteca Nacional y la Biblioteca Pública de la Universidad Nacional de La Plata comparten lógicas similares de acceso al material documental, en las que se combinan un criterio cronológico, que restringe la consulta de algunos textos anteriores a 1920 o 1930 respectivamente, y los criterios de autor, tema y tipo de publicación, a partir de los cuales se ordenan los ficheros. En la intersección de estos diferentes criterios yo debía encontrar las obras sobre crianza infantil escritas por mis "nativos" médicos, para tratar de entender de qué manera estaban pensando la crianza, interviniendo en ella y construyendo la noción de infancia en el período 1890-1930. Pero ello implicaba aprender también acerca de cómo dirigirme y presentarme ante los bibliotecarios, esas personas que, según sus características personales y profesionales, ejercían más o menos discrecionalmente su enorme poder de darme acceso y extraer de ese todo abstracto y misterioso llamado acervo, los textos de mis informantes clave.

Pronto descubrí que la lógica implícita en el fichero hacía que obras de un mismo tema aparecieran en ordenamientos diferentes. Así, por un lado, a partir de algunos nombres de médicos pediatras e higienistas que ya conocía, organicé una búsqueda por autor que me mostró que estos actores sociales habían escrito en medios diversos (libros, revistas científicas, revistas de divulgación, periódicos), obteniendo un primer indicio del carácter multifacético de su producción y del lugar que como intelectuales y no sólo como profesionales de la medicina, ocuparon en la época. Por otro lado, fui descubriendo que las obras médicas sobre crianza infantil aparecían en el fichero temático tanto bajo rótulos específicos como "puericultura", "higiene" o "pediatría", dentro del sector de "medicina", como bajo otros más genéricos del tipo "infancia", "niño" o "educación", lo cual, si bien significaba una complicación práctica, permitía vislumbrar el lugar ocupado por la infancia como nudo de discursos diversos y objeto disputado por distintas disciplinas.

Una vez localizada la obra, los datos de la fecha de publicación determinaban el camino a seguir. Las obras posteriores a 1920 o 1930 -según la biblioteca- debían pedirse en la sala general, atestada de estudiantes, donde empleados siempre ocupados y acostumbrados a que se les pidieran las últimas ediciones de tratados de 
medicina, miraban con cierta condescendencia mi solicitud y, con sospechosa frecuencia, decían que la obra en cuestión no había podido ser localizada. “iPero esos textos que me pedís son muy viejos! Mirá que sobre ese tema tenemos otros mucho más nuevos, eh." - solían comentar. La necesidad de encontrar textos antiguos para hacer una investigación histórica era el argumento que los tranquilizaba y parecía convencerlos de la seriedad de mis propósitos. Esas obras eran consideradas "libros" o "revistas" y, como tales, podían ser fotocopiadas.

Las obras anteriores a 1930 o 1920 entraban en la categoría de "documentos", a los que su antigüedad otorgaba cierto carácter sagrado y preservaba del contacto más directo. Para encontrarme con ellos, debía ingresar en la "Sala de publicaciones raras" de la Biblioteca Pública de la UNLP o en la "Sala de investigadores" de la Biblioteca Nacional. Fue posible entrar a trabajar en esos ámbitos luego de cumplir ciertos trámites formales que probaron el carácter científico de las actividades a desarrollar. En este ámbito, la importancia de la investigación parecía ser directamente proporcional a la antigüedad de los textos. Ambas salas especiales compartían cierto aire de sacralidad, del que participábamos los pocos que en ellas hojeábamos, en respetuoso silencio, nuestros libros y periódicos antiguos. Los empleados, graves y serios, con una formación especializada, parecían más familiarizados con el material, por el que mostraban un cariño especial.

En las bibliotecas especializadas en medicina, la búsqueda fue más restringida t puntual, ya que el trabajo se centró en colecciones de determinadas publicaciones periódicas previamente seleccionadas. Allí también, sin embargo, el tipo de material consultado generaba extrañeza por su antigüedad. Tenía la sensación de que era la primera persona en varios años en consultar los enormes tomos polvorientos que agrupaban los números de La Semana Médica o de los Archivos Latinoamericanos de Pediatría, tomos que los empleados traían de los estantes más altos o más escondidos. Si bien afirmar que se trataba de una investigación histórica satisfacía la curiosidad de mis interlocutores, nunca logré que dejaran de llamarme "doctora", en el supuesto de que todos los usuarios de esas bibliotecas debían ser médicos.

Esta primera etapa de trabajo no sólo comenzó a mostrarme la diversidad de situaciones y "territorios" que implica el trabajo en archivo, sino la centralidad que en cada uno de ellos adquieren los valores asociados a la antigüedad de los textos: lo viejo como material científico desactualizado o como documento del pasado; lo 
nuevo como la novedad del descubrimiento científico o como lo efímero, que carece del aura de aquello que sobrevivió al paso del tiempo.

\subsection{Las fuentes.}

El relevamiento de fuentes dio como resultado un conjunto de obras amplio y heterogéneo. Escritas por médicos pediatras y/o higienistas (salvo unas pocas, cuyos autores son pedagogos o profesores de higiene en escuelas públicas), iban desde tesis presentadas a la Facultad de Medicina de Buenos Aires, hasta transcripciones de conferencias para todo público dadas en parroquias barriales; desde revistas científicas especializadas, como los Archivos Latinoamericanos de Pediatría, hasta publicaciones periódicas destinadas puramente a la divulgación, como Madre y Niño. Corresponden en gran parte al período de desarrollo de la literatura médica en nuestro país que, según Recalde (1997), se habría iniciado en el último tercio del siglo XIX y habría sido paralelo a la organización de los estudios de medicina y a los avances de la corporación médica ${ }^{8}$.

Si bien la búsqueda se centró en autores que desarrollaron su producción científica en nuestro país, consideré necesario relevar también las obras de varios autores extranjeros que constituyeron la principal influencia de los médicos de Buenos Aires ${ }^{9} \mathrm{y}$, en sus versiones traducidas al castellano, fueron los primeros manuales de crianza consultados por las madres o los libros de estudio de los futuros médicos. Un seguimiento a lo largo del tiempo de los textos extranjeros que llegaban a nuestro país permite percibir cuáles eran las corrientes y escuelas de medicina que orientaban la higiene y la pediatría nacionales. Así, si hasta fines de la década del 20 hay un predominio casi absoluto de autores franceses y alemanes, a comienzos de los años 30 ya encontramos la referencia a textos de médicos norteamericanos.

\footnotetext{
8“El desarrollo de la literatura médica se inició en el último tercio del siglo pasado y fue paralelo a la organización de los estudios y a los avances de esa corporación. Estuvo vinculado también a la actividad de la 'Generación científica del '80', que se tradujo en el cultivo sistemático de las ciencias exactas y naturales y la creación de instituciones especializadas y de la prensa científica." (Recalde, 1997: 63).

${ }^{9}$ El caso más claro es el de la obra del médico francés Pinard, a partir de la cual se habría difundido el término "puericultura" entre los higienistas argentinos. En 1909 su manual de puericultura fue traducido al castellano y se constituyó en un modelo para manuales posteriormente escritos por médicos argentinos (Pinard, 1909).
} 
Asimismo, cabe aclarar que, aunque se propuso un estudio con alcance nacional, la mayor parte de las fuentes encontradas fueron editadas en la ciudad de Buenos Aires y consisten en obras de médicos que desarrollaron su carrera en esa ciudad. En menor medida, aparecen obras de profesionales que ejercieron en ciudades como La Plata, Rosario, Santa Fé o Córdoba. El haber trabajado con los acervos de bibliotecas situadas en Buenos Aires y en La Plata posiblemente contribuyó a este sesgo en la procedencia de las fuentes.

Para cada obra se consignaron, además del título, autor y los datos de edición, datos sobre el formato y tipo de publicación, así como posibles menciones al público al que se la dirigía y objetivos a los que se la destinaba. A partir de estos elementos, el conjunto diverso de textos sobre crianza infantil fue organizado en dos grandes grupos: obras eruditas, destinadas a un público médico, y obras de divulgación, orientadas al público en general. Respecto del primer grupo de obras, no se prestó interés a los textos específicamente clínicos, de semiología, etc., sino a aquellos que permitieran una aproximación a las discusiones sobre la pediatría como especialidad y los temas de crianza y crecimiento del niño sano. El ordenamiento construido se expresa en el cuadro siguiente y se encuentra detallado en la Bibliografía Fuente.

I- Obras eruditas. Destinadas al medio académico y a un público especializado. Escritas por los médicos para presentar posiciones y discutir con sus pares o con otros profesionales vinculados al campo de la niñez. Entre ellas encontramos:

a) Revistas científicas y artículos publicados en revistas científicas, entre ellas: La Semana Médica (surgida en 1894); Archivos Latino Americanos de Pediatría (1905-1929); Revista de Derecho, Historia y Letras (editada entre 1899 y 1923); Revista de Instrucción Primaria.

b) Actas y trabajos presentados en congresos. Especial atención merecen las presentaciones realizadas en el Primer Congreso Nacional del Niño, en Buenos Aires en octubre de 1913.

c) Tesis presentadas en la Facultad de Medicina de Buenos Aires (hasta 1921 las tesis constituyeron un requisito para la conclusión 
de la carrera de medicina y la obtención del título de médico). Se considera especialmente el conjunto de tesis organizadas y publicadas en la denominada "Colección Candioti de Medicina", entre 1870 y 1920.

d) Libros y folletos científicos.

II- Obras de divulgación. Destinadas a un público lego. Escritas por médicos (en algunos pocos casos, por pedagogos o profesores de higiene) con la finalidad de vulgarizar los principios de la puericultura y transmitirlos a las madres, a las nodrizas o a las niñas en edad escolar. Entre ellas encontramos:

a) Manuales, con formato de libro. Tienen el objetivo de proporcionar a las madres una guía práctica e integral para la correcta crianza de sus hijos, desde el embarazo hasta los dos o tres primeros años de vida. Muchos fueron escritos por destacados médicos de la época, como es el caso de Gregorio Aráoz Alfaro y de Luis Agote, autores de dos de los primeros manuales de puericultura publicados en el país: El libro de las madres (1899) y La salud de mi hijo (1901), respectivamente.

b) Cartillas, folletos, textos de conferencias. En su mayoría fueron editados por organismos públicos, ya fueran oficiales (Municipalidad de la Ciudad de Buenos Aires, Instituto Nacional de la Nutrición, Facultad de Ciencias Médicas de la Universidad Nacional de La Plata) o asociaciones no estatales (Instituto Popular de Conferencias o las universidades populares vinculadas al Partido Socialista: Universidad Popular de la Boca, Sociedad Luz). También se encuentran algunas cartillas editadas por firmas comerciales de productos para la alimentación del niño, como, por ejemplo, la Fosfatina Falières.

c) Revistas. Puede mencionarse Madre y niño. Revista de higiene y de educación de la primera infancia, publicada en Buenos Aires entre 1905 y 1907.

d) Textos escolares. Siguen los programas de materias de higiene y puericultura de escuelas primarias de niñas, de colegios nacionales 
de escuelas normales. Los primeros aparecen hacia 1910. Están dirigidos principalmente a las niñas en su calidad de futuras madres y educadoras. Los temas tratados coinciden en líneas generales con los presentados en los manuales para madres.

\subsection{El trabajo con las fuentes.}

Ahora bien, con aproximadamente un centenar de documentos relevados y sistematizados, se me presentaron nuevas cuestiones a considerar: ¿cómo trabajar con esos textos relevados? ¿Cómo dialogar con mis informantes de fines del siglo XIX y comienzos del XX, para poder reconstruir su universo de significados y prácticas con respecto a la crianza y la niñez? ¿Qué estatus podía atribuir a sus discursos volcados por escrito?

Son innegables las diferencias entre construir conocimiento antropológico a partir de diálogos con los "otros" y hacerlo a partir de textos que éstos, en el pasado, volcaron voluntariamente por escrito para hacerse públicos, como sucede en esta investigación. En este caso, es como si el antropólogo escuchara una conversación entre actores posicionados y comprometidos, a los cuales no puede pedir, mediante preguntas, que llenen los silencios o lagunas en la información. Sin embargo, como señala Vianna (2002), en tanto se busque en los documentos escritos analizados no una verdad que los trascienda, sino sus posibles verdades como producciones sociales, el proceso es semejante al de cualquier etnografía. En ese sentido, los documentos escritos constituyen narrativas socialmente producidas en la misma medida en que lo son los testimonios directos que el etnógrafo recoge en el campo. Tanto el análisis de documentos como cualquier otro proceso de construcción de etnografías, exige estar atento a las condiciones de producción de las narrativas con las cuales se está trabajando. Y esto no se debe a que los documentos escritos sean discursos más socialmente fabricados que los verbales, sino que es condición del trabajo con cualquier tipo de narrativas socialmente producidas.

A los fines de situar los lugares desde los cuales los médicos producían, debatían y buscaban legitimar sus ideas sobre la crianza, durante el trabajo de archivo se relevaron no sólo las distintas obras publicadas por cada uno de ellos, sino también datos biográficos, académicos y de los distintos cargos públicos que fueron 
ocupando -información que solía aparecer en la portada, la introducción o el prólogo de los trabajos. Esto permitió ir situando a estos agentes en el espacio social, mostrando, como se verá más adelante, que obtenían la legitimidad para pretender imponer su discurso sobre la crianza infantil, de la participación simultánea en ámbitos académicos y de gestión estatal, y dando cuenta de la red de relaciones tejidas entre ellos, que se ponía de manifiesto en las citas mutuas y en la escritura de prólogos para los libros de los colegas afines. En realidad, fue en este proceso de construcción de conocimiento comenzado con las fichas y notas de campo, que los médicos de fines del siglo XIX y comienzos del XX se tornaron mis "nativos"

Una de las dificultades que se me presentaron en este trabajo con fuentes escritas fue la limitación para acceder a la dimensión de las prácticas de los diferentes actores involucrados en el proceso de medicalización de la crianza infantil. O, mejor dicho, para acceder a prácticas que no fueran exclusivamente de carácter discursivo.

En el caso de los médicos, la escritura de textos para prescribir o simplemente divulgar los principios científicos de la crianza infantil, puede ser considerada una práctica pedagógica sobre la maternidad y el cuidado infantil, aunque no la única llevada a cabo en la época estudiada. La escritura y publicación de tesis, de artículos en revistas científicas, la presentación de informes o de trabajos en congresos, por otro lado, constituyeron elementos centrales de sus prácticas académicas, institucionales y profesionales en general.

El conocimiento de las prácticas de crianza efectuadas por las madres y familias de la época resultó más complicado, pues debió realizarse indirectamente a partir de la exploración de los textos médicos. Al respecto, sobre todo en el análisis de los manuales, cartillas y conferencias destinados a la divulgación, fue necesario no perder de vista su carácter de discursos prescriptivos o propositivos que, más que caracterizar modos concretos de criar a los niños, enunciaban un deber ser, un conjunto de reglas o principios que se pretendía establecer. En efecto, el trabajo con este tipo de material entraña el riesgo de tomar reglas, indicaciones y normas como las prácticas reales, como la propia vida social; riesgo que, en este caso, implicaría dejar afuera la gran variedad de acciones, experiencias concretas que las familias pondrían en juego en la crianza de sus niños, así como también la complejidad de las negociaciones, sanciones, estrategias de persuasión, puestas en práctica por los 
propios médicos en su búsqueda de implantar prácticas higiénicas de cuidado infantil. En otros términos y tal como lo muestra Vianna (2002), entre las reglas explícitas y la acción efectiva de individuos o grupos hay una enorme gama de posibilidades de negociación, apropiación, y discordancia. Las prácticas de cuidado pueden ser consideradas como experiencias que combinan esas posibilidades y no como aplicaciones de las reglas prescritas.

Sin embargo, las fuentes analizadas permitieron un acceso indirecto a algunos comportamientos maternos a través de las críticas y quejas enunciadas por los médicos acerca de prácticas como el recurso a los curanderos, la falta o irregularidad de la asistencia a los consultorios o dispensarios médicos y el uso "interesado" de esas instituciones atribuido a algunas madres que llevarían allí a sus hijos para obtener la leche o alimentos preparados que allí se les entregaba - quejas y críticas que, por otra parte, siguen siendo formuladas actualmente por los médicos del sistema público de salud, mostrando que la disputa por establecer un modo de llevar a cabo la crianza de un niño aún no ha concluido.

Por otro lado, el análisis de situaciones y prácticas contemporáneas también ha contribuido a comprender las distancias que también en el pasado habrían existido entre las prescripciones de la medicina y los comportamientos reales de madres y otros familiares, los niños y los propios médicos, con respecto a la crianza. En ese sentido, observaciones actuales realizadas en el "Consultorio de niño sano" del Servicio de Pediatría de un hospital público me han permitido observar la variedad de evaluaciones e indicaciones, así como de las formas de realizarlas que existen entre los diferentes pediatras de un mismo servicio y, más aún, que un mismo médico pone en práctica según las diferentes familias con las que interactúa y las circunstancias específicas en que se lleva a cabo la consulta. ${ }^{10}$ En la misma dirección, el estudio de Serre (1997) sobre las actuales prácticas de intervención con familias, llevadas a cabo por los trabajadores de centros de atención de la salud infantil en Francia, también muestra que sus clasificaciones, percepciones y acciones no pueden resumirse a criterios teóricos y abstractos, sino que resultan más bien de un sentido práctico, en el sentido que da Bourdieu (1991) a este concepto. Elementos presentes en los profesionales, como la posición en la estructura jerárquica de la institución, la

\footnotetext{
${ }^{10}$ Estas observaciones fueron realizadas durantes tres meses del año 2003 en el Servicio de Pediatría del Hospital Alejandro Korn de la localidad de Melchor Romero, en las afueras de la ciudad de La Plata.
} 
posición social, más o menos cercana a la de los usuarios de los servicios de salud, la solidaridad femenina, la empatía con ciertas madres, la propia trayectoria familiar y social, relativizan o median la imposición simbólica de reglas y pautas preestablecidas.

Llegados a este punto, podemos advertir que la investigación antropológica de prácticas y representaciones producidas en el pasado implica un desafío a las concepciones clásicas del campo, referidas con frecuencia a un espacio físico delimitado y a la observación participante como una experiencia particular que implica una relación directa con los "otros". Sin embargo, el trabajo en archivo muestra que la propia concepción del campo puede ser ampliada para incluir un período de tiempo o eventos diferentes en lugares diversos, pues la relación que construye a los "otros" como tales no depende de distancias geográficas, sino de procesos epistemológicos.

En esos procesos, que implican un esfuerzo constante de extrañamiento y desnaturalización de representaciones y de prácticas sociales, el uso de la historia constituye una estrategia importante. Desde esta perspectiva, el trabajo en archivo iría más allá de intentar oír y reproducir literalmente las versiones del mundo que ofrecen las voces del pasado; por el contrario, podría ser una herramienta central para provocar rupturas epistemológicas en la comprensión de procesos sociales del presente, como lo son las construcciones de la niñez y la crianza.

\section{Itinerarios conceptuales y estructura de la tesis ${ }^{11}$}

El tema abordado en esta tesis se sitúa en la confluencia de discusiones provenientes -sobre todo, pero no exclusivamente- de la antropología y de la historia, tanto vinculadas a la construcción social de la niñez como al lugar que, con relación a ella, ha ocupado el saber médico. Por ello, a lo largo del recorrido realizado, la construcción y análisis de los datos fue nutriéndose del diálogo con estudios y debates provenientes de diferentes autores y disciplinas.

\footnotetext{
${ }^{11}$ He preferido que los aportes conceptuales aparezcan puestos en juego con mayor profundidad en el desarrollo de los temas de los diferentes capítulos, por lo que el lector sólo encontrará en este apartado consideraciones generales que le permitan enmarcar y comprender el sentido con que ha sido organizado el recorrido del análisis.
} 
Un aporte central lo constituyeron las indagaciones y debates sobre la infancia que, a partir de la década de 1990, se consolidan como un campo de estudios en las ciencias sociales argentinas, acompañando desarrollos teóricos a nivel internacional. Dos sistematizaciones recientes, elaboradas por Llobet (2011) y Carli (2011) respectivamente, brindan un completo panorama de estos estudios, a los que coinciden en caracterizar por su carácter multidisciplinar y por su diálogo con las políticas públicas orientadas a la niñez. ${ }^{12}$

Considerando más específicamente la antropología argentina y latinoamericana, el estado de la cuestión presentado por Szulc y Cohn (2012) también muestra un campo de investigación relativamente reciente, en proceso de consolidación y crecimiento desde la década de 1990. De los numerosos estudios que lo integran, he tomado, por un lado, los aportes de los trabajos más directamente vinculados con los modos de gobierno, moralización y normalización de la niñez y las familias, así como las vinculaciones de niños y familias de sectores populares con políticas públicas e instituciones en diferentes contextos (Vianna, 2002; Fonseca y Schuch, 2009; Lugones 2009; Villalta, 2010; Santillán, 2011). Por otro lado, ha sido importante la contribución de varias investigaciones etnográficas sobre la niñez y la crianza en sociedades indígenas (Nunes, 1999; Cohn, 2002; Lopes da Silva, Macedo e Nunes, 2002; Hecht, 2004; Szulc, 2007; Remorini, 2009; Enriz, 2011) que, si bien parecen estar más alejadas del tema de esta tesis, han constituido una poderosa herramienta de desnaturalización del discurso médico sobre la crianza al describir y analizar otros modos de construir y experimentar las primeras etapas de la vida, así como otras prácticas de cuidado y educación infantil. Fuera del contexto latinoamericano, destaco los aportes de Gottlieb (2000) y de los trabajos reunidos en la compilación de Bonnet y Pourchez (2010), en tanto se centran en la construcción y los cuidados de la primera infancia, etapa que raramente constituye el eje de los trabajos antropológicos sobre la niñez. Destaco que, más allá de críticas posteriores, los trabajos de Margaret Mead (1962, 1990, 1993) constituyen una referencia

\footnotetext{
${ }^{12}$ Llobet (2011) sistematiza los estudios sobre infancia en las ciencias sociales argentinas a partir de tres grandes líneas o perspectivas de análisis: 1) de inspiración culturalista y "psi", orientada a las formas de producción de la infancia y las rupturas con las modalidades de esta construcción propias de la modernidad; 2) de tradición foucaultiana, orientada a analizar los procesos de control social y gubernamentalidad de la niñez; 3) los estudios de políticas sociales. Carli (2011) prefiere ordenar (provisoriamente) la producción sobre infancia en Argentina, siguiendo los abordajes de diferentes disciplinas: 1) aportes del psicoanálisis, 2) aportes de la sociología, el derecho y el trabajo social, 3) aportes del os estudios literarios, de la comunicación y de la cultura, 4) aportes de la antropología y de la antropología de la educación, 5) aportes del campo de la historia y de la historia de la educación.
} 
indudable para la constitución del campo de la antropología de la niñez, habiendo sido pioneros en considerar a los niños sujetos de las investigaciones etnográficas y vinculando las prácticas de crianza con culturas particulares.

Aunque provenientes de la sociología, han sido centrales en esta investigación los planteos de la línea de investigación constituida en Gran Bretaña en términos de "nueva sociología de la niñez". En ese marco, trabajos como los de Jenks (1996), James, Jenks y Prout (1998) proponen un "nuevo paradigma” para abordar la niñez que resalta su carácter singular, social y culturalmente construido; el atravesamiento de variables étnicas, de clase y de género en las definiciones y experiencias de la niñez, así como el carácter activo de los niños en la vida social y la producción cultural. Esta propuesta teórica y metodológica ha contribuido a realizar una crítica a las teorías de la socialización y del desarrollo que converge con las propuestas contemporáneas de la antropología de la niñez y de perspectivas críticas de la psicología, como la de Rabello de Castro (2001).

Desde una perspectiva sociológica bastante diferente, la investigación de Boltanski (1969) acerca de la relación entre puericultura y moral de clase en la sociedad francesa constituye un estudio clásico que impulsó gran parte de los interrogantes de esta tesis.

En cuanto a las contribuciones de los estudios históricos, no puede dejar de mencionarse la obra de Philippe Ariès (1981) que, más allá de críticas posteriores, constituyó un trabajo pionero en instalar la idea de la infancia como producto de una construcción histórica singular en Occidente. Otros autores como Shorter (1977), Perrot (1989), Gélis (1990) o Donzelot (1990), también fueron referencias ineludibles para una primera historización de las nociones de niñez, de familia y de crianza.

Ya más cercanos al contexto geográfico e histórico abordado en la presente tesis, cabe referir un conjunto de trabajos históricos recientes, que abordan de diferente manera temas como el papel de la medicina higienista en la construcción de niñez y la maternidad, la salud materna e infantil, las políticas públicas destinadas a la niñez o la relación entre Estado, familia e infancia, como son los de Nari (1996, 2004), Guy (1998 a y b), Cowen (2000), Billorou (2007, 2008), Biernat y Ramaciotti (2008) y los reunidos en la compilación de Lionetti y Míguez (2010). A ellos debe sumarse el estudio de Carli (2002) cuyo análisis de los discursos sobre la niñez 
producidos desde la pedagogía en Argentina, ha proporcionado un interesante punto de comparación con la construcción de la infancia desde el saber médico.

Centrados en un análisis antropológico de la medicina y sus procesos de construcción de objetos de estudio y modos de abordaje, los trabajos de Chazan (2000), Bonet (2003) y Rohden (2009) constituyeron aportes significativos para comprender el proceso de constitución de una "medicina del niño" en la Argentina de comienzos del siglo XX. A su vez, a este análisis contribuyó especialmente, desde la historia, el conjunto de estudios sobre la profesionalización de la medicina en nuestro país, realizados por González Leandri (1996, 2000, 2006). Tres trabajos específicos sobre la constitución y características de la pediatría como especialidad médica en Brasil (Rivorêdo, 1998; Castellanos, 2003 y Pereira, 2006), realizados desde diferentes disciplinas de las ciencias sociales, si bien enfocan fenómenos producidos en otra sociedad, han proporcionado valiosos elementos para pensar procesos semejantes en nuestro país.

El planteo del tema de esta investigación en términos de la medicalización de la crianza infantil implicó, a su vez, considerar obras como las de Conrad (1982), Menéndez (1990) o Foucault (1993; 2006) que, desde diferentes perspectivas, permiten situar el saber biomédico en el marco de complejas relaciones de poder en las sociedades modernas. Desde el punto de vista histórico, el análisis de la medicalización se vio enriquecido por los textos de Barrán (1995), aquellos incluidos en la compilación de Lobato (1996), Armus (2005) además de los de Belmartino (2005) y Di Liscia (2005).

A partir de los interrogantes iniciales, en el diálogo entre los datos construidos a partir de las fuentes y los mencionados aportes bibliográficos, se fueron delineando los nudos temáticos de esta tesis, que han dado lugar a sus tres capítulos centrales.

Tal como lo ejemplifican los testimonios contemporáneos con que se abre esta Introducción y también lo señala Rodríguez Ocaña (2003), considero que la mirada médica es uno de los elementos centrales en la definición del cuidado infantil y del estatus de la niñez en la actualidad. La historización de esta relación de la medicina con los niños y sus cuidadores, implica desnaturalizar el modo de entender la niñez o la infancia, para abordarla en términos de una categoría socialmente 
construida, producto de procesos de clasificación, del establecimiento de distinciones con respecto a otros grupos etarios; procesos que, a su vez, sitúan a quienes son en ella incluidos- los niños- en un estatus social particular, de inmadurez y dependencia, con respecto a los adultos.

En ese sentido, cabe reconocer no sólo que la niñez como categoría social específica, percibida y tratada en esos términos, es resultado de procesos históricos relativamente recientes, ligados al advenimiento y desarrollo de la modernidad occidental (Ariès, 1981; Perrot, 1989; Gélis, 1990), sino también el papel clave que en ello han tenido los saberes científicos y, entre ellos, la medicina.13

La definición médica de la infancia puede ser considerada un ejemplo, entre otros, de la demarcación y clasificación de grupos sociales que, con base en las etapas de la vida, pero también en la "raza", el "sexo", o en características socioculturales, las disciplinas científicas modernas establecen en su abordaje del fenómeno humano. En el caso particular de la niñez, este proceso ha dado lugar a la configuración e institucionalización de una especialidad médica: la pediatría y, vinculada a ella, la puericultura. Como podrá verse en el Capítulo 1, este proceso conlleva la construcción de un principio de clasificación que distingue entre los cuerpos y las enfermedades de los adultos y los de los niños, dando lugar simultáneamente a la definición de un objeto específico de intervención y a la constitución de un grupo de profesionales especializados en su abordaje. Si bien el objetivo de esta investigación no ha sido realizar un estudio específico de un grupo profesional, considero necesario comenzar situando socialmente a los médicos pediatras como agentes productores de prácticas y representaciones sobre la niñez y la crianza. A su vez, la constitución de esta "medicina del niño" es abordada como resultado de cambios sociales más amplios en la relación entre niños y adultos y en el marco específico de la "cuestión social” en la Argentina de fines del siglo XIX y comienzos del XX.

Si bien, como lo ha mostrado la antropología (Balandier, 1975; Spencer, 1990; Thorne, 2004), en todas las sociedades hay un procesamiento social del

\footnotetext{
${ }^{13}$ El concepto de "saber" es utilizado aquí a partir de una interpretación libre del modo en que lo plantea Foucault, en términos de un modo de construir conocimiento, que implica formulación de interrogantes, construcción de objetos de estudio, de conceptos, categorías y metodologías de indagación, vinculado a determinadas relaciones de poder y, por ello, participando en un modo de constituir sujetos sociales. Aspectos del saber se formalizan en la conformación de disciplinas científicas y se institucionalizan mediante la constitución de profesiones o especializaciones profesionales.
} 
proceso vital y una construcción de clasificaciones y grupos etarios a partir de sus diferentes momentos, es en las sociedades occidentales modernas donde ese proceso ha sido concebido en términos de una línea evolutiva que sitúa a la etapa de la niñez en un momento de incompletud, comienzo y espera. Estas características y el consiguiente lugar social atribuido al niño, son particularizadas por la medicina argentina del periodo 1890-1930, que retoma elementos presentes en otros saberes y debates de la época, pero abordados desde la preocupación por la salud y la enfermedad, tanto a nivel individual como colectivo. Esta construcción médica de la niñez constituye el eje del Capítulo 2.

A lo largo del mismo intento mostrar que en la búsqueda y establecimiento de peculiaridades que permitan distinguir la niñez de otras etapas de la vida -y de otros objetos de la medicina- la pediatría y la puericultura hacen de las nociones de crecimiento y de desarrollo las bases de su teoría y su práctica. Tal como lo reseña Szulc (2007), el surgimiento del concepto de infancia en la Europa del siglo XVIII dio comienzo a un interés científico por definir su "naturaleza" particular, sus propiedades naturales, una preocupación por revelar qué tipo especial de seres humanos son los niños y qué los hace esencialmente diferentes de los adultos. El crecimiento y el desarrollo constituyen para la medicina del niño la manifestación de esa "naturaleza" infantil, que hace a las características físicas -pero también moralesdel niño, irreductibles a las de otras etapas de la vida y, por lo tanto, necesitadas de un abordaje específico. A partir de estos procesos, se establecen criterios de normalidad y también se construyen periodizaciones de la niñez, que la dividen en varias sub-etapas. Una de ellas, la "primera infancia", recortada entre el nacimiento y los dos años de vida, concentrará las preocupaciones de la pediatría y la puericultura, constituyendo el foco de las disputas sobre la crianza.

El carácter de ser incompleto, pero con capacidad de transformarse progresivamente hacia la adultez, que la medicina y otros saberes modernos atribuyen al niño, lo sitúa en un estatus social específico: como objeto de cuidados, formación educación y asistencia (Jenks, 1996). La crianza se inscribe como parte de estos procesos, enmarcados en teorías de la socialización, mediante los cuales los adultos buscan guiar, modelar, vigilar, cuidar, el crecimiento y el desarrollo infantil. Las definiciones de crianza la vinculan, con distintos énfasis, tanto al cuidado como a la educación (Soto y Violante, 2008; Santillán, 2011) aunque coinciden en situarla como un conjunto de prácticas socialmente establecidas que la generación adulta 
pone en juego para tratar a la generaciones nuevas, generalmente durante sus primero años de vida. Bonnet et Pourchez (2010), a su vez, sistematizando un conjunto de investigaciones en diferentes sociedades, que encuadraron bajo el nombre de "antropología de la primera infancia", prefieren hablar de "cuidado" infantil, definiendo a éste al mismo tiempo como una técnica, un ritual, así como un revelador de la identidad e del estatuto social del niño y de su familia.

Partiendo de estas consideraciones, en el Capítulo 3 abordo los mecanismos mediante los cuales la medicina de fines del siglo XIX y comienzos del siglo XX busca situarse y ser reconocida como saber experto en la crianza infantil, en una disputa con otras ideas y prácticas de cuidado de los niños existentes entonces en Argentina. Este proceso es conceptualizado en términos de "medicalización", entendida en términos generales como el proceso continuo de extensión de las categorías e intervenciones de la medicina -también conceptualizada como biomedicina o medicina hegemónica ${ }^{14}$ - hacia nuevos ámbitos de la vida, los comportamientos y las relaciones sociales (Conrad, 1982; Foucault, 1993; Menéndez, 1990). Corrêa (en Chazan, op. cit.) señala que el término alude, además, a una redefinición de eventos vitales (en este caso, la niñez, pero también el envejecimiento, la reproducción, etc.) en términos médicos.

Para dar cuenta del modo en que el proceso de medicalización de la crianza se lleva a cabo, en dicho capítulo comienzo analizando el proyecto pedagógico que la medicina construye y despliega a través de la puericultura, diferenciando sus estrategias educativas y medios de divulgación de acuerdo a los diferentes sectores sociales a los que se dirige. Considerando que sus destinatarias principales son definidas como la "joven madre" y "la madre del futuro", resulta indispensable abordar el papel de la pediatría y la puericultura en la construcción de una serie de representaciones acerca de la condición femenina, centradas en el nuevo valor social atribuido a la maternidad.

En una segunda parte, considero importante explorar los aspectos de la vida del niño, así como las prácticas de cuidado materno, que se constituyen en objeto de

\footnotetext{
${ }^{14}$ Con medicina, biomedicina o medicina hegemónica se hace referencia a un conjunto de prácticas y teorías acerca de la enfermedad, el padecimiento, el sufrimiento, la muerte, concebidos como procesos biológicos, que a fines del siglo XVIII se configura como un saber legitimado como el único válido por criterios científicos y el Estado. (Menéndez, 1990).
} 
las prescripciones médicas, así como los principios que guían estas indicaciones, prescritas en términos de un "método para criar", atravesado por categorías morales.

El capítulo concluye con una suerte de balance de los alcances logrados por la medicalización de la crianza en el periodo histórico estudiado, en el que se intenta mostrar no sólo las transformaciones que la medicina puede haber generado en los modos de cuidar y formar a los niños, sino también las resistencias y reapropiaciones con respecto a ese saber que madres y familias pueden haber puesto en juego, desde sus conocimientos y prácticas populares, religiosas, familiares. Ello conduce a subrayar la necesidad de pensar la crianza como una arena de disputas -más que como un conjunto de prácticas y representaciones monolítico y estable- y a la medicalización como un proceso complejo, tenso e inacabado, .

Finalmente, en las Conclusiones, recupero los aspectos centrales de cada capítulo, para considerar en términos generales la posibilidad de situar el saber y las prácticas médicas como parte de los modos de gobierno de los niños y las familias, en vinculación con el Estado, pero sin dejar de lado las resistencias, contradicciones, apropiaciones, de los sujetos implicados. Luego, a modo de cierre del recorrido realizado, realizo una breve reflexión acerca del modo en que la preocupación por la crianza ilumina las relaciones entre adultos y niños y el lugar de éste en las sociedades occidentales.

Siendo que, como lo plantea el epígrafe de Chombart de Lawe con que se abre esta tesis, las representaciones nos hablan tanto de quienes las crean y las expresan como de quienes son por ellas construidos, este trabajo se centra, entonces, en una mirada particular sobre la niñez: la de los médicos que se desempeñaron en Argentina a fines del siglo XIX y las primeras décadas del XX. Explorar las nociones de niñez puestas en juego en un determinado momento socio histórico no sólo nos permitirá conocer las características y el lugar que en él tiene la infancia, sino también, a la manera de "un test proyectivo sobre el sistema de valores y aspiraciones de una sociedad", aproximarnos a la comprensión de la colectividad que las produce. 


\title{
CAPÍTULO 1
}

\author{
PEDIATRÍA Y PUERICULTURA: \\ CONSTITUCIÓN DE UNA “MEDICINA DEL NIÑO”
}

\begin{abstract}
"El empirismo más peligroso dominaba, hasta hace poco, en el tratamiento de las enfermedades de los niños. Hace apenas algunos años, las causas de las enfermedades eran ignoradas; el prejuicio ejercía su acción libremente [...].

"[...] el estudio de la Pediatría, apenas conocido hasta hace pocos años, ha tomado un impulso considerable. [...] Es que esta rama de la medicina descansa sobre bases ciertas; se ha substituido al empirismo, las ideas exactas de la ciencia que nunca mejor y con mayores resultados fueron aplicadas; nos enseña a preservar y a corregir los males, y nos enseña que el niño muere generalmente por ignorancia o por error". (Morquio, "La Pediatría moderna en sus relaciones con la vida profesional (Lección de fin de curso)", 1906)
\end{abstract}

"Como em todos os outros níveis de organizaçao da modernidade, também a biomedicina vai aos poucos -e desde muito cedo- tendo que lidar com a reinstauraçao da Diferença. Seus saberes auxiliares ou particulares, a anatomia comparada, a biologia, a antropología física, a psiquiatria, vao fornecendo os argumentos necessários à transposiçao para o mundo da 'corporalidade' de demarcaçoes morais justificatórias de novas hierarquizaçoes dos seres humanos" (Dias Duarte, "Prefácio", en Rohden: Uma ciência da diferença, 2009).

En el año 1813, uno de los debates de la Asamblea General Constituyente tuvo como eje el cuidado de los niños. Según refiere Cowen (2000), médicos y representantes de la iglesia católica se enfrentaron a partir de un tema específico: el momento y el modo de administrar el bautismo. Un informe presentado a los 
asambleístas por el Protomedicato ${ }^{15}$ denunciaba que el bautismo realizado con agua fría e inmediatamente luego del nacimiento provocaba gran cantidad de muertes entre los recién nacidos, por lo que proponía su aplazamiento hasta el octavo o noveno días de vida, así como su realización con agua tibia. Los integrantes de la Asamblea consideraron que la primera medida podía herir la susceptibilidad de los padres y de los párrocos, dado que algunos niños podrían morir antes de ser redimidos del pecado, por lo que sólo recomendaron templar el agua bautismal.

Más allá de su resultado, esta polémica muestra las tempranas disputas e intervenciones de diferentes actores e instituciones acerca de la niñez y de los criterios que debían orientar el modo de tratarla. Aún más, es posible percibir dos concepciones de niño: como portador del pecado original o como víctima inocente de creencias religiosas; concepciones que a su vez conllevan distintas nociones de cuidado: orientado hacia la salvación del alma y la posibilidad de alcanzar la vida eterna, u orientado hacia la salud, la salvación del cuerpo como posibilidad de la vida terrenal. ${ }^{16}$

Un siglo más tarde, la mortalidad infantil se ha tornado un problema social prioritario en la agenda pública y ya no se duda en elegir la salvación de la vida terrenal. La preservación del "capital humano de la nación” y ya no la salvación de las almas es el objetivo que guía las acciones destinadas a la infancia. La crianza de un niño, especialmente durante sus primeros años, se ha vuelto un proceso demasiado trascendente y riesgoso como para permanecer en la esfera de los cuidados familiares y religiosos, pasando a requerir la guía y supervisión de especialistas. Son los médicos quienes pasan a ocupar ese nuevo lugar de expertos lugar en cuya construcción también participan.

Como parte de un intenso proceso de medicalización de la vida en general y de la niñez en particular, enmarcado en la preocupación por la población de la nación, a fines del siglo XIX comienzan a configurarse nuevas especialidades médicas: la pediatría, centrada en el abordaje clínico y el seguimiento del

15 El Protomedicato era una institución surgida en e reino de España como Real Tribunal de Protomedicato, con la función de fiscalizar y controlar el ejercicio de "el arte de curar". Trasladada a las colonias, funcionó en el Río de La Plata desde 1779 hasta 1821, como cuerpo técnico encargado de vigilar y regular el ejercicio de las prácticas curativas (con un papel central en la persecución de los curanderos, por ejemplo), así como de formar a nuevos médicos.

16 "Salud y "salvación" comparten una raíz etimológica común: el término en latín "salvus". "Salud" proviene del latín salus, salutis y éstos a su vez, de salvus: alude a 'salud, buen estado físico', 'salvación, conservación', 'saludo'. "Salvación" deriva del latín salvatio, -onis, que también proviene de salvus. El adjetivo salvus significa 'que está bien de salud', 'sano', 'bien conservado','salvo', ‘intacto', 'bueno', 'entero', ‘vivo'. Corominas (1973); Alonso (1958), Blanquez Fraile (1946). 
crecimiento y desarrollo y, vinculada con ella pero también con la higiene, la puericultura, como "ciencia de aplicación" orientada a la transmisión y divulgación de métodos de crianza "racionales y científicos".

A lo largo de este capítulo pretendo dar cuenta de ese proceso de constitución de un saber médico especializado en la niñez. Intentaré mostrar que en el mismo movimiento en que construyen un particular objeto de conocimiento e intervención la infancia $\mathrm{y}$, más específicamente, la primera infancia- y elaboran prácticas específicas para abordarlo e intervenir en él, ciertos médicos se constituyen como un grupo profesional especializado (Colangelo, 2008).

Este proceso de especialización debe comprenderse en el marco de cambios sociales más amplios en la relación entre adultos y niños (Amstrong, en James, Jenks y Prout, 1998), cambios que implican el reconocimiento de la niñez como una categoría social específica y su construcción como un problema social en el marco de la preocupación por la población del estado recientemente organizado. En este sentido, subrayo que no ha sido posible concebir una especialidad médica para los niños sin que estos fueran reconocidos con un estatuto particular y un lugar social específico, pero que, al mismo tiempo la pediatría y la puericultura habrían contribuido a la configuración de la categoría de niñez o infancia y a los modos de relación niño-adulto considerados como apropiados (Castellanos, 2003) ${ }^{17} \mathrm{Ha}$ sido, entonces, a partir de esa relación mutuamente constitutiva como se habrían estructurado una práctica profesional (pediatría y puericultura) y una categoría social (infancia o niñez).

A su vez, considero importante vincular las prácticas de diferenciación al interior de la ciencia médica y la construcción de un discurso experto especializado en la niñez, con las prácticas de poder implicadas en la política poblacional. Para este abordaje, resulta especialmente inspiradora la sugerencia de L'Estoile, Neiburg y Sigaud (2000), quienes sostienen que los discursos expertos y los debates sobre la política de las poblaciones se despliegan en un espacio que es en parte común,

\footnotetext{
${ }^{17}$ Las fuentes consultadas muestran un uso de ambos términos: "infancia" o "niñez", por parte de los médicos de la época. Si bien "infancia" aparece con más frecuencia cuando se hace referencia a las políticas destinadas a esta categoría etaria: "protección a la infancia" "asistencia a la infancia", vinculadas a la denominación de los organismos públicos que las llevan a cabo (Dirección de Protección a la Infancia, por ejemplo), no hay elementos para plantear una diferencia de significados puesta en juego con respecto a "niñez", que también aparece en textos académicos y de divulgación.
} 
existiendo constantes pasajes y mutuas legitimaciones entre esos discursos expertos y prácticas de poder estatal.

Cabe aclarar que, si bien no es objetivo de esta tesis realizar un trabajo de sociología de un grupo profesional, resulta indispensable situar a los médicos como agentes sociales para analizar la producción de los discursos y prácticas sobre la crianza infantil. Tal como señala Das Chene (1997), ver el trabajo de archivo como una empresa etnográfica no puede limitarse al contenido de los textos, sino que hace necesario anclarlos en el proceso de su producción, en las órbitas de conexión e influencia que les dan vida y fuerza. Es decir, considerar quién habla en esos textos, a quién habla y en qué registro.

\section{1. El cuidado del "capital humano de la nación": salud infantil y cuestión social.}

"El bienestar de las naciones -afirma un médico anónimo argentino al comenzar el siglo XX- se encuentra radicado en los hogares maternales, y tiene su fundamento en la salud de los niños" (Guía maternal, 1900). Los hijos ya no sólo son considerados valiosos para su familia, sino en términos de "capital humano de la nación", un capital a cuidar, desarrollar y administrar.

Este discurso económico de conservación de los hijos resulta de una nueva preocupación por la población, que deja de ser considerada un dato o un elemento dado por la naturaleza, para comenzar a ser construida desde el Estado a través de políticas migratorias, sanitarias y educativas. ${ }^{18}$ En términos de Foucault (2006), el surgimiento del concepto de población estaría vinculado al nuevo arte de gobernar que surge en las sociedades modernas cuando el poder del soberano se extiende más allá del poder exclusivamente territorial, para abarcar y administrar también "la cosas" existentes en su territorio. La población se constituye en objeto de análisis y de gestión, en relación con el cual se desarrollan la demografía y la higiene, dado que no se trata sólo de la cantidad de habitantes que deben poblar el territorio nacional, sino de las características -salud y vigor- que deben reunir para constituir la clase trabajadora.

18 Tal como señala Torrado (2007), "población” es un concepto abstracto del análisis demográfico, construido en base a la estadística. En este sentido, Otero (2007) señala que la estadística occidental del siglo XIX tuvo la función de suministrar una imagen de nación, definiendo el conjunto de características consideradas distintivas de los habitantes de cada Estado nacional. 
Las asociaciones que se establecen entre riqueza, población y salud (González Leandri, 2000) enmarcan el amplio proyecto higienista que forma parte del Estado nacional argentino a partir del último tercio del siglo XIX; proyecto caracterizado por Recalde (1997) en términos de una verdadera "utopía higienista", en tanto amplio programa orientado a logar la "salud biológica y social", abarcando prácticamente todos los aspectos de la vida. ${ }^{19}$ El higienismo constituye así el eje de abordaje de la denominada "cuestión social" de la época, que puede ser definida como la preocupación acerca de la capacidad de mantener la cohesión social ante las consecuencias no deseadas de la modernización capitalista y la inmigración masiva. ${ }^{20}$ Expresadas en la construcción social de un conjunto de problemas asociados a la pobreza urbana (insalubridad, hacinamiento, enfermedades contagiosas, mortalidad infantil), remite a procesos que atraviesan las grandes ciudades de la Argentina de la época, especialmente Buenos Aires y Rosario. Tal como lo plantea Míguez (1999), en el período histórico considerado son muy marcados los contrastes sociales entre la capital y las ciudades del Litoral con respecto al interior del país y las zonas rurales. Aún en las grandes ciudades como Buenos Aires existe una gran diversidad social y étnica que, como veremos más adelante, exige de los pediatras e higienistas la implementación de estrategias pedagógicas y lenguajes diversos sobre la crianza infantil para llegar a las madres y familias de los diferentes sectores.

Entre los problemas vinculados a la cuestión social, la mortalidad infantil ocupa un lugar central. Durante las primeras décadas del siglo $\mathrm{XX}$, se considera que la producción de futuros ciudadanos se ve amenazada no sólo por el progresivo descenso de la natalidad, sino sobre todo por una elevada mortalidad infantil, que afecta principalmente a los lactantes. Desde esa perspectiva y siguiendo el ejemplo europeo, la tasa de mortalidad infantil se transforma en uno de los principales indicadores del "estado material y moral de una nación" (Carreño y Schwarcz, 1927), enmarcada en la preocupación demográfica por el lento crecimiento vegetativo de la

\footnotetext{
19 "Desde mediados de la década de 1870 se fue configurando una utopía higienista: un programa encaminado a lograr 'la salud', biológica y social. Al formular este proyecto los médicos pusieron de manifiesto su vocación de 'arquitectos sociales'. Su aspiración fue que el poder público sancionara legalmente sus prescripciones, encargándose de su ejecución o de la vigilancia de su cumplimiento. Los particulares también debían aceptar la tutela profesional y todos los aspectos de la vida íntima debían quedar sujetos a su regulación." (Recalde, 1997, p.82).

${ }^{20}$ El concepto general de "cuestión social" es tomado de los planteos de Castel (1997). Para la caracterización de la "cuestión social" en Argentina en relación al tema aquí abordado, ver Tenti Fanfani (1990) y González Leandri (2000).
} 
población y unida a una inquietud eugenésica acerca de la calidad de esa poblaciónsu "composición racial, social y moral". ${ }^{21}$

Dada su extrema vulnerabilidad ante la muerte, la primera infancia (periodo que abarca los dos primero años de vida) es recortada como una etapa crucial, cuya salud convoca el saber de la medicina y gran parte de las políticas sanitarias de la época. La mortalidad que afecta a los recién nacido y lactantes es vista desde fines del siglo XIX como una verdadera "sangría" para el Estado, tal como lo expresa un médico higienista en 1888:

"Llamamos todos los días al inmigrante, le ofrecemos la perspectiva de hacer fortuna, le mostramos nuestras riquezas, le deslumbramos con nuestros elementos de trabajo, nos enorgullecemos de que nuestra población aumente, de que nuestras rentas se acumulen y no encontramos un remedio que poner a ese tonel de las Danaidas [la mortalidad infantil] por donde se nos escapa diariamente el capital con crecidos intereses -capital precioso que no estimamos en su valor porque no produce todavía." (Podestá, 1888, p.18).

En 1890, dando cuenta de la preocupación oficial al respecto, el intendente de Buenos Aires, Francisco P. Bollini, nombra una comisión de médicos y demógrafos, encabezada por el higienista Emilio Coni, para determinar las causas de la elevada tasa de mortalidad infantil de la ciudad y sugerir acciones para su disminución. ${ }^{22} \mathrm{~A}$ partir de los resultados del estudio, reunidos en el informe Patronato y Asistencia de la Infancia en la Capital de la República comienzan a idearse una serie de medidas preventivas -en un principio centradas en la capital del país-, que abarcan desde la propuesta de una reglamentación del trabajo de las mujeres en las fábricas y la creación de instituciones de asistencia materno infantil, hasta la divulgación de

\footnotetext{
${ }^{21}$ En Argentina, las propuestas eugenésicas de los estudios científicos positivistas y los proyectos políticos locales, por lo menos hasta entrada la década de 1920, son de carácter preventivo: orientadas a crear una "raza" nueva a partir de la existente y con influencia de las ideas del "transformismo" neolamarckiano, que sostiene la posibilidad de transformación de los individuos y las "razas" a partir de la incorporación de caracteres del medio. Hacia la década del 30 las propuestas eugenésicas se endurecen y vinculan a proyectos políticos de derecha, consolidándose la línea afín a una eugenesia positiva. (Nari, 2004).

${ }_{22}$ El trabajo con las estadísticas en el periodo considerado presenta dificultades, sobre todo para las cantidades y porcentajes a nivel nacional. En la ciudad de Buenos Aires, en 1900 las defunciones de niños menores de un año representan el 54,5\% del total de muertes totales acontecidas y las de niños de 0 a 5 años, el 44,1\%. (Nari, 2004). A nivel nacional, según el trabajo de Otero (op. cit.), la mortalidad infantil es en 1910 de 147,8 niños menores de un año muertos cada mil nacidos vivos. En 1914, esta cifra ha descendido a 116 por mil y en la década de $193^{\circ}$, a 97,3 por mil.
} 
métodos de crianza higiénica mediante conferencias o la edición de guías y cartillas. $^{23}$

Cabe entender esas caracterizaciones, acciones y propuestas como parte del proceso de construcción de un problema social, en los términos más generales analizados por Bourdieu (1995). En efecto, tal como sucede con respecto a otros "problemas sociales" y parafraseando al autor, puede señalarse que la mortalidad infantil como categoría y como problema ha sido producida mediante de un trabajo colectivo de construcción y clasificación de la realidad social que implicó reuniones, peticiones, deliberaciones, organización de comisiones y organismos de asistencia, proyectos, etc., a lo largo del cual la muerte de los niños dejó de ser un problema privado, para pasar a ser un problema público e, incluso, un problema oficial. ${ }^{24}$

En el mismo sentido, Amstrong (1986) analiza el surgimiento de la mortalidad infantil como un problema socio-médico y el desarrollo de sus diferentes formas en Gran Bretaña, durante el siglo XX. Estudiando los registros de defunciones muestra que, si bien recién en 1877 las muertes de niños menores de un año fueron informadas específicamente en términos de "tasa de mortalidad infantil", los datos para hacerlo estaban disponibles desde bastante antes. La creación de una tasa específica de mortalidad infantil evidenciaría, entonces, la aparición de una conciencia social de estas muertes de bebés y, como parte del mismo proceso, la consolidación del reconocimiento social del bebé como una entidad particular.

Volviendo a la Argentina, si bien la mortalidad infantil concentra gran parte de las preocupaciones poblacionales a largo de todo el periodo 1890-1930, a partir de la década de 1920 adquiere relevancia la "denatalidad" o disminución de la tasa de nacimientos, como consecuencia de un más efectivo control de la natalidad por parte de la población. Sin embargo, persiste la insistencia en la necesidad de cuidar a la primera infancia como inversión para el futuro de la nación:

${ }^{23}$ Emilio R. Coni, presidente de la comisión, incluye entre los principales factores de morbi mortalidad infantil, las condiciones de vida y de trabajo de las madres obreras, proponiendo entre otras acciones, la protección indirecta de los niños a través de la protección de las madres pobres y las obreras. (Mazzeo, 1988).

24 "En todos los casos, se descubrirá que el problema aceptado como evidente por el positivismo ordinario [...] ha sido socialmente producido dentro de y mediante un trabajo colectivo de construcción de la realidad social; que fueron necesarios comités, reuniones, asociaciones, ligas de defensa, movimientos, manifestaciones, peticiones, demandas, deliberaciones, votos, tomas de posición, proyectos, programas, resoluciones, etc., para que lo que era y pudo haber seguido siendo un problema privado, particular y singular, se convirtiera en un problema social, un problema público del que se pueda hablar públicamente [...] o, incluso, en un problema oficial, objeto de tomas de posición oficiales, hasta de leyes y decretos." (Bourdieu, 1995, p.179). 
"Para ser un hombre sano y fuerte es necesario haber sido un niño en iguales condiciones, y es la puericultura la que da las reglas para que esto último se realice en la medida que las circunstancias lo permitan. Los estados y las sociedades que más atención han prestado y prestan a la salud de su infancia han podido reintegrarse con creces los esfuerzos de todo orden que en ese sentido han realizado: ese hombre sano y fuerte, que fue ayer el niño solícitamente atendido, devuelve hoy, con pingües intereses, el capital moral y material que exigió su atención al entrar en la vida.

En una nación como la nuestra, de población desproporcionada a su enorme territorio, el cuidado del niño, aparte primordiales razones humanitarias, exige redoblar el esfuerzo para que sean los argentinos de mañana los que pueblen sus llanuras y cultiven sus campos, labrando así su propio bienestar y el de la sociedad y el país que, con clara noción de sus deberes, atendieron su salud y la propia existencia en los albores de ésta.”(Casaubon, en Liceaga, 1930, p.7).

La necesidad de disminuir la mortalidad infantil y las enfermedades que la provocan no es la única preocupación que, en la época analizada, suscita la niñez. Problemas como el abandono, la mendicidad, el trabajo callejero y el delito infantiles van siendo recortados, definidos, explicados, en el marco de una serie de representaciones socialmente construidas sobre las características de la infancia; representaciones mediante las cuales, como veremos en el Capítulo 2, se establece el modo en que los sujetos deben atravesar esta etapa y se definen sus comportamientos y características físicas considerados normales.

Ríos y Talak (1999) identifican dos circuitos en los que tienen lugar las vidas de los niños de Buenos Aires entre 1890 y 1920 y que condensan las representaciones construidas sobre la niñez: el circuito familia-escuela, donde se configura la identidad del niño como hijo y alumno, y el circuito que tiene como centro la calle, alternando con instituciones de encierro, a partir del cual se construye la identidad del niño como “menor". A partir de ellos, la categoría de niñez o infancia se subdivide entre "niños" y "menores", constituyéndose éste última en categoría clasificatoria de la infancia pobre.

Si bien esos otros "problemas" o categorías infantiles no son objeto de la presente tesis, configuran el contexto más amplio de discusiones en los que las teorías e intervenciones médicas sobre los niños tienen lugar y con las cuales dialogan. En efecto, no sólo los médicos se interesan en definir y dar respuesta a las nuevas cuestiones que se construyen en relación a la infancia, especialmente las de sectores populares. A partir de fines del siglo XIX, en el marco de la ampliación de la presencia 
estatal en la asistencia social, una serie de agentes sociales - pedagogos, psicólogos, juristas, pedagogos, filántropos, médicos, entre otros- comienzan a elaborar, compartir y/o disputarse nominaciones, clasificaciones, acciones -de asistencia y protección, de educación, de corrección, entre otras- sobre la infancia y, a través de ella, sobre las familias. De allí que considere necesario situar el discurso y las prácticas de pediatría y la puericultura en un "campo de la infancia" en proceso de formación, en el que participan distintas disciplinas científicas y agentes. ${ }^{25}$ La conformación de este campo puede verse objetivada, por ejemplo, en la implementación de varios eventos científicos que tiene a la niñez como objeto y en los que los médicos participan activamente (entre ellos, el Primer Congreso Nacional de Niño realizado en Buenos Aires en 1913 y el Primer Congreso Panamericano del Niño también realizado en Buenos Aires en 1916), así como en los insistentes reclamos de distintos sectores por una legislación específica para la "infancia abandonada o delincuente", concretada en 1919 con el Primer Código de Menores.

En síntesis, abordar la constitución de una rama de la medicina especializada en los niños, remite a tener en cuanta los procesos de construcción de la niñez como categoría, grupo social y experiencia transitada por los sujetos. Si bien no es posible universalizar el modo en que estas transformaciones son analizadas para el contexto europeo por los trabajos clásicos de autores como Ariès (1981), Donzelot (1990) o Shorter (1977), encontramos que también en Argentina es en el marco de una ampliación de la presencia estatal en la asistencia social, hacia fines del siglo XIX, cuando la infancia se torna objeto de conocimiento científico y vehículo de intervención en las familias. ${ }^{26}$

\footnotetext{
${ }^{25}$ El concepto de "campo" es empleado en el sentido que le atribuye la teoría social de Bourdieu $(1990,1995)$

${ }^{26}$ Cowen (2000), en un estudio sobre el tratamiento de la primera infancia en el Buenos Aires de fines del siglo XVIII y comienzos del XIX, alerta sobre la necesidad de particularizar el análisis en base a las transformaciones que allí se estaban produciendo. No obstante, si bien el autor demuestra claramente que la primera infancia " $[. .$.$] era en el período tardo colonial y primeras décadas del siglo$ XIX, objeto de una creciente preocupación por parte de autoridades, círculos ilustrados y aun, aunque menos claramente, de sectores sociales que probablemente escapaban a las prácticas y costumbres de la elite porteña", consideramos que aún no había adquirido el carácter de problema de Estado que tomaría a fines del siglo XIX.
} 


\section{2. La pediatría: el proceso de construcción de una especialidad profesional}

Si la consolidación de la biomedicina como modelo médico hegemónico ${ }^{27}$ puede situarse en Europa hacia fines del siglo XVIII (Menéndez, 1990; Foucault, 1993; Bonet, 2003), la medicina de la infancia comienza a recortarse como especialidad recién a fines del siglo XIX. Los nombres de los abordajes que la representan en sus comienzos: "puericultura" y "pediatría", surgirán en Francia en 1864 y 1872 respectivamente (Badinter, 1985). Hasta entonces, el cuidado de la salud y de las enfermedades de los niños había estado prioritariamente en manos de las mujeres de la familia, de curadores populares y, sólo en ciertos casos graves, de médicos y cirujanos (Badinter, 1985; Perrot, 1989).

En nuestro país, es posible situar la constitución de la medicina como un campo científico profesional hacia 1870. Entendiendo el proceso de profesionalización médica en términos de la delimitación, por parte de los médicos diplomados, de un espacio para la práctica legítima y monopólica del "arte de curar", González Leandri (1996; 2000) considera que los médicos en el Buenos Aires de la segunda mitad del siglo XIX ya conforman una profesión culta o erudita ("learned profession"), una elite pequeña pero influyente que depende fundamentalmente de una legitimación estatal ${ }^{28}$. Al igual de lo que sucede en Europa y en el resto de Latinoamérica, se tornan hombres de peso y prestigio en la vida cultural y política, siendo considerados como expertos no sólo en el campo médico, sino también el social más general. Se les reconoce autoridad para abordar no sólo los problemas específicos de salud y enfermedad, sino también a la hora de diseñar diferentes políticas públicas para la población del Estado recientemente conformado, en el marco del surgimiento de la "cuestión social". 29

Belmartino (2005) señala que la profesión médica se manifiesta en las dos primeras décadas del siglo XX como un actor a la vez homogéneo y múltiple. Por un lado, los médicos comparten una serie de preocupaciones vinculadas a la "cuestión

\footnotetext{
${ }^{27}$ Ver nota $\mathrm{N}^{\mathrm{o}} 14$ de la Introducción.

${ }^{28}$ González Leandri (1996) analiza la conformación de los médicos como grupo profesional tomando como punto de partida la distinción entre "learned" y "consulting professions", en base a la manera en que alcanzan el monopolio del saber y las intervenciones, ya sea mediante al apoyo del Estado y grandes mecenas o el apoyo de amplias clientelas respectivamente.

29 Tanto Belmartino (2005) como González Leandri (1996; 2000) dan cuenta de la estrecha relación que se construye entre la elite médica y la estatal a fines del siglo XIX.
} 
social", la visión acerca de su papel como reformadores sociales y el marco teórico del positivismo, que hace de la ciencia el medio adecuado para la interpretación y la transformación de la realidad $\operatorname{social}^{30}$. Pero, por otro lado, si bien los médicos comparten la visión acerca de la importancia de la función social que desempeñan, ligada al valor de la ciencia, la expresan desde diferentes posturas ideológicas que dan lugar a distintas propuestas con respecto al sistema de atención de la salud. Tal como lo expresa Lobato (1996), existen diferencias entre las ideas y prácticas de los médicos que son miembros de la elite institucionalmente vinculada al poder y las propuestas de médicos socialistas como Augusto Bunge y Ángel Giménez, las de católicos como Juan Cafferatta o las propuestas higiénico-naturistas de algunos anarquistas. En este sentido, gran parte de ellos pueden ser situados como parte de la "cultura liberal reformista" (Zimmerman, 1994) que prospera entre políticos e intelectuales argentinos entre fines del siglo XIX y las primeras décadas del XX y que, comprendiendo distintas filiaciones ideológicas (liberalismo, catolicismo social, socialismo), recibe influencias innovadoras de distintos campos de las ciencias y da lugar a nuevas prácticas profesionales: higienismo, criminología, derecho laboral ${ }^{31}$.

A lo largo de la última década del siglo XIX, en el marco de procesos locales de construcción de la mortalidad infantil problema social, pero también formando parte de un movimiento existente a nivel internacional, la pediatría comienza a delinearse como una especialidad dentro de las ciencias médicas. Siguiendo especialmente las escuelas pediátricas francesa y alemana -los médicos latinoamericanos de la época viajan con frecuencia a Francia y Alemania para visitar y formarse en los servicios médicos de atención de niños del los hospitales de esos países-, este proceso se produce más o menos simultáneamente en los diferentes

\footnotetext{
${ }^{30}$ Terán (2000), prefiere caracterizar la vida intelectual en Buenos Aires entre 1880 y 1910, en términos de una "cultura científica", antes que de "positivismo". Esto le permite referirse, en un sentido más amplio, a "un conjunto de intervenciones teóricas que reconocen el prestigio de la ciencia como dadora de legitimidad de sus propias argumentaciones" (p.9).

${ }^{31}$ De acuerdo a Zimmermann (1994), esta "cultura" puede caracterizarse por ciertos rasgos distintivos: 1) en cuanto a su base social son profesionales (principalmente abogados y médicos) de participación en el campo académico y político; 2) de "convicciones progresistas" (frecuentemente anticlericales) sus posturas frente a la solución de la cuestión social se dirigieron a la búsqueda de una "vía media" entre lo que denominaban como "laissez faire ortodoxo" y el "socialismo de Estado"; 3) sus posiciones reformistas en lo social se basaron en el "legalismo", o la convicción de que la política parlamentaria era el ámbito propio para la búsqueda de las soluciones al conflicto social; en un "cientificismo" que acentuaría la importancia de las ciencias sociales como guías de la política estatal en la materia; y en la incorporación de "tecnología social", es decir experiencias de reformas sociales internacionales a las condiciones locales de la Argentina.
} 
países de América Latina (Puga, s/f) ${ }^{32}$. Médicos franceses como Budin, Dufour, Pinard, Ausset y Variot son considerados los maestros y referentes en los cuales inspirarse para emprender la lucha contra la mortalidad infantil.

Para abordar este proceso, considero pertinente retomar la perspectiva desarrollada por Bonet (2003) en su análisis de la constitución de la identidad profesional de los médicos de familia de (2003) y algunos elementos señalados por González Leandri (1996, 2006), en su estudio de los comienzos de la profesión médica en Argentina. Mientras el primero ofrece un abordaje más amplio, que da cuenta tanto de la conformación e institucionalización de un nuevo grupo profesional como de los simultáneos procesos de construcción epistemológica de sus nuevos objetos de estudio, el segundo se centra específicamente en los procesos de institucionalización, que se producen tanto al interior del grupo profesional como en su relación con el Estado.

Hablar de la construcción de una especialidad profesional implica dar cuenta de un proceso que involucra dos aspectos simultáneos: la construcción epistemológica de un principio de clasificación -a partir del cual se delimitan nuevos objetos de estudio y/o enfoques- y la institucionalización de un grupo profesional.

El principio de clasificación que pone en juego la pediatría se funda en la delimitación de etapas del ciclo vital, correspondiendo a un modelo de segmentación de las especialidades médicas que Bonet (op. cit.) llama "segmentación por edad y sexo" 33 . Como veremos más adelante, a partir del criterio etario la primera etapa del

\footnotetext{
${ }^{32}$ En México, la definición los objetivos y características de la pediatría como ciencia moderna, así como su incorporación al plan de estudios de la Escuela de Medicina, se producen en los primeros años del siglo XX, dando continuidad a una serie de transformaciones que, desde fines del siglo XIX, están dándose en la ciencia médica en general y en la mirada hacia la niñez. (Del Castillo Troncoso, 2001). En Colombia, también en la primera década del siglo XX se constituye la pediatría como especialidad, a partir de la fundación del primer hospital infantil y del comienzo de las clases especializadas en medicina infantil en la Universidad Nacional. Como parte del mismo proceso, en 1917 se conforma la Sociedad de Pediatría de Bogotá. (Rodríguez Jíménez, 2007). Para el caso de Brasil, Pereira (2006) señala que es entre fines del siglo XIX y mediados del XX cuando se profesionaliza una medicina orientada hacia los niños, vinculada a la elaboración de un marco de referencias científicas sobre la singularidad de la infancia, sus enfermedades y la peculiaridad de sus respuestas a los tratamientos médicos.

${ }^{33}$ En este modelo, las etapas del ciclo vital y el sexo de la persona funcionan como principios de clasificación a partir de los cuales se diferencian especialidades como pediatría, clínica médica o medicina interna (destinada a los adultos), geriatría, ginecología. El autor diferencia cuatro modelos de segmentación que estructuran el campo de las especialidades médicas y que han ido poniéndose en juego en diferentes momentos de la historia de la medicina: 1) "segmentación anatómica" (divide las especialidades médicas por órganos y sistemas: cardiología, neurología, gastroenterología, etc.); 2) "segmentación por edad y sexo" (pediatría, geriatría, etc.); 3) "segmentación por orientación" (especialidades diferenciadas entre aquellas de "orientación vertical" y de "orientación horizontal", según traten una sola franja etaria o las persona en todas sus etapas) y 4) "segmentación por amplitud"
} 
ciclo vital es recortada como un momento particular, atribuyendo a los sujetos que lo transitan características singulares que impiden su abordaje desde las teorías y prácticas médicas destinadas a otras edades.

A su vez, para que el saber del grupo profesional sobre el objeto de estudio e intervención así recortado sea reconocido en términos de una nueva especialidad -en este caso, la pediatría-, debe obtener algún grado de legitimidad, tanto al interior del campo científico profesional de la medicina, como afuera y más allá del mismo. Ello implica la puesta en juego de diferentes "estrategias de persuasión", tanto orientadas hacia "el adentro" de la profesión, como hacia "el afuera" (González Leandri, $1996)^{34}$.

Al interior de las ciencias médicas, dichas estrategias se centran en la demostración de la especificidad anatómica y fisiológica de la niñez y en la institucionalización de la nueva especialidad a través de la creación de espacios académicos y eventos científicos propios, asociaciones profesionales y revistas especializadas. Hacia el exterior del campo científico, la legitimación de la pediatría se busca a través de una batalla contra los saberes legos, desestimados en términos de "prejuicios" e "ignorancia"35, así como en el reconocimiento del Estado y la participación -especialmente en combinación con la puericultura- en las políticas públicas. En efecto, la atención de la salud y el control higiénico de la población constituyen una de las áreas donde la preocupación del Estado y el naciente entramado profesional se han interrelacionado de manera más temprana en Argentina (González Leandri, 2006), por lo que no es posible entender el papel de pediatras -y también de los higienistas dedicados a la puericultura- sin considerar las políticas públicas desarrolladas en los ámbitos que estos médicos consideran de su incumbencia. A su vez, sin embargo, la profesionalización no resulta posible sin la

(la división entre especialidades se da en relación a un abordaje individual o familiar-comunitario: las especialidades clínicas y la medicina familiar). (Bonet, 2003).

${ }^{34}$ Tal como lo explica el autor: "las estrategias de persuasión orientadas hacia "el afuera" de la profesión se complementan con otras dirigidas hacia "el adentro", "promoviendo la cristalización de criterios de demarcación, diferenciación y exclusión. Tal cristalización, clave en todo proceso de profesionalización, es a su vez el resultado de la pugna entre los distintos grupos que ejercen una misma actividad: mientras los grupos con más poder e influencias intentan disciplinar, subordinar y a veces excluir a otros, éstos, en respuesta, elaboran estrategias de supervivencia y reacomodamiento que muchas veces culminan en las redefinición de nuevas áreas o en la creación de nuevas disciplinas" (González Leandri, 1996, p.24).

${ }^{35}$ Este aspecto de la legitimación de la pediatría se profundizará en el capítulo 3, por lo que aquí sólo se hace esta breve mención. 
conformación de una creencia entre la población en la eficacia de la medicina y sin su participación como usuarios de los servicios médicos recientemente creados.

\subsubsection{El estudio de "un sujeto completamente nuevo".}

El discurso de los comienzos de la pediatría muestra un pasaje del estudio de las manifestaciones de las enfermedades en los niños, al de las enfermedades de los niños (Amstrong, en James, Jenks y Prout, 1998). Es decir que, como veremos para el proceso producido en la Argentina, ya no se trata de la presentación de patologías generales en un cuerpo más pequeño, sino de los modos de enfermar y sanar propios de un sujeto cualitativamente diferente de los adultos. Ello da cuenta del triunfo de una serie de argumentos fundados en el estatuto social específico de la infancia por sobre aquellos otros que defendían el carácter común del cuerpo de niños y adultos y, por lo tanto, una atención clínica común a pacientes de cualquier edad (Rivorêdo, 1998). ${ }^{36}$

Ahora bien, al acompañar este movimiento con mayor detalle, surgen varios interrogantes que requieren profundizar el análisis de las fuentes documentales: ¿cuál es el fundamento que guía este proceso? ¿Por qué es necesario desarrollar una medicina específica para los niños? ¿Acaso no sirven los conocimientos desarrollados para estudiar e intervenir en los cuerpos de los adultos? ¿Dónde radica la diferencia entre niños y adultos?

Tal como Luis Morquio, profesor de Clínica Infantil de la Facultad de Montevideo $^{37}$, advierte a sus alumnos, se considera que en la niñez el sujeto y su cuerpo presentan características particulares que hacen que incluso patologías denominadas de la misma manera que las de los adultos, adquieran manifestaciones y modalidades de evolución diferentes, requiriendo un diagnóstico y una terapéutica especiales:

\footnotetext{
${ }^{36}$ Rivorêdo (1998) sitúa esta polémica sobre la pertinencia de la atención médica de los niños entre fines del siglo XVIII y comienzos del XIX. Si bien la ubica como un "primer momento de afirmación de la pediatría", consideramos que no puede hablarse de pediatría en esa época, sino más bien de debates que precedieron y generaron ciertas condiciones conceptuales para el efectivo surgimiento de la especialidad a fines del siglo XIX y comienzos del XX.

${ }^{37} \mathrm{Si}$ bien se propuso trabajar con obras de pediatras que escribieron en Argentina, se decidió incluir en el análisis los textos del uruguayo Luis Morquio por mantener las universidades de Montevideo y Buenos Aires un intercambio constante de ideas y profesionales y ser aquel una referencia constante para la consulta de los pediatras argentinos. Desde 1894, Morquio dirige el Asilo de expósitos y Huérfanos de Montevideo y en 1900 es nombrado Profesor Titulas de Medicina Infantil de la Universidad de la República.
} 
"[En la Clínica de Niños, a diferencia de las otras materias] El sujeto es completamente nuevo, y si en algunos momentos la misma denominación patológica pudo halagar vuestros oídos, recordando algo conocido, en presencia del hecho clínico habéis encontrado una cosa muy distinta, por su semeiología, por sus reacciones especiales, por la modalidad de su evolución y por su terapéutica. $[\ldots]$

“[...] para saber reconocer una afección pulmonar o pleural en un niño, poco os servirían vuestros conocimientos del adulto, porque sus manifestaciones funcionales ofrecen caracteres que le son propios y porque su semeiología, a base de auscultación y de percusión, es de tal manera especial, que para lograr la localización exacta del mal se requiere generalmente un hábito que sólo la experiencia y el estudio del sujeto permiten alcanzar" (Morquio, 1906a, p. 398).

El niño es considerado "el sujeto más susceptible" al contagio de enfermedades (por ejemplo, la tuberculosis) y a los efectos de las variaciones estacionales en su organismo (el invierno favorece las infecciones respiratorias y el verano las infecciones digestivas). Sin embargo, por otro lado, a esta edad la prevención se muestra más eficaz y la mayoría de las causas de enfermedad son evitables.

También se plantea que en el cuerpo infantil, a diferencia del adulto, las enfermedades se manifiestan con especial intensidad y evolucionan rápidamente hacia un desenlace favorable o desfavorable.

"La modalidad característica de la patología infantil son las reacciones intensas y rápidas; la precipitación de los hechos, agravando rápidamente una situación que toma fácilmente el aspecto alarmante; la necesidad, a cada instante, de la medicación de urgencia; el desenlace rápido, en un sentido o en otro." (Morquio 1906b, p. 464).

Asimismo, se señala que, a temprana edad, estas manifestaciones patológicas presentan amplias variaciones según las características individuales, debido a una presencia más pura de los factores hereditarios, aún no demasiado moldeados o afectados por el ambiente:

"Debemos tener presente, como una modalidad propia de la edad, las reacciones individuales frente a los estados patológicos, para lo cual da grande facilidad el conocimiento del niño y de sus 
antecedentes, modalidades propias que se reproducen siempre de una manera igual, a veces exagerando una situación con caracteres alarmantes, o simulando una enfermedad determinada; son reacciones especiales, subordinadas a las diatesis hereditarias." (Morquio 1906b, p. 464).

Esas particularidades atribuidas a la infancia imponen ciertas características a la práctica médica, sobre todo en cuanto a la realización del diagnóstico. En una época donde las enfermedades se diagnostican en gran parte a través de la exploración directa del cuerpo del paciente y del interrogatorio sobre sus síntomas, trabajar con niños a los que se supone incapaces de razonar plenamente y de expresarse con claridad y precisión, requiere desarrollar condiciones especiales y tomar en cuenta las percepciones maternas:

"La asistencia de niños exige de parte del médico sino una técnica especial, condiciones de adaptación que permiten abordar el sujeto sometido a nuestra cura, generalmente reacio a una exploración debida. La parte más importante de la semiología infantil la constituye el interrogatorio de la madre, con el que basta muchas veces para saber de qué se trata y sin el cual no es posible diferenciar estados similares que comportan en muchos casos terapéutica distinta; el interrogatorio debe ser llevado y dirigido convenientemente; hay que saber eliminar las exageraciones y aprovechar los múltiples detalles que sólo el ojo experto de una madre inteligente es capaz de despistar [...]." (Morquio 1906b, pp. 463-464).

Si ello hace más difícil la tarea de diagnosticar, ésta se ve facilitada, por otro lado, por la nitidez con que se presentan las enfermedades en el niño, aún no marcado por procesos patológicos pasados en etapas anteriores o por la influencia del ambiente. En este y otros aspectos atribuidos a la "naturaleza infantil", podemos comenzar a reconocer una serie de similitudes con las características atribuidas por gran parte de la antropología clásica a los pueblos "primitivos": en ambos se describen manifestaciones puras de su constitución física o social, presentadas en sus formas elementales y aún no "contaminadas" por el ambiente o por la "civilización", 38

"El terreno infantil necesita para su estudio profundo una larga y paciente atención, y exige una adaptación particular de

\footnotetext{
${ }^{38}$ Profundizaré sobre estas características en el próximo capítulo.
} 
carácter y de criterio médico. El diagnóstico es generalmente fácil, porque las enfermedades se desarrollan con toda su pureza; es una página en blanco, como se ha dicho, donde la enfermedad se inscribe con caracteres precisos; pero la experiencia y el conocimiento del sujeto, facilitan enormemente la tarea. Sabemos que los fenómenos subjetivos no existen en la primera infancia, y que son insuficientes e inexactos en la segunda; de aquí la necesidad de una buena observación, de un conocimiento asiduo del sujeto, tanto bajo el punto de vista fisiológico como patológico, del auxilio inteligente de los padres con datos indispensables; todo lo cual nos permite valorar las manifestaciones sintomáticas, sin necesidad del análisis acabado, frecuentemente difícil de realizar." (Morquio 1906b, p. 464).

El concebir el cuerpo del niño como "una página en blanco", como un “organismo nuevo", dotado de defensas naturales, otorga expectativas favorables acerca del resultado del tratamiento médico. De esta manera, la capacidad de reacción del organismo infantil torna la intervención médica mucho más eficaz que en otras edades.

"Hay que saber que el niño tiene una tendencia espontánea y natural a reaccionar favorablemente; la terapéutica debe recordar esta cualidad, concretándose a favorecer y a estimular el desarrollo de los poderosos medios de defensa que tiene ese organismo nuevo, con indicaciones limitadas y justas [...]". (Morquio 1906b, p. 465).

En síntesis, tanto en el modo de adquirir y manifestar la enfermedad, como en las posibilidades de cura, el cuerpo del niño es considerado más susceptible, más vulnerable, que el de los adultos pero, a la vez, con mayor resistencia, fortaleza y posibilidades de curación. ¿Cómo se explica esta aparente contradicción, esta capacidad para sucumbir rápidamente a la enfermedad, pero también para resistir y curarse?

Como veremos en el capítulo siguiente, es la noción de plasticidad, de maleabilidad de la niñez, que implica tanto incompletud como potencialidad, la que da sentido y coherencia a las representaciones que guían la teoría y la práctica de la pediatría. Y esta noción se funda en la definición de la niñez a partir de los procesos de crecimiento y desarrollo. Crecimiento y desarrollo -"las dos funciones esenciales de la vida de un niño" (Archivos Latinoamericanos de Pediatría, $\left.\mathrm{N}^{\circ} 11,1906\right)$ - hacen de la infancia una primera etapa vital y del niño un ser inacabado, en proceso de constituirse como un ser humano completo -es decir, como adulto- de manera 
gradual y progresiva. Es porque el niño aún no ha tomado su forma definitiva que puede reaccionar de una manera o de otra ante las enfermedades y la cura, haciendo necesaria la intervención de los expertos tanto en aspectos físicos como "morales":

"Toda la vida del niño está sujeta a su crecimiento y a su desarrollo; esta evolución se opera dentro de reglas fisiológicas que deben ser vigiladas y dirigidas conscientemente, para evitar desviaciones y para corregirlas cuando éstas se produzcan. Es del mayor conocimiento de su naturaleza, de sus condiciones físicas y psíquicas, de las causas que provocan las enfermedades, físico y morales, de la manera de corregirlas, que ha surgido todo un conjunto de problemas, higiénicos y sociales, que se traducen en leyes y organizaciones, que constituyen hoy la defensa del niño en todas sus manifestaciones." (Archivos Latinoamericanos de Pediatría, 1919, s/n, p.276).

Así, a partir de centrar la definición de la niñez en el crecimiento y el desarrollo, la pediatría no sólo se dedicará al estudio y tratamiento de las enfermedades infantiles, sino también, al seguimiento de dichos procesos en el niño sano, a fin de prevenir posibles desviaciones del recorrido esperable. La puericultura sumará su enfoque higienista y preventivo a la clínica y la pediatría definirá su objeto en términos amplios: la etapa que se extiende entre el nacimiento y la pubertad, especialmente en lo que concierne a los procesos de crecimiento y desarrollo que le son propios, abordada no sólo en sus aspectos patológicos, sino también en su "evolución normal" a lo largo de diferentes sub-etapas:

"Tomando por base la fisiología del niño, estudia su crecimiento y su desarrollo, desde su nacimiento hasta la pubertad y en las diversas etapas de esta evolución, tanto en el orden físico como en el patológico, establece los principios higiénicos a los cuales debe subordinarse.

El programa es amplio; es la vida del niño, sin restricciones, de la que se destacan sus períodos culminantes: el lactante, la edad escolar y la pubertad." (Morquio, 1906a, p.400). 


\subsubsection{La institucionalización de la pediatría}

En consonancia con la delimitación del niño como objeto de estudio y tratamiento, la pediatría se institucionaliza como rama o especialidad médica en diferentes ámbitos.

En el espacio académico, tomando como ejemplo las transformaciones de la carrera de medicina de la Universidad de Buenos Aires, encontramos que en 1883 es nombrado el primer profesor de la "Cátedra de Enfermedades de los Niños y Clínica respectiva" -Manuel Blancas, de origen español-, con lo cual la medicina de la niñez pasa a ser tratada en una materia específica. Hasta entonces, los contenidos referidos a las enfermedades en la infancia habían estado incluidos en los programas de las cátedras de Clínica Médica o la Cátedra de Partos (Puga, s/f). A partir de 1906 la cátedra se denomina de "Clínica Pediátrica" y en 1919 pasa a llamarse "Clínica de Pediatría y Puericultura", con lo cual se incorpora el aspecto preventivo e higiénico al abordaje exclusivamente clínico (Meroni, 1980).

A su vez, desde fines del siglo XIX comienzan a crearse servicios de atención de enfermedades de los niños en hospitales generales y se construye una nueva sede para el Hospital de Niños de Buenos Aires, permitiendo ampliar y complejizar su atención, así como cumplir adecuadamente su función de Hospital Docente. ${ }^{39}$ Como parte de esas transformaciones institucionales, en 1905, la Casa Cuna de Buenos Aires es transformada en Hospital de Niños Expósitos. El Hospital de Niños de La Plata, creado en 1889, también empieza a ser remodelado y reorganizado según criterios modernos durante la primera década del siglo XX.

El proceso de especialización también se visualiza en la creación de publicaciones y de eventos científicos dedicados exclusivamente al tratamiento médico de la niñez. Según Recalde (1997) el desarrollo de la literatura médica en

\footnotetext{
${ }^{39}$ El Hospital de Niños de la Ciudad de Buenos Aires (actualmente Hospital Ricardo Gutiérrez), es fundado en 1875 bajo dependencia de la Sociedad de Beneficencia, siendo actualmente considerado el primer hospital pediátrico de América Latina. En 1883 se convierte en Hospital Docente, en consonancia con la creación de la Cátedra de Enfermedades de los Niños y Clínica respectiva. En 1892, el Congreso Nacional aprueba la asignación de dos millones de pesos provenientes de la lotería a construcción de un edificio nuevo y especializado para albergar el Hospital de Niños. Las obras edilicias se concluyen en 1908. La Memoria de este hospital presentada en 1905, ya da cuenta de la existencia de consultorios externos según diferentes especialidades: consultorio de medicina, de cirugía, de nariz, oído y garganta, de enfermedades de los ojos, de enfermedades de la piel, de enfermedades nerviosas y de enfermedades gastrointestinales. (Archivos Latinoamericanos de Pediatría, año II, $\left.\mathrm{N}^{\circ} 2,1906\right)$.
} 
nuestro país se iniciaría en el último tercio del siglo XIX y habría sido paralelo a la organización de los estudios de medicina y a los avances de la corporación médica.

La Semana Médica, publicación semanal de la Academia de Medicina incluye, desde su comienzo en 1894, artículos sobre enfermedades presentes en los niños ("convulsiones en la infancia", "diarrea en los niños", "las gastro-enteritis de los niños de pecho"), así como una preocupación por la mortalidad infantil a través de estadísticas presentadas en informes periódicos. En 1900 -mostrando el pasaje del estudio de enfermedades en los niños al de las enfermedades de los niños- pasa a tener una sección denominada "Pediatría", con artículos generales sobre alimentación del niño o elección de la nodriza adecuada, por ejemplo, y otra llamada "Clínica Pediátrica", con artículos sobre casos clínicos y su resolución. Las problemáticas de la niñez también pueden aparecer en las secciones sobre "Higiene" o sobre "Puericultura", presentes en algunos números de la revista.

A fines de la década de 1890 se fundan la Revista del Hospital de Niños Ricardo Gutiérrez (en 1897) y la Revista de Higiene Infantil, del Patronato de la Infancia (en 1892). Sin embargo, no es hasta 1905, con la creación de los Archivos Latinoamericanos de Pediatría. Revista Mensual Internacional, que el nuevo colectivo profesional comienza a contar con un órgano de comunicación y discusión científica propio, tal como se expresa en su primer editorial:

"Ilustrados colegas:

La especialización en el dominio de la medicina infantil está ya demasiado extendida en toda América Latina para que los médicos de niños sigamos publicando el fruto de nuestra observación y de nuestros trabajos en las revistas generales de medicina.

Como en Europa, los médicos que en estos países nos ocupamos de higiene y de medicina infantil, necesitamos de órganos especiales, y hemos creído por eso de positivo interés general reunir toda la producción pediátrica latinoamericana en una sola revista, que constituya así una verdadera 'hoja central' tan completa como sea posible, no sólo para la medicina y la cirugía, sino también para la higiene de la infancia."

$[\ldots]$

"Estrechar las relaciones intelectuales entre los trabajadores americanos, estimular sus producciones difundiéndolos en América y Europa, propender, en fin, al progreso de la medicina y de la higiene infantil, tales son los propósitos que perseguimos y para la mejor realización de los cuales esperamos poder contar con el valioso concurso de todos los médicos estudiosos de la América 
latina." (Archivos Latinoamericanos de Pediatría, año I, No¹, 1905, p. 2)

Los Archivos Latinoamericanos de Pediatría se publican mensualmente, incluyendo artículos en castellano, portugués y francés. Su comité editorial está integrado por algunos de los médicos con más reconocimiento académico y estatal de Brasil, Uruguay y Argentina: Olinto de Oliveira, de Porto Alegre, Fernández Figueira, de Río de Janeiro, Luis Morquio, de Montevideo, y Gregorio Aráoz Alfaro, de Buenos Aires.

La revista presenta diversas secciones temáticas, que no aparecen necesariamente en todos los números; entre ellas: "Observaciones clínicas", "Artículos originales", "Protección y asistencia de la infancia”, “Análisis bibliográficos", "Cuestiones del día", y "Crónica". Esta última incluye los relatos de visitas científicas o de los debates de congresos en los que han participado médicos latinoamericanos y permite percibir la importancia que tienen en la época los viajes realizados a Europa para conocer los servicios de pediatría dirigidos por los más prestigiosos médicos de Francia y Alemania. ${ }^{40}$

La publicación se interrumpe entre 1909 y 1911, cuando la revista pasa a ser bimestral. De su dirección ya no forman parte los médicos brasileños quienes, no obstante, siguen participando como redactores y como autores de artículos. La redacción pasa a organizarse en tres secciones principales, cada una con su secretario: medicina, cirugía, higiene y protección de la infancia. Concluye en 1929, cuando los Archivos Latinoamericanos son reemplazados por los Archivos Argentinos de Pediatría. Para entonces, cada uno de los países que integraba la revista original cuenta con una abundante producción científica especializada y un desarrollo institucional propios, que vuelca en su propia revista. A su vez, a las publicaciones especializadas, comienza a sumarse la redacción de normas de diagnóstico y tratamiento, boletines informativos, folletos y libros especializados (Puga, s/f).

Es a través de los Archivos Latinoamericanos de Pediatría que se difunden las convocatorias para la conformación de las primeras asociaciones profesionales de pediatras (a nivel nacional e internacional) y a la realización de los primeros congresos científicos dedicados a la nueva especialidad. Así, en el número de abril de

\footnotetext{
${ }^{40}$ A partir de la década de 1930, este lugar de referencia para los médicos pediatras latinoamericanos será ocupado en gran parte por los Estados Unidos.
} 
1907 circula una primera invitación en francés a conformar la Société Internationale de Pédiatrie, enviada a uno de los directores de la Revista por un médico ruso, profesor en la Universidad de Kharkow, en Ucrania. Con la propuesta de creación de esta asociación se busca explícitamente el reconocimiento y legitimación, al interior de las ciencias médicas, de la pediatría como una rama independiente y de similar importancia a la de la clínica general: “[...] una sociedad internacional- se afirma en dicha carta- es indispensable para otorgar a la pediatría el lugar que le pertenece por derecho y para recompensarla así por todos los beneficios que ella ya ha brindado a la humanidad" (Archivos Latinoamericanos de Pediatría, 1907, p. 138, traducción propia) ${ }^{41}$. En la carta que acompaña un proyecto de reglamento de la Société, se expresa que gracias a sus conquistas científicas, la pediatría no sólo merece un lugar semejante al de las demás ramas de la medicina, sino que también se ha convertido en un objeto de "envidia" científica, pues la mayor parte de los problemas individuales y sociales no puede ser resuelto sin su ayuda. En este sentido, debe resultar de interés no sólo para las poblaciones infantiles, sino también para las personas y poblaciones adultas, en tanto permite detectar tempranamente enfermedades que influyen más tarde en el hombre o en la mujer.

En Argentina, siguiendo esta tendencia internacional y por iniciativa del reconocido médico Gregorio Aráoz Alfaro (en ese momento, miembro de la dirección editorial de los Archivos Latinoamericanos de Pediatría y Jefe del Servicio de Niños del Hospital San Roque), en octubre de 1911 se funda la Sociedad Argentina de Pediatría ${ }^{42}$. Su órgano oficial son los Archivos Latinoamericanos de Pediatría ${ }^{43}$ y, a partir de 1929 es el organismo que dirige los Archivos Argentinos de Pediatría. En Uruguay, a fines de 1914 se constituye la Sociedad de Pediatría de Montevideo, que reúne a los médicos de los servicios de niños de la Facultad de Medicina y de la Asistencia Pública.

\footnotetext{
41 "Outre la nécessité urgente de se rendre compte des résultats obtenus sur les questions essencielles de diétetique, de pathologie et de thérapeutique du premier âge, une société internationale est indispensable pour donner à la pédiatrie la place qui lui appartiens de droit et pour la récompenser ainsi de tous les bienfaits qu'elle a déjà rendus à l'humanité." (Archivos Latinoamericanos de Pediatría, Año III, No 4, abril de 1907, p. 138).

${ }^{42}$ La Sociedad Argentina de Pediatría se funda a partir de una reunión de médicos pediatras realizada en la casa de Aráoz Alfaro. Allí se nombra una comisión compuesta por los doctores Aráoz Alfaro, Genaro Sisto y Ernesto Gaing, con el fin de que redacten los Estatutos y Reglamentos de la nueva Sociedad. Éstos son posteriormente discutidos en una asamblea realizada en la Sociedad Médica Argentina y se constituye efectivamente la Sociedad, cuya comisión directiva (elegida por voto secreto) queda conformada por Ángel Centeno (presidente), Gregorio Aráoz Alfaro (Vice-presidente), Genaro Sisto (Secretario general), Ernesto Gaing (Secretario de Actas), Mamerto Acuña (Bibliotecario), N. Arraga, M. Castro y M. Viñas (Vocales).

${ }^{43}$ En la revista se incluyen las transcripciones de las sesiones periódicas de la Sociedad, en las que se presentan y discuten casos clínicos.
} 
Una de las tareas centrales para el cumplimiento de la finalidad científica que se atribuyen las asociaciones de pediatras, es la organización de congresos de la especialidad. Entre los primeros antecedentes de congresos especializados en problemas de la infancia organizado por médicos pueden mencionarse los congresos internacionales "Des Gouttes de Lait" (sobre las "Gotas de Leche", instituciones de asistencia a la alimentación de los lactantes), realizados en Europa. A través de la discusión que genera, en 1907, el intento de cambiar el nombre de los congresos internacionales "Des Gouttes de Lait", por el de "Congrès de la protection de l'Enfance du premier âge" (Congreso de la Protección de la Primera Infancia), es posible observar cómo los médicos tratan de presentarse con una especificidad con respecto a otras profesiones o instituciones que se ocupan de la niñez. Al respecto, un grupo de médicos franceses comienza a hacer conocer una circular en la que plantean su disconformidad con el nuevo nombre por considerar que las cuestiones concernientes a la higiene alimentaria y la pediatría de la primera infancia, eje de los congresos Des Gouttes de Lait y monopolio de la medicina infantil, tendrían un lugar restringido en el campo demasiado amplio de los temas del nuevo congreso. Se plantea la importancia de la especialización como una marca de la época y se defiende el conservar un congreso médico frente al nuevo, que incluiría otros temas de carácter social y administrativo. (Archivos Latinoamericanos de Pediatría, año III, No 11, noviembre de 1907).

Si ya desde comienzos del siglo XX los congresos internacionales de medicina o de ciencias en general incluían una sección sobre Pediatría, el primero con carácter específico: el Primer Congreso de la Asociación Internacional de Pediatría, se realiza en París en 1912. En nuestro país, los pediatras ocupan un lugar destacado en la organización del primer Congreso Americano del Niño, realizado en Buenos Aires en 1913, y participan activamente en el segundo, realizado en Montevideo en $1919 .{ }^{44}$

Puede afirmarse que hacia 1920 el proceso de constitución de la pediatría como especialidad médica se encuentra consolidado. Como parte del mismo, lo pediatras comienzan a construir su propio relato histórico del origen de la especialidad y de las transformaciones producidas en el abordaje médico de la niñez,

\footnotetext{
${ }^{44}$ Nari (2004) señala que los congresos del niño de América del Sur fueron impulsado, en un comienzo, por médicas feministas de la región quienes, sin embargo, habría ido perdiendo lugar en la organización. La Liga para los Derechos de la Mujer y del Niño en Buenos Aires fue la organizadora del realizado en 1913, reuniendo no sólo a médicos, sino también sociólogos, pedagogos, funcionarios y especialistas en salud pública. Para un trabajo más detallado sobre los primeros congresos del niño, ver Guy (1998).
} 
presentándolas de manera teleológica, como el resultado lógico del avance de las ideas científicas y de la progresiva derrota de la ignorancia y el prejuicio:

"El empirismo más peligroso dominaba, hasta hace poco, en el tratamiento de las enfermedades de los niños. Hace apenas algunos años, las causas de las enfermedades eran ignoradas; el prejuicio ejercía su acción libremente [...].

"[...] el estudio de la Pediatría, apenas conocido hasta hace pocos años, ha tomado un impulso considerable. El empuje es universal; todos los países han constituido sus cátedras de enseñanza, que se multiplican diariamente; los congresos, las asociaciones y las publicaciones especiales, nos demuestran a cada instante, la marcha triunfal de esta campaña humanitaria. Es que esta rama de la medicina descansa sobre bases ciertas; se ha substituido al empirismo, las ideas exactas de la ciencia que nunca mejor y con mayores resultados fueron aplicadas; nos enseña a preservar y a corregir los males, y nos enseña que el niño muere generalmente por ignorancia o por error" (Morquio, 1906a, pp.399-400).

Así, el proceso complejo que, como vimos, implica disputas y nuevos posicionamientos al interior de la ciencia médica y en relación con otras profesiones, así como la conformación de grupos o asociaciones a nivel nacional, regional o internacional, es percibido y presentado por los propios actores como un producto del "progreso" ineludible de las ideas y de las instituciones. En la "marcha triunfal de esta campaña humanitaria" es incluida también la puericultura, una nueva área de conocimientos médicos que se delinea junto a la pediatría o como parte de ella.

\subsection{La puericultura o la "ciencia de criar niños"}

De acuerdo con higienista Emilio Coni (1916), el término "puericultura" fue acuñado en 1864 por el médico francés A. Caron para referirse a "la ciencia o el arte de criar niños" ${ }^{, 45}$. Sin embargo, no se habría vulgarizado hasta la última década del siglo XIX, a partir de los trabajos de los franceses Budin y Pinard, mediante los

\footnotetext{
${ }^{45}$ Caron caracteriza a la puericultura en los siguientes términos: "La Puericultura es la ciencia que aprende a criar fisiológicamente a los niños y, por consiguiente, ella debe abarcar el estudio de todas las cuestiones de filosofía, de anatomía, de fisiología, de anatomía, de fisiología, de higiene, de física, de química, de eteorología, cuya aplicación metódica y razonada puede lo más eficazmente concurrir al libre y fácil desarrollo del organismo humano" (Caron, apud Kaminsky, 1914, p. 41).
} 
cuales se difunde entre los médicos argentinos. ${ }^{46}$ Es sobre todo Pinard quien formula las bases teóricas de la puericultura y quien también la consagra como ciencia escolar, escribiendo un manual de crianza infantil destinado a las niñas y yendo él mismos a enseñar la nueva disciplina a una escuela primaria de París para demostrar que esto es posible sin que el pudor de las alumnas resulte ofendido.

Como parte de la pediatría y a la vez con una relativa autonomía con respecto a ella, la puericultura se constituye como el área o la disciplina médica especializada en la crianza infantil, especialmente durante la etapa de la "primera infancia", que abarca aproximadamente los primeros dos años de vida. A diferencia de la pediatría clínica, se orienta exclusivamente hacia los cuidados cotidianos del niño sano mediante la transmisión a las madres de métodos de crianza considerados "racionales y científicos". Partiendo de la idea de que educar a la madre es la mejor forma de proteger indirectamente al hijo, y uniendo la acción médica con la acción social, persigue fines eminentemente preventivos: se trata de enseñar a la familia $\mathrm{y}$, sobre todo a la madre, a criar a sus niños a partir de principios científicos, como garantía una infancia sana. ${ }^{47}$ En este sentido, la puericultura es pensada como una inversión a largo plazo ya que proporciona hombres y mujeres sanos y fuertes para integrar la población de la nación:

"La puericultura, etimológicamente hablando, es el arte de cultivar bien los niños, lo que traducido científicamente quiere decir que es una ciencia de aplicación cuyo objetivo es velar por la salud de los niños, la que lleva involucrada en sí la perpetuación de la especie, el perfeccionamiento y la hermosura de las razas, confundiéndose por lo tanto su finalidad con los más altos destinos de los pueblos." (Lamarque, 1929, p.8).

Se considera que, para cumplir ese objetivo, debe comenzar desde la gestación, o aún antes, con el requisito de unos padres sanos. Se habla así una puericultura "preconcepcional o eugenésica" (anterior a la fecundación), una

\footnotetext{
${ }^{46}$ En su tesis sobre puericultura, presentada en la Universidad de Buenos Aires, la médica argentina E. Kaminsky reseña que la palabra "puericultura" se habría vulgarizado hacia 1895, cuando Pinard hizo una comunicación a la Academia de Medicina de Francia, definiéndola como "la ciencia que tiene por objeto la investigación de conocimientos relativos a la reproducción, a la conservación y al mejoramiento de la especie humana" (1914, p.42).

${ }^{47}$ Más adelante veremos que, si bien parte de la idea de la maternidad como función natural y del amor materno como producto del instinto, el discurso médico de la puericultura relativiza la fuerza del "instinto ancestral de la raza" y acentúa la necesidad de crear una "conciencia de aprender la profesión de madre" (Nari, 1996).
} 
"puericultura intrauterina" y una "puericultura extrauterina o post-natal" (Aráoz Alfaro, 1900). ${ }^{48}$

De este modo, el objeto último de intervención de la puericultura es, más que el niño como individuo, un sujeto colectivo: la niñez como "capital humano de la nación”. En este sentido, se enmarca en la preocupación más amplia -ya mencionadaacerca de la conformación de la población del estado nacional, amenazada por las elevadas tasas de mortalidad infantil que afectan principalmente a los lactantes. De allí que sea presentada por los propios médicos como una ciencia surgida de las necesidades de la época: "La sociedad moderna siente la urgencia de la nueva ciencia -afirma uno de ellos- porque se halla enferma de despoblación” (Feinmann, 1915, p.2).

La delimitación disciplinaria y la relación entre pediatría y puericultura no están definidas de manera clara ni uniforme. La puericultura aparece como la intersección entre el enfoque preventivo de la higiene, orientado hacia la salud de la población (lo cual traza la gran diferencia con los enfoques clínicos), y la especificidad del objeto de la pediatría, en cuanto a una franja de edad particular. Esto último la hace, para algunos autores de la época, parte indudable de la pediatría mientras que, para otros, ambos abordajes médicos de la niñez constituyen dos disciplinas con igual rango dentro de la medicina. En esto influye el lugar de quienes están formulando las definiciones: los médicos que se identifican como pediatras suelen incluirla como parte de su saber (de hecho, Aráoz Alfaro, Sixto, Feinmann y otros "fundadores" de la pediatría argentina son autores de manuales de puericultura), mientras que quienes se definen como higienistas le otorgan mayor autonomía (Coni, por ejemplo). Los propios actores de la época también se presentan a sí mismos ya como pediatras, ya como higienistas, en diferentes momentos y relaciones. Por ello, a lo largo de esta tesis, recuperando las autodenominaciones "nativas", veremos que aparecen nombrados como "pediatras", como "pediatras e higienistas" o simplemente como "médicos" o "médicos de niños".

Tampoco entre quienes hoy en día se dedican al estudio de los comienzos de las ciencias médicas y de las políticas públicas destinadas a la niñez hay uniformidad

\footnotetext{
${ }^{48}$ Como ya fuera dicho, en los planteos la puericultura de principios de siglo XIX, las preocupaciones eugenésicas se centran en prevenir o evitar la "degeneración de la raza" que podían producir males como el alcoholismo, la sífilis y la tuberculosis de los padres.
} 
de criterios: algunos, como Billorou (2008) la sitúan como una rama de la medicina, mientras que otros, como Castellanos (2003), la abordan como una parte de la pediatría. Esta dificultad surge, en parte, cuando se pretende proyectar los actuales criterios de distinción entre especialidades médicas a una época en la que el proceso de especialización al interior de la medicina es incipiente para ciertas áreas, como la concerniente a la niñez. No hay una delimitación nítida entre pediatría y puericultura que, en el momento estudiado, se encuentre validada por titulaciones diferenciadas. Sin embargo, sólo uno de los dos saberes médicos centrados en la niñez: la pediatría, se constituirá en una especialidad médica reconocida en las carreras académica y hospitalaria. $^{49}$

Tal vez un elemento que contribuya a entender la relativa autonomía entre ambas especialidades, sus distinciones y superposiciones, es el hecho de que los fundadores de la puericultura, los médicos franceses Budin y Pinard, no provinieran de la pediatría sino de la obstetricia, y que desde allí se interesaran en los cuidados de los niños durante su primera infancia, en la que veían una continuidad de los procesos de gestación y nacimiento. En efecto, la puericultura centra sus acciones en torno de una de las etapas en que es subdividida la niñez: la más temprana, la primera infancia, marcada por los comienzos del proceso de crecimiento y desarrollo y por la estrechez del vínculo entre el niño y su madre, en lo que en la época comienza a llamarse "binomio madre-hijo".

A partir de 1890 aproximadamente, siguiendo un proceso que se da en Europa, la puericultura se despliega como un amplio proyecto pedagógico, que puede ser visto como un trabajo minucioso de implantación de la creencia en el valor de la salud del niño y en la capacidad objetiva y racional de la ciencia para asegurarlo (Boltanski, 1969). Esta tarea no se produce sobre un vacío de prácticas y representaciones, sino que - como veremos más adelante- implica una disputa constante con los saberes populares y domésticos sobre el niño y la crianza. En este sentido, siguiendo a Boltanski (op. cit.), podríamos situar a la puericultura, junto con el trabajo social y la higiene en general, como parte de una empresa más vasta que apunta a regular la vida privada, intentando sustituir las maneras habituales de actuar

\footnotetext{
${ }^{49}$ De hecho, la pediatría ha continuado su proceso de afirmación como especialidad médica, mientras que la puericultura ha quedado como un abordaje paramédico, limitado al acompañamiento de la madre durante los primeros meses del niño.
} 
por prácticas obligatorias y reglamentadas. ${ }^{50}$ Las estrategias pedagógicas implementadas serán diversas y utilizarán distintos medios según las clases sociales a las que estén destinadas. Las respuestas producidas estarán también lejos de ser uniformes y definitivas. Antes bien, como lo muestran las preocupaciones de la pediatría actual, si bien las familias han incorporado parte de las recomendaciones médicas, también las han resignificado, adaptado y han dado continuidad a prácticas y saberes propios, que se enmarcan en concepciones particulares de niñez, de salud, de maternidad.

A lo largo de las dos primeras décadas del siglo $\mathrm{XX}$, el reconocimiento institucional de esta "nueva ciencia" va ampliándose, tanto en la formación universitaria de los médicos, como -y especialmente- en los organismos estatales encargados de las políticas sanitarias y asistenciales. Este proceso evidencia una relación estrecha entre la constitución de un saber científico orientado al conocimiento de un sector particular de la población y políticas estatales de administración de esa población.

Así, como ya hemos visto, en 1919 la puericultura queda incluida en el nombre de la cátedra dedicada a medicina infantil, que pasa a llamarse "Clínica de Pediatría y Puericultura". Las revistas especializadas en la medicina del niño incluyen secciones sobre higiene y puericultura, y los temas relativos a la crianza y cuidado de la salud durante la primera infancia son materia de varias tesis de la Facultad de Medicina. ${ }^{51}$

Junto a las obras científicas especializadas, comienzan a proliferar manuales, revistas, folletos y cartillas de divulgación, destinados a transmitir a las madres los

\footnotetext{
${ }^{50}$ La explicación del modo en que este proceso se lleva a cabo, varía según los autores que analizan las transformaciones de la familia y la niñez en Europa. Mientras para Boltanki (op. cit.), por ejemplo, se trataría de la difusión e imposición de un modo de vida desde la burguesía hacia la clase obrera, para otros, como Donzelot (1990) o Meyer (1977), el proceso debe verse más bien en términos de una extensión del control del Estado sobre las familias, a través de dos tipos de estrategias diferenciadas, según se las aplique a la familia burguesa o a la familia proletaria.

${ }^{51}$ Con respecto a las tesis para obtener el título de Doctor -en la época, trabajos breves, de síntesis de algún tema particular- cabe reconocer que ya desde la década de 1880 abordaban temas como la lactancia, el destete y la alimentación en general, pero su tratamiento no aparecía vinculados tan claramente a las políticas públicas y al proyecto pedagógico que implicaba la puericultura, como si los estará en el pasaje al siglo XX. Como ejemplos, pueden mencionarse las tesis de Lema (1895), Cervera (1897), Muniagurria (1897), Vacarezza (1900), Tierney (1901), Foster (1902), López (1907), Kaminsky (1914), Magliano (1914), Heudtlass (1919). La tesis de Esther Kaminsky (1914) se titula explícitamente Puericultura y es realizada por esta médica luego de su experiencia como practicante de la Asistencia Pública, como practicante mayor de la Inspección de Nodrizas y practicante del Hospital San Roque.
} 
"principios científicos" de la crianza infantil. Entre sus autores se encuentran algunos de los médicos más prestigiosos de la época, como Luis Agote, que no es considerado médico especializado en la niñez pero publica, en 1901, el manual de puericultura titulado La salud de mi hijo, o Gregorio Aráoz Alfaro, autor en 1899 de El libro de las madres, texto que será varias veces reeditado en los años siguientes.

En el ámbito institucional, la puericultura pasa a ocupar un lugar central en las acciones y programas de organismos públicos, como la Administración Sanitaria y Asistencia Pública de la Municipalidad de Buenos Aires, en cuyo marco, en 1892, se crea un Patronato y Asistencia de la Infancia. La presencia de este enfoque o disciplina médica se intensifica a partir de la creación, en 1908, de la Sección de Protección de la Primera Infancia, que dirige dispensarios de lactantes, institutos de puericultura y una oficina de inspección de nodrizas. ${ }^{52}$ Ubicados en barrio pobres de la ciudad de Buenos Aires, como Barracas o La Boca, los dispensarios de lactantes preparan y entregan alimentos y son también consultorio externos para recién nacidos, donde se lleva a cabo la "asistencia educativa" a las madres (Billorou, 2008). En los institutos de puericultura se realiza el seguimiento médico del recién nacido, pero también hay salas de internación para niños pequeños, acompañados de sus madres. A estos establecimientos se suman las "Gotas de leche", encargadas de entregar leche esterilizada y harinas elaboradas, que en un comienzo son de carácter privado y luego también bajo dependencia de la Asistencia Pública. ${ }^{53}$ La Oficina de Inspección de Nodrizas controla las condiciones de salud, calidad y cantidad de leche de las mujeres que trabajan de nodrizas, así como también vigilan la alimentación y cuidado que reciben sus propios hijos. ${ }^{54}$

El pediatra Genaro Sisto da cuenta de este proceso de construcción institucional en los siguientes términos:

"La puericultura es una ciencia de estos últimos tiempos. El concepto social respecto de su utilidad ya no se discute, y la prueba evidente de su importancia es el progreso que han adquirido todas las instituciones que tienen atingencia con la misma. La creación de

\footnotetext{
${ }^{52}$ Como antecedente de las instituciones europeas creadas para la protección de la primera infancia que sirvieron de inspiración a las ideadas por médicos argentinos, puede mencionarse la fundación, en 1892, del primer Consultorio de Lactantes en París, dirigido por Pierre Budin y destinado al seguimiento del crecimiento y desarrollo infantiles.

${ }^{53}$ Estos establecimientos también se inspiran a los creados en Francia con el nombre de "Gouttes de Lait".

${ }^{54} \mathrm{El}$ funcionamiento de estos establecimientos y el modo en que participan del proceso de medicalización de la crianza, son tratados con mayor detalle en el Capítulo 3.
} 
institutos especialmente dedicados a cuidar los niños en su primera edad, a dar consejos a las madres y alimentos a los niños, se han extendido por todas partes con diversos nombres [...] y nuestra ciudad de Buenos Aires se ha incorporado definitiva y resueltamente entre las ciudades que mejor han comprendido esta función redentora, que realiza la doble función de enseñaza maternológica y de asistencia dietética científica del niño lactante." (Sisto, en Feinmann, 1915, p.vi).

Este desarrollo de instituciones estatales destinadas a la niñez, sin embargo, no debe generalizarse para todo el territorio nacional, pues al interior del país recién entrada la década de 1930 se le destinan políticas nacionales, centralizadas en el Departamento Nacional de Higiene (Billorou, 2008). En efecto, la comparación de la disminución de los índices de mortalidad infantil lograda en la Capital con los altos niveles de éstos en el interior, es una de las razones desde las cuales se reclama una organización de la protección materno-infantil a nivel nacional (Biernat y Ramacciotti, 2008). Como respuesta, el Departamento Nacional de Higiene crea en 1923 la Sección de Asistencia y Protección a la Maternidad e Infancia, bajo la dirección de Aráoz Alfaro, dependencia que, sin embargo, demorará varios años en poder hacer efectivas sus propuestas.

También la escuela pública se constituye en una mediadora que hace posibles las intervenciones del Estado sobre la infancia en materia de salud, no sólo a través de la conformación del Cuerpo Médico Escolar sino de la enseñanza de higiene y puericultura. ${ }^{55}$ Como veremos más adelante, la difusión del mensaje higiénico sobre la crianza infantil es ocupa un lugar central en las escuelas de niñas, puesto que las reglas de crianza de un niño pasan a formar parte de aquello que las mujeres deben saber para cumplir su rol en la sociedad.

\subsection{Los médicos de niños: modos y espacios de ejercicio profesional.}

\subsubsection{La construcción de un perfil profesional.}

Si bien en la época analizada hay una progresiva constitución de especialidades médicas, muchas de éstas no implican incumbencias excluyentes -como lo son en la

\footnotetext{
${ }^{55}$ Las vinculaciones entre la medicina higiénica y el sistema escolar son analizadas especialmente por Lionetti (2011 a y b).
} 
actualidad-, estando la profesión médica coordinada por redes informales de referencia entre generalistas y especialistas, por relaciones flexibles de equipo médico (Belmartino, 2005). En este marco, la conformación de una especialidad médica orientada a la niñez no implica una exclusividad de los pediatras en el tratamiento médico de los niños, pues éstos siguen siendo atendidos en gran parte por los médicos clínicos generales. No obstante, los pediatras, desde los espacios académicos y de atención en los servicios de los hospitales, son quienes, cada vez más, generan y validan el saber específico sobre el niño, trasmitiéndolo a los médicos sin especialización ${ }^{56}$.

Esta distinción relativa entre especialistas en niños y médicos en general se pone de manifiesto en la reseña bibliográfica, publicada en La Semana Médica, acerca del libro de divulgación La salud de mi hijo, escrito por Agote, en la que el comentarista anónimo señala que la obra no sólo es útil para las madres, a quienes está dedicada, sino también "para los médicos poco versados en achaque de pediatría, quienes en ella podrán a cada paso hallar indicaciones oportunas acerca de los innumerables petits rien de que está plagada la medicina práctica" (La Semana Médica, 1901, año VIII, N52, p.34). Asimismo, aparece explícitamente señalada al inaugurarse la sección "Notas prácticas" de los Archivos Latinoamericanos de Pediatría, con un trabajo de Aráoz Alfaro titulado "Indicaciones generales sobre el tratamiento de las gastroenteritis infantiles", en el cual se aclara a pie de página: "Este trabajo, como otros que seguirán apareciendo en el mismo sitio, son destinados no al especialista de niños, sino a los médicos prácticos en general, que son lectores de nuestra revista y que, en buen número, han solicitado esta sección de terapéutica práctica." (Archivos Latinoamericanos de Pediatría, 1906, Tomo II, №1, p. 21).

Junto a esta distinción entre el "especialista de niños" y el "médico práctico general", se delinea otra más ligada al tipo de enfoque con que se aborda la salud infantil: el enfoque clínico, más centrado en la atención de casos individuales de enfermedad y el enfoque higienista, propio de la puericultura, de carácter preventivo,

\footnotetext{
${ }^{56}$ Algo semejante observa el médico vienés Escherich en su visita a los Estados Unidos, realizada en 1905 y relatada en su artículo "Impresiones sobre la pediatría americana". Comenta que la pediatría en aquel país ya es en ese momento reconocida como "ciencia independiente", una especialidad, en tanto posee secciones hospitalarias especiales y un movimiento asociativo desarrollado (entre las varias asociaciones pediátricas, se destaca la American Paediatric, que publica Archives of pediatrics y la revista Pediatrics). Sin embargo, observa que en la práctica la pediatría no está plenamente establecida como especialidad, dado que la mayor parte de los pediatras y hasta los profesores de pediatría ejercen también la clínica general, siendo muy pocos los médicos notables que se dedican exclusivamente a la clínica infantil. (Archivos Latinoamericanos de Pediatría, 1906, año II, № 2).
} 
vinculado a la función pública y las políticas destinadas a la protección de la salud de la comunidad. Tal como se expresa en un artículo de la Semana Médica del año 1916, en el que se comparan ambos abordajes -que trascienden la pediatría- ello implica espacios diferentes de inserción profesional que, sin embargo, como veremos en el próximo apartado, pueden combinarse:

"[Es necesario] precisar la actuación del médico oficial en su carácter de funcionario público y en sus relaciones con las autoridades respectivas, con las colectividades beneficiadas de su ciencia y con las instituciones sanitarias que deben dirigir o de que deben formar parte.

Al lado de este práctico [el médico clínico particular] cuyo crédito y medios de vida se basan exclusivamente en las intervenciones de perentoria indicación, hay ancho campo para aquellos otros que, puestos al servicio de la comunidad, han de constituir de ex profeso, los guardianes avanzados de la salud pública.

El primero, siempre individualista, vivirá de la enfermedad, mejor dicho, tendrá sus ganancias relacionadas directamente con los accidentes imprevistos, con el desarrollo de las epidemias y con el surgimiento de las desarmonías físiológicas de toda naturaleza; el segundo, individualista y colectivista, vivirá de la salud, esto es, se alegrará de no tener enfermos en su jurisdicción, y su reposo y buen nombre estribarán en este éxito, siendo el Estado el llamada esencialmente a sostenerlo. Ambos, en fin, llevan el mismo lema en su bandera: 'Lucha contra las enfermedades': el higienista a la vanguardia, previéndolas, evitándolas e impidiéndolas; el clínico a la espalda, atacándolas directamente con su oportunos esfuerzos terapéuticos." (La Semana Médica, 1916, año XXIII, p. 176).

En el proceso de conformación del perfil profesional del pediatra clínico se percibe, en la primera década del siglo XX, un punto de inflexión entre el modelo de la clínica clásica, fundada en la observación directa, la percepción aguzada, la capacidad de interpretar los síntomas, y el modelo considerado más moderno, basado en los métodos de diagnóstico a partir de la experimentación y los análisis de laboratorio. Esto aparece en la caracterización de la labor de Manuel Blancas, primer encargado de la Cátedra de Enfermedades de los Niños de la Facultad de Medicina (desde 1884), a quien se describe a partir del ejercicio de la clínica y de una transmisión del saber ligada a la noción de "maestro", por contraposición del perfil profesional de quienes lo sucederían, más vinculado a la producción científica, la investigación y la confianza en nuevos medios tecnológicos para el diagnóstico.

En su lección inaugural del curso de 1907, Ángel Centeno, reemplazante de Blancas en la mencionada cátedra, que ahora se llama Clínica Pediátrica, da cuenta de 
esta transición entre esta suerte de "vieja guardia" de la clínica y las nuevas generaciones de pediatras:

"El doctor Blancas, como otros muchos de nuestros maestros, no puede ser actor en el movimiento vertiginoso del microscopio y del laboratorio, que comienza entonces a difundir las luces de sus grandes revelaciones; pero se constituye en un espectador protector de todo lo nuevo, entregando a los jóvenes el inmenso contingente de su labor clínica y de su madura experiencia.

$[\ldots]$.

"Profundo en semiología y en clínica, sabía manejar el análisis minucioso, no obstante de no ser su método predilecto; era original en muchas de sus apreciaciones, pero el rasgo peculiar, que daba característica a su personalidad de profesor, era, sin duda, el tacto médico, las vistas de conjunto y cierta suspicacia penetrante para arribar al diagnóstico, sin detenerse en la anamnesia, ni en los dictados, muchas veces tiránicos, del laboratorio. Blancas era un maestro de clínica con todos los contornos de la vieja escuela, de esa gran escuela Trousseauniana, en que todo salía de la clínica misma, que ha enseñado a interpretar y a formar juicios netos y precisos con los simples medios exploratorios primitivos, puestos al servicio de una observación sagaz y finísima, sin radioscopía, sin cito ni hemodiagnóstico, y sin el poderoso concurso que las nuevas verdades y la experimentación han rodeado posteriormente a la clínica pura, ensanchando sus grandes horizontes de progreso." (Archivos Latinoamericanos de Pediatría, 1907, año III, Nº 4, pp. 113-115).

Más tarde, en la nota en que se comunica el nombramiento del Dr. Mamerto Acuña como Profesor de Clínica Pediátrica de la Facultad de Medicina de Buenos Aires, en 1919, pueden encontrarse algunas características que corresponden al nuevo perfil del médico pediatra académico: tesis de doctorado, investigación, publicación de trabajos científicos sobre cuestiones clínicas y de un libro de divulgación, desempeño en servicios hospitalarios, participación en asociaciones médicas, todo desde la puesta en práctica de un "espíritu metódico de observación y de crítica". (Archivos Latinoamericanos de Pediatría, 1919, 2ª serie, tomo XIII, Nº1).

Ambos perfiles -el de clínico y el de higienista- no son considerados excluyentes y suelen combinarse en el ejercicio profesional de algunos de los médicos de niños más prestigiosos de la época: Aráoz Alfaro, Centeno, Acuña, entre otros. Tal vez sea el primero de ellos quien con mayor frecuencia escriba sobre la necesidad de valorizar la prevención, la educación y la formulación de políticas de asistencia, 
como parte del ejercicio profesional del médico de niños, con un valor equivalente al del tratamiento de niños enfermos. Así, en el prefacio de la primera edición de su manual de crianza infantil, justifica su dedicación a la tardea de divulgación:

"Vulgarizar esos preceptos, tratar de introducirlos en los hogares argentinos, con la autoridad que puedan dar muchos años de dedicación a la medicina infantil, es, a mi juicio, obra de humanidad y de patriotismo. Y por eso no he retrocedido ni ante las dificultades de la vulgarización científica - dificultades grandes para quien hasta ahora no ha escrito sino para el público médico - ni ante la posibilidad de críticas por parte de los que creen que sólo para los hombres de ciencia debe escribirse.

"Estoy convencido de que si consigo expresar en este libro, con bastante claridad y exactitud, las ideas y los preceptos racionales que deben presidir la crianza del niño, habré realizado una obra mucho más provechosa para la sociedad y para el país que con todos mis trabajos propiamente científicos. Tarea humilde y obscura es, pero digna de quien se duele de tantos sufrimientos fácilmente evitables, de tantos hogares desgraciados por falta de una dirección adecuada" (1929 [1899], p.viii).

También el profesor Morquio busca transmitir esta perspectiva a los futuros pediatras, a quienes expresa en su curso de clínica infantil:

"Habéis aprendido que las causas generales de las enfermedades en esta edad son en su mayoría evitables y entonces vuestra noción de médico se hará sentir elogiosamente, preservando de las enfermedades y de la muerte a numerosos niños, por vuestros prudentes consejos de profilaxia y por vuestra terapéutica acertada y racional; y de esta manera llenaréis un rol social de primer orden, concurriendo a la disminución de la mortalidad infantil, que es uno de los problemas más serios que afligen a la humanidad" (Morquio,1906a, p.399).

Como ya he señalado, junto al proceso de división del trabajo y tendencia a la construcción de monopolios que implica la especialización profesional, se producen pasajes e intercambios entre los discursos científicos y las prácticas de poder que implica la gestión de la población (L'Estoile, Neiburg y Sigaud, op. cit.). Es justamente este carácter multifacético, definido en términos de ejercer la "misión social" de la pediatría y de la puericultura el que, en una época donde las especialidades médicas no están rígidamente delimitadas, permite a estos profesionales reclamar un lugar 
específico tanto en el campo académico-científico como en el campo social más amplio. $^{57}$

\subsubsection{Los espacios de ejercicio profesional.}

Pediatría y puericultura se constituyen y consolidan en una época en que el Estado ha avanzado en la creación, organización y supervisión de un sistema de atención de la salud, pero la Sociedad de Beneficencia aún posee y administra gran parte de los establecimientos destinados a tal fin. ${ }^{58}$ En este marco, los médicos de niños participan de una disputa más amplia entre los defensores de una administración totalmente estatal de la asistencia médica y social, y aquellos que proponen una combinación de supervisión estatal e iniciativa privada, tal como lo expone Nari (2004):

"Instituciones de asistencia y beneficencia, públicas, privadas y semipúblicas, coexistieron a lo largo de todo el período estudiado en la atención, protección y vigilancia de madres y niños. Los médicos fueron penetrando en todas ellas con más o menos conflictos. Gradualmente y dentro de ámbitos públicos sus auxiliares, las enfermeras, fueron desplazando a las monjas en el cuidado y atención de los enfermos. Los médicos aceptaron, con fervor o resignación, la existencia de las instituciones de beneficencia, dirigidas por mujeres de la elite. También hubo oposiciones y posiciones críticas, fundamental pero no exclusivamente entre los médicos socialistas. [...] Pero la mayoría aceptó la existencia de esos establecimientos con cierta resignación y ánimos de colaboración, puesto que reconocían que la provisión de servicios y camas por parte de instituciones públicas era aún insuficiente $\mathrm{y}$, por lo tanto, no podían desechar otras posibilidades de atención médica". (p.127).

\footnotetext{
${ }^{57}$ Castellanos (op. cit) reconoce en esto una impronta de la pediatría, que se continúa hasta el día de hoy. Encuentra que los pediatras clínicos actuales (exceptuando los que están ultra especializados) terminan trabajando sobre la infancia como categoría y problema social, con lo cual se sienten habilitados para abordar aspectos de los niños que trascienden ampliamente sus enfermedades en el sentido biológico.

${ }^{58}$ La Sociedad de Beneficencia, creada en 1823 durante el gobierno de Rivadavia para organizar en gran parte la educación y la asistencia social en general, ha perdido para la época aquí analizada, gran parte de su poder e incumbencias iniciales (sobre todo cuando sus escuelas de niñas pasan a depender del Consejo General de Escuelas, del Estado) pero continúa dirigiendo varios hospitales de la ciudad de Buenos Aires. Mantuvo siempre una relación ambigua con el Estado, de donde provino su apoyo financiero, ambigüedad derivada de su carácter de entidad privada creada por el Estado para cumplir funciones públicas, desempeñando sus tareas de asistencia en forma privada pero en gran parte con fondos públicos.
} 
Si bien la puericultura es una de las especialidades médicas que formula y respalda una mayor intervención del Estado en el área de salud (Billorou, 2008), por lo menos durante las dos primeras décadas del siglo XX, la práctica médica ligada al cuidado infantil se desarrolla tanto en instituciones públicas como privadas. ${ }^{59}$

Cabe aclarar que, como ya se ha señalado, la distribución de los servicios médicos en el territorio nacional es muy desigual: la mayor cantidad de médicos y de instalaciones con camas de internación se encuentra en la Capital Federal, seguida por las demás ciudades de urbanización temprana (Córdoba, Rosario, Santa $\mathrm{Fe}$ ), acompañando la actividad económica y la prosperidad derivada de la integración al mercado nacional o internacional (Belmartino, 2005).

Dentro del sistema público Belmartino (op. cit.) plantea la necesidad de distinguir entre los servicios administrados por agencias del Estado (municipal, provincial, nacional) y los gestionados por las sociedades filantrópicas o de beneficencia. En el ámbito privado se encuentran los consultorios particulares de los médicos (algunos instalados en los suburbios) o los que funcionan en incipientes empresas médicas, los servicios de mutualidades y de los hospitales de las colectividades. En cada uno de esos diferentes espacios varían las formas de vincularse con los pacientes y con las fuentes de financiamiento.

En los hospitales públicos -estatales y de beneficencia-, así como en los dispensarios de lactantes y los institutos de puericultura, los médicos son remunerados por salario o, en muchos casos, atienden en forma gratuita, movidos por un impulso filantrópico pero también debido a que en ese tipo de instalaciones están concentrados no sólo los pacientes afectados por enfermedades de cierta complejidad, sino también los recursos de diagnóstico y terapéutica disponibles para su atención. "El hospital público se constituye por consiguiente en un lugar donde el médico continúa su formación profesional $\mathrm{y}$, a la vez, dispone de los recursos técnicos que demanda la atención de sus pacientes privados” (Belmartino, 2005, p.30).

\footnotetext{
59 Aun cuando a fines del siglo XIX los higienistas se habían enfrentado con la Sociedad de Beneficencia de Buenos Aires, limitando sus iniciativas a través de la creación de la Asistencia Pública y la Administración Sanitaria, más tarde dicha Sociedad comienza a integrar a numerosos médicos en sus establecimientos para conformar los cuerpos consultivos y asesores de los mismos.
} 
En los espacios privados, perciben honorarios, ya sea mediante el pago directo por parte de los pacientes o a través de alguna de las formas de cobertura mutual existentes. Es posible suponer que el vínculo que médico y paciente establecido en el consultorio particular es más personal y estrecho que en los servicios públicos. En general, como señala Belmartino (op. cit.), son los mismos profesionales quienes por la mañana atienden a la población pobre en el hospital u otro centro asistencial y, por la tarde, reciben otros pacientes en su consultorio particular, pequeñas clínicas o los escasos sanatorios, en un momento en que la práctica profesional aun no requiere instalaciones demasiado complejas. Además, los médicos más reconocidos en la época combinan la atención de pacientes en ámbitos públicos y/o privados, con la actividad académica y el desempeño en la función pública. Por ejemplo, en 1905 la revista Madre y Niño publica el aviso del consultorio particular del Dr. Genaro Sisto, quien también se desempeña como médico en el Hospital de Clínicas, como profesor en la Facultad de Medicina y Vocal del Cuerpo Médico Escolar. Como lo muestra este caso, las instituciones de salud no son las únicas, donde se lleva a cabo la intervención médica sobre la niñez, sino que también la escuela pública es un espacio de inserción profesional, específicamente a través del Cuerpo Médico Escolar. ${ }^{60}$

Es posible afirmar que en el proceso de construcción de una especialidad profesional, su participación en espacios de gestión de la salud pública no constituye un impedimento para estos médicos, sino lo que les permite distinguirse y jerarquizar su profesión frente a otros grupos. $\mathrm{Al}$ contrario, puede pensarse que es en el ámbito de la gestión pública donde, apelando a la necesidad social de su práctica, logran legitimar primero su actuación sobre la infancia y -más específicamente- sobre la primera infancia como nueva área de conocimiento, para luego disputar su reconocimiento en el ámbito científico y académico. En este sentido, como ya fuera dicho, los discursos científicos y los debates sobre la política de las poblaciones no se generan y reproducen en universos distintos, sino que se despliegan en un espacio que, al menos en parte, les es común (L'Estoile, Neiburg y Sigaud, 2000). Así, si tomamos datos de la actuación profesional de algunos médicos conocidos por su labor en la consolidación de las áreas de la pediatría $\mathrm{v}$ la puericultura, vemos que en sus trayectoria se combinan el desempeño como funcionarios en la Asistencia Pública o el Departamento Nacional

\footnotetext{
${ }^{60}$ El Cuerpo Médico Escolar es creado a fines del siglo XIX como dependencia del Consejo Nacional de Integrado por médicos inspectores, tiene entre sus funciones la inspección edilicia y de la higiene escolar, así como la incorporación de temas de higiene en el currículum de los alumnos.
} 
de Higiene, como docentes universitarios, como médicos en hospital y en consultorios particulares, investigadores científicos y escritores de textos de divulgación. Además, algunos asesoran las actividades de instituciones de beneficencia. Un caso claro es el de Gregorio Aráoz Alfaro (nacido en 1870 y muerto en 1955) quien, a lo largo de sus vida profesional, se desempeñó como Catedrático Titular de Semiología y Ejercicios Clínicos de la Facultad de Medicina de Buenos Aires, presidente del Departamento Nacional de Higiene, Jefe del Servicio de Niños del Hospital San Roque, Miembro correspondiente de la Sociedad de Medicina de Montevideo y de la Academia Nacional de Medicina de México, presidente de la Academia Nacional de Medicina, Secretario de la Asistencia Pública, Fundador y primer vice-presidente de la Sociedad Argentina de Pediatría, Director de los Archivos latino-americanos de Pediatría, además de cómo autor de numerosos textos científicos y de divulgación.

El breve recorrido hasta aquí realizado permite afirmar que el campo profesional de la medicina del niño y la categoría social de niñez o infancia son elementos producidos - en sus comienzos, pero también actualmente- en un conjunto de prácticas sociales presentes en la constitución de toda una red institucional dirigida a la conservación de los niños (Castellanos, 2003).

En la década de 1920 termina de constituirse un sistema institucional sanitario de amplia cobertura social hacia la niñez - por lo menos en la ciudad de Buenos Aires y ciudades del Litoral- que había comenzado a delinearse a fines del siglo XIX. Varios dispensarios de lactantes e institutos de puericultura dependientes de la Asistencia Pública, así como maternidades y consultorios pediátricos en los hospitales, se encargan gratuitamente de la atención materno-infantil en la Capital y las principales ciudades del país, a la vez que circulan entre la población numerosas publicaciones de divulgación de los métodos científicos de la crianza infantil y la puericultura forma parte de los programas de estudio de la enseñanza primaria y secundaria. Al mismo tiempo, existen cátedras de pediatría y puericultura en las principales universidades del país y los médicos pediatras cuentan con publicaciones y eventos científicos propios. 
Pero, si a comienzos del siglo XX la profesión médica ya ha logrado el reconocimiento jurídico que le otorga derecho exclusivo en la cura de enfermedades, y la pediatría aparece consolidada como especialidad hacia 1920, la práctica de la mayor parte de la población, la medicina hogareña y la automedicación continúan siendo los modos más comunes de lidiar con los malestares físicos (Armus y Belmartino, 2001). El consejo de una mujer de la familia o una vecina suele ser el primer recurso ante una enfermedad infantil y, si a veces se llama al médico para casos graves, el cuidado cotidiano del niño sano es una atribución femenina que pertenece al ámbito doméstico. Esto hará del ejercicio del saber y la práctica médicos sobre la crianza un conflicto constante con otros saberes y prácticas, conflicto a través del cual no sólo se busca imponer un conjunto de pautas y principios sobre el cuidado infantil, sino un modo de entender la niñez y definir su lugar con respecto a otros grupos sociales. 


\title{
CAPÍTULO 2
}

\author{
MALEABILIDAD Y EVOLUCIÓN: \\ LA NIÑEZ CONSTRUIDA POR LA MEDICINA
}

\begin{abstract}
"El organismo del niño, es más que una realidad, una promesa; más que un presente, un porvenir.

$\mathrm{Su}$ alma como su cuerpo, inician una evolución que la conduce a una constitución definitiva; sus ideas son confusas; sus movimientos son casi todos involuntarios; sus órganos, aun cuando funcionan, deben perfeccionarse y vigorizarse en el trabajo que cada uno de ellos realiza. En una palabra: el niño crece." (Muniagurria, La flor humana. Texto de puericultura elemental para uso de las escuelas primarias de niñas de la República, 1923).
\end{abstract}

De esta manera, el médico Camilo Muniagurria, Profesor de Clínica Pediátrica y Decano de la Facultad de Medicina de la Universidad de Rosario, explica las características de la niñez a las alumnas de escuela primaria a las que destina su "texto de puericultura elemental". En pocas frases aparecen sintetizadas las nociones con que, desde el saber médico -pero no sólo desde él- es definido el niño como ser genérico: el niño es "promesa", "porvenir", antes que "realidad" y "presente". Los elementos que conforman su cuerpo y su alma son aún débiles, confusos, no han terminado de constituirse y consolidarse, por lo que es más un mañana, un futuro a realizarse, que una entidad actual. Para que se torne una realidad -que sólo será en el momento de la adultez- debe transformarse, transitar una evolución, un proceso progresivo de fortalecimiento y perfeccionamiento que, como se verá, no está exento de riesgos. Y es precisamente este tránsito, este no ser aun un sujeto pleno sino el 
estar en camino hacia ello, lo que define a la niñez desde la medicina: "el niño crece".

En este capítulo busco explorar el modo en que la niñez es delimitada y caracterizada como una etapa de la vida y como estatus social por la medicina infantil de fines del siglo XIX y comienzos del XX. Las características particulares que la pediatría y la puericultura atribuyen al niño como sujeto y como integrante de un grupo etario determinado, serán abordadas en términos de una "teoría nativa" sobre los primeros tramos de la vida, es decir, procurando una mirada distanciada que la muestre como una de las tantas construcciones posibles sobre las edades y la persona.

Para ello, parto de considerar a la niñez como una categoría socialmente construida, en el sentido en que lo plantea Bourdieu (1983, 1995), es decir, como producto de procesos de clasificación, de selección, conocimiento y reconocimiento de determinadas características y relaciones como propias de una etapa específica de la vida y del simultáneo establecimiento de distinciones con respecto a otras (juventud, adultez, vejez, etc.). A través de estas clasificaciones no sólo se establecen divisiones en el mundo social entre partes o momentos de la vida, sino que también se instituyen grupos sociales -etarios- y se sitúa a quienes los integran -en este caso, los niños- en un lugar social particular.

En ese sentido, los trabajos antropológicos en diferentes sociedades han permitido afirmar que no son las fases de maduración biológica en sí mismas, sino las relaciones que el sujeto establece dentro de su grupo doméstico, del parentesco y de la sociedad como un todo, las que delinean y expresan los cambios dentro del transcurso de la vida (Fortes, en Balandier, 1975; Spencer, 1990; Thorne, 2007). ${ }^{61}$ En ese marco, ciertos aspectos asociados a las transformaciones biológicas son socialmente seleccionados y leídos como señales indicadoras de que el individuo está listo para pasar de una fase a la siguiente, siendo este pasaje frecuentemente ritualizado. Por consiguiente, la niñez como grupo no comienza a existir como tal, para sus integrantes

\footnotetext{
${ }^{61}$ La literatura antropológica, sociológica y psicológica ha conceptualizado el proceso de la vida de los sujetos y de los grupos sociales en términos de "ciclo de vida" o "curso de la vida". Se ha criticado el concepto de "ciclo de vida", en tanto implicaría un recorrido lineal, pre-establecido e irreversible, que dejaría poco margen para incorporar discontinuidades, crisis imprevistas y cambios. Una síntesis de las diferentes perspectivas y discusiones involucradas en la construcción y uso de ambos conceptos, puede encontrarse en Remorini (2009).
} 
y para los demás, hasta que no es distinguida y recortada a través del conocimiento y reconocimiento de ciertas características que, al ser leídas como propias de una clase particular de personas, las transforma en una categoría social. En este proceso de construcción social de la niñez, que no es unívoco ni armónico, sino que implica disputas y relaciones de poder, se ponen en juego nociones particulares de persona, temporalidad, cuerpo, familia, maternidad, lazo social, entre otras.

A su vez, considero importante en este capítulo abordar la niñez como un status de persona, como un lugar social particular, construido relacionalmente con respecto al lugar social de otros grupos etarios -especialmente la adultez- y comprendido a través de imágenes, representaciones, códigos, construcciones, con frecuencia heterogéneos y disputados, tal como lo señala Jenks (1996). De acuerdo con esta autora, las formas de pensar la infancia presuponen una forma de pensar las relaciones entre niño y adulto, dos posiciones sociales que se definen mutuamente a partir de sus fronteras; fronteras que en las sociedades occidentales modernas son definidas a partir de las oposiciones débil/fuerte, inocente/responsable, incompleto/completo, instintivo/racional, incapaz/competente, entre otras. ${ }^{62}$

Teniendo en cuenta este marco general, veamos de qué modo las diversas obras escritas por pediatras e higienistas entre 1880 y 1930 permiten rastrear el modo en que la niñez es construida por el saber y las prácticas médicas de ese momento histórico particular.

Una primera definición y caracterización del niño suele ser presentada en los primeros capítulos de los manuales de puericultura: luego de tratar los procesos de gravidez y nacimiento, se explica cómo es ese sujeto, el recién nacido y luego el bebé, al que estará dedicado el resto del libro y con el que muchas madres se encuentran por primera vez. También los tratados de pediatría dedican parte de sus primeros tramos a transmitir a los futuros médicos cuáles son las peculiaridades de la niñez, para abordar luego las patologías que le son propias, con sus correspondientes diagnóstico y terapéutica según los momentos o sub-etapas que la integran: nacimiento, primera infancia, segunda infancia.

62 Vianna (2002) conceptualiza esta relación establecida entre niños y adultos en las sociedades occidentales, en términos de "minoridad". Si bien suele restringirse este concepto al ámbito jurídico, la autora muestra que la relación de "minoridad" es una lógica que ordena las relaciones entre niños y adultos en diferentes esferas de la vida social. 
Así, si en la época delimitada para este análisis la atención de la salud infantil en general se considera prioritaria para el futuro de la nación, el saber de la medicina y las políticas sanitarias se particularizan en relación a un grupo específico: la llamada "primera infancia", encarnada en la figura del bebé. El recién nacido y el lactante, que atraviesan esa sub-etapa infantil, constituyen el objeto privilegiado de los las reflexiones y consejos médicos sobre la crianza, por estar atravesando el momento más propenso a las enfermedades y la muerte. Por ello, en este capítulo se presentan los conceptos y aspectos mediante los cuales lo médicos construyen la niñez en general, para luego profundizar en la descripción y análisis que realizan acerca de la primera infancia.

A través de sus obras, ya sea de los textos eruditos o de aquellas destinadas a la divulgación, los médicos van estableciendo las características que permiten distinguir la niñez de otras etapas de la vida, retomando elementos presentes en otros saberes y debates de la época, pero con el tinte particular de la preocupación por el mantenimiento de la salud y el tratamiento de la enfermedad, así como por las características atribuidas al cuerpo infantil en tanto "organismo". Ello suele expresarse en términos de la definición y la explicación de la "naturaleza infantil", expresión que -como veremos- alude a aquellas características consideradas propias del niño, irreductibles a las de otras etapas de la vida, poniendo en juego una serie de distinciones entre naturaleza y civilización, herencia y ambiente, instintos y comportamientos aprendidos (Colangelo, 2011).

\section{1. Crecimiento y desarrollo: la especificidad de la niñez como etapa de la vida.}

La infancia aparece situada, en los textos médicos, como parte de una secuencia temporal más amplia, que abarca la totalidad de la vida de los sujetos. Ésta es concebida como una sucesión lineal de etapas que se extienden entre el nacimiento y la muerte, correspondiendo la niñez a la primera, a la fase o etapa inicial, delimitada cronológicamente por el nacimiento y la pubertad. Entre estos límites, se atribuyen a la niñez características anatómicas, fisiológicas y del comportamiento particulares que la distinguen de las restantes etapas de la vida; características que, como se vio en el capítulo anterior, se tornan -a la vez que resultan de- en el fundamento de una especialidad profesional. 
En uno de los primeros tratados de pediatría escritos por médicos argentinos, su autor, Garrahan (1930 [1921]) comienza explicando:

"Abarca la niñez largo período de vida -desde el nacimiento hasta la pubertad, cerca de tres lustros- período durante el cual se realiza el crecimiento y desarrollo. Caracterizan a esa época inicial de la existencia, particularidades anatómicas y fisiológicas vinculadas al crecimiento y al desarrollo, particularidades que se modifican sucesivamente con el avance de la edad. Y también tiene la niñez su patología especial: enfermedades propias de determinadas edades, reacciones mórbidas diversas según se trate de recién nacidos, de lactantes, o de niños mayores." (Garrahan, p.17).

Así, como vemos, la especificidad de la niñez, sus características particulares, se atribuyen a los procesos de crecimiento y desarrollo, que hacen de ella un estado transicional, una continua transformación orientada a alcanzar un estado diferente, que es el de la adultez. "Toda la vida del niño está sujeta a su crecimiento y a su desarrollo"- se afirma en el Congreso del Niño realizado en 1919 (Archivos Latinoamericanos de Pediatría, 1919, №4, p.276). En el mismo sentido, Garrahan explica que "Hay en el organismo joven un verdadero impulso de crecimiento desconocido en su intimidad y vinculado a la esencia misma de la vida" (op. cit. p. $18)$.

El crecimiento es explicado como el aumento progresivo de tamaño y masa corporal; el desarrollo, como diferenciación anatómica y funcional, como complejización de la estructura de los órganos y sus funciones.

"El desarrollo -diferenciación anatómica y funcional- se pone de manifiesto en las modificaciones sucesivas de los órganos y en el perfeccionamiento de las aptitudes. Es así que pueden observarse cambios notables en la estructura del sistema nervioso, óseo, etc., con el avance de la edad, del mismo modo que se comprueba el progreso de las funciones, las cuales se hacen cada vez más complejas [...]" (Garrahan, 1930 [1921], p. 18).

Crecimiento y desarrollo son considerados procesos naturales que actúan en la niñez simultáneamente, aunque con relativa independencia. Ambos constituyen la expresión de características innatas, hereditariamente establecidas, pero que requieren que el niño se mantenga sano y sea adecuadamente alimentado para poder desplegarse y manifestarse plenamente. El niño tendría dos períodos de crecimiento 
intensivo: el que sigue al nacimiento y el de la pubertad; períodos que, justamente demarcan los límites de la infancia. El desarrollo, es decir, la diferenciación, sería mayor durante el primer período de crecimiento que en los restantes pero, a su vez, se prolongaría hasta muy tarde (Garrahan, op.cit.).

Asimismo, sobre todo en autores de la última década del siglo XIX y los primeros años del XX, crecimiento y desarrollo son considerados una reedición de la evolución de la especie, desde una explicación que considera que la ontogenia reproduce la filogenia:

"Así como, la evolución del embrión humano, es la repetición zoológica de todas las especies que le anteceden, la vida primera del niño, parece ser la reproducción histórica de toda la humanidad." (Feinmann (1915p. 16).

Lo propio del niño es, entonces, crecer y desarrollarse, y ello implica dejar de ser niño a través de una serie de transformaciones no sólo anatómicas y fisiológicas, sino también psíquicas y "morales". Esto hace de la infancia -y muy especialmente, de la primera infancia- una realización futura, antes que una experiencia del presente. Estas transformaciones son pensadas como una secuencia lineal, progresiva, de etapas, que implica un recorrido evolutivo desde lo simple a lo complejo, de lo inmaduro a lo maduro, y cuya meta está definida de antemano: el adulto racional, completo, maduro y competente. El atravesar ordenadamente y en el momento previsto cada una esas etapas se torna el criterio de normalidad infantil, aunque autores como Garrahan (op. cit.) admiten que el crecimiento no se cumple con la misma regularidad en todos los sujetos y suele realizarse por "empujes". Es en el marco de esta concepción de la niñez y de las etapas de la vida que, tal como señala Pereira (2006), la muerte infantil aparece como precoz y patológica, al interrumpir el recorrido vital del ser humano, impidiéndole llegar a su etapa final.

Estas ideas tendrían continuidad en la pediatría actual que, de acuerdo al análisis que realiza Castellanos (op. cit.), continúa tomando al niño en su devenir hacia el adulto. Este autor señala que el desarrollo se torna una categoría homogeneizadora en el abordaje médico de la niñez, en tanto la diversidad hallada entre diferentes niños es reducida, opacada, por la unidad del ser en desarrollo. Como también señala Rabello de Castro, “[...] las explicaciones sobre la naturaleza del 
desarrollo afirman el carácter universal de las trayectorias de la vida humana” (2001, p.28).

Crecimiento y desarrollo suponen un estado inicial de incompletud e inmadurez, pero también una plasticidad, una maleabilidad del niño, que hacen posible su transformación progresiva hacia la etapa adulta, o su desviación, su “deformación” si este tránsito carece de una guía adecuada:

"[...] esta evolución se opera dentro de reglas fisiológicas que deben ser vigiladas y dirigidas conscientemente, para evitar desviaciones y para corregirlas cuando éstas se produzcan. Es del mayor conocimiento de su naturaleza, de sus condiciones físicas y psíquicas, de las causas que provocan las enfermedades, físico y morales, de la manera de corregirlas, que ha surgido todo un conjunto de problemas, higiénicos y sociales, que se traducen en leyes y organizaciones, que constituyen hoy la defensa del niño en todas sus manifestaciones." (Archivos Latinoamericanos de Pediatría, 1919, $\left.\mathrm{N}^{\mathrm{o}} 4, \mathrm{p} .276\right)$.

Efectivamente, la concepción del niño como un ser maleable hace posibles $-\mathrm{y}$ necesarias- las nociones de crianza y de educación, tal como veremos en el próximo capítulo: del modo en que las madres, guiadas por el médico, moldeen esa "blanda masa" que es el niño, depende que el Estado pueda obtener más tarde "el hombre fuerte de físico, sano de alma, flexible y abierto de inteligencia" (Aráoz Alfaro, 1929 [1899], p.ix).

Sin embargo, cabe advertir que este modo de explicar los primeros tramos de la vida de los seres humanos que puede parecer obvio y natural por ser el que continúan presentando la ciencia y el sentido común, corresponde sólo a una versión entre las muchas que han construido las sociedades humanas. En efecto, el proceso de maduración humana ha sido organizado e interpretado de modos histórica y culturalmente variables (Thorne, 2007). Aún más, puede afirmarse que el ver la vida como un proceso de maduración progresiva es en sí misma una concepción particular que tiene que ver con una noción específica del tiempo, de las transformaciones, así como con un modo de concebir y construir la persona. ${ }^{63}$

\footnotetext{
${ }^{63}$ Con "construcción de la persona" se alude, en términos generales, a la definición social de humanidad, a los procesos considerados necesarios para que un ser adquiera el atributo de ser humano y al modo en que la sociedad interviene en esos procesos, que son continuos y no finitos.
} 
En numerosas sociedades, las transformaciones que acontecen en el transcurso de la vida no consisten en procesos de maduración, de complejización progresiva, sino en el reemplazo de una categoría de persona por otra diferente. Los ritos de pasaje marcan la finalización y muerte simbólica de una categoría social (por ejemplo, la niñez), para dar surgimiento de una nueva. Cada categoría implica un ciclo completo que, al llegar a su fin, debe ser sustituido por otro, en el que se es otra clase de persona (Groppo, en Chaves, 2005). A diferencia de estas sociedades, en las que la persona se construye como parte inescindible del grupo social y participando en una temporalidad que es también la de los ciclos de la naturaleza y del cosmos, en las sociedades occidentales modernas, vinculadas al despliegue del capitalismo, la persona se construye como un individuo, autónomo y autosuficiente, en el marco de una conciencia lineal y segmentada del tiempo y de la existencia, asociada a las ideas de evolución y progreso. ${ }^{64}$

Por lo tanto, lejos de ser la expresión de procesos naturales, "crecimiento" y "desarrollo" responden a un sentido del cambio socialmente construido. Jenks (1996) caracteriza esta construcción en términos de una teoría naturalizada del tránsito social del niño en relación con el mundo adulto, teoría que la antropología clásica ha considerado en términos de "enculturación" o, tal como lo hace la sociología, como “socialización”. En términos críticos, la mencionada autora considera que ambos conceptos remiten los supuestos del niño como un ser pre-cultural o pre-social y de la sociedad y la cultura como estructuras de relaciones o sistemas de pautas y significados establecidos, que preceden y trascienden las prácticas y representaciones de los actores sociales. En este sentido, puede afirmarse que los conceptos de crecimiento y desarrollo no sólo se ponen en juego en el ámbito de la medicina, sino que constituyen las dos grandes metáforas a partir de las cuales las sociedades occidentales modernas han comprendido y explicado la niñez. En este sentido, es a través de ellas que se establece una articulación entre la mirada médica y el tratamiento social del niño, y que las nociones y argumentos de la pediatría encuentran resonancia en el discurso social más amplio, expresado en políticas, instituciones, programas, destinados a la niñez. ${ }^{65}$

\footnotetext{
${ }^{64}$ El antropólogo Louis Dumont (1993) ha explicado estas dos lógicas sociales y de construcción de la persona a través de la construcción de dos modelos de sociedad: las "sociedades holistas" y las "sociedades individualistas".

${ }^{65}$ En el marco de una definición social común de la niñez, asociada al crecimiento y al desarrollo, diferentes disciplinas científicas o áreas de la vida social establecen sus puntos de referencia para
} 
La metáfora del "crecimiento" hace del cambio anatómico que se produce en la infancia un indicador de una transición social. A su vez, combinando las nociones de tiempo, naturaleza y progreso, el "desarrollo" se constituye en la metáfora primaria a través de la cual la niñez es explicada y articulada con la noción de futuro: implica la idea de una temporalidad lineal a lo largo de la cual el niño inevitablemente debe cambiar, el supuesto de que este cambio es un proceso natural, realización de lo que es biológicamente inherente y la noción de progreso, de mejoramiento gradual e inevitable, como guía de las transformaciones esperadas (Jenks, 1996). Al respecto, resulta interesante la discusión que abren James, Jenks y Prout, (1998) en cuanto a los límites que la materialidad del cuerpo infantil y las modificaciones que en él se producen, ponen a este abordaje constructivista acerca del crecimiento y el desarrollo. Los autores sitúan, no obstante, la dificultad de encontrar en el cuerpo algún elemento pre-social y plantean el modo en que en estas discusiones se reeditan las distinciones entre naturaleza y cultura, así como el papel de ambas en estos procesos. Haciendo un balance de los argumentos, más que negar la objetividad de las transformaciones corporales y psíquicas en la niñez, cabe preguntarse por qué son pensadas de modo unilineal, en términos de progreso y futuro, más que de presente, mientras que, por ejemplo, las múltiples transformaciones que acontecen en la adultez no son consideradas la clave natural para definir a esta etapa ni para homogeneizar a sus integrantes y, mucho menos, sus actividades y espacios.

En el discurso médico analizado - pero no sólo en él- crecimiento y desarrollo son, a su vez, presentados como los procesos a partir de los cuales se establece la distinción entre niñez y adultez, siendo su intensidad directamente proporcional al tamaño de la brecha que separa ambas etapas:

"El niño es bien distinto del adulto en su tamaño y en su constitución. $\mathrm{Y}$ es con el crecimiento y el desarrollo que esas diferencias disminuyen paulatinamente hasta llegar a desaparecer. Se comprende entonces, que cuanto menor sea su edad, mayores sean tales diferencias." (Garrahan, op. cit. pp. 19-20).

clasificar y codificar cronológicamente dichos procesos, según la forma predominante del discurso y las relaciones sociales que involucran a los niños: pueden tener que ver con la responsabilidad moral y criminal, el consentimiento sexual, habilitación para la participación política, el consumo, etc. 
Sobre la base de la oposición inmadurez/madurez, se insiste en que el niño no debe ser considerado como un adulto en miniatura -definición que, dada la insistencia de los autores, habría predominado hasta poco tiempo antes-, sino que tiene características que le son propias en función de su edad. Así, por ejemplo, en el discurso inaugural del $2^{\circ}$ Congreso Americano del Niño, realizado en Montevideo en 1919, el pediatra Luis Morquio señala que "Las necesidades del niño varían según la edad; ya no es exacta la definición que hacía del niño un pequeño hombre." (“Crónica”, Archivos Latinoamericanos de Pediatría, 1919, №4, p.276). A su vez, el médico naturista Antonio Valeta, en su manual de divulgación titulado La salud del nene, funda sus consejos en la particularidad infantil, recuperando las ideas de Rousseau: "El niño no debe ser ni animal ni hombre, sino niño; -dijo el filósofo Rousseau" (Valeta, 1917, p.42).

Sin embargo, tal como lo plantea Jenks (op. cit.), ni las diferencias entre niños y adultos dependen en sí de las diferencias físicas ni la transformación de niño en adulto deriva directamente del crecimiento y desarrollo, sino que se trata de estatus de persona diferentes, que se establecen y tienen sentido en una determinada estructura social, con un determinado modo de procesar la temporalidad y, sobre todo, de establecer relaciones de poder entre grupos etarios. En ese sentido, Carli (2002), siguiendo a Laclau, caracteriza las relaciones entre niños y adultos como contingentes y asimétricas, es decir, no necesarias ni horizontales, sino producto de construcciones históricas atravesadas por el poder. Abordando desde otro ángulo esas relaciones de poder, Bourdieu (1983) alerta sobre el poder de producir efectos sociales de las clasificaciones etarias, a partir de las cuales se genera un orden naturalizado, con lugares desiguales en los que cada uno debe mantenerse.

La necesaria problematización de las explicaciones que las fuentes médicas naturalizan, nos conduce a pensar en la niñez y adultez como dos lugares sociales que se definen mutuamente a partir de sus fronteras: la idea del niño como ser inacabado, incompleto o inmaduro, lo sitúa en el lugar de la incompetencia y la dependencia, a la vez que requiere e implica la visión del adulto como maduro, completo, racional y competente. Morfología y fisiología diferentes constituyen, entonces, las explicaciones "nativas" que permiten hacer inteligibles estas relaciones socialmente establecidas entre adultos y niños, relaciones definidas y prescritas en términos de cuidado, protección, formación. 


\subsection{1 - Los patrones de crecimiento como expresión de la salud individual y colectiva}

A lo largo del recorrido hasta aquí realizado, pudimos ver que la definición de la infancia que construye la medicina de fines del siglo XIX y comienzos del XX, es de carácter relacional -se produce con una simultánea construcción de la adultez- y está anclada en una particular noción de temporalidad, que implica un modo de articular presente y futuro: la niñez remite a lo que aun no es pero está presupuesto, a una realización futura antes que una experiencia del presente. En el presente, el niño es puro potencial, una página en blanco a ser escrita o una "blanda masa a ser moldeada" (Araóz Alfaro, op. cit.). Definido también como "el cofre en el cual se encierran los gérmenes de un destino" (Muniagurria, 1923), es valioso como porvenir, es decir, por aquello en que se convertirá cuando deje de ser niño mediante los procesos de crecimiento y desarrollo:

"El concepto del niño en la actualidad, ha alcanzado un grado de perfeccionamiento, que representa uno de los más elevados exponentes de cultura y de sentimientos nobles y generosos. No solamente vemos en el niño de hoy, un ser delicado y frágil, que merece y exige toda nuestra protección, sino también vemos en él al hombre de mañana, al continuador de nuestra raza, que transmitirá a las generaciones futuras nuestras aspiraciones, en el sentido de una vida cada vez más sana, más pura y más bella." ("Crónica", Archivos Latinoamericanos de Pediatría, 1919, №4, p.276).

Esta asociación entre niñez y futuro es el eje que articula dos grandes núcleos de representaciones sobre la infancia presentes en los textos médicos: 1) la imagen de la infancia como población, como "capital humano de la nación”, y 2) la visión de la infancia como una etapa particular en la vida de los individuos, las representaciones que hacen a la definición de lo que es un niño y a las características físicas, mentales, afectivas, a partir de las cuales se define la "naturaleza" infantil.

De este modo, el niño es un individuo particular, en tránsito de desarrollo de sus facultades físicas y mentales en el seno de su familia y, a la vez y como consecuencia de lo anterior, una riqueza económica potencial, un "capital humano", en tanto parte de la población. Es en este doble carácter, individualizado y como integrante de una futura masa poblacional trabajadora, que aparece vinculando el 
ámbito doméstico y el Estado y que los discursos y prácticas tendientes a su conservación encuentran resonancia:

"Los millares de vidas infantiles que la muerte arrebata, constituyen un cuantioso drenaje de energía para un país, puesto que esos pequeños seres serán los obreros de mañana, los que en todas las esferas de la actividad, concurrirán con sus esfuerzos a las más salientes manifestaciones del progreso." (Oliva, 1917, p.635).

A través de una serie de "metáforas agrícolas", utilizadas por varios autores, de la época, aparece con fuerza la idea del niño como potencialidad presente y realización futura. Al igual que las semillas, el bebé no es casi nada en el presente, pero guarda en sí todas las potencialidades de la vida adulta. "[...] es la planta tierna que requiere luz, calor, y una tierra fecunda, donde extender sus raíces tenues para vigorizar el tronco con jugos abundantes y de buena calidad." (Podestá, 1888, p. 50). Si la semilla es buena (es decir, sin defectos hereditarios) y la madre le proporciona las condiciones adecuadas para su germinación, la savia nutritiva (su leche) y el riego a través de la educación, llegará a ser un hombre sano y vigoroso, apto para contribuir al bienestar de la nación. De allí que la puericultura sea también definida como "cultivo del brote humano":

"Entre las flores, las plantas y los pájaros, que se crían con tan delicado acierto, constituyendo ramas aparte del saber, llega a ocupar un lugar también el cultivo del brote humano. La flor de nuestra especie empieza a interesarnos; la puericultura ha surgido a la ciencia, entre la floricultura y la avicultura, que son sus vecinas gentiles." (Feinmann, 1915, p.2)

También en los discursos pedagógicos sobre la infancia en la Argentina de comienzos del siglo XX, Carli (2002) encuentra que el niño es explicado a partir de la metáfora de la planta nueva como un elemento de la naturaleza que requiere un medio y un acompañamiento adecuados para desarrollarse. Pedagogos de la época, como Carlos Vergara, José Zubiaur, Sara Eccleston y Juana Manso explican su tarea en términos del cultivo del retoño o la planta nueva que representa a la niñez y el propio nombre de "jardín de infantes" o "kindergarten", acuñado por el pedagogo alemán Froebel ${ }^{66}$, deriva de dicha analogía.

66 El pedagogo alemán Friedrich Froebel o Fröbel vivió entre 1782 y 1852, siendo considerado uno de los principales impulsores de la educación preescolar para niños de 3 a 7 años. Para ello, propuso y 
Ya sea en el campo de la medicina o de la pedagogía, pueden reconocerse en estas metáforas ideas presentes en Rousseau, quien en su obra Emilio suele referirse al niño como "tierno renuevo" o "tierno arbolito". De una u otra manera dan cuenta, como se verá en el próximo capítulo, no sólo del carácter nuevo, frágil y flexible atribuido al niño, sino sobre todo y por ello mismo, de la necesidad de evaluar y guiar su evolución.

En consonancia con la concepción de los procesos de crecimiento y desarrollo como el modo en que la niñez existe, es decir, como transformación hacia la adultez, la medicina comienza a utilizar métodos para observar y evaluar la manera en que ese tránsito se lleva a cabo, tanto en los individuos como en las poblaciones. Para ello, a partir de la década de 1920, recibe aportes de la antropometría y, más específicamente de la "auxología", área del conocimiento que aborda los aspectos físicos del crecimiento y desarrollo del ser humano. ${ }^{67}$

El peso y la estatura, en su relación con la edad, son construidos como indicadores del crecimiento, como medidas que expresan, traducen ese proceso a través de las variaciones corporales y su cuantificación. Su utilización supone la creación de patrones de normalidad, que oficien de parámetros de comparación para las medidas de los niños y poblaciones infantiles reales. Estos patrones de normalidad se construyen a través de la utilización de la estadística: es el promedio de las medidas de diferentes individuos el que se torna el parámetro o estándar de normalidad, asociado a una condición saludable. Aquellos valores de peso y estatura que se desvíen del promedio por defecto o por exceso, serán atribuidos a un retraso o una alteración patológica del crecimiento.

El desarrollo, más complejo de cuantificar, se reflejaría indirectamente en el aumento de tamaño corporal y en la adquisición de diferentes capacidades fisiológicas y habilidades motrices y conductuales. Su evaluación se realiza mediante la presencia de determinados eventos en los momentos esperados del curso de la niñez -también definidos como promedio de lo que sucede en la mayoría de los

llevó a cabo en 1837 la creación de una institución denominada "kindergarten" o "jardín de infantes", en la que los niños aprenderían a través de juegos creativos, interacciones sociales y formas de expresión natural. Proponía que este tipo de establecimiento educativo fuera un ambiente en el que los niños se desarrollaran tan libremente como las flores en un jardín (de ahí el nombre Kindergarten, que significa en alemán "jardín de los niños").

${ }^{67}$ El creador de la "auxología" o ciencia especializada en el estudio del crecimiento físico del ser humano fue el francés Paul Godin, formado en antropología física. 
sujetos-, como son, por ejemplo, el cierre de las fontanelas, la dentición, la aparición del habla, el comienzo de la marcha, etc. Rabello de Castro (2001) encuentra que también en el abordaje del desarrollo infantil que realiza la psicología a inicios del siglo XX, -abordaje actualmente denominado "psicología del desarrollo"-, hay una búsqueda de ajuste a un recorrido estandarizado, con conductas y habilidades cognitivas a alcanzar en cada momento, a partir del cual se construye la noción de "niño normal", abstracción que reduce la enorme variabilidad de los niños y niñas reales. $^{68}$

Los métodos y técnicas para relevar e interpretar las medidas que expresan el crecimiento forman parte de las discusiones e información intercambiadas en las publicaciones pediátricas de la época analizada. Así, por ejemplo, en uno de los números de los Archivos Latinoamericanos de Pediatría de 1906, se reseña un libro del médico brasileño Ugolino Penteado sobre la práctica y el valor de la "puerimetría" (práctica de pesar y medir periódicamente a los niños), basado en el trabajo realizado en el Instituto de Protección y Asistencia de la Infancia de Río de Janeiro. El autor discute las ventajas y desventajas de diferentes aparatos de medición, como el "puerímetro" o el "poediómetro", y menciona la existencia de varias tablas que permiten comparar el peso y la altura en la primera y la segunda infancias (Archivos Latinoamericanos de Pediatría, Año II, №2, febrero de 1906). ${ }^{69}$

Siendo considerado el peso el indicador privilegiado para evaluar la salud del niño, especialmente durante la primera infancia, los pediatras argentinos hacen referencia a diferentes tipos de balanzas especializadas o "pesa-bebés", describiendo hay modelos franceses y alemanes. Aráoz Alfaro, en su manual de puericultura, aconseja a los padres adquirir una de esas balanzas en los comercios de instrumental médico y pesar al niño con frecuencia, por lo menos durante sus primeros meses, para asegurarse que éste se desarrolla normalmente. Afirma que "El pesa-bebés no debe, pues, faltar en casa de padres cuidadosos" (op. cit., p.207) y que las familias pobres que no pueden adquirir su propia balanza, disponen de dispensarios y

\footnotetext{
${ }^{68}$ Resulta interesante la observación de Rabello de Castro (op.cit.) en cuanto a que la uniformidad relativa que puede encontrarse en el desarrollo de diferentes niños sería no un hecho de la naturaleza, sino más bien el resultado de prácticas de atención y educación estandarizadas.

${ }^{69}$ Brasil fue uno de los países de América Latina que sistematizó más tempranamente la medición y evaluación del crecimiento infantil. En 1904 comenzó a funcionar en el Dispensario Moncorvo, en Río de Janeiro, el Servicio de Puerimetría, con la misión de pesar y medir sistemáticamente a los niños. En las primeras décadas del siglo XX ya se utilizaban cuatro fórmulas estadísticas para verificación de la salud infantil. Sin embargo, la relación edad-peso-estatura ha sido la fórmula preferida para evaluar la salud y estado nutritivo de los niños brasileños. (Pereira, op. cit.).
} 
consultorios gratuitos de lactantes donde hacer pesar a sus niños. Recomienda que durante el primer mes el bebé sea pesado diariamente o cada dos días, cada semana en los cinco meses siguientes y cada quince días o cada mes de allí en adelante. Para que los padres dispongan de parámetros para evaluar el crecimiento de su hijo, ofrece una tabla con los aumentos de peso cotidianos y mensuales esperados para el primera año y los aumentos anuales entre el primero y los doce años del niño.

El registro, control y seguimiento de la evolución del peso del niño se establece como rutina médica en los dispensarios de lactantes e institutos de puericultura; rutina que puede considerarse el antecedente de la actual práctica institucionalizada del control periódico de salud infantil. Por ejemplo, en el dispensario de Lactantes "La Gota de Leche", de la ciudad de Buenos Aires, los niños que concurren son pesados semanalmente, observándose con ello si el régimen indicado por el médico ha sido puesto en práctica por la madre, constituyéndose el peso también en un medio indirecto de control de las prácticas familiares de crianza. En el archivo del establecimiento se registra la curva de peso de todos los niños que concurren a él, anotándose en el mismo cuadro la cantidad de leche que cada uno de ellos necesita para su crecimiento, "lo que constituye un acopio de material sumamente valioso", como señala su director, el médico Enrique Foster (1907, p.106).

En el informe sobre el funcionamiento del Dispensario de lactantes $\mathrm{N}^{\circ} 8$ de Buenos Aires, presentado en 1917 por su jefe Enrique Bordot, se expone que en los establecimientos de ese tipo, además de anotar el peso del niño en un cuaderno o en la historia clínica de cada paciente, se le entrega anotado en una tarjeta a sus padres, para que éstos puedan seguir la evolución del niño. Ya en ese momento, además, las prescripciones realizadas son controladas en el domicilio del niño por la inspectora adscripta a cada dispensario.

La curva o diagrama de peso que se confecciona para cada niño expresa su proceso individual de crecimiento y también, al ser comparada con la cantidad promedio de gramos que todo niño debería aumentar en cada momento, se torna un indicador de salud o, por el contrario, de la presencia de anomalías o enfermedades. Tal como lo expresa el mencionado Enrique Foster, se considera que el diagrama de peso 
“[...] demuestra inmediatamente con la seguridad de un dinamómetro vital, el estado de salud de un lactante; sus progresos, sus probabilidades de vida, la detención de su desarrollo, su declinamiento. Según que el niño aumente o pierda su peso, el médico es advertido; se tranquiliza o se inquieta; resuelve su abstención o interviene; toda indicación desfavorable es aprovechada para una modificación del régimen alimenticio, un redoble de vigilancia, etc. La balanza no tiene un lenguaje abstracto; marca por así decir, ella misma sobre una hoja, las fluctuaciones regulares o irregulares ascendentes o descendentes del peso del niño.” (1911, p. 130).

Las escuelas públicas, en vinculación con las propuestas de la higiene escolar, también son espacios donde se miden y registran los datos de peso y estatura de los niños, como parte de la información relevada para la confección de la ficha escolare de cada alumno -que incluye también datos como la conformación de la familia del niño y la presencia en ella de enfermedades o "taras hereditarias", las condiciones habitacionales y la situación laboral de los padres. $^{70}$

Enmarcado en los conocimientos de la fisiología del crecimiento, el seguimiento periódico del peso y de la estatura (menos sistemáticamente registrada en la primera infancia) proporciona elementos para evaluar la gravedad de ciertos casos clínicos y para distinguir entre enfermedades crónicas y agudas (Ballester Añón y Perdiguero, 2003). En el discurso médico de la época, por comparación con el niño normal, que crece y se desarrolla siguiendo el patrón esperado, se delinean otros tipos de niño: el niño débil, el niño raquítico, el niño escrofuloso o tísico. Estos niños "otros" suelen ser caracterizados y clasificados en relación a aspectos sociales construidos como problemas en la época. Así, en diálogo con otros saberes y agentes que participan en el campo de la infancia, los médicos suelen hacer referencia al "niño del conventillo", el "niño hijo de madre obrera", el "niño hijo de madre soltera", el "niño hijo de padres enfermos". De alguna manera, como también lo encuentran Ballester Añón y Perdiguero (op. cit.) para el caso de España y Francia, estos primeros estudios del crecimiento refuerzan la percepción de la existencia de situaciones de desigualdad social que atraviesan también a la infancia y proveen elementos para la intervención social.

\footnotetext{
${ }^{70}$ Un análisis más detallado del estudio y clasificación de los niños en el sistema escolar, mediante la confección de fichas escolares individuales, implementada desde fines de la década de 1880, así como de las propuestas enmarcadas en la higiene escolar, puede encontrarse en Di Liscia (2004) y en Lionetti (2011).
} 
Los datos de crecimiento y desarrollo construidos por los médicos en establecimientos de salud y escolares no serán sistematizados estadísticamente a nivel nacional o regional hasta más tarde. ${ }^{71}$ A diferencia de Europa, donde a partir de las primeras décadas del siglo XX comienzan a publicarse estudios que incluyen estadísticas de peso y talla de niños de diferentes edades y a realizarse los primeros análisis comparativos de esos datos entre diferentes países y regiones (Ballester Añón y Perdiguero, op. cit), en Argentina la preocupación estadística está centrada en la mortalidad infantil y la necesidad de construir datos confiables sobre la misma, no sólo en la capital sino en el interior del territorio nacional. Como ejemplo, pueden mencionarse las recomendaciones realizadas en el $2^{\circ}$ Congreso Americano del Niño, en 1919, en cuanto a establecer la mayor uniformidad posible en los datos estadísticos sobre mortalidad infantil, además de instituir un certificado de defunción especial para los niños de primera infancia, donde se haga constar también la legitimidad o no de su nacimiento -factor al que se asocia la posibilidad de negligencia materna- y la clase de alimentación recibida -teniendo en cuenta el gran porcentaje de muertes por gastroenteritis en niño alimentados con biberón (Archivos Latinoamericanos de Pediatría, Tomo XIII, N³, 1919). En 1929, el médico Emilio Coni publica un cuadro estadístico sobre la mortalidad infantil en la República Argentina, correspondiente al sexenio 1911-1916, realizando uno de los primeros análisis comparados entre provincias y territorios nacionales del país (Coni, 1920) (Ver Anexos, Cuadro No1).

A manera de síntesis, propongo subrayar el planteo de Ballester Añón y Perdiguero (op. cit.) en cuanto a que los estudios sobre crecimiento surgen en el marco de un cambio de mentalidad hacia la infancia, pero a al a vez contribuyeron a establecer nuevos puntos de vista sobre los niños, más específicamente, refuerzan su concepción como seres incompletos, maleables y en evolución. Asimismo, proporcionan un medio para articular el análisis de las características de cada niño como individuo, con las de la población infantil:

"El conocimiento en profundidad del cuerpo de los niños permitía las comparaciones entre ellos y no con los adultos, y planteaba la posibilidad de establecer el arquetipo del niño saludable, como patrón de referencia con el que deberían ser comparados para ver el grado de

\footnotetext{
${ }^{71}$ Las normas y estándares nacionales de crecimiento infantil comienzan a construirse en Argentina en la década de 1960 y son recién publicados como tales por la Sociedad Argentina de Pediatría en 1987.
} 
adecuación del niño, o colectivo de niños que se estuviera estudiando, a este modelo ideal." (Ballester Añón y Perdiguero, op. cit., p.70).

A su vez, Canguilhem (1971) permite visualizar cuánto hay de particular y de poco obvio en esa concepción y modo de formular la normalidad como justo medio o como promedio estadístico, en tanto establece una equivalencia implícita entre norma (regla) y promedio (distribución estadística de regularidades). "Normal", en ese sentido, es un término equívoco, en tanto designa al mismo tiempo un hecho y un valor atribuido a ese hecho por quien lo nombra, a partir de un juicio de apreciación previamente adoptado; conlleva una suerte de deslizamiento de lo más frecuente a lo deseado o lo ideal. El proceso de establecimiento de patrones de normalidad en la niñez implica juicios y asignación de valores, con base en elecciones efectuadas desde determinadas preocupaciones, definidas como tales en ciertos contextos sociales, como lo es la preocupación por la población en la cual se enmarca el interés de la pediatría y la puericultura por definir y evaluar el crecimiento infantil.

Foucault (1999) recupera estos dos sentidos sobre lo "normal": la norma incluye un principio de clasificación y un principio de corrección (permite clasificar en más o menos normal, en función de una gradación cuantitativa y busca ajustar conductas y características de los individuos y poblaciones a partir de capacidades jerarquizadas en términos de valor). Ambos sentidos se vinculan con el proceso de regulación de individuos y poblaciones del que participa el saber médico en las sociedades occidentales modernas: la normalización. Normalizar la crianza es, en este sentido constituir, formar individuos, pero también poblaciones. Sin embargo, no debe perderse de vista la dimensión de lucha que conlleva este proceso, tal como lo señala Castro (2004), en su análisis de este concepto foucaultiano:

“[...] la descripción de Foucault se refiere a una sociedad de normalización, no a una sociedad normalizada. La normalización describe el funcionamiento y la finalidad del poder. Pero aunque la realización de este objetivo haya alcanzado una extensión notable, no por ello es hegemónica; debe enfrentarse con los movimientos de lucha y cuestionamiento." (p.250). 


\section{2. Las etapas de la infancia}

Siendo la infancia comprendida a partir del crecimiento y el desarrollo, todo estudio o acción sobre el niño buscará situarlo en un proceso temporal longitudinal. Desde el discurso médico analizado, se plantea que

"Las necesidades del niño varían según la edad [...]. En todos los momentos de su vida tiene su individualidad; el lactante, el escolar, el adolescente, representan entidades con valer y necesidades propias; con sus derechos, con sus deberes después que podrán variar, pero que en el conjunto, están regidas por disposiciones naturales y legales, de orden científico y de orden sociológico." (Morquio, Discurso inaugural del $2^{\circ}$ Congreso Americano del Niño, Archivos Latinoamericanos de Pediatría, 1919, s/n, p.277).

Con este fundamento, los autores de la época establecen diferentes momentos o fases dentro de la etapa infantil, construyendo una serie de clasificaciones de la niñez a partir de determinadas características físicas o del comportamiento, seleccionadas y transformadas en parámetros cronológicos. Así, por ejemplo, en un texto sobre El niño sano y su alimentación, el médico Martínez Zuviría (1918) explica que:

"El niño al venir al mundo se llama recién nacido."

"A los diez o quince días el niño tiene cicatrizada su herida del ombligo y se llama lactante." [...]

Se llama así [lactante] al niño durante todo el período que es alimentado exclusiva o predominantemente con leche, es decir los dos primeros años." (pp.12-14).

En otras obras médicas de la época, el recién nacido y el lactante son incluidos en una etapa más amplia, que los abarca a ambos: la primera infancia. Así lo exponen los autores de un manual de divulgación titulado El niño. Su higiene, sus cuidados:

"La infancia comprende la época de la vida que se extiende desde el nacimiento hasta la pubertad. Se divide así:

Primera infancia (desde el nacimiento hasta los dos años).

a) Recién nacido (hasta la caída del cordón o el mes de edad).

b) Lactante (desde el primer mes hasta los 2 años o 2 años y medio).

Segunda infancia (desde los 2 años hasta el desarrollo puberal)."

(Carreño y Schwarcz, 1927, p.7)

En el marco de un texto académico destinado a los alumnos de la carrera de medicina, Garrahan (op. cit.) presenta una clasificación similar, luego de discutir las 
clasificaciones de autores extranjeros como Hutinel, Marfan y Griffith, que establecen una distinción entre la segunda y la tercera infancias, situada hacia los seis o siete años de edad). Siguiendo al pediatra argentino Dámaso Centeno, prefiere distinguir sólo entre la primera y la segunda infancia, tomando como parámetro el ritmo e intensidad del crecimiento y desarrollo físicos:

"La primera infancia, desde el nacimiento hasta los dos años o dos y medio, época durante la cual el crecimiento y desarrollo son muy activos y se hace la primera dentición.

La segunda infancia, período más largo, transcurre después de los dos años: el crecimiento es más lento que durante la primera infancia (y sobre todo, que durante el primer año), pero en la época anterior a la pubertad vuelve a intensificarse en forma llamativa" ( $p$. 22).

Otros autores separan al recién nacido como constituyendo una etapa propia ¿una suerte de pre-infancia?-, haciendo comenzar la primera infancia propiamente dicha con la caída del cordón umbilical. Es el caso de Mariano Etchegaray (1915), quien presenta uno de los esquemas más detallados de periodización de la niñez:

"La vida del niño se divide en varios períodos, caracterizados por sus condiciones fisiológicas y patológicas, que son:

$1^{\circ}$ El recién nacido. Se llama así al niño, desde el nacimiento hasta la caída del cordón umbilical, que se produce del $5^{\circ}$ al $8^{\circ}$ día de haber nacido.

$2^{\circ}$ Primera infancia, que corresponde desde la caída del cordón umbilical hasta el fin del segundo año.

$3^{\circ}$ Segunda infancia, que corresponde desde el fin del segundo año hasta el sexto o séptimo año.

$4^{\circ}$ Tercera infancia o edad escolar, que corresponde desde el sexto o séptimo año hasta la pubertad.

$5^{\circ}$ La pubertad, en la cual la niña se transforma en mujer y el niño en hombre, varía entre los doce y quince años." (p.157).

Sea de uno u otro modo, la vida del niño es pensada como una secuencia de etapas -o sub-etapas, teniendo en cuenta que la niñez es ella misma construida como una etapa de la vida-, cada una de las cuales está marcada por la aparición o desaparición de ciertas características o capacidades, seleccionadas y leídas en términos de fronteras entre momentos sucesivos y progresivos de la existencia infantil. 
Esas fronteras también constituyen marcas simbólicas de los diferentes lugares vinculares y sociales más amplios que va ocupando el niño en su familia y en las instituciones más amplias. Así, por ejemplo, la caída del cordón umbilical, que marca el límite de la etapa de recién nacido, implica el fin del lugar que ocupaba el niño durante el embarazo, como parte inescindible de su madre. El destete y la dentición, a su vez, señalan el fin de la etapa de lactante y con ello, una mayor independencia del niño respecto de su madre, desde una perspectiva que caracteriza al bebé como conformando con ella un binomio, el "binomio madre-hijo"72 A partir de la "segunda infancia", la institución escolar se transforma en un organizador cronológico central del transcurso de la niñez.

La sucesión ordenada de etapas, al considerarse fundada en "particularidades anatómicas y fisiológicas del niño" (Garrahan, op. cit., p.20), pasa ser considerada natural y universal, transformándose en un criterio de normalidad para evaluar la vida de los niños reales: no debe faltar ninguna ni es aconsejable que se las pase antes o después del tiempo previsto. ${ }^{73}$ En ese sentido, como veremos en el próximo capítulo, se insiste en que las prácticas de crianza deben adecuarse a estos diferentes momentos o estadios del desarrollo infantil: para cada uno de ellos hay un alimento apropiado, vestidos adecuados, ejercicios y juegos recomendables.

Sin embargo, los parámetros cronológicos que delimitan esas etapas tienen la amplitud suficiente como para que, dentro de ciertos márgenes, cada niño "normal" las transite con sus particularidades individuales. Tal como advierte Garrahan: "si bien separan épocas con características especiales, no tienen límites netos" (op. cit., p.21). Por ejemplo, se admite que el aprendizaje de la marcha puede producirse entre los diez y los quince meses, pero pasado este periodo, su ausencia es signo de alguna patología. Lo mismo sucede con la dentición, que puede aparecer en diferentes momentos, pero debe estar presente al terminar la primera infancia.

A cada una de las etapas de la infancia, a su vez, los médicos atribuyen una susceptibilidad particular para determinadas patologías- una "susceptibilidad mórbida"-, a partir de lo cual también se definen divisiones o capítulos de la

\footnotetext{
${ }^{72}$ Este concepto de "binomio madre-hijo" comienza a ser formulado en el momento histórico que abarca el presente estudio, pero se prolonga en el tiempo, constituyendo un concepto recurrente en el discurso pediátrico actual.

${ }^{73}$ Jenks (op. cit.) considera que esta compartimentalización y secuenciación temporales de la experiencia de la niñez en estadios, conceptualizados en términos de "desarrollo" e institucionalizados luego por la teoría piagetiana, formarían parte de las estrategias de control social de la modernidad occidental sobre los sujetos.
} 
pediatría: "patología del recién nacido", "patología y alimentación del lactante", "afecciones comunes en la niñez" (Morquio, 1906).

Asimismo, cabe aclarar que las clasificaciones de la niñez que la medicina produce entre fines del siglo XIX y las primeras décadas del XX no se producen aisladamente, sino que se complementan y se entrecruzan con otras clasificaciones generadas por saberes expertos de la época, como la pedagogía, la psicología o el derecho, desde los cuales también se establece un correlato entre etapas o momentos del desarrollo infantil y vínculos legales y sociales en general que involucran a los niños. ${ }^{74}$

\subsubsection{La primera infancia como objeto de estudio}

Una vez presentadas las clasificaciones de la niñez, las obras de puericultura se consagran casi por completo a la primera infancia, encarnada en la figura del bebé. Esa franja etaria comprendida entre el nacimiento y los dos años, que incluye al recién nacido y al lactante, ocupa también gran parte de los textos eruditos de pediatría. En la forma de definirla, veremos como ciertas características como la lactancia, la ausencia del habla y de la capacidad de caminar, la dependencia respecto a los adultos, son socialmente distinguidas y leídas en términos de una etapa particular de la niñez, a la que la vulnerabilidad ante la muerte torna crucial para la continuidad de individuos y poblaciones.

La primera infancia no adquirió contornos nítidos dentro del amplio territorio de la niñez hasta el siglo XIX. Si bien tratados sobre educación física del niño escritos en Europa en los siglos XVII y XVIII ya atribuían una especificidad al niño pequeño, denominando "puericia" o simplemente "infancia" a los primeros años de vida $^{75}$, no había precisión en el modo de recortar y nombrar a esta etapa.

\footnotetext{
${ }^{74}$ En el ámbito del derecho se produce, dentro de la categoría "minoridad", una clasificación entre "menores abandonados" y "menores delincuentes", utilizándose a la vez el criterio de la edad como expresión del desarrollo psíquico -el momento en que se hace presente la capacidad de "discernimiento" con respecto al carácter los propios actos- para establecer responsabilidades penales. El derecho laboral también marca fronteras entre momentos de la infancia, vinculadas a aspectos del desarrollo psicofísico, en relación a la habilitación o prohibición para el desempeño laboral. Desde la pedagogía van a comenzar a establecerse edades mínimas para el ingreso de los niños al sistema escolar y momentos óptimos para transitar cada uno de sus niveles.

75 Ver, por ejemplo, el análisis que realiza Joaquim (1997) de los manuales de educación física del niño (equivalentes a los manuales de puericultura), escritos en Portugal a fines del siglo XVII y
} 
Según los planteos de Ariès (op. cit), más allá del esfuerzo para hablar específicamente de los niños pequeños, la lengua francesa del siglo XVII no disponía de palabras que permitieran distinguirlos de los niños mayores. Durante el siglo XVIII, incorporó algunas palabras de otras lenguas o de jergas usadas en las escuelas o en oficios, para referirse a los primeros años, pero aún no se disponía de un vocablo que aludiera al niño de meses. Recién cuando, en el siglo XIX, tomó prestado del inglés la palabra baby (que hasta el siglo XVII designaba al niño en edad escolar), el francés pasó a disponer de un nombre específico: bébé para el lactante.

También para las disciplinas científicas la primera infancia se constituyó tardíamente en objeto de estudio. La ausencia de habla o su carácter rudimentario en esta etapa ha sido considerada una dificultad para su abordaje científico. Desde esta inaccesibilidad a las percepciones adultas y científicas con que se ha pensado al bebé, se le ha atribuido, por un lado, un carácter totalmente rudimentario, pero también una cierta idea de misterio, de enigma. ${ }^{76}$ En el caso de la medicina, como se ha visto, el no poder explicar verbalmente las sensaciones y dolores (en una época en que el diagnóstico se basaba en gran parte en el interrogatorio al enfermo), hizo que su incorporación como paciente no se concretara plenamente hasta el siglo XIX.

En los estudios antropológicos, los bebés han estado ausentes como sujetos de las etnografías prácticamente hasta la actualidad. Gottlieb (2000) explica esta omisión como resultado del supuesto de que, como los bebés no hablan, no pueden dar cuenta de su cultura (desde el postulado que asocia la cultura con el habla), además de ser considerados como carentes de agencia y totalmente dependientes de los adultos. Sin embargo, como expone esta autora, la pasividad está muy lejos de responder a una descripción completa de la vida de un recién nacido y resulta más bien de una visión particular de las sociedades occidentales, visión desde la que los bebés son considerados pre-culturales y atados a la biología. Por el contrario, diferentes aspectos del cuerpo de los bebés pueden revelar muchos datos culturalmente ricos y la pasividad poco tiene que ver con la percepción que otras sociedades tienen sobre la primera infancia.

durante el siglo XVIII, en los que las denominaciones de "puericia" o "infancia" se utilizan para hacer referencia a los primeros años de vida.

${ }^{76} \mathrm{Al}$ respecto, resulta interesante encontrar en el discurso actual de padres y pediatras, referirse al bebé durante sus primeros meses, como una "caja negra", es decir, como dotado de un mecanismo que produce efectos, pero cuyo funcionamiento profundo se desconoce. 
En la actualidad, la construcción de la primera infancia como objeto de conocimiento e intervención se ve complejizada por el entrecruzamiento del saber médico con la psicología, la pedagogía y algunos elementos de psicoanálisis. Para el caso de la psicología y la psiquiatría, tal como lo plantea Hoffmann (1992), la conformación de una especialidad en la primera infancia es reciente. Éste autor propone definir una "rama de la Primera Infancia" en la psicología, en términos de "aquel campo de la salud mental que tiene que ver con niños cuya edad va desde la concepción hasta los tres años" (1992, p.41).

Serre (1997) señala que en Francia la noción actual de "primera infancia", que se considera abarcando hasta los seis años, se desarrolla a partir de los años cincuenta, bajo el efecto conjugado de tres elementos: la multiplicación de establecimientos que se ocupan del cuidado de esta franja etaria (guarderías, escuelas maternales, centros de protección materno infantil), la formación de un cuerpo de profesionales especializados (educadoras de primera infancia, psicólogos infantiles, puericultores) y la elaboración de un saber específico, que se desarrolla en la confluencia de la medicina y el psicoanálisis e implica la existencia de especialistas que tiene su monopolio y la misión de inculcarlo.

\subsubsection{El recién nacido y el lactante: las características del niño de primera infancia}

Volviendo a las prácticas y representaciones de la medicina argentina entre 1890 y 1930, encontramos que en la caracterización del bebé se condensan y acentúan las particularidades atribuidas a la niñez en general: comienzo, incompletud, maleabilidad, dependencia de los adultos. En este sentido, Garrahan (op. cit.) afirma que "Es indudable que la primera infancia constituye la época en la cual son más marcadas las características especiales del niño [...]” (p. 20).

Este carácter germinal adjudicado a la primera infancia aparece claramente en un texto francés de mediados del siglo XIX, cuya traducción en castellano circula en Buenos Aires en las décadas de 1880 y 1890. Su autor, el médico Alfred Donné se refiere a la primera etapa de la niñez como "ese manantial de donde provienen mas tarde la fuerza ó la debilidad, el vigor ó los achaques" y advierte que "El origen de muchos males de la vida data de la primera infancia, es necesario cuidar lo más 
posible de la entrada en la carrera, dirigiéndola bien para que la marcha sea firme y segura después" (1847, p.35).

Desde esta perspectiva, se considera que el niño nace como un ser esencialmente incompleto, imperfecto, en el que todo está por desarrollarse y tomar forma: “[...] viene al mundo en completo desarrollo, pero éste es aparente; todos los órganos están formados, pero su estructura y funcionamiento son rudimentarios" (Etchegaray, 1915, p.157); “[...] es un organismo imperfecto, desigualmente desarrollado, con órganos incompletos, contenidos en un esqueleto óseo y muscular en plena formación" (Bertelli, 1924, p. 65). Para ser considerado sano, según Garrahan (1930 [1921]) deber haber nacido a término, ser hijo de padres sanos de edad media, no presentar malformaciones y tener la capacidad para regular la temperatura corporal. Todas sus características lo hace especialmente vulnerable y desvalido, por lo tanto, totalmente dependiente del cuidado de los adultos.

En efecto, dado que las características que la naturaleza ha otorgado al recién nacido no son suficientes para asegurar su supervivencia, la protección y atención por parte de los demás seres humanos se tornan indispensables para él:

"El niño al nacer [...] Es el ser menos bien dotado en ese momento de la vida; es inferior a los que luego han de ser infinitamente más débiles que él, que apenas nacidos, sin embargo, realizan funciones de locomoción y buscan su alimento. La naturaleza le provee de éste, es verdad; pero si precioso para su conservación, como parte, está muy lejos de constituir el todo. El hombre ha hecho lo demás y hemos visto cómo favorece su subsistencia rodeándolo de cuidados para defenderlo de la hostilidad del medio. Hemos aprendido a vestirlo, a limpiarlo, a alojarlo y a dirigir su alimentación." (Bertelli, 1924, p. 65).

“[...] el recién nacido humano, es en el momento de su nacimiento, el peor aventajado de todos los animales.

[...]

El pequeño ser humano, el niño, no tiene ningún abrigo, está desnudo, no puede ni sabe caminar. La única cosa que sabe hacer, es mamar, es decir tomar su alimento; pero, como lo veremos, no sabe elegir entre lo que es bueno y lo que es nocivo. Se debe pues conocer todo aquello que le es necesario, se debe saber todo para él." (Pinard, 1924 [1904], p.30).

Así, al nacer, el bebé parece estar más próximo de los animales y sus conductas instintivas, que de los demás seres humanos, pues la razón aún no se le ha desarrollado. Las imágenes que de él presentan los textos de pediatría y de 
puericultura remiten a un ser pre-cultural, atado a la biología como lo habrían estado los pre-humanos en etapas anteriores de la especie, desde un enfoque que -como ya señalara- ve en la ontogenia la síntesis y reedición de la filogenia o evolución de la especie. Se menciona el estado rudimentario de los sentidos, el carácter inconsciente y reflejo de su sensibilidad y movilidad, así como la ausencia de manifestaciones intelectuales.

"[...] sus facultades psico-motoras son casi insignificantes. Es un sordo mudo fisiológico, y apenas si presenta algunos movimientos instintivos e incoordinados, muy débiles por cierto para servirle de defensa; otros que parecen espontáneos, como ser, ciertos movimientos de la boca y de la cara, de las manos y de los pies, tampoco son muy considerables para ese propósito (Feinmann, 1915, p.124).

También se lo caracteriza como “[...] un pequeño poltrón que no debe preocuparse más que de comer bien y dormir mejor -llenando estas tareas con la delicadeza que requiere su estado, se le asegura la existencia contra las eventualidades de otras enfermedades a que está expuesto.” (Pinard, 1924 [1904]). El llanto es su lenguaje particular, a través del cual puede expresar sus deseos e incomodidades. $^{77}$

Luego, a medida que sus sentidos se van desarrollando, comenzará a percibir y a interactuar con el mundo exterior:

"Las primeras impresiones sensibles del recién nacido, tienden a su conservación propia. A la alimentación instintiva, que tiene por objeto el desarrollo de su cuerpo, se une luego la percepción sensitiva. Paulatinamente, el niño entra en relación con los objetos que le rodean, recogiendo las impresiones del exterior; y obrando enseguida por la volición espontánea de su sistema muscular, manifiesta sus alegrías ó sus penas, sus deseos y sus temores, traduciendo sus ideas por medio de signos." (Guía Maternal, 1900, pp.26-27).

\footnotetext{
77 Esta visión del recién nacido como pre-cultural, atado a la biología, poco tiene que ver con la perspectiva de otros pueblos, en muchos de los cuales las manifestaciones y deseos de los bebés son entendidos de manera muy diferente a este modelo de pasividad que sostiene la visión occidental hegemónica. Tal como lo expone Gottlieb (2000), en otras sociedades los infantes suelen ser considerados seres con conocimientos y volición, más allá de que no hablen, y determinantes de las vidas de quienes los rodean. La autora analiza específicamente el caso de los bebés Beng, de Costa de Marfil, quienes son considerados reencarnaciones de ancestros y durante los primeros años recuerdan su existencia previa en el "después de la vida". Los bebés Beng tiene una profunda vida interior y sus padres tienen la tarea de discernir, recurriendo a adivinos, los deseos que aquellos traen de su vida anterior, para poder satisfacerlos. Gran parte de las decisiones y actividades cotidianas de los adultos dependen, así, de estos niños pequeños.
} 
De esta manera, al caracterizar la etapa del lactante, los autores presentan diferentes aspectos del desarrollo sensorial, el desarrollo motriz y la evolución psíquica del niño, incorporando elementos de lo que luego se llamaría psicología del desarrollo. Médicos como Enrique Feinmann dan cuenta de un extenso conocimiento de los trabajos de los psicólogos infantiles de su época:

"Principios de psico-fisiología infantil.

La psico-fisiología infantil comprende, por un lado, los fenómenos de la sensorialidad orgánica ya estudiada, y por el otro, la sensibilidad afectiva, que comprende las manifestaciones elementales del miedo, de la cólera, de los celos, de la simpatía y de la antipatía humanas. El alma de los niños contiene, desde su primera edad, el germen de todos estos sentimientos que mueven sus inclinaciones y forman su temperamento, su voluntad y su carácter. La educación moral de los niños, debe comenzar por eso, según enseña muy bien Bernard Pérez, desde la cuna, para evitar las desviaciones que sufre la conciencia, cuando se abandona a una eflorescencia espontánea." (Feinmann, 1915, p.134). ${ }^{78}$

El bebé es presentando en este momento como un ser que comienza a desplegar las capacidades que se encontraban "en germen" y que se consideran la base de su personalidad y salud futuras, haciendo de la primera infancia la etapa crucial a moldear mediante la crianza.

Las explicaciones sobre la evolución que sufre el niño a lo largo de la primera infancia son especialmente extensas en los manuales de puericultura, buscando ofrecer a las madres elementos para comprender y evaluar el desarrollo de sus niños. Los autores exponen con detalle la "evolución de los sentidos". Mientras para algunos iniciarían su aparición la sensación de temperatura y luego la del tacto, para otros el gusto y el olfato serían los primeros sentidos en desarrollarse, aunque todos coinciden en que el oído y la vista se desarrollarían con lentitud durante las primeras semanas de vida.

"Primero aparece la sensación de temperatura, luego la del tacto. El olfato y el sabor se desarrollan con lentitud. El oído no experimenta modificaciones importantes durante los primeros meses y, si las partes del aparato ocular están desarrolladas desde el nacimiento, la

\footnotetext{
78 Bernard Pérez, francés, estudió la psicología infantil hacia fines del siglo XIX; más específicamente, se interesó en la relación entre el desarrollo mental de niño y sus manifestaciones en el arte.
} 
organización del cerebro aún no está suficientemente desarrollada para recibir la sensación luminosa". (Guía Maternal (1900, p.28).

Los medios de expresión del bebé son el llanto, los gritos y, más adelante, la sonrisa. Recién más tarde, aproximándose al año, comenzarían los rudimentos del lenguaje. Aráoz Alfaro describe detalladamente este proceso de adquisición del habla:

"A los dos meses, más o menos, emite los primeros sonidos gue, oh, agó, etc., y, poco a poco, van apareciendo las sílabas ba, da, bo, etc., que pronuncian ya, generalmente, a los 5 ó 6 meses. Entonces el niño principia a imitar los sonidos que oye, y no tarda en decir papá, mamá, etc. A un año puede reconocer al papá y a la mamá, y pronunciar estas palabras cuando ellos aparecen.

En el curso del segundo año, el vocabulario aumenta y las palabras se hacen más distintas. Cumpliendo los dos años, los niños construyen frases y comprenden el sentido de las que pronuncian.

A los tres años el niño habla corrientemente." (Aráoz Alfaro, 1929 [1899], p.218).

La misma gradualidad estaría presente en el desarrollo de los movimientos, considerados progresivamente más complejos y voluntarios, así como en el aprendizaje de la marcha. Resulta interesante -como ya fuera enunciado- que si bien los autores establecen márgenes de normalidad para la edad en que deben adquirirse las diferentes habilidades motoras y psíquicas, plantean que, dentro de ellos, cada niño se desarrollará de acuerdo a características individuales, dado que ninguno de ellos es igual a otro.

Llegados aquí, revisando el modo en que las características del niño de primera son explicadas desde la pediatría y la puericultura, encontramos algunos elementos que contribuyen a comprender el énfasis de la medicina en no dejar su proceso evolutivo librado a "las fuerzas de la naturaleza".

El estado rudimentario del nacimiento y la gradual aparición de capacidades de distinto tipo, darían cuenta del estado de transformación permanente y progresiva que define a la niñez y de la compleja vinculación que se produce en este proceso de desarrollo entre aspectos físicos y psíquicos. La condición de posibilidad, pero también de probables riesgos, de este proceso evolutivo es el carácter incompleto, 
inmaduro y, sobre todo, maleable, del bebé. De allí que se considere que todo el proceso madurativo debe ser acompañado por una correcta educación higiénica, tanto física como moral. "Hay que empezar la educación del niño desde el nacimiento" (Aráoz Alfaro, 1929 [1899], p.66.), repiten una y otra vez los médicos de niños.

En otros términos, las características de entidad incompleta y en desarrollo atribuidas al bebé hacen de él un ser totalmente vulnerable a las primeras influencias, una suerte de hoja en blanco en la que todo puede ser escrito. De allí, la idea de que los hábitos adquiridos en esta etapa de la vida son difíciles de erradicar, haciendo necesaria una crianza guiada por principios científicos y basada en la firmeza y mesura de carácter.

\section{3. La definición de una "naturaleza" infantil.}

El término "naturaleza" aparece una y otra vez en las explicaciones de los pediatras sobre la niñez, aunque de manera polisémica. Con él se hace referencia tanto a la especificidad y a la irreductibilidad de las características físicas y psíquicas del niño, una suerte de "esencia" infantil, como también a los aspectos innatos e instintivos que el niño debe perder para transformarse en un ser humano completo, o a la fuente de los principios que regulan su funcionamiento normal y que deben guiar sus cuidados. ${ }^{79}$

\footnotetext{
${ }^{79}$ El carácter polisémico del término "naturaleza" en las teorías científicas es abordado por Luz (1997) en su análisis del lugar de las concepciones de naturaleza, razón y sociedad en la racionalidad científica moderna. $\mathrm{Al}$ abordar la construcción de las disciplinas sociales y naturales a partir del siglo XVIII, señala que: "las categorías de Naturaleza y natural no tienen, en el pensamiento clásico (ni tampoco en el pensamiento evolucionista subsiguiente del siglo XIX), el rigor racional de un concepto que se pretenda científico, como, por ejemplo, los de fuerza, masa, movimiento y hasta cierto punto el propio concepto de ley. Además de los sentidos de 'esencia', 'providencia', 'reino', 'fuente original de la vida', pueden tener también el significado de 'Mundo', 'Cosa' u 'Objetividad'. El imaginario de las disciplinas sociales, así como el de la sociedad civil, está impregnado de todos esos sentidos de las categorías Naturaleza y Natural, que aparecen como postulado teórico de todas las ciencias. En la época clásica, la Naturaleza es la 'cosa en sî́ de la ideología científica.” (Luz, 1997, p.73).

Por otro lado, Joaquim (1997), alerta sobre la necesidad de considerar qué definición de "naturaleza" ponen en juego los actores de cada época, evitando el posible error de suponer al concepto de naturaleza como equivalente al de biología, como podría proyectarse desde el sentido común contemporáneo. En su análisis histórico de la construcción social de la feminidad en Portugal a través de los discursos pedagógicos, encuentra que, cuando en siglo XVIII se busca definir una "naturaleza femenina", hay oscilaciones ligadas a las complementariedades y oposiciones entre cuerpo y alma, sensibilidad y razón, en el marco de un juego -ambivalente y ambiguo- constante entre razón y naturaleza.
} 
Anclando fuertemente en el segundo de estos sentidos -aunque combinando también elementos de los otros dos-, la oposición naturaleza/civilización o cultura atraviesa y da sentido a las distintas imágenes, definiciones y análisis médicos de las características del niño y, como veremos en el próximo capítulo, del proceso de crianza que lo tiene por objeto.

Desde la idea de que la razón aún no se ha desarrollado en el bebé, se considera que éste obra sobre todo instintivamente, de un modo egoísta y exigente. Es presentado a la vez como un ser inocente, pero también como un ser apasionado y caprichoso, un pequeño déspota si se le permite hacer lo que él quiere - puede transformarse en "un pequeño tiranuelo caprichoso y molesto" (Araóz Alfaro (1929 [1889], p.66). En este sentido, tal como es señalado por Ríos y Talak (1999), el discurso positivista sobre la niñez no la homologa directamente a la inocencia o la pureza. Desde la ley biogenética haeckeliana, vigente en el discurso académico entre fines del siglo XIX y mediados de la década de 1910, el desarrollo del individuo recapitula las etapas del desarrollo de la especie, por lo que es de esperar que el período de la infancia de cada individuo, puramente guiado por impulsos instintivos, contenga manifestaciones de violencia y aún tendencias criminosas propias de la personalidad del hombre primitivo, es decir, de la "infancia de la humanidad". Estas características estarían acentuadas en la primera infancia, en tanto etapa "más primitiva" de la niñez" y, por lo tanto, más alejada de la razón, la moral y más ligada a lo instintivo y lo salvaje. Dando cuenta de esta perspectiva y combinándola con las formulaciones de Lévi-Bruhl sobre la mentalidad primitiva, el médico Enrique Feinmann, en un apartado acerca de la "higiene moral", hace referencia a

“[...] la observación biogenética, que asigna al sentido moral el último lugar en la evolución de la conciencia y del espíritu. Esta circunstancia de ser la última adquisición de la especie humana, explica que sea la más frágil, la que más fácilmente se pierde y se olvida, y la que con menos seguridad se transmite por herencia." (1915, p.134).

Sin embargo, en las representaciones de pediatras e higienistas argentinos de comienzos del siglo $\mathrm{XX}$, ese carácter impulsivo, caprichoso, pre-moral, instintivo,

De acuerdo con Nari (2004), recién avanzado el siglo XIX el significado de "naturaleza" se fijaría en un sentido equivalente a "biología", aunque ello no implicara el inmediato abandono de sus sentidos anteriores. 
del niño, está en tensión con la idea de la inocencia, bondad y pureza, que también se asigna a la naturaleza infantil. En esta perspectiva puede reconocerse la influencia del pensamiento de Rousseau, cuyo libro Emilio es frecuentemente citada por los médicos especializados en la niñez. Especie de "manifiesto" acerca de la niñez y la pedagogía, esta obra del siglo XVIII no abandona la analogía entre niños y "salvajes", pero atribuye a ambos disposiciones positivas y virtudes naturales que se deben, justamente, a no haber sido corrompidos aún por las relaciones y convenciones de la sociedad europea de la época. Esta concepción de la niñez está presente en médicos naturistas, de inspiración anarquista, como el uruguayo Antonio Valeta, pero también entre los pediatras académicos como Aráoz Alfaro.

La concepción del niño como "primitivo", cabe subrayar, excede ampliamente el campo de la medicina. Tal como señala Szulc (2007), las analogías entre pensamiento primitivo y pensamiento infantil -ya sea con un signo valorativo positivo o negativo- se encuentran presentes en los abordajes de la antropología clásica, que hace del estudio del pensamiento infantil un recurso para aproximarse al pensamiento de los "otros" culturales. También en las primeras formulaciones de la psicología y del psicoanálisis se establecen semejanzas entre el psiquismo infantil y la mentalidad de los pueblos "premotivos".

En la pedagogía de fines del siglo XIX y comienzos del siglo $\mathrm{XX}$, la discusión sobre la naturaleza infantil tiene especial relevancia, en tanto conlleva explicaciones y posiciones acerca de los principios y métodos a poner en práctica en la educación. En términos de Carli (2002), en este debate acerca de la naturaleza humana del niño "La interpretación positivista acerca de la naturaleza salvaje del niño, se oponía a la interpretación krausista del niño como un sujeto ligado al orden divino y a la bondad de la naturaleza" (p.94). ${ }^{80}$

\footnotetext{
${ }^{80}$ Mientras la primera, representada por pedagogos como Víctor Mercante, reconoce su inspiración en ideas de Comte, Lombrosos, Le Bon, Binet, la segunda, que tiene en Carlos Vergara uno de sus principales exponentes, recupera las concepciones de la niñez presentes en las obres de Rousseau, Pestalozzi, Krause. La concepción pedagógica del filósofo alemán Karl Krause, caracterizada como "espiritualista" o, en términos más generales, "romántica" combinaba una filosofía panteísta con una filosofía masónica y recuperaba ideas pedagógicas de Tólstoi en cuanto a considerar a los niños como seres humanos plenos y completos quienes, por lo tanto, tenían la capacidad de ser libres (Carli, op. cit).
} 
Esta tensión entre las representaciones que asocian la niñez con la idea de la inocencia y aquellas otras que ven en el carácter caprichoso y despótico la esencia de la naturaleza infantil, puede ser problematizada a partir de los planteos Badinter (1991) y de Chombart de Lauwe (1991), quienes permiten situar estas concepciones en el marco más amplio del pensamiento y la sociedad occidentales. A su vez, desde la sociología de la niñez, Jenks (op. cit) las sintetiza mediante dos imágenes: el niño “dionisíaco" y el niño "apolíneo"; imágenes que remiten a dos tradiciones en la conceptualización de la niñez, sostenidas y reforzadas por creencias religiosas, ideologías políticas y doctrinas científicas.

Badinter (op. cit) y Chombarte de Lauwe (op. cit.) muestran que la idea de la culpabilidad moral del niño, representado como un ser ignorante, caprichoso, pronto a caer en el mal si se le permite hacer lo que quiere, es sostenida hasta bien entrado el siglo XVII por la teología católica inspirada en San Agustín. La naturaleza, de la cual el niño está próximo, lleva el peso del pecado y de la animalidad. También Descartes ve a la infancia en términos de un período de debilidad del espíritu, en el que el entendimiento está bajo total dominio de las sensaciones. En este marco, la oposición naturaleza-civilización recubre una oposición de valores negativo-positivo: es necesario arrancar el niño a su naturaleza primera mala y llegar al modelo del hombre como razón-civilización. Desde esta perspectiva, pedagogos y teólogos denuncian la ternura y la tolerancia de las mujeres para con sus hijos. Las caricias y ternuras maternas aparecen como debilidad y pecado; no sólo arruinan, corrompen al niño, sino que dan cuenta de la debilidad egoísta de la madre. Esta concepción corresponde a la imagen de la niñez "dionisíaca" propuesta por Jenks (op. cit): expresión del puro desborde irracional, movido por impulsos instintivos, que deben ser contenidos y encuadrados. En efecto, en relación con la infancia dionisíaca, la crianza y la socialización en general, son vistas como una batalla contra un sujeto testarudo, que debe ser doblegado, dominado para su propio bien y el de la sociedad.

Hacia fines del siglo XVIII, bajo la influencia de Rousseau, la naturaleza es revalorizada en términos de pureza y autenticidad, invirtiéndose el sistema de valores. Ahora es la proximidad con la naturaleza y los orígenes la que hace al niño un ser puro y verdadero, comparable con el "buen salvaje". Es ésta la imagen de la infancia que Jenks (op. cit) caracteriza como "apolínea" y que adjudica al niño disposiciones y virtudes naturales que sólo requieren acompañamiento y cuidado para poder aflorar t desplegarse. Este niño, a diferencia del "dionisíaco", no es 
socializado y controlado a través del castigo físico de un cuerpo con deseos irracionales, sino mediante la observación, la vigilancia y la protección que permitan el despliegue de sus potencialidades.

Sin embargo, cuando volvemos la mirada hacia los discurso concretos, encontramos que ambas visiones sobre el niño (salvaje, pre-moral, instintivo, o puro e inocente) si bien se han originado en diferentes momentos y desde distintas posturas teórico filosóficas, coexisten en el momento analizado y aun en la actualidad. Opuestas, superpuestas, en tensión, estas imágenes darán sentido a las prácticas y a las representaciones médicas sobre la niñez y la crianza infantil hasta el día de hoy.

En síntesis, ya sea considerado en términos positivos o negativos, la proximidad a la naturaleza y a la "esencia" de lo humano parece ser lo que caracteriza a los individuos en la primera etapa de su vida - así como a los "primitivos" en la historia de la humanidad. La educación debe consistir, entonces, en el encauzamiento de estos deseos instintivos e irracionales que se presentan tempranamente. De ahí- como veremos en el próximo capítulo, la importancia atribuida a la normalización de las conductas infantiles a través de la incorporación de horarios en sus actividades y de la sistematización de las operaciones que hacen a su cuidado corporal. Este cuidado del cuerpo debe ser complementado con el cultivo de la inteligencia y la moral, para el cual la medicina del niño también ofrece indicaciones. A la vez, seguir estas recomendaciones también implica una regulación de los comportamientos maternos y de los papeles familiares en general, por lo que puede afirmarse que la estrategia pedagógica de la puericultura se dirige, en última instancia, a la mujer madre y al grupo familiar. 


\title{
CAPÍTULO 3
}

\author{
EL “ARTE DE CRIAR NIÑOS”: \\ LA PEDAGOGÍA MÉDICA DE LA CRIANZA
}

"[...] al niño no se lo puede abandonar a las brutalidades del instinto; necesita vivir bajo una acción educadora que le haga comprender lo desordenado e injusto de las pasiones, y lo bello y saludable del buen vivir en compañía de su prójimo; y que, al mismo tiempo, le ponga en excelentes condiciones de salud y de desarrollo orgánico para participar dignamente de aquella vida de relación." (Augusta Moll Weiss, en Revista Madre y Niño, 1905).

Crianza. Del lat. criantia, f.s. XIII al XX. 1. Acción y efecto de criar o alimentar y cuidar. 2. Época de la lactancia. 3. f.s. XV al XX. Urbanidad, atención, cortesía, educación. 4. XIV. Criatura. 5. XIII. Procreación, descendencia. (Alonso, Enciclopedia del idioma, 1958).

Criar. Del lat. CREARE. 1097. 'Nutrir a un niño o un animal', instruir, educar', 'crear, producir de la nada', 'engendrar, procrear'. (Corominas, Breve diccionario etimológico de la lengua castellana, 1973).

"Promesa", "porvenir", “argentino del mañana", "capital humano de la nación", "blanda masa", "frágil organismo", son algunos de los modos con que el discurso médico se refiere al niño en la época aquí analizada. En efecto, como hemos visto en el capítulo anterior, la niñez es definida a partir de su carácter de indefensión e incompletud y su necesaria transformación hacia el futuro estado de adultez.

Dada la importancia del producto futuro: el adulto singular, pero también genérico -"el hombre"-, ciudadano, trabajador, sano y fuerte, parte de caudal demográfico que poblará y desarrollará económicamente un país nuevo, este tránsito 
hacia la adultez no puede dejarse librado al azar ni a la naturaleza. No puede ser abandonado "a las brutalidades del instinto", tal como afirma Moll Weiss en el epígrafe. ${ }^{81}$ Sobre todo porque, según afirman los autores, a diferencia de los animales, la naturaleza ha despojado al recién nacido humano de la capacidad de asegurar su propia supervivencia, haciendo que los cuidados de los demás seres humanos se tornen indispensables.

Definido como un individuo a hacerse, a completarse, el niño es caracterizado, como pudimos observar en el capítulo anterior, a partir de su alta maleabilidad, sobre todo durante la primera infancia, etapa crucial en la que se definirá la incorporación de patologías o condiciones saludables, de buenos o de malos hábitos, difíciles de desterrar posteriormente. Por ello, las tareas de los adultos no se limitan a la protección, sino que consisten también en darle forma, en guiar su crecimiento y desarrollo para que su organismo y su mente no adopten una morfología o un funcionamiento inadecuados y no generen conductas inapropiadas para "el buen vivir en compañía de su prójimo" (Moll Weiss, 1905, p.20). De allí que la idea de "criar" y la definición de una "crianza correcta" sean materia de preocupación y debate en la época considerada, pero también en el presente. Más aún, pueden ser consideradas nociones políticas en tanto ponen en juego la definición y la construcción de la persona en relación con determinado modelo o proyecto de sociedad. Esto se manifiesta en el carácter crucial que la medicina y otros saberes científicos de fines del siglo XIX y comienzos del XX atribuyen a la crianza: del modo en que sea moldeada esa "blanda masa" que es el niño depende que el Estado pueda obtener más tarde "el hombre fuerte de físico, sano de alma, flexible y abierto de inteligencia" (Aráoz Alfaro, op. cit.).

La etimología de los términos "crianza" y "criar" permite reconocer tres tipos de procesos que la modernidad occidental vinculó a la niñez y a su relación con la adultez: 1) la alimentación y el cuidado, 2) la educación y 3) la procreación o engendramiento. Estos tres procesos aparecen como objeto del saber médico sobre la niñez que se consolida hacia comienzos del siglo XX.

\footnotetext{
${ }^{81}$ Augusta Moll Weiss, francesa, no era médica, aunque se dedicara en parte a la divulgación de la puericultura. Consagrada sobre todo a la sistematización y divulgación de los principios de la economía doméstica, fundó en 1897 la Escuela para Madres de París. Una sección fija de la Revista Madre y Niño estaba dedicada a versión traducida de una serie de textos suyos sobre el desarrollo infantil.
} 
Por un lado, la medicina, a través de la "puericultura preconcepcional", se propone garantizar el engendramiento de niños sanos y fuertes. Por lo tanto, se considera que su labor debe comenzar desde la gestación, o aún antes, con el requisito de unos padres sanos. Se habla así una puericultura "preconcepcional o eugenética" (anterior a la fecundación), una "puericultura intrauterina" y una "puericultura extrauterina o post-natal". A su vez, si bien sus prescripciones hacen énfasis en la alimentación y los cuidados corporales (modo de asear, vestir, sostener al niño), estos aspectos aparecen estrechamente vinculados a una idea de educación, entendida como "el cultivo de la inteligencia y de la moral". En algunos textos médicos, sin embargo, el verbo “criar” aparece más restringido al amamantamiento o alimentación del niño, mientras que "educar" es utilizado para dar cuenta del acompañamiento del proceso de desarrollo y los aprendizajes que debe ir haciendo el niño a lo largo de él. Con énfasis en uno u otro de estos aspectos, la noción de cuidado está en la base de las concepciones de crianza y del lugar del niño que contribuye a instalar la medicina, aunque van más allá de ella. La definición de una crianza "correcta" que surge de los textos de puericultura, implica la definición de formas socialmente adecuadas de cuidar y formar a un niño, ligadas a la idea de normalidad.

A partir de la conformación de la familia burguesa moderna, que autores como Shorter (1977), Ariès (1981) o Flandrin (1991) sitúan en las sociedades europeas occidentales hacia el siglo XVIII, las funciones de crianza pasan a centrarse en los progenitores, muy especialmente en la madre. Sin embargo, desde el discurso de la medicina se considera que el amor y el instinto maternos, aunque necesarios, resultan insuficientes. Numerosos peligros amenazan el normal desarrollo del niño, dotado de un "mecanismo [...] fácil pero frágil" (Feinmann, 1915, p.39), y sólo el médico posee el saber especializado que garantiza el éxito del proceso. "Para cuidar un niño, para protegerlo contra los peligros que lo amenazan, es necesario saber y para saber, es necesario aprender", afirma, entre otros, el médico Camilo Muniagurria (1923, p.13).

La transmisión de ese saber, planteado en términos de la ciencia o el "arte" de criar niños, constituye el eje de los textos puericultura, es decir, de aquellos que los pediatras de la época destinan a la divulgación: manuales, revistas, cartillas, 
folletos. Estos textos escritos son acompañados de otras medidas destinadas a inculcar los "principios científicos de crianza", sobre todo en las madres de los sectores populares: creación de escuelas de madres, seguimiento y consejos vertidos en establecimientos de salud (dispensarios de lactantes, institutos de puericultura, consultorios pediátricos de hospitales) y presencia de las visitadoras de higiene. Por otro lado, la puericultura comienza a enseñarse en las escuelas de niñas, dado que el cuidado del niño desde una perspectiva higiénica pasa a formar parte de lo que las mujeres deben saber para cumplir su rol en la sociedad. Gran parte de las enfermedades que causan la elevada mortalidad infantil podrían evitarse, en palabras de la médica Esther Kaminsky (1914) “[...] con tal solo educar a las futuras madres en la ciencia de la verdad y preparándolas, desde niñas, para la grandiosa y noble misión de la maternidad, que están llamadas a desempeñar en un día no lejano.” (p.91).

Con especial énfasis en la alimentación, dado que la mayor parte de la mortalidad infantil de la época está ligada a los problemas digestivos derivados de la lactancia artificial, pero también en el vestido, el aseo, las salidas, los juegos y actividades físicas del niño, estas reglas de la "buena crianza" están orientadas por "la salud" como ideal. La misma es entendida en un sentido amplio que abarca la "salud física", la "salud moral" y la "salud social" y se expresa en la infancia a través del logro de un "crecimiento normal" y de un "desarrollo regular".

Teniendo en cuenta los aspectos hasta aquí mencionados, en este capítulo propongo indagar en el proyecto pedagógico que la medicina construye y despliega a través de las obras de puericultura, como parte de una disputa con otros saberes sobre el niño y la crianza, como los populares, familiares y religiosos. De allí que haga hincapié en el análisis de las obras producidas con fines de divulgación, especialmente en los manuales con formato de libro, pero también las cartillas y artículos de revista. Las múltiples estrategias educativas puestas en juego por los médicos de niños son vinculadas con los diferentes sectores sociales a los que se orientan. A lo largo de su análisis, van delineándose los personajes que se construyen como destinatarios de los consejos médicos: la madre primeriza y la "madre del futuro". 
A su vez, considero importante explorar los aspectos de la vida del niño y de las prácticas maternas que se constituyen en objeto de las prescripciones médicas y los principios que guían estas indicaciones, a fin de dar cuenta del modo en que el proceso de medicalización del cuidado infantil se produce entre 1890 y 1930. Ello requiere no perder de vista el papel de las mujeres y familias en dicho proceso, en el que están lejos de ocupar un papel pasivo.

\subsection{El discurso médico sobre la crianza: la "cruzada de la razón contra la ignorancia"}

A través de los textos médicos analizados, un argumento se delinea como eje y justificación de los temas tratados: la vida de los niños se ve amenazada por dos enemigos, la miseria y la ignorancia, descritas como "dos viejas arpías que se nutren del cuerpo sonrosado de los niños" (Muniagurria, 1923:7). Pero -se plantea- si la primera puede ser disminuida a partir del progreso material del país y por medio de políticas sociales, la ignorancia es más difícil de combatir, por reproducirse en el interior de cada familia y oponer más resistencia a la razón. Cabe a los médicos luchar contra una toda una serie de creencias y hábitos arraigados en la mentalidad del pueblo, responsables, en última instancia, de las altas tasas de mortalidad infantil.

Esa es la misión específica atribuida a la puericultura que, como ya vimos en el capítulo 1, se diferencia de la clínica pediátrica por compartir con la higiene un objetivo centrado en la profilaxis y una metodología basada en la educación. Desde una perspectiva que ve en la ciencia el estadio superior del conocimiento, este enfoque o disciplina de la medicina infantil ${ }^{82}$ es situado como superación de una larga historia de tratamientos inadecuados hacia los niños:

"Los hombres empiezan a ocuparse de los niños. Sobre las cunas sin suerte de los tristes, llegan las primeras voces de interés y de ayuda. En adelante, el alma de los pequeños y de los desheredados conocerá menos el rigor de sus destinos y los peligros sin razón de haber nacido." (Feinmann, 1915. p.1)

Partiendo de la idea de que educar a la madre es la mejor forma de proteger indirectamente al hijo, y uniendo la acción médica con la acción social, las acciones

\footnotetext{
${ }^{82} \mathrm{La}$ ambigüedad de la relación entre puericultura y pediatría, vinculada al estatus que la última ocupa al interior de las ciencias médicas, es discutida en el Capítulo 1.
} 
de la puericultura se orientan a enseñar a las familias, y sobre todo a las madres, a criar a sus niños a partir de los principios científicos de la higiene, como garantía una infancia sana. "Popularizar la ciencia de la higiene y especialmente de la higiene infantil -se señala- quiere decir instruir; e instruir significa combatir a fondo, y desde sus añosas raíces, la ignorancia y las preocupaciones, el descuido y el escepticismo, que son los mayores factores de enfermedad y de muerte." (Guaita, en Aráoz Alfaro, 1929, prefacio).

Se espera que la guía de la ciencia tome en la crianza del niño el lugar hasta entonces ocupado por los consejos de los curadores populares y de las mujeres de la familia o cercanas a ella. Hasta el momento, estos saberes habían sido -y en parte continuarían siéndolo- las fuentes habituales de aprendizaje y de consulta acerca de la crianza infantil. Los médicos observan con preocupación que

"Guían y aconsejan, por lo general, a la madre primeriza, vecinas 'de experiencia', que nunca supieron criar a sus propios hijos, y curanderas, las que aconsejan a la joven madre, en más de una ocasión, de un modo perjudicial y a veces funesto para la salud del niño". (Kaminsky, 1914, p.90).

La enseñanza informal llevada a cabo por otras mujeres de la familia es desautorizada en términos de "prejuicios que sobre la crianza del niño se transmiten por tradición de madres a hijas" (Bertelli, 1924, p.94) y las prácticas de autoatención $^{83}$ con respecto al niño, así como la confianza de las madres en sus propias percepciones, son consideradas causantes de enfermedad y muerte: "Hay otro factor de gravedad y muerte: el optimismo, ese que hace decir a las madres: 'No es nada, con esto, con aquello que voy a darle o hacerle, se le pasará"” (Bertelli, ibidem).

Frente a un saber que las vecinas y parientas legitiman con base en la experiencia de haber criado a los propios hijos, los pediatras arguyen que ese aprendizaje empírico no puede compararse a la observación sistemática de cientos de niños que ellos han podido realizar en su trabajo en los hospitales. Hacen referencia al conocimiento "[...] que es fruto de la experiencia adquirida por los médicos que han visto y estudiado centenares de niños en los Hospitales del mundo entero, lo que

\footnotetext{
${ }^{83}$ Siguiendo a Menéndez (1990), la autoatención refiere a un modelo de abordaje de procesos de salud y enfermedad basado en el diagnóstico y atención por parte del propio sujeto o su grupo familiar o comunitario inmediatos, sin mediación de ningún curador especializado.
} 
no pasa con las viejas madres experimentadas por haber visto diez o quince niños criados a capricho, y que no han sucumbido por fortuna." (Martínez Zuviría, 1918, 27). De este modo, la experiencia encuadrada en los métodos de la ciencia -el análisis estadístico que permitiría la observación de "centenares de niños"-, es la única aceptada para producir conocimiento verdadero. ${ }^{84}$

Las disputas con los curadores populares -los "curanderos"- son especialmente intensas y también se fundan en la ausencia de fundamento racional y científico de sus acciones y prescripciones. Son considerados más peligrosos que abuelas y vecinas, en tanto intentan competir con los médicos en la elaboración de diagnósticos y en la indicación de medicamentos u otras terapéuticas. Sus prácticas se presentan como fundadas en el engaño y la sugestión de los pacientes, en la que residiría su poder de convocatoria, pues "[...] hasta los bienaventurados que tienen uso de razón hecho y derecho, se prestan a los engaños y maravillas de este gremio de dilettanti de la profesión médica." (Podestá, 1888, p.105).

A partir de las descripciones y acusaciones de médicos como Podestá (op. cit.), es posible conocer el tipo de dolencias infantiles tratadas por los curadores populares y los métodos con que lo hacen. Son mencionados el "empacho", el "daño", el "mal de los siete días", el "baile de San Vito", la epilepsia, parasitosis, luxaciones y fracturas. Especialmente peligroso es considerado el diagnóstico y tratamiento del "empacho", en tanto involucra las enfermedades digestivas del lactante, principal causa de mortalidad infantil:

"Maestros en la curación de las afecciones del aparato digestivo tan frecuentes en los niños mal alimentados, diagnostican todo con el nombre de empacho, empacho que quiere decir un pedazo de comida, endurecida que se pega a la boca del estómago o al espinazo.

Ellos dan sus remedios y sus emplastos para despegarlo para hacerlo subir o bajar, según el tiempo y las circunstancias de la pegadura (Podestá, op. cit., pp.109-110).

Se observa con preocupación la publicidad que de sus productos curativos (jarabes, gotas, ungüentos) y trabajo hacen en diarios y revistas. Se critica, además, la impunidad de que gozan para ejercer su práctica curativa, aun cuando ésta ha sido declarada ilegal y puede ser sancionada desde el Consejo de Higiene:

${ }^{84}$ Luz (1997) analiza la razón científica como el criterio de producción de verdades que construye y legitima la modernidad occidental. La autora caracteriza la ciencia moderna como una forma de orden del mundo y un régimen específico de producción de enunciados de verdad, en el cual las 'reglas de producción' son más importantes, en última instancia, que su 'veracidad' en tanto tal. 
"La tolerancia de esta práctica clandestina, aparte de rebajar la profesión médica a la condición de un oficio de comadres - introduce en el seno de las familias de criterio obtuso, ideas equivocadas y conceptos ridículos sobre las enfermedades y los remedios." (Podestá, op. cit., p. 108).

La descripción extensa -e indignada- que de sus procedimientos realiza Podestá (op. cit.) a fines del siglo XIX condensa gran parte de la perspectiva médica sobre las prácticas curativas populares y el modo en que disputan su clientela con los profesionales de la medicina. Asimismo muestra, tal como lo señala González Leandri (1996), “[...] que las frecuentes invocaciones a los curanderos y curanderas fue una de las maneras con que el 'cuerpo médico' fue definiendo, a partir de sus bordes, su propia imagen profesional.” (p.42):

"Desempeñan admirablemente su papel y en medio de su ejercicio clandestino, se permiten no pocas veces, la suprema fruición de examinar y comentar aun mojada, la receta que ha dejado el facultativo.

Para los niños son una especialidad - tienen el secreto de sus enfermedades y el remedio infalible para curarlas.

Sus diagnósticos están basados ordinariamente en algo oculto, misterioso, una especie de mito del mal, que se ensaña con las criaturas.

Las madres crédulas, supersticiosas, oyen azoradas una relación de cosas incomprensibles, se quedan perfectamente convencidas de que el curandero es un semi-dios (el médico un inservible) y salen satisfechas, sonrientes del consultorio del sabio apretando contra su pecho un niño enfermo y una botella de remedio elaborado expresamente, en el alambique lucrativo de su bienhechor.

Si el niño cura, cosa fácil y posible por otra parte - la cliente se hace lenguas para aclamar, ponderar al curandero - si se muere, el médico que lo ha asistido antes, tiene la culpa." (Podestá, op. cit., p. 107).

"[...] la homeopatía, es su caballo de batalla" y "Tienen sus oráculos, sus palabras misteriosas, sus conjuros y recurren a ciertos librajos de tapas gastadas, con hojas amarillas y olor a humedad de pieza cerrada -diccionarios probablemente, comprados en la cachivacherías.

"En las grandes solemnidades los abren, los comentan en presencia del cliente embobado que los mira con ojos de oveja muerta, pensando en el arcano de ciencia y de misterio que encierra la cabeza hueca del sabio." (Podestá, op. cit., p.109). 
Estos fragmentos, a su vez, presentan indicios sobre los posibles itinerarios terapéuticos que, en la época, se pondrían en práctica ante la enfermedad de un niño, en los cuales no sería raro combinar la consulta a diferentes especialistas (médicos y curanderos) en búsqueda de eficacia curativa.

El éxito de los curanderos es atribuido a la ignorancia de la población: "El curanderismo, la superstición han costado muchísimas vidas y seguirán costándolas mientras la gente obcecada y estulta fomente sus supercherías e inmundicias." (Bertelli, op. cit.p.94). Por lo tanto, si bien existen medios legales para combatir sus prácticas, los médicos consideran que sólo una educación que permita la incorporación de explicaciones fundadas en la racionalidad científica será eficaz para evitar su influencia.

La racionalidad que, de acuerdo a los médicos, requieren los cuidados infantiles también es el argumento que permite criticar, a nivel de las políticas públicas, los modelos tradicionales de la beneficencia y de la caridad católica. Frente a la caridad, fundada en una relación interpersonal, ejercida discrecionalmente y dependiente de la voluntad de un individuo, pero también frente al abordaje de la beneficencia laica, que se limita al tratamiento filantrópico de los efectos de la cuestión social, se propone una asistencia científica de la población, que investigue y trate racional y objetivamente las causas de los problemas sociales que afectan a la infancia. Sin embargo, al igual que sucede con las madres, a cuyo papel se comparan las damas de la Sociedad de Beneficencia, no se trata de negar su valor como cuidadoras de los niños, sino de subordinar sus prácticas a la guía y los preceptos de la ciencia. ${ }^{85}$ En otros términos, se busca establecer una división de tareas que deje a la mujer en el lugar de cuidadora y al médico, en el de orientador y organizador científico de la asistencia, estableciendo un alianza entre ambos que favorezca la “conservación de los niños” (Donzelot, 1990).

Como iremos viendo, la puericultura se despliega como un amplio proyecto pedagógico que puede ser entendido como un trabajo minucioso de implantación de una creencia en el valor de la salud infantil y en la capacidad objetiva y racional de la

\footnotetext{
${ }^{85}$ Esto permite a algunos médicos de principios del siglo XX plantear que la beneficencia no tiene por qué desaparecer, ya que pone en juego sentimientos solidarios y proporciona una infraestructura (en edificios, personal) que el Estado aún no tiene, pero que, para rendir sus frutos, debe ser organizada y supervisada por los médicos.
} 
ciencia médica para asegurarlo. En esta empresa, se beneficia de los cambios que en la ciencia médica ha generado la revolución pasteuriana, legitimando gran parte de sus recomendaciones sobre la crianza infantil. ${ }^{86}$ En efecto, tal como observa Boltanski (op. cit.), los descubrimientos de Pasteur acerca del papel de los microorganismos como causa de las enfermedades proveen a la pediatría y la puericultura de un saber positivo, demostrable científicamente, en nombre del cual se seleccionan y fundamentan numerosas reglas prácticas de crianza, sobre todo las que se refieren a la alimentación y la higiene del niño.

Sin embargo, pese a la insistencia de los médicos, las madres no abandonan fácilmente la consulta a otras mujeres próximas (madres, suegras, amigas) o a curanderos, a la hora de resolver dificultades en la crianza de sus hijos. La idea de que la crianza de un niño es un asunto médico no parece resultar fácilmente asimilable, posiblemente porque forma parte de las actividades de la cotidianeidad familiar y tal vez, también, debido a la distancia social que separa a gran parte de la población de la figura del médico. ${ }^{87}$ De allí que la tarea de vulgarización de los principios de la higiene infantil que emprenden los pediatras sea percibida por ellos en términos de una verdadera y ardua "cruzada contra la ignorancia". Las estrategias para llevarla a cabo combinan elementos del modelo de la transmisión escolar de conocimientos con otros más próximos a la prédica misionera, estrategias que apuntan a introducir razonamientos científicos con consejos que buscan inculcar una verdad. ${ }^{88}$

Llegados aquí, considero oportuno realizar dos señalamientos acerca del modo en que concibo este proceso de medicalización de la crianza que continuaré analizando en los próximos apartados. En primer lugar, no se trató de un proceso unívoco y definitivo sino, por el contrario, complejo, difícil - aún inacabado-, que involucró no sólo la acción de los pediatras, sino también de las mujeres y familias, las cuales resistieron, negaron, pero también negociaron y en parte incorporaron, concepciones y prácticas higiénicas en la crianza de sus niños. Además, implicó un proyecto

\footnotetext{
${ }^{86} \mathrm{La}$ "revolución pasteuriana" alude a las transformaciones en las concepciones médicas (y científicas en general) generadas por los descubrimientos de Pasteur acerca del papel de los microorganismos teoría microbiana-. en el origen de las enfermedades y el consiguiente desarrollo de las técnicas de asepsia, antisepsia e inmunización para evitarlas.

${ }_{87}^{87}$ Retomaré este aspecto del tema con mayor detalle hacia el final de este capítulo.

${ }^{88}$ Boltanski (op. cit.) señala que el espíritu que preside la difusión de las reglas de puericultura en Francia a fines del siglo XIX no puede ser disociado de la ideología que guía la instauración de la escuela primaria obligatoria, siendo el de la transmisión escolar el modelo de las estrategias educativas construidas por la medicina. Además, la escuela pública pasa a ser un lugar donde esas reglas también son enseñadas.
} 
genuinamente emprendido y vivido por los médicos de la época como una cruzada contra el oscurantismo. Con ello pretendo evitar ver en sus estrategias el producto de un cálculo conciente y premeditado de control, para poder entenderlas como fundadas en su propia convencimiento en el carácter legítimo y salvador de la ciencia que, consideraban, debía generalizarse por el bien general.

\subsection{La pedagogía médica de la crianza.}

La lectura de las obras de divulgación sobre puericultura muestra que, si bien sus autores apuntan a un público femenino, no se dirigen a todas las mujeres por igual. Por el contrario, su análisis deja entrever diferencias según los sectores sociales a los que éstas pertenecen. Ello revela que, más allá de las características generales que comparten como posibles receptoras de las palabras de los médicos, estas mujeres no conforman un grupo homogéneo, sino atravesado por la diversidad y la desigualdad de la sociedad de la época.

De este modo, para dar cuenta de la recepción que los pediatras de la época buscan y pueden obtener con sus consejos y prescripciones sobre la crianza infantil, es necesario tener en cuenta la existencia de una sociedad heterogénea, compleja, que atraviesa diferentes transformaciones entre 1890 y 1930. En este contexto, las estrategias pedagógicas implementadas desde la medicina del niño serán diversas y utilizarán distintos medios según los sectores sociales a las que estén destinadas, si bien el foco principal está puesto en las familias de sectores populares urbanos. ${ }^{89}$

Tal como lo señala Míguez (1999), las familias argentinas de fines del siglo XIX y comienzos del XX presentan una gran diversidad étnica y social, que se manifiesta en las diferencias existentes entre familias de distintas procedencias, pero también entre familias rurales y urbanas, familias populares y de elite. Su composición y estructura van variando de acuerdo a los flujos migratorios, las

\footnotetext{
${ }^{89}$ Autores como Donzelot (1990) y Boltanski (1969) refieren que en la sociedad francesa de mediados del siglo XVIII a fines del XIX, los médicos participan de la elaboración de diferentes tipos de respuestas a la necesidad de "conservación de los hijos", según se orienten a la burguesía o a la clase obrera. Donzelot las denomina respectivamente 'difusión de la medicina doméstica' y 'economía social'. Boltanski, más centrado en la puericultura, hace la distinción a partir de los diferentes estilos utilizados en los textos de divulgación. Si bien son abordajes inspiradores para analizar los procesos en la Argentina de la época aquí analizada, podrían ser matizados considerando, por ejemplo, el papel de las discusiones y reclamos de los propias organizaciones políticas obreras - sobre todo socialistas, pero también anarquistas- quienes también proponen la implementación de medidas higiénicas y la difusión de principios científicos para el cuidado de los niños, en el marco de la crítica a las condiciones de vida que impone la desigualdad social.
} 
características del mercado de trabajo y de la estructura habitacional. De allí que, de acuerdo con Nari (2004), si bien puede hablarse de una tendencia hacia la consolidación de la familia nuclear a lo largo del periodo estudiado, ésta aparece como bastante incierta hasta el siglo XX.

En las primeras décadas del siglo $\mathrm{XX}$ es posible percibir, de acuerdo con Míguez (op. cit.), el comienzo de la construcción de un modelo familiar, el de "clase media" que, si bien no reemplaza la diversidad de relaciones y prácticas familiares reales, tiende a transformarse en el modelo universal de familia a nivel de las imágenes. Este modelo de familia de clase media, que trasciende el sector social de pertenencia, remite la mujer al hogar y exalta su función de madre. Hacia la década de 1930, el fuerte proceso de urbanización y la presencia del primer medio masivo de comunicación social: la radio, contribuyen a homogeneizar los estereotipos de familia que se proponen como modelos para el conjunto social, aunque las estructuras reales de las familias de sectores populares continúen presentando algunas diferencias.

En ese contexto socialmente complejo y en el marco de la "cuestión social", el principal objetivo perseguido por los médicos higienistas es llegar a las mujeres de la clase obrera, en tanto madres de la población más afectada por la mortalidad infantil, aunque esto no excluya la necesaria educación de las mujeres de todos los sectores sociales. Como señala Recalde (1997),

"Desde el principio los higienistas advirtieron la existencia de tasas diferentes de morbi-mortalidad en los niños de distintas clases sociales y subrayaron la especial gravedad del problema en los sectores populares. Sin omitir que el desconocimiento de las nociones más elementales de higiene infantil era común a las madres de cualquier extracción, se ocuparon preferentemente de los grupos más castigados por la miseria." (pp.138-139).

La alimentación es el aspecto de la crianza infantil que concentra las mayores preocupaciones de pediatras e higienistas, dada su relación estrecha con la mortalidad infantil. El abandono de la lactancia materna, ya sea por voluntad o por necesidad materna, y su consiguiente reemplazo por la alimentación artificial se 
asocia a las numerosas muertes de los niños menores de dos años. ${ }^{90}$ En efecto, las dificultades para una adecuada conservación de las leches animales comercializadas en la época, así como para la esterilización de biberones y recipientes, hacen de las infecciones digestivas derivadas de la lactancia artificial la mayor causa de las muertes durante el primer año de vida. ${ }^{91}$

Insistiendo en que "La lactancia natural, al seno, no puede ser reemplazada de ninguna manera" (Araóz Alfaro, op. cit., p.69), el recurso a una nodriza (o alimentación natural "mercenaria") es aceptado por los médicos sólo en aquellos casos en que la salud de la madre le impide amamantar. Aun en estas situaciones, no deja de señalarse que ello implica el abandono del hijo del ama: "La figura del hijo del ama es reiteradamente pintada por la pluma de los médicos, a veces con una explícita intención impresionista: para vender su leche a otro niño, las amas privan al suyo del jugo materno, condenándolo a una muerte segura.” (Recalde, 1997, p.131).

Sin embargo, aunque no abandone la cruzada en pro de la lactancia materna, comenzando el siglo XX, el discurso médico asume que este tipo de alimentación infantil puede a veces resultar imposible por circunstancias físicas y sociales, sobre todo en las mujeres obreras, que deben salir a trabajar al poco tiempo del nacimiento de sus hijos y, sin recursos para contratar a una nodriza, recurren a la alimentación artificial, con todos los riesgos de ella derivados. Considerando estos casos, los médicos analizan las ventajas y desventajas de las leches de diferentes animales (vaca, burra, cabra), recomiendan distintos modos de diluirla, mezclarla con harinas, cocinarla, etc., sin dejar de insistir en la diferencia cualitativa con respecto a la leche humana y a los trastornos digestivos que pueden producir en el bebé. Para disminuir en parte estos peligros, también se crean establecimientos como las "gotas de leche" o las cantinas maternales que, entre otros propósitos, brindan a las madres pobres las leches y papillas ya preparadas.

\footnotetext{
${ }^{90}$ Los médicos de la época estudiada establecen una distinción entre tres tipos posibles de alimentación durante la primera infancia: 1) alimentación natural: con leche de mujer; puede ser materna o mercenaria, según se realice con el seno de la madre o de una nodriza; 2) alimentación artificial: con leche de vaca u otros animales o con preparados y conservas diversas de leches y 3 ) lactancia mixta: alimentación al pecho, complementada con otro alimento, generalmente leche de vaca.

${ }^{91}$ Según datos publicados en la Guía Maternal (1900), al comenzar el siglo XX se estima que aproximadamente la mitad de los niños alimentados artificialmente (con biberón o cuchara) morirán durante su primera infancia.
} 
De esta manera, si bien el hincapié se hace en "la profunda ignorancia que domina entre las madres" (Kaminsky, 1914, p.45), también se reconoce que la pobreza impide a gran parte de ellas alimentar adecuadamente a sus hijos, afirmándose, por ejemplo, que "[...] la causa principal de la pobreza de secreción láctea de la gran mayoría de las mujeres que acuden a la Asistencia Pública, obedece a la falta de alimentos." (Kaminsky, op.cit, p.56). Según lo plantea con pesimismo esta médica en sus tesis sobre Puericultura, mientras esta situación no se modifique y la mujer que es madre no reciba una buena alimentación durante el tiempo en que amamante a su hijo, no se habrá modificado una de las causas principales de la mortalidad infantil y la eficacia de las instituciones de asistencia médica será efímera y relativa. Establecimientos como las cantinas maternales o las gotas de leche considera- pueden proveer alimentos a la madre o al niño durante cierto tiempo, pero esto no modifica la situación de pobreza a la que ambos regresan luego de ser atendidos. $^{92}$ Sin embargo, ello no pone en duda la labor educativa que se pueda desplegar desde esas instituciones, pensada como la acción más eficaz a largo plazo. Esta educación adquiere, para médicos como Acuña, la función de moralizar y civilizar, además de asistir, a la creciente población inmigrante, percibida como una masa heterogénea, pobre e ignorante:

"En Buenos Aires, donde la natalidad es cada vez más crecida, donde acude una inmigración numerosa, compuesta en su gran mayoría de elemento pobre e ignorante de principios higiénicos, donde pronto se harán sentir sobre la clase obrera factores más complejos, de orden económico, que repercutirán funestamente sobre el niño, nos parece imponerse, como necesidad presente y como exigencia futura, la creación de estas instituciones, que encierran estos dos grandes atributos de la sociabilidad humana: caridad, moralidad." (Acuña, 1903, p.966).

En un momento histórico -sobre entre fines del siglo XIX y la segunda década del XX- en que gran parte de la población femenina no está alfabetizada y/o habla otra lengua, la difusión a través de material escrito implica una limitación en la tarea educativa de la puericultura. Esto es planteado claramente por el autor anónimo de la reseña del libro de divulgación La salud de mi hijo, escrito por Luis Agote:

\footnotetext{
${ }^{92}$ Estos planteos convergen con los de socialistas como Gabriela Laperrière de Coni, que impulsan medidas de protección materno-infantil que trasciendan la asistencia inmediata, como la sanción de leyes de protección laboral para las mujeres que trabajan o la instalación de salas-cuna en las fábricas.
} 
"¿Lastima grande que, por mucho que se haya esmerado el Dr. Agote en dar a su libro las condiciones de sencillez y claridad exigidas por la poca o nula preparación científica de los lectores a que está destinado, falte todavía tanto camino para llegar al desiderátum de la perfección! Apresurémonos a agregar que la culpa no es del doctor Agote, sino de la irremediable constitución de la sociedad; porque, en efecto, de cien madres, ¿Cuántas habrá que realmente entiendan el libro de que nos ocupamos, a pesar de su claridad y de los esfuerzos de adaptación al medio intelectual en que ha de circular, revelados por le autor en cada línea de su obra? De cien madres tomadas al acaso en todas las clases sociales, ¿Cuántas no hay, en fin, que apenas saben leer?... ¿Y las madres extranjeras, que tanto abundan en nuestro país?..." (La Semana Médica, Año VIII, No 52, 1901, p. 812).

De ahí que manuales, folletos, cartillas, si bien constituyen importantes fuentes para analizar el tema, deban considerarse como parte de un conjunto mucho más amplio de estrategias utilizadas en la época para divulgar entre las madres los principios científicos de la crianza infantil; estrategias que no sólo se apoyan en textos escritos, sino también en conferencias realizadas en clubes, parroquias y sociedades obreras, así como en los consejos dados directamente a las madres por médicos y visitadoras de higiene de las instituciones públicas de salud.

\subsubsection{Seguimiento, consejos, visitas: el papel de las instituciones especializadas en la primera infancia.}

Como ya adelantáramos en el Capítulo 1, la prevención de la mortalidad infantil y la instrucción de las madres de sectores populares se cuentan entre los objetivos centrales de una serie de instituciones de asistencia pública de la salud, especializadas en la primera infancia, cuyos modelos se toman de las existentes en Francia $^{93 .}$

En la ciudad de Buenos Aires, a partir de una ordenanza municipal del 13 de noviembre de 1911, formulada por el concejal Delio Aguilar, estas instituciones son ordenadas según brinden dos tipos de protección a la primera infancia: la abierta y la cerrada. La primera, de carácter ambulatorio, se lleva a cabo en los dispensarios de lactantes, la inspección de nodrizas y los consultorios externos de los institutos de

\footnotetext{
${ }^{93}$ Los tipos de instituciones y el modo en que funcionan en Francia y en la Capital Federal, son reseñadas en 1920 por Emilio Coni en su obra Protección a la madre y al hijo. Puericultura práctica argentina (intra y extrauterina).
} 
puericultura; luego se le suman las "gotas de leche", creadas por la Sociedad de Beneficencia. La de carácter cerrado, para los casos que requieren internación, se realiza en los institutos de puericultura (muchos de ellos anexos a los principales hospitales) donde, por reglamento, el niño debe ser internado junto con su madre. A ello debería sumarse la creación de escuelas de niñeras, que funcionarían en los Institutos de Puericultura, ofreciendo una enseñanza desarrollada a lo largo de dos cursos: uno teórico, de un mes, dictado en la Escuela de Enfermería, y otro práctico, de tres meses, seguido en los Institutos de Puericultura y en servicios especiales de los hospitales de la Asistencia Pública. ${ }^{94}$

En la provincia de Buenos Aires, durante la primera década del siglo XX, la Dirección de Salubridad establece consultorios gratuitos para niños, gotas de leche y boticas de leche, en La Plata y en algunas otras ciudades ${ }^{95}$. También indica a los intendentes municipales la conveniencia de otorgar premios a las madres que amamantaran a sus hijos hasta después de los 15 meses.

Una completa sistematización y caracterización de esas diferentes instituciones de las primeras décadas del siglo XX puede encontrarse en los estudios de Biernat y Ramacciotti (2008), Billorou (2007; 2008) y Nari (2004). Partiendo de ellos, aquí me centraré en el modo en que son concebidas por los pediatras como espacios educativos, además de asistenciales, así como en las prácticas mediante las cuales abordan concretamente la crianza del niño y buscan normalizarla. En este sentido, es especialmente valiosa la información brindada por las evaluaciones periódicas de su organización y funcionamiento, publicadas en los Archivos Latinoamericanos de Pediatría (Acuña, 1903; Foster, 1906, 1907, 1911; Bordot, 1917; Oliva, 1917, 1918; Ávila Méndez, 1919).

Los dispensarios de lactantes atienden niños de hasta dos años y son concebidos con la función explícita de enseñar a las madres los cuidados que éstos requieren, además de entregar alimentos (elaborados en un sector de éstos: "la Cocina de la Leche") en los casos en que éstas no puedan amamantar y atender

\footnotetext{
${ }^{94}$ No he encontrado fuentes que den cuenta de la puesta en funcionamiento de estas escuelas de niñeras.

${ }^{95}$ En La Plata, la primera Gota de Leche comienza a funcionar en 1905, anexa a la Sala de Primeros Auxilios. Durante la primera década del siglo, también se establecen una gota de leche en Avellaneda y una botica de leche en Bragado (Kaminsky, op.cit.).
} 
padecimientos que no sean de carácter infecto-contagiosos. ${ }^{96}$ Como parte de ellos se fusionan las "gotas de leche", en un comienzo centradas en la asistencia alimentaria. El médico a cargo y sus auxiliares explican a las madres las prácticas más adecuadas para criar a sus hijos, especialmente las concernientes a la alimentación, haciendo de la lactancia materna una verdadera prédica: "los consultorios son cátedras en que sin cesar se predican estas ideas" (Oliva, 1918, p.158) - sintetiza el Director de la Sección de Protección de la Primera Infancia de la Asistencia Pública de Buenos Aires. En otros términos,

“[...] son escuelas de madres, en donde se les alecciona acerca de los cuidados que se relacionan con la crianza de sus hijos, inculcándoles como nociones fundamentales: que le leche de la madres es el mejor alimento para el hijo y que la madre tiene por lo mismo el deber sagrado de amamantarlo. Sobre este punto, la propaganda que se hace es incesante [...]." (Oliva, 1917, p.636).

También el espacio de los institutos de puericultura es utilizado para instruir a las madres, aprovechándose sobre todo el tiempo que las mujeres pasan en el sector internación acompañando a sus hijos. ${ }^{97}$ La internación conjunta del niño y su madre garantiza que aquél no sea abandonado, además de la "[...] habilitación de las madres para dirigir la crianza de sus hijos, en cuyos detalles se les instruyen con toda minuciosidad; posibilidad de restablecerles la secreción láctea a las que por habérseles restringido ingresan, colocándolas nuevamente en condiciones de reanudar la lactancia." (Oliva, 1917, p.640).

Para que sus hijos sean atendidos en los dispensarios de lactantes, las madres deben llevar un certificado de pobreza expedido por la Asistencia Pública y, en algunos de ellos, el certificado de nacimiento del niño. Una vez evaluado el estado del niño mediante un examen físico detallado y registrados sus datos familiares, se lo inscribe, dando comienzo a su seguimiento médico mediante consultas semanales. El procedimiento es similar en los consultorios externos de los institutos de puericultura. En cada consulta -antecedente del control periódico de salud prescrito

\footnotetext{
${ }^{96}$ De acuerdo con Kaminsky (1914), el personal de cada dispensario está compuesto por un médico, una auxiliar, una enfermera, un ordenanza y las "inspectoras", a cargo de la "inspección domiciliaria de los lactantes".

${ }^{97} \mathrm{Su}$ personal está integrado por un médico jefe, un médico agregado, un practicante de séptimo año de la carrera de Medicina, una auxiliar, encargada de los libros, una enfermera, una preparadora a cargo de la cocina de lactantes, una niñera, un ordenanza (Kaminsky, 1914).
} 
por la pediatría actual- se ponen en práctica una serie de rutinas de observación, medición, registro de características del niño, a través de las cuales se evalúa su crecimiento y desarrollo, como vimos en el Capítulo 2. Como veremos, son varios los instrumentos de registro utilizados: registro general de pacientes, cuaderno individual con la historia cínica, tarjeta individual, ficha de inspección domiciliaria. Los datos obtenidos y registrados son considerados indicadores de la crianza que está recibiendo el niño y permiten al médico reforzar, reajustar o modificar las indicaciones dadas a la madre. También se tornan la evidencia del cumplimiento o incumplimiento de las prescripciones médicas, lo cual puede dar lugar a un control más estricto, con la ayuda de las visitas domiciliarias. Este procedimiento es explicado detalladamente por el médico Enrique Bordot, Jefe del Dispensario de Lactantes $\mathrm{N}^{\circ} 8$ :

"Cada niño que viene por primera vez es anotado en el Registro General y tiene además un cuaderno llamado 'Cuaderno individual' donde se anota su historia clínica completa (antecedentes hereditarios, personales, peso, medidas, estado actual, tratamiento, etc.). Una vez examinado y cuando la madres ha recibido las instrucciones necesarias, se le entrega una tarjeta que lleva el número de orden de la historia y donde consta el peso semanal del niño, para que los padres puedan darse cuenta y se interesen en la marcha y el desarrollo de su hijo. Cada niño debe ser llevado al Dispensario por lo menos una vez por semana para ser pesado y para modificar en caso necesario su alimentación. Todos estos se anotan en el cuaderno para que el médico con una simple ojeada pueda darse cuenta del estado del niño, de la alimentación que recibe y del tratamiento al cual está sometido. Estas prescripciones son controladas en el domicilio del niño por una Inspectora adscripta a cada Dispensario." (Bordot, 1917, p.649).

Los padres del niño ya no parecen estar capacitados para saber si su hijo se encuentra bien, sino que ahora es el médico quien tiene el saber suficiente para discernirlo mediante la medición del peso y la estatura. Son las cifras en centímetros o en gramos y volcadas en la tarjeta o ficha correspondientes a su hijo las que, traducidas con la ayuda experta, les permite saber cómo está éste: "Estas fichas despiertan el interés y la emulación de las madres, juzgando el estado de sus hijos según el aumento o disminución de peso”. (Ávila Méndez, 1919, pp.565-566). Vemos así como se va demarcando una diferencia entre cuidadores legos y especializados del niño, no sólo en los casos de enfermedad, sino apara el cuidado del niño sano. 
Sin embargo, aunque la concurrencia a dispensarios de lactantes e institutos de puericultura aumenta de año en año, como señalan los médicos que los dirigen, también suele ser discontinua o interrumpirse antes de que el niño cumpla los dos años. ${ }^{98}$ Para estos casos de "deserción", la acción desde el consultorio resulta limitada, por lo que se recurre a un sistema de visitas domiciliarias, primero a cargo de "inspectoras a domicilio" y luego, al profesionalizarse la tarea, de visitadoras de higiene. Tal como señala Billorou (2008), al encomendar esta tarea a mujeres, suponiendo que esto facilitaba la construcción de un vínculo de confianza femenina con las madres, los médicos intentan reducir la distancia tanto espacial como cultural entre las madres y las instituciones de salud. Esta función auxiliar de la medicina es explicada claramente por el médico Silvestre Oliva:

"Por definición, la inspección domiciliaria de los niños acogidos a los beneficios de la puericultura oficial, debe ser solícita, inteligente y severa para que resulte provechosa, pues es el medio que tiene en sus manos el jefe de un servicio, para prolongar su acción educativa sobre las madres y asegurar el exacto cumplimiento de sus instrucciones." (Oliva, 1918. p.149).

La figura de la inspectora a domicilio es incorporada por los dispensarios de lactantes en 1912. Se trata de "señoras de reconocida honorabilidad" (Kaminsky, 1914), "señoras de experiencia empírica y educación acreditadas, sin otra mayor condición que la buena voluntad que depositan en su labor" (Ávila Méndez, 1919, p. 559). En cada visita deben observar y comprobar si las familias cumplen efectivamente con las prescripciones realizadas por el médico y el modo en que lo hacen, para lo cual

" [Efectúan sus visitas a distintas horas del día] a fin de verificar el uso que se hace de los alimentos suministrados por la Cocina de Lactantes, y si siguen estrictamente las prescripciones del médico; repitiendo lo aconsejado por el facultativo en caso de que la madres hubiese interpretado mal, y otras veces impidiendo que obren de mala fe; de modo que estas inspecciones domiciliarias sirvan al mismo tiempo como medida de disciplina y para vulgarizar los conocimientos relativos a la crianza de los niños" (Kaminsky, 1914, pp.58-59).

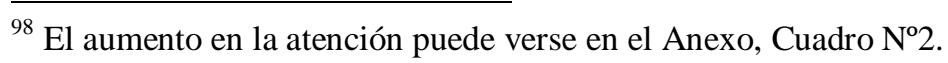


Su tarea se completa con el reforzamiento verbal de las indicaciones ya dadas por el médico, la insistencia en la necesidad de llevar al niño al dispensario y el registro de sus observaciones y apreciaciones en una detallada ficha, mediante la cual se evalúan el cuidado que recibe el niño, las características de la vivienda y la situación económica de la familia. ${ }^{99}$ Pero, sin dejar de reconocer su buena voluntad para el desempeño de esas tareas, los pediatras comienzan a objetar su falta de formación científica, planteando que "[...] carecen de los conocimientos que el puesto exige para el cumplimiento inteligente y proficuo de su misión.” (Ávila Méndez, 1919, p. 559). Dando respuesta a estos reclamos, en 1924 se crea la carrera de Visitadoras de Higiene Social, dependiente del Instituto de higiene de la Universidad de Buenos Aires, con una duración de dos años (Oliva, 2007).

Tanto en la "prédica" sobre la crianza higiénica realizada por los médicos en dispensarios e institutos de puericultura, como en las recomendaciones y advertencias de las inspectoras y visitadoras de higiene, podemos reconocer las denominadas por Vianna (2002) y por Lugones (2009) como "estrategias" o "formas de aconsejamiento". A diferencia de los consejos en su sentido más corriente, se trata de un tipo de prácticas que combinan técnica y moral. Implican una situación asimétrica entre quien aconseja y quien recibe el consejo y son parte de acciones de carácter pedagógico de saberes expertos con respectos a los portadores de saberes legos. ${ }^{100}$

\footnotetext{
${ }^{99}$ Ficha de inspección que completan las inspectoras en su visita domiciliaria:

"-Niño: alimento, cuidado, higiene. 1. ¿Dónde se encuentra el niño en el, momento de la inspección? 2. ¿Tiene algún objeto en las manos o boca (usa chupón) y lo asea como? 3. ¿Quién cuida al niño? 4. Estado de aseo del niño y sus vestidos.5. ¿Cómo lo alimenta y con qué intervalo? 6. ¿Qué alimento recibe del Dispensario? 7. ¿A qué hora retira comúnmente los frascos del Dispensario? 8. ¿Cuántas veces y qué alimentos ha tomado el niño hasta la hora de la inspección? 9. ¿Cómo y en qué le prepara el alimento, y qué le agrega? 10. ¿En qué biberón o recipiente y con qué utensilio se le da el alimento, y cómo lo higieniza? 11. ¿Dónde conserva los frascos del alimento, y los vacíos están limpios? 12. ¿Lo bala y lava al niño, cómo y cuántas veces? 13. ¿Tiene su cuna para dormir? 14. ¿Es llevado regularmente al Dispensario?

-Familia: habitación. 15. ¿Categoría de la casa. Piso bajo o alto? 16. ¿Cuántas piezas ocupan y cuánto pagan? 17. ¿Subalquilan alguna pieza y por cuánto? 18. ¿Cuántas personas duermen en la pieza del niño y cuántas camas contiene? 19. Aseo general. 20. Procedencia del agua empleada en la casa. 21. ¿Hay algún animal en la pieza del niño? 22. ¿Pieza del niño: orientación, asoleamiento, claridad, humedad, tamaño, materiales de construcción, número de puertas y ventanas, da sobre el patio?

- Estado económico. 23. Categoría de la familia.

- Datos complementarios. 24. Observaciones.” (Ávila Méndez, 1919, pp. 559-560).

${ }^{100}$ Ambas autoras utilizan el concepto en estudios sobre relaciones tutelares que se producen en la justicia de menores. Lugones (op. cit.), en su estudio sobre las prácticas de las administradoras de justicia en los tribunales Prevencionales de Menores de Córdoba, presenta una serie de características de estas formas de aconsejamiento: el tono persuasivo y convincente, aunque enfático y usando el imperativo, la incitación a que se haga algo por el bien del aconsejado, su oralidad, el empleo de ejemplos moralizantes y el reconocimiento implícito de una asimetría entre aconsejado y quien
} 


\subsubsection{Los consejos escritos: cartilla, manuales y revistas de divulgación}

La literatura médica sobre la niñez y la crianza tiene sus antecedentes en algunos tratados sobre educación infantil publicados en Europa desde fines del siglo XVII (Joaquim, 1997). Sin embargo, estos textos, aun cuando han sido escritos por médicos, no se sitúan desde un saber especializado en la infancia ni parten de una definición médica de esta etapa de la vida. Consisten más bien en un conjunto de consejos heterogéneos que, lejos de seguir un eje claro, combinan reglas morales, ejemplos, imágenes y proverbios de la época. Tal como observa Boltanski (op. cit.) la revolución pasteuriana permite a la medicina, a partir de 1880 aproximadamente, dotar a sus indicaciones sobre la crianza de una teoría en torno de la cual se cristalizan reglas y saberes hasta entonces dispersos, mal articulados entre sí, incluso contradictorios. La puericultura se constituye en un cuerpo coherente de conocimientos teóricos y de reglas prácticas que se expresan en textos organizados en torno de ciertos temas fundamentales, con capítulos y apartados articulados entre sí y fundamentados en los mismos principios científicos.

Asimismo, como hemos visto, a diferencia de los anteriores, los textos médicos de divulgación escritos en Argentina a partir del siglo XIX se inscriben en una preocupación más amplia por la mortalidad infantil como parte de la cuestión social y por o tanto, con una finalidad ligada a la educación de la población. Por ello, además de un cambio de estilo, su escritura muestra una diversificación de estilos de acuerdo a los diferentes sectores de esa población a los que sus pretenden llegar.

Entre el material escrito especialmente para las madres de sectores populares se destacan las cartillas publicadas por la Municipalidad de Buenos Aires, o por distintas bibliotecas y universidades populares impulsadas por el Partido Socialista, como la sociedad Luz ${ }^{101}$. Entre estos textos, podemos destacar: Alimentación del niño de pecho. Consejos a las madres, (Municipalidad de Buenos Aires,

aconseja. Son consideradas por la autora como técnicas de minorización, que restauran la relación tutelar con niños y familias.

${ }^{101}$ En el periodo histórico analizado, la prédica higienista no es sólo una estrategia del Estado, sino que forma parte de los proyectos de socialistas y anarquistas, desde una perspectiva compartida en cuanto a ver en la ciencia positivista el marco de referencia para analizar la sociedad. Dora Barrancos (1991) menciona que materias como "Higiene" y "Fisiología" suelen formar parte de los programas de las primeras escuelas obreras creadas por los socialistas, como la Escuela Libre para trabajadores, creadas en 1897, y la Escuela Socialista de Propaganda, surgida en 1899. Según la autora, los esfuerzos educacionales del socialismo, tienden, sin embargo, a una fórmula de complementariedad con la escuela oficial, más allá de los cuestionamientos que se le realice. 
Administración Sanitaria y Asistencia Pública, 1914); Aguilar, Delio: La cartilla de las madres, (Universidad Popular de la Boca, 1919); Higiene del embarazo. ¿Qué deben hacer las madres para impedir la muerte de sus hijos de pecho? (Municipalidad de la ciudad de Buenos Aires, Museo Municipal de Higiene y Asistencia Social, 1928).

En la ciudad de Buenos Aires, la edición oficial de material escrito con consejos a las madres, es establecida mediante la Ordenanza de Aguilar en 1911. Las primeras cartillas, editadas por la Municipalidad de Buenos Aires en la época de la elevada afluencia de inmigrantes previa a la Primera Guerra Mundial, son confeccionadas en castellano y luego traducidas al francés, italiano, inglés, alemán, ruso y turco, distribuyéndose en las maternidades, oficinas del Registro Civil, Hotel de Inmigrantes, dispensarios de lactantes, institutos de puericultura y la Oficina de la Inspección de Nodrizas. (Kaminsky, 1914). En la provincia de Buenos Aires, también en la primera década del siglo $\mathrm{XX}$, se redacta e imprime una cartilla con instrucciones populares a las madres, que se reparte en las Oficinas del Registro Civil a toda persona que denuncie el nacimiento de un hijo.

En general, en esos textos breves se habla a una mujer que trabaja fuera de su casa o que por falta de recursos no puede pagar la atención de un médico privado y debe recurrir a las instituciones públicas para obtener una ayuda en la crianza de su hijo. Así, por ejemplo, la mujer a la que se dirige el médico Delio Aguilar en $L a$ cartilla a las madres, no puede costearse un ama en caso de no poder amamantar a su hijo, por lo que se le recomienda recurrir a la leche de mujer que le proporcionarán en un dispensario público. En otro texto, entre las causas que impedirían a una madre amamantar a su hijo, se menciona "la necesidad de trabajar fuera de su casa" (Municipalidad de Buenos Aires, 1914), y se recomiendan los dispensarios de lactantes y la Inspección de Nodrizas como lugares a donde puede recurrirse en busca de consejos e instrucciones para criar a los niños. En muchas de estas cartillas o folletos se incluye una lista de todos los dispensarios de la ciudad de Buenos Aires, con sus direcciones, por si la familia no puede pagar un médico particular.

Por otro lado, se atribuye a algunas mujeres de sectores populares un grado de conciencia e instrucción que las haría aptas para recibir y multiplicar el mensaje higienista entre otras madres, analfabetas y más desprotegidas. De ahí la recomendación: "En obsequio al bien general, se ruega la divulgación de las nociones consignadas en este folleto entre las personas que no saben leer." 
(Municipalidad de Buenos Aires, 1914). También en la cartilla editada por la Universidad Popular de la Boca se exhorta a la lectora a que proteja y ayude al niño que vea desamparado, aunque no sea el propio, instruyendo a sus padres: "Si es necesario, ayude generosamente a los padres de ese niño, aunque más no sea, haciéndoles leer esta cartilla u otro libro de puericultura." (Aguilar, 1919). Del mismo modo, en 1922, en una conferencia pronunciada en la parroquia San Cristóbal Sud, Clemente Onelli solicita a sus oyentes que expliquen a las mujeres más pobres e ignorantes los medios de prevenir la mortalidad infantil:

“[...] ustedes que son del barrio y por lo tanto pueden tener más facilidades para encontrarse con ellas, traten de razonarles, de explicarles y llevarlas al convencimiento de que esta es la parte de la ciudad donde por desgracia se mueren mayor número de criaturas." (Onelli, 1922, p.5).

Asimismo, cabe señalar el modo particular con que los autores de estos folletos y cartillas se dirigen a sus lectoras: más que consejos, parecen impartir órdenes y proferir amenazas en caso de que no se sigan sus instrucciones. A diferencia del tono amable y paternal que suele preponderar a lo largo de las numerosas páginas de los manuales con formato de libro, en estos textos predomina el tono imperativo, a lo largo de una serie de frases cortas que, en algunos casos, se organizan y enumeran como los artículos de un código. Por ejemplo, la cartilla sobre Alimentación del niño de pecho, publicada por la Municipalidad de Buenos Aires en 1914, está organizada en 57 artículos, en los que se resumen, con tono imperativo, todas las indicaciones sobre la crianza. El artículo $\mathrm{N}^{\circ} 1$ establece: "La madre tiene para con su hijo deberes y obligaciones ineludibles; entre estos ninguno es tan imperioso ni tan sagrado como el de alimentarlo con su propio seno.” (p.1). Este estilo de discurso médico coincide con el que observa Boltanski (op. cit.) en las obras de vulgarización publicadas en Francia a partir de 1890, en las cuales los autores dan órdenes antes que consejos; en parte porque a partir del fundamento científico proporcionado por la revolución pasteuriana pasan a sentirse detentores de una verdad indiscutible y en parte porque no se dirigen a miembros de su propia clase social, sino a mujeres de los sectores populares a las que consideran que no hay que dejar margen de duda sobre las indicaciones realizadas. 
Llegados a este punto, resulta importante señalar la diferencia que Romero (1995) establece entre los sectores populares urbanos del período que se extiende entre 1880 y fines de la década de 1910, y aquellos de las décadas de 1920 y 1930, en cuanto puede contribuir a entender variaciones en el acceso a la información escrita sobre puericultura en la época aquí estudiada.

Los primeros presentan una marcada heterogeneidad en cuanto a la diversidad de orígenes y tradiciones, de condiciones laborales y de destinos sociales esperables, pero comparten una fuerte identidad clasista, crítica y contestataria, centrada en el mundo del trabajo.

"Sobre esta masa magmática y fluida, en vías de conformación, operó el Estado en busca de legitimidad y consenso para el orden político y social, aunque su instrumento principal, la educación, tuvo en lo inmediato un efecto reducido ante la masa de extranjeros adultos y escasamente escolarizados. También operaron, quizá con mayor éxito, intelectuales contestatarios; entre ellos, los anarquistas encontraron un eco notable al empalmar sus consignas políticas con los problemas y necesidades inmediatos de los sectores populares." (Romero, op. cit., p.10).

Corresponde a las características de los sectores populares de este primer período la edición y distribución oficial de escritos con consejos médicos sobre la crianza en varios idiomas, así como el importante papel desempeñado por las organizaciones obreras anarquistas y socialistas en la transmisión de principios higiénicos.

Luego de la Primera Guerra Mundial, iría constituyéndose otra identidad de los sectores populares, que Romero (op. cit.) caracteriza como popular, barrial y reformista. En su conformación incide la creciente argentinización de la población, a través de la escolarización y alfabetización crecientes en la lengua nacional, que hace a los hijos de los inmigrantes más permeables a los distintos discursos circulantes, especialmente los del Estado, junto con el proceso de movilidad social y de búsqueda de proyectos individuales. En la construcción de estas nuevas identidades colectivas, la sociabilidad barrial (anclada en instituciones como sociedades de fomento, bibliotecas populares, clubes, comités políticos de barrio) tiene un papel central, en tanto articuladora y resignificadora de los mensajes provenientes del Estado, de los nuevos medios de comunicación y de la cultura letrada que circula a través de numerosas publicaciones baratas. 
Sobre todo a partir de los años 20, podemos pensar en las bibliotecas barriales como espacios donde las mujeres -tanto obreras, como docentes o mujeres de pequeños comerciantes o de profesionales-, pueden encontrar manuales y otras obras destinadas a la divulgación de los preceptos de la puericultura y donde reciben el mensaje del higienismo a través de las frecuentes conferencias que allí tienen lugar (Romero, 1990; González, 1990) ${ }^{102}$. Distintos aspectos de la higiene individual y social, entre los que se incluye la puericultura, constituyen algunos de los núcleos temáticos privilegiados, no sólo en las conferencias pronunciadas en distintas asociaciones barriales, sino también en el Instituto Popular de Conferencias de la Capital Federal. ${ }^{103}$

A su vez, junto a las asociaciones barriales, bibliotecas y edición de libros baratos vinculadas a la tradición de izquierda (socialistas) y al progresismo liberal, existe otra red, impulsada por la iglesia católica, que recurre a medios muy parecidos, aunque sus contenidos puedan tener tenían una orientación distinta. Así, también las parroquias porteñas se tornan ámbitos de difusión de los principios de la puericultura a través de conferencias, como la pronunciada por el médico Clemente Onelli (op.cit.) en la Parroquia de San Cristóbal Sud, en 1922, con el título de Diez niños nacen, siete niños mueren. Conversación familiar a las madres.

El énfasis puesto en la instrucción de las madres de los sectores populares no excluye, sin embargo, la preocupación por la falta de conocimientos sobre la crianza infantil que los médicos también observan en las mujeres de "las clases más acomodadas":

"En las clases más acomodadas no bastan los cuidados que dicta la ternura maternal, ni el celo con que la madre defiende a su hijo de las causas de enfermedad, es menester que ella conozca estas causas, que sepa apreciarlas en su justo valor y que con más caudal de conocimientos prácticos y de recursos eficaces, pueda interpretar las

\footnotetext{
${ }^{102}$ González (1990), en su análisis de las actividades culturales y el fomentismo en un barrio porteño, menciona entre los temas frecuentemente tratado en las conferencias pronunciadas en la biblioteca barrial, el referido a diversos cuidados de la salud y la higiene. También organizadas por dicha biblioteca, a lo largo de 1929, se realizaron una serie de reuniones informales entre vecinos y médicos de la zona para abordar temas tales como crianza infantil y lactancia, profilaxis e higiene, prevención de enfermedades y alimentación.

${ }^{103}$ El Instituto Popular de Conferencias es fundado en 1914 por el director del Diario La Prensa y funciona con conferencias mensuales sobre temas diversos en un salón del edificio del periódico. Como ejemplos, podemos mencionar: Aráoz Alfaro, "Los niños que sufren", conferencia dada el 19 de septiembre de 1924; Madrid Páez, Samuel, "La asistencia médica preventiva de la Infancia", conferencia dada el 5 de agosto de 1927.
} 
necesidades de su pequeño hijo, objeto de tantas zozobras y ternuras. (Podestá, 1888, p.8).

En este sentido, si pasamos a analizar los manuales con formato de libro, encontramos que, si bien sus autores comienzan dirigiéndose a las "jóvenes madres" en general o inclusive afirman destinar sus consejos a las "mujeres del pueblo", a lo largo de la obra parecen hablar más bien a la mujer de la elite o perteneciente a una incipiente clase media. Hacen suponer que su lectora es una madre que no trabaja fuera de su casa y que dispone de tiempo suficiente como para seguir la lectura de los manuales desde los primeros síntomas de su embarazo, advirtiéndole también sobre los peligros de la contratación de una nodriza mercenaria - posibilidad que no está al alcance de todas las familias. Esto aparece, por ejemplo, en los manuales redactados por dos de los más prestigiosos médicos de comienzos del siglo XX: La salud de mi hijo, de Luis Agote, editado en 1901 y El libro de las madres, de Gregorio Aráoz Alfaro, publicado en 1899 y reeditado en sucesivas oportunidades hasta la década del 30. Así, en el prólogo redactado por el médico J.M. Jorge para el texto de Agote (1901), se comenta el destino que se espera para el libro:

"[...] basta que una madre inteligente de las muchas que seguramente existen en su clientela, lo lea, para que sea introducido en todos los hogares. Esta joya de título seductor ocupará siempre un sitio de preferencia en el boudoir de las jóvenes madres, en las mesas de luz, debajo de la almohada, y creo que no soy exagerado, diciéndole que en el cofre y junto con los dijes que adornan su exquisita coquetería, no ha de ser olvidado un ejemplar de LA SALUD DE MI HIJO." (p.vii).

Y si en su presentación de la edición de 1929 de El libro de las madres, Aráoz Alfaro comenta que "En esta nueva edición, proseguirá, pues, su camino de penetración en la masa popular, llevando a los hogares nociones y enseñanzas destinadas a evitar en lo posible la enfermedad y el sufrimiento y a formar la infancia sana, vigorosa y equilibrada que anhelo para mi patria." (Aráoz Alfaro, 1929, p. xi), al criticar, más adelante, a las mujeres que se niegan a amamantar a sus hijos, expresa:

"No hablemos de las mujeres pobres que, avaras o necesitadas en extremo, buscan el oficio lucrativo de nodrizas y entregan su propio hijo a otras amas baratas para que los dejen arrastrarse por el piso inmundo del conventillo, recogiendo suciedades y migajas que llevan a su hambrienta boca en vez de la leche de un seno mezquino destinado a 
servir a dos o más niños. No. De esa categoría de desgracias nos ocuparemos en otro sitio.

Aquí nos referimos a la dama aristocrática, rica o medianamente colocada, que tiene sed de paseos y de diversiones, o que se asusta, no tanto de la falta de libertad que le impondrá la crianza de su hijo, sino ante todo de que su cuerpo se deforme, de que sus senos se marchiten y su bella tez se decolore." (op. cit., p.75).

Escritos con estilos diversos, desde los más lacónicos y apegados a la explicación de procesos biológicos y consejos prácticos, hasta aquellos más atravesados por exhortaciones morales, los manuales de crianza infantil con formato de libro presentan una estructura y temas recurrentes. Suelen comenzar con un prefacio o una introducción donde el autor define sus objetivos de divulgación, plantea la importancia de la ciencia de la higiene y se dirige a las madres apelando a las dificultades y el valor de su misión de criar niños. A lo largo de los capítulos siguientes se refiere a la higiene de la mujer embarazada, al parto y a los primeros cuidados del recién nacido. Un lugar central ocupan el tema de la lactancia materna, la comparación con los otros dos tipos de lactancia: la mercenaria y la artificial, y el destete. Luego de apartados dedicados al vestido, la habitación, la cuna del niño, sus juegos y distracciones, su necesidad de sol y aire libre, se pasa a tratar las enfermedades más comunes en la primera infancia y el cuidado del niño enfermo, así como los primordios de su educación moral e intelectual, con el paso a su segunda infancia. ${ }^{104}$ Numerosos dibujos ilustran las explicaciones, ayudando a comprender las secuencias de operaciones a través de las cuales se aconseja alimentar al niño, bañarlo o vestirlo.

A un público similar parece dirigirse también una de las primeras revistas periódicas de divulgación de los principios científicos de la crianza infantil: Madre y Niño. Revista de Higiene y Educación de la Primera Infancia, publicación mensual

\footnotetext{
${ }^{104}$ Por ejemplo, el Libro de las madres, de Aráoz Alfaro (1929 [1899]) comienza con una primera parte dedicada a "La concepción y el nacimiento", en cuyo primer capítulo: "Preparando el porvenir. Algunas palabras sobre higiene preconcepcional y eugénica", se refiere a la legislación sobre matrimonio y los impedimentos médicos para el mismo, en los casos de problemas que puedan afectar la descendencia. La segunda parte se titula "El niño y su crecimiento" y se refiere específicamente a los cuidados que debe recibir el recién nacido. Luego sigue "Alimentación del niño", la tercera y más extensa de las partes del libro; la misma incluye la discusión de las ventajas y desventajas de los tipo de alimentación del niño y aborda aspectos del desarrollo y crecimiento. Las partes cuarta, quinta y sexta, con las que concluye el libro, se titulan respectivamente "La limpieza personal. La habitación y el mobiliario. Los vestidos", "Higiene de los músculos y del sistema nervioso. Higiene moral" (dedicada a la "educación física" y la "educación moral e intelectual") y, finalmente, "El niño enfermo".
} 
ilustrada que hace su aparición en agosto de 1905 y se prolonga por lo menos hasta 1907. Sus secciones principales incluyen consejos sobre distintos aspectos de la crianza y del desarrollo infantil, algún texto literarios sobre la maternidad y la niñez, un correo de lectoras y la sección "Amigos de los niños", dedicada a pediatras reconocidos por su aporte a la protección de la niñez. En el planteo de sus objetivos se hace referencia las madres en términos generales: "Madre y Niño tiene por objeto indicar a las madres las reglas prácticas para el cuidado de sus hijos desde el nacimiento hasta su mayor edad" (Año I, No 1, agosto de 1905, p.1). Pero a lo largo de la lectura encontramos a una madre que está siempre en su casa, que puede intentar enseñar los rudimentos de la lengua francesa a su hijo a través de un curso publicado por entregas, llamado "Bebé políglota", y a las que se destinan las propagandas de importantes tiendas de Buenos Aires y los avisos de los consultorios particulares de los médicos ${ }^{105}$ y parteras más reconocidos de la época. En el segundo año de su publicación, la revista incorpora la sección "Galería contemporánea", donde aparecen “[...] los retratos de nuestras matronas más altamente colocadas en sociedad y que dedican sus actividades en beneficio de la infancia desvalida o instituciones de beneficencia", así como las fotografías de niños que corresponden a los “[...] más hermosos ejemplares de nuestra aristocrática sociedad” (año I, No 5 , diciembre de 1905, p.8).

De este modo, si el objetivo privilegiado por los médicos de fines del siglo XIX y comienzos del XX es llegar a las mujeres de la clase obrera, esto no excluye la necesaria educación de las mujeres de todos los sectores sociales, como parte de una misión civilizatoria encaminada a modificar las conductas privadas de todos los integrantes de la sociedad.

\footnotetext{
${ }^{105}$ Por ejemplo, publican los avisos de sus consultorios particulares los médicos Genaro Sisto, y Uriarte Castro, a quienes también se les dedica sendas semblanzas en la sección "Los amigos de los niños", que aparece en cada número.
} 


\title{
3.3. Condición femenina y maternidad en el discurso médico sobre la crianza.
}

\author{
"Pobres madres que lloráis a vuestros hijos perdidos, \\ ¡cuánto más intenso sería vuestro dolor y también vuestro \\ remordimiento, si pudierais sospechar que no habéis hecho todo lo \\ necesario para prevenir la desgracia que os aflige!..." (Guía \\ maternal o El arte de criar hijos sanos, 1900).
}

No es posible comprender el modo en que la medicina aborda la crianza, sin considerar el conjunto de representaciones sobre la condición femenina y la maternidad que le están estrechamente unidas. En efecto, al hablar del niño y de sus necesidades, la puericultura -y la pediatría en su totalidad- están participando en la construcción de un determinado modelo de mujer y de madre.

Como ya hemos visto, en un contexto en que la infancia ha pasado a constituir el "capital humano de la nación" y, como tal, necesita ser protegida, la madre pasa a resultar imprescindible para engendrar herederos y ciudadanos y se torna responsable de la salud de su hijo. En las palabras con que el higienista Luis Agote presenta su manual de puericultura, puede percibirse el modo en que la preocupación por la infancia en tanto población incide en la construcción de un ideal de madre: una mujer que, debiendo centrar su existencia en la procreación, es convocada para "salvar" a la sociedad y la nación:

"A las madres argentinas

"En ningún momento de nuestra historia, la República ha necesitado tanto de hijos fuertes y sanos, capaces por el vigor armónico de su organismo, de vencer los efectos de una crisis, que no sólo es política y económica, sino también esencialmente social. Para contrarrestar sus desastrosos efectos, es necesario aunar en un solo esfuerzo firme y constante, todas las fuerzas vivas del país, entre las cuales ocupan lugar prominente las de la madre, por las múltiples funciones que la sociedad y la naturaleza le han señalado." (Agote, 1901., pp. III-IV)

Desde un discurso que homologa femineidad a maternidad, se plantea que la procreación y la crianza de los hijos constituyen una misión intransferible para la mujer, en tanto conforman el aspecto central de la "naturaleza femenina". Para ello, 
toda mujer está dotada de un instinto especial: el "instinto materno", un amor hacia su hijo que surge espontáneamente, aunque debe ser moldeado socialmente. ${ }^{106}$

"La misión primordial de una mujer, en la sociedad y en la vida, es la de ser madre en el sentido más noble y más amplio de la palabra. Así lo ha establecido la ley de la naturaleza al vincular a su propio organismo el organismo naciente del nuevo ser con un lazo que, iniciado en el primer instante de su evolución, no se destruye por el nacimiento sino que se prolonga todavía, en forma más sutil e indirecta, si se quiere, pero por ello no menos estrechamente dependiente, durante todo el período de la lactancia." (Muniagurria, 1924, p.15).

Siguiendo a autoras como Nari (1996; 2004) o Guy (1998), este discurso de la puericultura participa del proceso de construcción de una nueva idea de mujer y de madre a la que contribuyen, además de la medicina, otros saberes científicos, concepciones religiosas, filantrópicas y feministas.

Hacia fines del siglo XIX el amor materno aparece como un valor social, a partir de procesos que autoras como Badinter (op. cit.) y Knibiehler (2001) vinculan con el Iluminismo del siglo XVIII. El nuevo ideal de madre higiénica, virginal, nodriza y amorosa “[...] se presentó como universal, ahistórico, natural. Inscripto en la misma naturaleza femenina, reformuló simultáneamente la idea de mujer: la femineidad acabó confundiéndose y reduciéndose a la maternidad; la mujer, a la madre." (Nari, 1996, p.154). Como veremos, en este modelo se apela una y otra vez a la naturaleza de modos diversos y hasta contradictorios. ${ }^{107}$ Así, esta noción servirá para fundamentar prácticas, prescribir funciones o explicar excesos en relación a la maternidad.

Encontramos, en primer lugar, una referencia a las funciones naturales de los órganos ligados a la gestación y la lactancia sustentando la idea de la maternidad como la función inherente a la mujer. Más allá de que varios higienistas comentan que el matrimonio está destinado a engendrar hijos sanos, la esencia de la reproducción parece residir en el cuerpo femenino. La recomendación de reglas de

\footnotetext{
${ }^{106}$ El carácter de construcción social y el origen histórico de la noción de instinto materno constituyen el eje del análisis de Badinter (1985).

107 Tal como sucede con el uso que en la época se hace de la noción de "naturaleza infantil", tampoco en este caso la naturaleza equivale exactamente a la biología necesariamente. Aunque la tenga como base, va más allá de ella, para aludir a lo propio de la mujer, una suerte de "esencia" femenina.
} 
higiene durante el embarazo y el parto parece más orientada a asegurar una madre al niño por nacer, que a la protección de la mujer ${ }^{108}$.

La lactancia materna, principal medio de evitar la mortalidad infantil, será la mejor prueba de amor maternal -un amor "de razón" y no sólo "de instinto"- y, a la vez, de amor a la patria, a la que ofrece hombres sanos y fuertes. Así, el discurso higienista hará del amamantamiento a la vez un deber de la madre y un derecho inalienable del hijo. Así lo expresan la máxima acuñada por el médico francés Pinard: "La leche de la madre pertenece a su hijo", y la sentencia que enuncia que "toda madre sana debe amamantar a su hijo" -aún hoy en día mencionadas por los pediatras. En el mismo sentido, en una cartilla con consejos a las madres, editada en 1913 por la Municipalidad de Buenos Aires, se afirma que "El hijo tiene, pues, derecho al seno materno y la madre el deber sagrado de dárselo. Quien le ha dado su sangre no puede negarle su leche.” (En Kaminsky, 1914, p.49).

Se considera que la continuidad entre madre e hijo existente durante la gestación se restablece después del parto a través del amamantamiento. Esta continuidad biológica es la base del amor materno filial y aparece fuertemente simbolizada por la sangre, que durante el embarazo nutre al bebé a través del cordón umbilical y luego se desplaza a los pechos de la madre, para transformarse en leche, también denominada la "sangre blanca"109. "Esa leche -se afirma- proviene de un organismo del que ha salido el mismo niño, y esa 'sangre blanca', como se ha dicho, deriva de la sangre roja de la madre que circula también por las venas del hijo." (Aráoz Alfaro, op. cit., p. 74). En los manuales de puericultura de fines del siglo XIX y primeros años del XX, es frecuente la mención de la transmisión de estados de ánimo, afecciones nerviosas y rasgos de carácter de la madre al hijo a través de la leche, idea que comenzará a ser relativizada y hasta criticada por los pediatras una o dos décadas después. ${ }^{110}$

\footnotetext{
${ }^{108}$ Así aparece expresado por uno de los higienistas más reconocidos de la época: "La primera medida tendiente a asegurar el bienestar del niño, consiste, en efecto, en conservar la madre y en conservarla en condiciones tales que pueda ser su nodriza y cuidadora." (Aráoz Alfaro, op. cit., p.28).

${ }^{109}$ Tal como lo observa Del Priore (1995), "no Ocidente cristão, leite e sangue sempre estiveram intimamente unidos, e sua capacidade de provocar doenças, enfermidades e melancolia prevalece ainda hoje no imaginário popular." (p. 242).

${ }^{110}$ Por ejemplo, se advierte:

"Las madres enfermas, coléricas, ebrias ó muy agitadas cometen un crimen al dar de mamar á sus hijos." (Guía Maternal, 1900, p. 40).

"Es también un hecho comprobado hasta la evidencia, el influjo de las afecciones morales sobre la calidad y la secreción de la leche; un susto, una rabieta, un patatús cualquiera, pueden llegar hasta suspender la secreción bruscamente, durante doce, veinticuatro y más horas." (Guía Maternal, op. cit., p. 48).
} 
Además de las ventajas para el niño, autores como Aráoz Alfaro mencionan los efectos positivos de la lactancia natural sobre la misma madre (quien se repondrá más rápidamente del parto), la familia y la sociedad, que “[...] está así segura de conservar mucho mayor número de vidas, así como de tener individuos más vigorosos y más fuertes, más aptos para producir trabajo y menos expuestos a las enfermedades variadas cuyas causas abundan en toda aglomeración humana [...]" (Aráoz Alfaro, op. cit., p. 72).

A través del amamantamiento, aparece también la idea de la maternidad como sacrificio constante, pero placentero, que puede extenderse a todo lo relacionado con la crianza del hijo: ${ }^{11}$

"Es muy cierto que después de haber dado la vida a un hijo, la lactancia maternal trae aparejadas innumerables molestias, desvelos, privaciones, cansancio constante y demás motivos de fatiga; pero también es cierto que todo ese cúmulo de penalidades, es para la madre amorosa un ramillete de flores de inagotable fragancia y de íntimos e intensísimos placeres. Satisfechas las madres que ven desarrollarse entre sus cariñosos brazos a los pedazos de sus entrañas, saben sacrificarlo todo por esa gran función de lactancia que les da con justo motivo el título de madre, viendo recompensados sus afanosos cuidados al contemplar el semblante risueño de su infante adorado, y al pensar que ella es la única persona que da vida a un ser tan querido y digno de lástima. Conceptuamos, por lo tanto, feliz, a la mujer que, juiciosa y sana, puede cumplir los deberes que la Naturaleza le ha impuesto, obteniendo así, únicamente ella, las primeras caricias de su hijo." (Guía Maternal, 1900, pp. 33-34).

La idea de crianza es así construida a partir de la noción de "desinterés" (monetario), desde la cual, las diferentes acciones de cuidado del niño son consideradas moral pero no económicamente valorables y valoradas (Vianna (op. cit.). Desde esta perspectiva, el amamantamiento se transforma, en el discurso médico, en la más sagrada de las tareas maternas y la mejor prueba de amor hacia el hijo. En tanto práctica que permite evitar la mortalidad infantil, ocupa el centro de las recomendaciones de los pediatras e higienistas, quienes combaten la costumbre de contratar nodrizas con la prédica de "volver a la naturaleza" dando el pecho al propio hijo. En esta línea de argumentación, algunos hacen referencia a las ideas de

\footnotetext{
111 "Ora, a maternidade, tal como é concebida no século XIX a partir de Rousseau, é entendida como um sacerdócio, uma experiência feliz que implica também necessariamente dores e sofrimentos. Um real sacrifício de si mesma." (Badinter, op. cit., p.249).
} 
Rousseau y otros aducen que en el reino animal, ninguna hembra rehúsa amamantar a su prole. Como consecuencia, la mujer que, pudiendo hacerlo, no amamante a su hijo, será frecuentemente acusada de "madre desnaturalizada". A través de este discurso sobre la lactancia, el personaje de la madre que aparece en los textos de puericultura se desdobla en la "buena madre", que acepta los sacrificios que impone el amamantamiento, viéndose recompensada por la salud y el crecimiento de sus retoños, y la otra, aquella que entrega sus hijos a los brazos mercenarios de una nodriza paga, ya sea por propia elección o por su situación social. ${ }^{112}$ Entre esas madres "desnaturalizadas", se considera necesario distinguir entre la nodriza pobre, que no amamanta a su bebé porque debe vender su leche para poder subsistir, y la madre rica y egoísta, que priva del seno no sólo a su hijo, sino al de la primera. Tanto una como la otra, suelen verse castigadas con la enfermedad o la muerte de sus hijos, desde un discurso que ve a la madre como la responsable de la supervivencia y salud de sus hijos ante su familia y ante el Estado, tal como lo expresa el epígrafe que encabeza este apartado.

Sin embargo, la lectura de fuentes anteriores nos muestra que esta naturalización de la lactancia materna es relativamente reciente para la época analizada. En efecto, los tratados médicos franceses de mediados y aún fines del siglo XIX, algunos de los cuales, como el de Donné (1847), son traducidos al español y editados en Argentina, son ambiguos con respecto a las ventajas de la lactancia materna. Tal como observa Faÿ- Sallois (1997), si bien la reconocen como la mejor forma de alimentación para el niño, no la presentan necesariamente como una práctica natural ni instintiva, ni un deber de la madre. Argumentan que debe resultar de una decisión "voluntaria y espontánea" por parte de la mujer quien no es por ello mejor madre y que, por el contrario, puede arruinar su salud al poner en ello un "celo excesivo" o ser arrastradas por un ardor maternal que "va más allá de lo que sus fuerzas le permiten" (Donné, op. cit., pp. 35-36). ${ }^{113}$ Unas décadas después, esta idea

\footnotetext{
${ }^{112}$ En Argentina no es común, como sí lo ha sido en Francia a lo largo de los siglos XVII a XIX (Donzelot, 1990; Flandrin, 1991) el envío de los niños al campo para ser criados en la casa de la nodriza; más bien, las familias acomodadas suelen contratar nodrizas a domicilio. Cuando en los textos de la época se habla de "nodrizas externas" o "amas externas", se hace referencia las que están a cargo de los niños de la Casa de Expósitos. Cabe suponer que junto a esas prácticas más reguladas institucionalmente, existen otras de carácter informal, establecidas entre mujeres emparentadas o con algún otro vínculo previo, en las que ante la dificultad de una de ellas, la otra ofrece amamantar a su hijo junto con el propio, dando lugar a la constitución de vínculos en términos de "hermanos de leche" o "hijos de leche".

${ }^{113}$ Vale la pena reproducir estos argumento en detalle:
} 
de que la madre debe decidir libre y espontáneamente si quiere amamantar a su bebé, es reemplazada por la sentencia que establece que "Toda madre sana debe amamantar a su hijo".

La prédica higienista en pro de la lactancia materna muestra que, desde el discurso médico, el amor y el instinto maternos son necesarios para la crianza de los niños, pero no resultan suficientes; dirigirlos mediante la instrucción es la misión central de los pediatras e higienistas. Éstos, entonces, partiendo de la idea de que las madres por sí solas no saben criar correctamente a sus hijos, asumen el rol de educadores, construyendo dos destinatarios privilegiados de sus consejos: la "joven madre", primeriza, que debe aprender los principios científicos de la crianza para asegurar el bienestar infantil, y la "madre del mañana", es decir, la alumna de escuela primaria o de colegio normal, que debe comenzar a prepararse desde niña para asumir con éxito ante el Estado su futura misión de madre-educadora.

\subsubsection{La instrucción de la "joven madre"}

Más allá de sus estilos diversos, los textos de divulgación de la puericultura convergen en el destinatario de sus consejos: la joven madre primeriza, inexperta, llena de buenas intenciones pero capaz de tornarse, sin una guía adecuada, en peligrosa para su propio hijo.

De acuerdo a las estadísticas del periodo analizado, presentadas por Nari (2004), esta mujer joven tiene su primer su primer parto entre los 20 y 24 años de edad. ${ }^{114}$ Se la imagina frecuentemente como una "casi niña", ávida de consejos, "un

\footnotetext{
"La determinación de criar debe ser voluntaria y espontánea. [...]; semejante determinación no debe abrazarse jamás por deber o complacencia. Las que no tengan vocación ó no quieran ser nodrizas de sus hijos deben renunciar á serlo. En nuestro concepto ni las familias, ni los mismos maridos deben empeñarse en obtener, á fuerza de súplicas ó por una especie de violencia moral, lo que no es natural y espontáneo en las interesadas; ninguna resolución exige más libertad que esta: en general se desempeña mal lo que no se hace voluntariamente. Es menester convenir en que hay madres, y madres excelentes que no pueden encargarse de los cuidados que reclama la primera edad: que no tienen inclinación para criar; no por eso debe creerse que dichas madres son necesariamente mujeres desnaturalizadas, sin afición ni amor sincero hacia sus hijos; semejante aplicación exagerada de principios nos conduciría a menudo á interpretar mal los sentimientos del corazón, y juzgar con demasiada severidad una disposición insignificante en sí misma. Por nuestra parte, confesamos que, en muchos casos, preferiríamos ver menos entusiasmo en ciertas madres jóvenes que, arrastradas por su ardor van más allá de lo que sus fuerzas les permiten, y cuyo celo no se conserva largo tiempo al nivel de este primer impulso." (Donné, op. cit.1847, pp.35-36).

${ }^{114}$ A lo largo de todo el periodo que va desde 1890 a 1930 casi la mitad de las mujeres tiene su primer parto entre los 20 y los 24 años (43,9\% en 1897, 48,4\% en 1907, 44,8\% en 1914, 44,3\% en 1925).
} 
terreno excelente para recibir y adoptar todo lo que se le inculque con el fin de criar a su tierno hijito" (Martínez Zuviría, 1918, p.6). Mientras el padre está prácticamente ausente en los textos, es ella quien, por su inexperiencia, siente las mayores dificultades para criar a su bebé y, además, tiene mayores posibilidades de tornarse una víctima de los consejos derivados del prejuicio y la ignorancia o de los dictados desordenados de su propio instinto.

"Hay tantos prejuicios que sobre la crianza del niño se transmiten por tradición de madres a hijas, que es necesario desterrar para siempre haciendo que la mujer que va a ser madre se instruya y, llegado el momento tan anhelado del nacimiento de su primer hijo, no sea éste también la primera víctima de la joven madre [...].”(Martínez Zuviría, 1918, p.6).

Desde la perspectiva de los médicos, esta joven debe ser especialmente ayudada para poder cumplir adecuadamente la tarea que la naturaleza le ha asignado: engendrar y criar niños sanos. Su amor y su instinto no bastan para asegurar la buena crianza del niño:

"No hay duda que en el amoroso corazón de las madres existe ese germen sublime, que se convierte en virtud, rivalizando en abnegación y en sacrificios, cual no ocurre en ningún otro ser de la creación. Empero, está probado que no basta el acendrado amor de las madres, ni las inspiraciones naturales para precaver á los tiernos hijos, de las mil contrariedades y peligros que rodean la primera infancia. Por esto es, que, [...] dedicamos todo este número á compendiar los principales consejos prácticos y las informaciones más adecuadas á la higiene de la primera infancia". (Guía Maternal, 1900, pp. 5-6).

El instinto materno, como otras fuerzas de la naturaleza, si no es guiado racionalmente puede conducir a excesos de ternura que terminan perjudicando a su hijo. Los pediatras argumentan, por ejemplo, que si la ley de la naturaleza establece que el niño debe ser amamantado por su madre, nada indica, por ejemplo, acerca de la frecuencia ni el modo en que esto debe ser hecho; esta tarea es la que corresponde a la ciencia médica, fundada en los conocimientos comprobables de la fisiología infantil.

Se pretende, entonces, que la guía de la ciencia tome en la instrucción femenina el lugar hasta entonces reservado a los consejos familiares y religiosos. Por ello -se aconseja- "Las madres de familia debieran tener al lado del devocionario un

Casi la totalidad de los restantes porcentajes se reparte entre las mujeres menores de 20 años y las que tiene entre 25 y 29 años (Nari, 2004). 
tratado de higiene privada o higiene de los hogares, y leerlo al despertar, a continuación de las oraciones de más acendrado misticismo." (Guía maternal, 1900, p.8). A través de la educación higiénica, asesorada por el médico, la joven madre destinatario privilegiado de los manuales de divulgación de la puericultura- logrará transformar su "amor de instinto" en "amor de razón", un amor con valor social, que le permita ofrecer a la patria hombres sanos y fuertes ${ }^{115}$.

De este modo, tal como lo plantea Nari $(1996 ; 2004)$, si bien se parte de la idea de la maternidad como función natural y del amor materno como producto del instinto, el discurso de la puericultura relativiza la fuerza del "instinto ancestral de la raza" y acentúa la necesidad de crear una "conciencia de aprender la profesión de madre" (Nari, 1996, p.158).

"Producto del instinto pero necesariamente fortalecido por la educación, el 'amor maternal' coronaba esta nueva imagen de mujer: la madre moderna, que resignificaba viejas tradiciones al mismo tiempo que incorporaba el discurso científico como instancia fundamental de legitimación." (Nari, 1996, p.157).

Desde un discurso que opone naturaleza/instinto/debilidad a educación/razón/firmeza, las mujeres suelen ser ubicadas, junto con sus hijos, en el primer polo, siendo el deber de los médicos aportarles elementos del segundo para asegurar el bienestar infantil. Sin embargo, como veremos., esta perspectiva va sufriendo transformaciones a lo largo del período estudiado, siendo complejizada a partir de la segunda década del siglo XX, cuando la mujer madre es convocada por los médicos como auxiliar de su mensaje higiénico, apelando a sus capacidades.

Sobre todo en manuales del siglo XIX, la mujer aparece compartiendo una naturaleza caprichosa e instintiva con el propio niño, actuando según impulsos dictados por las emociones, siendo el médico el encargado de encauzarlos aportando reglas racionales. "Ni el celo, ni la mejor voluntad, ni el amor materno falta á las madres en nuestra época, sino solamente una buena dirección.” - afirma Donné (1847) a mediados del siglo XIX. La incapacidad de dominar sus debilidades instintivas, puede llevar a la joven madre a una exageración egoísta del amor hacia el hijo,

\footnotetext{
${ }^{115}$ Badinter explica esta transformación del ideal materno para el caso de Francia: "No fim do século XVIII, o amor materno parece un conceito novo. [...] Mais o que é novo, em relação aos dois séculos precedentes, é a exaltação do amor materno como um valor ao mesmo tempo natural e social, favorável à espécie e à sociedade.” (Badinter, op. cit., pp.145-146).
} 
cediendo a sus menores reclamos. En palabras del mismo autor, “[...] de lo que más carecen muchas madres para criar bien a sus hijos es de fuerza y de firmeza; casi todas confunden constantemente sus instintos de ternura materna con el sentimiento de su deber, y así se dejan arrastrar á debilidades de las cuales son las primeras víctimas sus hijos [...].” (op. cit., p.6).

La crítica al "exceso de cariño materno" será un tema recurrente en autores posteriores. Así, Aráoz Alfaro (op. cit.) aconseja a las madres aprender a dominar su sensibilidad y, por ejemplo, saber resistir al llanto de sus hijos sin tomarlos en brazos, pues sólo una educación basada en la firmeza y ejercitada desde el primer día garantizará que el niño no se convierta en pequeño déspota hogareño. De este modo, no sólo puede verse en la puericultura una "ciencia o arte de criar niños", sino también una verdadera pedagogía de la maternidad, ya que no sólo busca normalizar los comportamientos de la primera infancia sino, sobre todo, disciplinar a la mujer en sus tareas maternales.

Sin embargo, entrado el siglo XX, se comienza a apelar no sólo al instinto y a las funciones biológicas a la hora de pautar el ejercicio de la maternidad, sino también a la "ternura e inteligencia", como capacidades femeninas ligadas a la función social que tienen la maternidad y la crianza:

"La inteligencia y la ternura que han reemplazado en la madre humana al instinto, suficiente en las madres animales, deben ser, pues, cultivadas en el sentido de su misión ineludible y mediata; tanto más cuanto que esa misión no puede ser circunscripta al hogar en el cual se realiza, sino que, sobrepasando sus límites, se expande en beneficio de la colectividad, determinando las virtudes físicas y morales de la raza. Es así como la mujer influye en forma personal y eficiente sobre el porvenir mismo de la patria." (Muniagurria, 1924, p.15).

Asesorada por el médico, ya no se ocupa sólo de llevar a buen término la crianza del niño en cuanto a la alimentación y los cuidados cotidianos, sino que tiene la responsabilidad de educarlo durante los primeros años, sobre todo en los aspectos morales y afectivos:

"En los primeros años de la vida, esto es, en los que siguen á la lactancia y á los pininos infantiles, la madre es el primer elemento de educación; y no sería posible privarla del derecho de educar que tiene sobre sus hijos, puesto que la misma naturaleza le ha encomendado esa misión. [...]. La buena madre es la que con su acendrado y puro cariño, 
modera las pasiones fogosas y extiende sobre la sociedad entera esa radiación de condescendencia y de amor que tanto ennoblece y dignifica a la familia humana. [...].”(Guía Maternal, op. cit., pp.114-115).

Autores como Aráoz Alfaro (op. cit.) consideran el papel social (educación, entrega de afecto), a la par que biológico (procreación y amamantamiento) de la mujer. Este papel no deja de pensarse como derivado de la "naturaleza" femenina, pero se trata aquí de una noción de naturaleza que no la ubica necesariamente en el lugar del puro instinto y la irracionalidad, sino como un sujeto capaz de aprender y aplicar racionalmente principios de la higiene, y con la que el médico puede contar para proteger la salud infantil. Al respecto, Nari (2004) señala que en la época estudiada, la maternidad abrió tanto perspectivas políticas de tutela y de control sobre las mujeres y sus cuerpos, como un medio de mayor autonomía y liberación (por ejemplo, incorporando tempranamente conocimientos sobre reproducción censurados por la religión), desde la formulación de derechos en términos de los "derechos de las madres", en que se apoya parte del feminismo de comienzos del siglo XX.

Ello entraña, no obstante, un riesgo que los médicos ven con preocupación: que estas mujeres, instruidas en las prácticas científicas del cuidado infantil, terminen prescindiendo de la guía del médico, es decir, que se desdibuje nuevamente la frontera entre cuidadores legos y expertos. Por eso, en esta alianza entre la madre y el médico de familia (Donzelot, op. cit.), pediatras e higienistas procuran dejar en claro que el lugar de la mujer es el de auxiliar del profesional. De ahí el epígrafe que Agote (1901) coloca en la portada de su libro de divulgación: "La madre debe ser el auxiliar inteligente del médico, pero nunca el médico mismo”.

Así, portadora de una misión natural ineludible que, sin embargo, debe aprender a llevar a cabo, oyendo la voz del instinto, aunque a través de las palabras de la ciencia, la joven madre debe ajustarse a la imagen de la madre moderna, responsable no sólo al interior de la familia sino ante el Estado de la educación física y moral de sus hijos, tal como lo muestra el siguiente fragmento:

"Me dirijo a las madres.

Ellas - las depositarias de esa fuerza obscura y latente hoy, visible y poderosa mañana, que se llama el niño, las destinadas a modelar esa blanda masa que, tanto en la organización física como en la textura moral definitivas, depende, generalmente, del impulso de los primeros años - ellas solas, aleccionadas y dirigidas por el médico [...] pueden darnos gérmenes sanos y vivaces de que la Escuela y el Estado 
sacarán más tarde el hombre fuerte de físico, sano de alma, flexible y abierto de inteligencia." (Aráoz Alfaro, op. cit., pp. ix-x).

\title{
3.3.2. Preparando a la "madre del futuro".
}

\begin{abstract}
"Niñas
Puesto que habéis leído con atención toda esta cartilla que ha sido escrita por vosotras, y para vosotras; puesto que recordáis con precisión cada uno de los preceptos que os permitirán ser las delicadas cultivadoras de 'LA FLOR HUMANA' -flor de carne e inocencia que es el niño;puesto que vuestra inteligencia y vuestro corazón se han nutrido, en sus páginas, de amor y de sabiduría, podéis consideraros, desde ya, como las madrecitas de todos los actuales niños argentinos, y como las generaciones de niños pequeños son la nación de mañana, podéis asegurar también que el destino de la Patria está en vuestras manos." (Muniagurria, La flor humana, 1923).
\end{abstract}

Si la misión central de la puericultura consiste en enseñar a las madres el arte de criar correctamente a sus hijos, lo ideal es que esta tarea comience lo más tempranamente posible. Muchas veces, se afirma, los consejos del médico llegan demasiado tarde, cuando los hábitos derivados de la ignorancia ya están arraigados en la mujer y no pueden ser modificados. De ahí que se sostenga que la mujer que es instruida desde temprano será una mejor madre y educadora de sus propios hijos. Con este fundamento, pediatras e higienistas logran que, poco a poco, la enseñanza de la puericultura se implante en algunas escuelas primarias, las escuelas normales y los colegios nacionales. Luego de algunos ensayos en escuelas normales y profesionales para mujeres de la Capital, impulsados por el médico Enrique Feinmann, en 1923 la asignatura "Puericultura" es incorporada oficialmente en los programas de las escuelas primarias y las escuelas normales. ${ }^{116}$

\footnotetext{
${ }^{116}$ Como antecedente, los médicos argentinos mencionan el curso sobre puericultura que, en 1902, Pinard comenzó a dar en una escuela primaria de niñas de París. Según Kaminsky (1914), en nuestro país la enseñanza de la puericultura en el ámbito escolar comienza en 1913, con un curso de 'ensayo' para las alumnas de las Escuelas normales y en el Liceo de Señoritas. Esta iniciativa es impulsada por Feinmann, quien gestiona su ampliación a toda la enseñanza secundaria femenina, siendo en 1914 designado por resolución del Ministro de Justicia e Instrucción Pública para dictar los primeros cursos extraordinarios de Puericultura en las Escuelas Profesionales para mujeres de la ciudad de Buenota Aires.

Feinmann describe, en líneas generales, los programas propuestos para la enseñanza de la puericultura:

“[...] comprenden los capítulos más importantes de la fisiología e higiene infantil. Desde luego, el estudio físico del niño, sus órganos, su peso, su crecimiento. Más adelante, las primeras nociones sobre su aseo, su toilette, sus vestidos y su menaje. Luego el estudio de la alimentación lo más detenidamente posible, porque sobre ella se acumulan todos los errores y los males del niño, desde
} 
$\mathrm{Al}$ respecto, resulta especialmente interesante el debate presentado en 1924 en la Revista de Instrucción Primaria, destinada a los maestros de primaria y a los alumnos de escuelas normales de la provincia de Buenos Aires, acerca de la conveniencia de la enseñanza de la puericultura en las escuelas primarias. En un número especial de la Revista de ese año, titulado La Puericultura. Encuesta sobre la necesidad de su implantación, son consultados educadores y médicos que han escrito sobre puericultura. Los puntos de discusión giran en torno al motivo y la conveniencia de su enseñanza en la escuela primaria, a si debe constituir una asignatura especial o formar parte de las enseñanzas cotidianas de la maestra y si sus destinatarios deben ser sólo las niñas o también los varones. Unos de los aspectos que suscita polémicas es la información acerca de la reproducción y, por lo tanto, la sexualidad humana, que la enseñanza de la puericultura conllevaría indirectamente. ${ }^{117}$ Los argumentos puestos en juego por los entrevistados serán varios y, en algunos aspectos, contrapuestos. Sin embargo, todos coinciden en la misión de "educar para la vida" que tiene la maestra -lo cual la aproxima a la misión materna- y la función de los alumnos como eslabones entre la escuela y la familia, entre la maestra y la madre. De esta manera, la enseñanza de la puericultura se transforma a la vez en inversión para las familias del futuro y en otros medio de educación de las propias madres de los niños:

"Esta nueva materia, además de su valor aplicativo indiscutible, ofrece al maestro inteligente, incalculables materiales para despertar en los niños un profundo sentimiento de amor al hogar convirtiéndolos en eslabones de unión entre la maestra y la madre."

"Es misión de la escuela contrarrestar la influencia funesta que los viejos prejuicios ejercen en los padres carentes de instrucción, haciéndoles llegar por medio de los hijos, ideas provechosas y contrarias a ciertas convicciones que desde hace ya mucho tiempo ha descalificado la ciencia." (Forgione, 1924, p.1-2).

No obstante, mientras varios de los consultados se inclinan por la idea de que "Esta materia debe enseñarse simultáneamente a varones y mujeres, pues no existen argumentos de peso, para que sea considerada del dominio exclusivo de la mujer" (Forgione, op. cit., p.2), para otros, constituye un dominio claro de la instrucción

hace siglos, en todas las clases sociales. Por último, el conocimiento del desarrollo muscular del niño, su educación física y moral, su higiene del sistema nerviosos y de los sentidos." (1915, 36-37).

${ }^{117}$ Lionetti (2011a) analiza un debate similar, unos años antes, en El Monitor de la Educación Común, Revista del Ministerio de Educación nacional. 
femenina, que debe formar a la niña en sus deberes naturales de esposa y madre, "preparándola para los fines y destinos que le asignan el hogar y la patria" (Muniagurria, 1924, p.14). En palabras de una educadora:

"Es indudable que la mujer tiene una organización propia, cuyo funcionamiento obedece, desde la célula inicial, hasta que su existencia acaba, al mandato sexual, en su forma femenina, así como el hombre se condiciona al mismo, en su forma masculina.

La educación moderna, que no desconoce ya, felizmente, estos principios biológicos fundamentales, debe orientarse en la senda de la evolución sexual, que implica evoluciones secundarias, tales como la ética, la intelectual pura, la estética, etc.

[...].

"De esto se desprenden dos conclusiones:

$1^{\circ}$ Que la educación de la mujer ha de ser distinta de la del hombre.

$2^{\circ}$ Que en la educación de la mujer han de intervenir los conocimientos que contribuyen a desarrollar sus funciones propias.

Consecuencias:

La preparación de la mujer para su misión de madre-educadora ha de ser el objetivo y finalidad de toda educación femenina." (Guillén de Rezzano, 1924, p. 9).

Al examinar con mayor detalle los argumentos que defienden la enseñanza de la puericultura a los niños de ambos sexos, encontramos que no desdibujan demasiado los papeles familiares que encontrábamos en los textos destinados a las mujeres madres. En efecto, no es para ocuparse mejor de la crianza de sus futuros hijos que los varones deben aprender nociones de higiene infantil, sino para transmitir estos conocimientos a su propia madre y así colaborar en el cuidado de sus hermanitos menores o, en otro sentido, para tornarse un mejor consejero de su esposa en el futuro.

"No veo por qué se quiere limitar la enseñanza del cuidado del nene a las escuelas de mujeres.

Nuestra mujer del pueblo (y ¡ay! Muchas veces también la burguesa más o menos adinerada y leída y la gran dama leída y escrevida que dicen los paisanos) que sólo tiene hijos varones, tiene tanto derecho como la madre de mujeres, a que la escuela le envíe con el hijo que a ella asiste, algo que le sirva para mejor criar al que todavía no va."(Malharro, 1924, p.8).

"El verdadero cariño por los niños nos induce a ilustrar, lo mismo a los varones que a las mujeres en los delicados deberes hacia los pequeñitos, porque si estas últimas serán las que por ley natural estarán 
obligadas a criar a sus hijos ¿no es conveniente que encuentren un buen consejero? Y, ¿por qué privar a la madre que tiene muchos varones [...] de los modernos procedimientos sobre puericultura?" (Rodríguez de Cano, 1924, p. 11).

De este modo, la crianza y educación de los niños continúa siendo "la misión más sagrada que la naturaleza ha confiado a la mujer" y el papel del hombre es el guía o consejero. Así parece expresarlo el hecho de que los escasos textos para enseñanza de la puericultura en la escuelas primarias publicados antes de 1930, se dirijan exclusivamente a un público femenino. "Vosotras, niñas..." o "toda niña debe saber que..." son expresiones que se repiten una y otra vez a lo largo de los mismos ${ }^{118}$. El fundamento de su acción pedagógica reside en que, siendo el sentimiento maternal natural en la mujer, ya estaría presente en las niñas pequeñas, esas verdaderas "madrecitas" de sus muñecas y sus hermanos. Así lo expresa, por ejemplo, Camilo Muniagurria, autor de La flor humana, uno de los libros de puericultura para niñas más recomendados por los educadores:

“[...] la niña pequeña puede ser desde el primer momento, en el ambiente del hogar familiar, el mentor inteligente e instruido que compense la ignorancia de la madre. El hermanito reemplazará a la muñeca."

"La niña pequeña ama a su muñeca con cariño maternal, porque el sentimiento de la maternidad tiene echado sus hondas raíces en el espíritu femenino sin ser influenciado por la edad." (Muniagurria, 1924, p.16).

Con este fundamento, la educación que se proponga para estas "madres del futuro, deberá consistir en una enseñanza no sólo intelectual, sino también afectiva y práctica $^{119}$, ya que "Vale más para una madre, saber cómo se prepara convenientemente un frasco de leche, que saber que la tierra se mueve alrededor del sol.” (Muniagurria, 1923, pp.22-23.)

\footnotetext{
${ }^{118}$ Esto aparece claramente, por ejemplo, en Arraga, Antonio, Modelo de conferencias sobre puericultura para darse en los colegios, 1910.

119 "El objeto de este libro es el de exponer los conceptos fundamentales de la Puericultura, en la forma más amena posible, y tratando de despertar en el alma de las niñas a quienes está destinado, reacciones afectivas que sirvan de base al aprendizaje inmediato y a su aplicación ulterior." (Muniagurria, 1923, p.2).
} 


\section{4. Un método para criar.}

Como ya hemos visto, la maleabilidad y el carácter de ser incompleto atribuidos al niño desde la perspectiva médica - pero también desde otros saberes sobre la niñez- son considerados el fundamento de la necesidad de una acción moldeadora por parte de los adultos que debe comenzar desde el nacimiento y ser guiada por expertos. La caracterización de este proceso aúna las nociones de cuidado -con sus connotaciones de atención y protección- y de formación -ligada a la educación- supuestas en el concepto de crianza.

Recuperando este doble significado de la crianza, los pediatras no sólo indican acciones concretas de cuidado, sino la necesidad de seguir un procedimiento que inscriba esas acciones en una serie ordenada de pasos a la que se atribuye un fundamento científico. En otras palabras: se proponen enseñar a las madres un método racional y científico para criar a sus hijos.

Dado que, como señalara en el capítulo anterior, los comportamientos del bebé son considerados pre-racionales, impulsivos y guiados por el instinto, con la aplicación de un método de crianza se busca regular y encauzar esas conductas infantiles, evitando los desbordes corporales y emocionales, y la adquisición de "costumbres" perjudiciales para su salud. Sobre todo porque -insisten los autores de los textos médicos- los hábitos adquiridos en esta etapa de la vida son difíciles de erradicar. Por ello, como lo muestra el siguiente fragmento, el modo de cuidar al niño debe ajustarse desde el primer momento a las pautas prescritas:

"El niño debe permanecer todo el día y toda la noche en su cuna, cambiándole únicamente de cuando en cuando la postura [...]. Sólo debe sacársele para alimentarlo y mudarlo. Haciendo esto desde el primer momento, el niño pronto se acostumbra, no necesitando que lo paseen, le canten o le muevan la cuna, porque esto le es perjudicial y pronto se convierten en hábitos, difíciles de suprimir después" (Etchegaray, 1915. p. 176).

En el mismo sentido se orientan los planteos de Aráoz Alfaro:

"Los padres tienen, pues, que hacerse sordos a los gritos del niños, y aunque les duela, deben no dejarles adquirir malas costumbres, como sucede cuando se les da el pecho cada rato, o cuando se les levanta y pasea momento por momento. El niño, tomado el pecho o cambiadas las ropas, debe ser puesto en su cuna y dejado allí, sin mecerlo ni 
hamacarlo. Si llora y se está seguro de que no es por frío o por mal arreglo de las ropas, o por un alfiler que lo pincha $u$ otra causa por el estilo, hay que dejarlo llorar; un momento después, calla y se duerme tranquilamente.

"Si se decide uno a sufrir los gritos durante algunos días, se puede estar seguro de no tener en la casa un pequeño tiranuelo caprichoso y molesto.

"HAY QUE EMPEZAR LA EDUCACIÓN DEL NIÑO DESDE EL NACIMIENTO." (Aráoz Alfaro, op. cit. p.66, con énfasis en el original).

Dando cuenta de la plasticidad atribuida al bebé y con tono tranquilizador, este autor afirma que "Admira, por lo demás, la prontitud y facilidad con que el niño se adapta al método racional que le ha sido impuesto." (Aráoz Alfaro, op. cit. p.87).

En esta perspectiva de la crianza, vista como una continua batalla contra los desbordes de los instintos infantiles, un permanente intento de dominar los impulsos que el bebé no puede controlar por sí solo, podemos reconocer la imagen de la infancia "dionisíaca" en el sentido expuesto por Jenks (op. cit): un niño que necesita ser disciplinado para no "echarse a perder", para no desviarse del recorrido que lo llevará a constituirse como un adulto "normal". Sin embargo -como iremos viendo más adelante-, la misma aparece combinada con un abordaje basado en la visión "apolínea" del niño, dado que el método propuesto para criarlo también es visto como el acompañamiento y vigilancia necesarios para que puedan desplegarse correctamente sus disposiciones naturales, las potencialidades aún latentes en el recién nacido.

El método de crianza prescrito implica un orden y una especial relación con el tiempo, a partir de lo cual se definen minuciosamente la secuencia y la duración de las diferentes operaciones de cuidado del niño. Ello se traduce en un conjunto de recomendaciones y reglas que constituyen el texto central de las obras de divulgación de la puericultura y que se refieren a la alimentación (frecuencia, duración, posición para amamantar), el baño y la higiene del niño en general (momentos del día en que se efectúan, frecuencia, duración), el vestido (prendas y modo de colocarlas) y aún las salidas y los juegos. Dichas reglas se orientan no sólo a una disciplina de los hábitos infantiles, sino también de las actitudes y prácticas de cuidado realizadas por los padres o, más bien por las madres, de las que se requiere firmeza y mesura de carácter: 
"Pero no todo, ¿cierto? ha de ser el interés del niño, 'ese pequeño egoísta'. Con tal que esté bien. ¡Oh, las madres siempre dispuestas al sacrificio! Sepamos educar, regular las cosas, ¡disciplinar! Hay que acostumbrar al niño a la regularidad, que es la conveniencia de la madre, para que pueda descansar y así nutrir y cuidar mejor su fruto. Se le alimentará con orden y suficientemente. Para ello establecerá la madre sus horas, las que más le convengan, dentro de las lactadas que establecimos, y se proporcionará su sueño tranquilo, su reposos y el reposo del hijo. El lactante, con tal de ser sano, se adapta más o menos al orden de nutrición que le imponen, y a un descanso más o menos largo de sueño". (Liceaga, 1930, p.58).

Tal como señala Boltanski (1969) en su trabajo clásico sobre puericultura y moral de clase, al establecer cómo se debe tratar a un niño las reglas de puericultura definen también qué es un niño y proporcionan al mismo tiempo las categorías a través de las cuales el niño será percibido y constituido como tal.

Explorar los discursos y las prácticas de la puericultura, implica pensar en la construcción del cuerpo infantil, o en el cuerpo infantil como construcción, tal como lo afirma Joaquim (1997), cuando dice que el cuerpo se construye tanto desde el imaginario desde el cual se lo define, percibe, explica, como desde las acciones más minuciosas, cotidianas, imperceptibles que se articulan en espacios definidos, en horarios, en ritmos, en gestos. Sin adentrarnos demasiado en desarrollos específicos de la antropología del cuerpo, veremos entonces como el cuerpo del niño es puesto en juego en las indicaciones médicas sobre la crianza.

Considerando con Le Breton (1990) que la existencia del ser humano es corporal, el tratamiento que se propone para el cuerpo infantil y los valores que se le asignan deben ser vinculados con un modo particular de construcción de la persona y de las relaciones sociales en un momento histórico específico. Tal como vimos en el capítulo anterior, las prácticas y representaciones sobre la niñez que construye la medicina del periodo estudiado son tributarias de las nociones de persona en términos del individuo moderno. El combate médico a ideas y prácticas sobre el cuerpo infantil asociadas a la magia, la religión, a la empatía entre procesos naturales y humanos, descalificadas en términos de supersticiones, forma parte de la disputa por imponer un saber que, apelando a la racionalidad y su carácter laico, permita distinguir y recortar ese cuerpo de sí mismo, de los otros y del cosmos, en los términos en que lo plantea Le Breton (op. cit.). Siendo que en las sociedades occidentales el cuerpo se constituye en signo del individuo, las prácticas de crianza 
propuestas desde la pediatría y la puericultura forman parte de los procesos de individualización del niño moderno.

\subsubsection{Racionalidad, regularidad, equilibrio: principios médicos de la crianza.}

La lectura de los diferentes manuales y cartillas de puericultura, permite identificar una serie de principios en que se funda el método de crianza propuesto: racionalidad, regularidad, orden, mesura, equilibrio. ${ }^{120}$ Para garantizar la salud del niño -afirman pediatras e higienistas- la crianza debe basarse en la regularidad. Dado que se trata de imprimir las primeras reglas en los cuerpos -y en las almas- humanos, el establecimiento de horarios y de secuencias ordenadas de actividades se torna central (Boltanski, 1969). En esto se combina la necesidad de prescribir y ordenar las actividades maternas de atención del niño, con la de inculcar una regularidad y un orden a las conductas del niño mismo.

Tal vez sea en torno al tema de la alimentación, uno de los ejes centrales de los manuales y cartillas, donde más se condensen las ideas de la necesidad de un método racional, basado en la regularidad, como garantía de un crecimiento sano: "La alimentación sea humana, mixta o artificial, [...] debe proporcionarse con método y a intervalos regulares." (Municipalidad de Buenos Aires, 1914, p.2).

Se supone que, dada la fragilidad del organismo del recién nacido y del lactante, un desorden en la administración del alimento se traduce en un desorden fisiológico; más concretamente, en un desarreglo digestivo. De esta manera, aun la lactancia materna, si no es regular y equilibrada, puede causar trastornos en el niño. Con este argumento, los médicos de niños establecen horarios para mamar, proponiendo hacer de la regularidad de la alimentación "una especie de primer 'servicio militar estomacal'; la primera educación y disciplina” (Liceaga, 1930, pp.58-59), aunque admitiendo cierta elasticidad con los horarios según las necesidades del niño. Cabe aclarar que los horarios y frecuencias indicados pueden variar entre los escritos de diferentes médicos - lo cual alerta sobre lo problemático

\footnotetext{
${ }^{120}$ Los mismos no aparecen formulados sistemáticamente como tales en las obras de puericultura consultadas, sino que su enumeración y sistematización resulta de las recurrencias puestas de manifiesto en el análisis del discurso médico.
} 
que puede resultar referirse a "la" pediatría, como si fuera un saber monolítico y uniforme- no obstante lo cual, todos coinciden en que debe ser el facultativo quien los indique y que de ninguna manera pueden quedar librados al parecer de las familias y las madres. ${ }^{121}$

Las mujeres y sus hijos, sin embargo, no parecen acomodarse demasiado al método propuesto, según se desprende de los comentarios insistentes de los médicos. Las que pueden permanecer todo el día junto a su hijo posiblemente le den pecho cada vez que llora y difícilmente cumplan con el reposo nocturno de seis a ocho horas que algunos pediatras proponen como modo de "hacer descansar" el aparato digestivo del bebé. De allí que se repitan las recomendaciones como la del autor de la Guía Maternal:

"No hay, pues, que seguir, como algunos han pretendido, las indicaciones que suministren los gritos del niño, que serían instintivos y revelarían la necesidad de alimento, según se dice. Está probado con numerosísimos ejemplos que si se hace tal cosa, los desórdenes digestivos son frecuentes, mientras que ningún niño se enferma por tener metodizada su alimentación en la forma indicada; al contrario, es en este último caso cuando se desarrolla espléndidamente y en toda normalidad.

(Guía Maternal, 1900, pp. 87-88).

Los autores de la época recomiendan la edad adecuada para el destete que, según las diferentes posturas, debe producirse cerca del año o hacia los dos años, y también explican, mediante descripciones e ilustraciones, las posiciones más adecuadas para amamantar. No obstante, no dejan de advertir que el método propuesto para la alimentación no debe tornarse rígido ni ser aplicado absolutamente de la misma manera en todos los casos. Por el contrario, debe tenerse en cuenta los "casos particulares que obligan a modificar algo las reglas" (Guía Maternal, op. cit., p.88) y "de ningún modo debe hacerse esto como una matemática” (Liceaga, 1930, p.58).

El baño y el aseo del bebé también son pautados por los médicos de niños, quienes recomiendan bañar al niño una vez al día, siempre en el mismo horario, más allá del clima, y cambiarle sus pañales y mantillas cada cuatro horas

${ }^{121}$ Por ejemplo, en la Guía Maternal (1900) se recomienda que, durante los dos primeros meses el niño mame cada hora y media durante el día y cada tres horas durante la noche. Del tercero al sexto mes se le dará cada tres horas. Otros autores aconsejan que el niño mame durante el día cada dos o tres horas durante los primeros dos o tres meses y que a la noche haga una pausa de seis a ocho horas 
aproximadamente, aprovechando esos momentos para lavarlo desde la cintura hasta los pies. Al respecto, en su manual de puericultura, Agote (1901) afirma que "Todas estas operaciones deben efectuarse siempre con rapidez. Una buena cuidadora debe hacerlas cuando más en diez o quince minutos, celeridad que exige el temor de un enfriamiento, al cual están muy sujetos organismos tan delicados.” (p.54). A lo largo de todas estas prácticas de cuidado y aseo, la manipulación del cuerpo del niño debe ser cuidadosa y realizarse mediante una serie de movimientos y posiciones, que autores como Pinard (op. cit.) describen e ilustran con sumo detalle (ver Anexos, Figuras 1 y 2):

“[...] ¿cómo tomar, cómo sostener a nuestros pequeñuelos que están en nuestras rodillas, para llevarlos y meterlos en el agua sin temor de exponernos a dejarlos caer o lastimarlos?

Estando colocados nuestros pequeñuelos transversalmente, de tal modo que su cabeza esté sobre nuestra pierna izquierda y los pies sobre nuestra pierna derecha, colocaremos suavemente los cuatro dedos, unidos y estirados, de nuestra mano izquierda al nivel de la nuca, debajo de su cuello hasta el momento en que la cara interna de nuestro pulgar siente la piel del niño. Levantando ligeramente la extremidad de los dedos, la mano forma entonces una canaleta que abraza bien el cuello y donde se aloja admirablemente la nuca." (pp.7-9).

El proceso de vestir al bebé requiere una secuencia minuciosa de operaciones, que ocupa varias páginas ilustradas de los manuales de puericultura, donde se exponen gráficamente el orden de colocación de cada una de las numerosas prendas que componen el ajuar infantil (Ver Anexos, Figuras 3 a 6). Se insisten en que la madre debe adquirir la suficiente práctica para que el procedimiento no demore demasiado, dado el riesgo de que el niño tome frío. Los autores mencionan y comparan dos tipos de vestimenta del niño: el "sistema inglés" y el "sistema francés", que incluyen prendas y modos de colocarlas diferentes. (Ver Anexos, Figuras 7 y 8). Luego de evaluar las ventajas y desventajas de cada uno de ellos, algunos (Guía Maternal, op. cit.) proponen un "sistema argentino", que combina de manera práctica elementos de los dos anteriores. Al respecto, en los diferentes números de la revista Madre y Niño se publican los anuncios de diferentes tiendas que multiplican la oferta de tipos de ajuar y de productos de cosmética destinados al niño, permitiéndonos ver su incipiente construcción como un nuevo consumidor durante las primeras décadas del siglo XX. 
Cabe observar, no obstante, que más allá del tipo de ajuar elegido y de la mayor o menor pericia de la madre para vestir al niño en los tiempos esperados, los médicos de la época resaltan la función que deben cumplir esas prendas: asegurar la protección del cuerpo infantil, pero permitiéndole la libertad de movimientos que su desarrollo requiere. Por ello- insisten- los vestidos del niño

"deben ser bastante amplios, y aplicados de manera que no perturben la libertad de los movimientos, ni de los de las piernas o brazos, ni mucho menos los del tórax, que tiene por objeto la respiración.

Nada de cintos ajustados ni de compresión alguna fuerte que los reemplace. Nada de corsé, tampoco en las niñas [...]" (Aráoz Alfaro, op. cit., pp. 236-237).

Esta insistencia en una vestimenta "racional y cómoda", que asegure al niño "su holgura, bienestar y descanso" (Liceaga, 1930, p.40), no constituye un detalle menor sino que da cuenta de un cambio en el modo de concebir la niñez y de abordar su educación con respecto al de épocas anteriores, que muchas madres parecen seguir poniendo en práctica. En ese sentido, a partir de algunos de los planteos de Vigarello (2005) acerca de los modelos de educación corporal en Francia, puede afirmarse que la Argentina de la época aquí analizada el movimiento corporal también cobra importancia en la educación infantil, siendo presentado como una liberación de la infancia de las coerciones anteriores, simbolizadas por corsés y fajas.

La crítica a las prácticas compresivas y la recomendación de la libertad de movimientos para un buen desarrollo infantil, ya habían aparecido en el siglo XVIII, con las ideas de Rousseau. ${ }^{122}$ Sin embargo, es hacia fines del siglo XIX cuando las encontramos plenamente presentes en los discursos médico y pedagógico, dando cuenta del pasaje del "modelado" como modelo de educación del cuerpo infantil (que asociaba corsés y fajas a la idea del molde o el tutor del árbol, mediante el cual se buscaba la rectitud física de un ser pasivo), a los "entrenamientos" (que buscan el fortalecimiento corporal mediante el movimiento, desde un modelo del cuerpo como motor energético susceptible de acrecentar rendimientos y productividades a través

\footnotetext{
${ }^{122}$ Un ejemplo de este pasaje en los modos de educación corporal del niño puede encontrarse en la obra del médico y profesor de medicina francés N. Andry: L'orthopédie ou l'art de prévenir et corriger dans les enfans, les difformités du corps, publicada en 1743. Esta obra, considerada el primer libro donde aparece el término "ortopedia", implica el comienzo de una pedagogía específica de la postura. Para un análisis exhaustivo de esta obra, ver Yutzis (2008).
} 
del ejercicio muscular; Vigarello, op. cit.) ${ }^{123}$ y a la libertad protegida de actitudes y movimientos (que busca posibilitar, incentivar y vigilar las transformaciones progresivas de un organismo en desarrollo a fin de permitir el despliegue de sus potencialidades en germen) ${ }^{124}$.

Desde estas últimas perspectivas, entrando en el siglo XX cada vez se critica con mayor énfasis el hábito "desgraciadamente muy común en la gente del pueblo, de envolver enteramente el tronco, las piernas y hasta los brazos del niño en una ancha tira de género, dura y sólida, que impide por completo todo movimiento" (Aráoz Alfaro, op. cit., pp. 255-256). Así, se plantea que la racionalidad de la crianza debería liberar al niño de "prácticas atrasadas", como el uso de fajas, pero también los castigos corporales, o las exigencias de una educación intelectual precoz, para permitirle desarrollarse libremente según su naturaleza ${ }^{125}$. Nuevamente, encontramos la oposición entre "las ideas y los preceptos racionales que deben presidir la crianza del niño" (Aráoz Alfaro 1929, p.viii), frente a los considerados "caprichos del instinto", excesos de amor maternal o supersticiones del saber popular.

Llegados aquí, podemos observar que, si por un lado encontramos una perspectiva médica sobre la crianza que remite a la imagen de la infancia “dionisíaca" -en los términos ya vistos en el capítulo 2-, en cuanto prescribe evitar el desborde instintivo del niño mediante horarios y procedimientos ordenados, la misma aparece combinada con un enfoque más bien vinculada con la imagen "apolínea" del niño como ser frágil e inocente, que requiere de prácticas de crianza que lo protejan y vigilen para que pueda desplegar sus potencialidades.

Desde una concepción de la niñez basada en los procesos de crecimiento y desarrollo, el discurso médico señala que la regularidad de las acciones de cuidado infantil se expresa en el proceso de transformación que el niño transita: se pretende que una crianza adecuada garantice al niño un "desarrollo regular", es decir, un

\footnotetext{
${ }^{123}$ Subyace a esto el reemplazo de la visión "antigua" de la motricidad, basada en la teoría de los humores, que consideraba que el cuerpo del niño se encontraba saturado de humores, por la visión del cuerpo como una máquina, basada en el funcionamiento de los músculos.

${ }^{124}$ En parte esta perspectiva coincide con el discurso pedagógico froebeliano, desde el cual se elabora la propuesta de educación infantil temprana a poner en práctica en los jardines de infantes. (Carli, op. cit).

${ }^{125}$ Cabe aclarar que, tal como lo muestran los estudios de Boltanski (op. cit) y Vigarello (op. cit.) para el caso de Francia, pero extensibles a la Argentina de la época analizada- gran parte de esas prácticas de crianza criticadas por los médicos de fines de los siglos XIX y XX (envoltura en mantillas, fajas, etc.) y atribuidas a supersticiones populares, tenían su origen en prescripciones médicas de siglos anteriores.
} 
proceso que vaya dándose gradualmente, sin adelantarse o sin demorarse con respecto a los momentos esperables. De allí que los cuidados que reciba el niño deban basarse en la necesidad de moderación, de búsqueda de un equilibrio, de un "justo medio" que evite los excesos a los que puede llevar un exagerado amor maternal, tanto de afecto y emociones, como de alimento o de abrigo. Desde esta perspectiva se critica "el afán por el niño gordo" que resulta de una "alimentación exagerada" (Municipalidad de Buenos Aires, 1914), pero también la exposición de los niños a relatos de terror, castigos excesivos o espectáculos emocionantes, que pueden perturbar su equilibrio emocional, "excitando su tierna fantasía" (Guía maternal, 1900). Esto debe tenerse en cuenta - consideran los médicos de la época- a la hora de planear los paseos y distracciones del niño de primera infancia, discutiéndose la conveniencia de que los pequeños asistan a representaciones teatrales o a funciones de cinematógrafo, que pueden impresionarlos en exceso. Asimismo, se critican los castigos físicos y se señalan las ventajas de la claridad y la firmeza en las indicaciones paternas por sobre los golpes, que pueden arruinar tanto el carácter como el físico infantil. En este sentido, Araóz Alfaro (op. cit.) afirma que

"Las reprensiones deben ser moderadas, y cuidadosamente escogidas de manera que no depriman al niño haciéndolo enteramente indigno ante sus propios ojos y los de los demás, y quitándole todo estímulo de enmienda. Los castigos corporales, las penitencias vergonzantes, son siempre contraproducentes. (Aráoz Alfaro, op. cit. p. 269).

En los discursos médicos hasta aquí analizados hemos podido ver una combinación de la ideas del niño como un ser pasivo a moldear -aunque ya no sea mediante fajas que den forma a su físico, sino más bien mediante acciones regulares que moldeen su fisiología, como en el caso de la alimentación-, con otras del bebé como un ser que debe desplegar sus posibilidades mediante el movimiento y el ejercicio controlados. Es posible que esta combinación/tensión presente en las indicaciones de la pediatría y la puericultura sobre la crianza, que podría verse como una contraposición entre ideas "antiguas" con otras "modernas", en realidad nunca haya abandonado totalmente la concepción de la primera infancia (aunque sí tal vez, de las etapas posteriores de la niñez), posiblemente porque el bebé sigue siendo considerado un ser aún demasiado maleable, poco firme, por lo menos durante los primeros meses. 


\subsubsection{Cuidado infantil y categorías morales}

La regularidad y el orden minucioso de las actividades de cuidado, la racionalidad, la mesura en la manifestación de los afectos, la protección que asegure libertad de movimientos, son las actitudes prescritas por los médicos de la época analizada para lograr el ideal de un niño normal y sano, es decir, ajustado a los parámetros de su "naturaleza infantil". En ello se pone en juego toda una taxonomía corporal y de comportamientos: gordo/delgado, fuerte/débil, grande/pequeño, excitado/apático; taxonomía que, a semejanza de lo observado por Serre (1997) en su estudio sobre la atención materno-infantil contemporánea en Francia, responde a un sistema de clasificaciones socialmente elaborado y está indisociablemente unida a categorías morales. $^{126}$

En efecto, tal como aparece también en otros estudios (Vianna, 2002 $2^{127}$; Boltanski, op. cit.), el lenguaje del cuidado infantil constituye un medio ideal para la traducción de significados y categorías morales, que son también categorías de clase y profesionales. En este sentido, Boltanski (op. cit.) encuentra que en las reglas de puericultura - tanto en los inicios de este enfoque médico como en la actualidad- se produce una convergencia de una moral austera y de técnicas científicamente fundadas ${ }^{128}$. Se pone de manifiesto la intención de "crear una nueva moral" para las madres y las familias, de modificar modos de vida y valores, más allá de la preservación de la salud física infantil. De allí que exijan de aquellos que deben aplicarlas, no una actitud puramente técnica, sino la adopción de una postura particular ante el mundo, que implica una noción y un uso de la temporalidad y una administración de los afectos. Reencontramos aquí la combinación de aspectos técnicos y morales que constituyen el contenido de las estrategias o "formas de

\footnotetext{
${ }^{126} \mathrm{El}$ trabajo de Serre (op. cit.) permite pensar como los registros del lenguaje corporal, en el sentido en que los analiza Bourdieu (1977) operan en la atención materno-infantil contemporánea, mostrando que a partir de ellos se definen ciertos tipos de cuerpos infantiles como "desviantes" como, por ejemplo, el "niño-rey", cuyas dos variantes corresponden a dos registros del lenguaje corporal: el de la conformación del cuerpo (el niño gordo, que da cuenta de un exceso o un error en la alimentación) y el hexis (el niño excitado, exuberante en sus manifestaciones, sin límites).

${ }^{127}$ Vianna (2002) analiza el modo en que significados y evaluaciones morales son traducidos en el lenguaje del cuidado infantil, a partir de un estudio contemporáneo sobre prácticas, expedientes y formas de gestión de la minoridad, realizado mediante el análisis de procesos judiciales de guarda y adopción

${ }^{128}$ Boltanski realiza este análisis partiendo de la distinción que establece Durkheim entre reglas técnicas (en este caso, las de la higiene, fundadas en la teoría microbiana de Pasteur) y reglas morales. Las reglas de higiene, al ser transmitidas por los médicos a partir de su autoridad, de alguna manera por sí mismas, recortadas de los saberes que las justifican y con una carga valorativa, se tornan reglas morales.
} 
aconsejamiento" conceptualizadas por Vianna (op. cit.) y por Lugones (op. cit.), tal como las abordamos en un apartado anterior.

En otros términos y tal como lo señala ese autor, además de estar fundadas en un saber médico racional, las prescripciones médicas sobre la crianza son portadoras de una filosofía implícita y exigen de aquellos que deben aplicarlas, un cierto tipo de actitud global ante la vida y, especialmente, con respecto al tiempo. Más allá de la sucesión y duración minuciosas de las acciones concretas de cuidado del niño, lo que se transmite y se aprende es que todo es mensurable y con una duración específica, que no depende de la voluntad o el deseo, sino de lo que es higiénicamente conveniente. Así, en hechos aparentemente tan banales como hacer hervir un biberón o despertar a un bebé para alimentarlo a horas fijas, está involucrada toda una visión de mundo vinculada al ascetismo, la contención de los impulsos inmediatos, el graduar las acciones presentes en función del futuro, el equilibrio en los afectos, etc. Al ser reglas preventivas las que establece la puericultura, exigen la puesta en práctica de un tipo particular de acciones que implican una anticipación y cuya eficacia es sólo probable (por ejemplo, si se lo amamanta, es probable que el niño no se enferme). Al requerir este tipo particular de actitud con respecto al tiempo (cumplir en el presente acciones largas y trabajosas para lograr un bien mayor en el futuro), las reglas de puericultura, en la perspectiva de Boltanski, adquieren un carácter ascético.

El modo en que son transmitidas por los agentes e instituciones de salud en tanto instancias legítimas de difusión y el modo en que son recibidas por los sujetos sociales, así como el tipo de sanción, de reprobación difusa que acompaña su trasgresión, también hacen que las reglas de puericultura se ofrezcan a la reinterpretación moral: puede suponerse que en la época estudiada, tal como sucede contemporáneamente, para las madres que no concurren al control pediátrico o no cumplen con las indicaciones del médico, la sanción suele ser la enfermedad del niño, pero también en gran parte la reprobación del médico, de las visitadoras sociales o de las otras madres (Boltanski, op.cit.). 


\subsection{Salud y vigor: las finalidades de una crianza higiénica}

A lo largo de los temas hasta aquí abordados, una idea atraviesa los discursos médicos, legitima la intervención médica en la vida cotidiana y da sentido a los consejos acerca de la "buena crianza": la noción de salud.

"La higiene da al hombre, a la madre, al niño, reglas fijas y constantes para asegurar el libre ejercicio de todas sus funciones; conserva, pues, la salud y prolonga la existencia. La higiene se propone asimismo mejorar, perfeccionar los instrumentos de la vida, extraer del fondo de la naturaleza humana, desde la primera infancia, desde antes del nacimiento de un nuevo ser, todo lo mucho que de sí puede dar, y conducir, sin riesgo, el organismo del niño, al mayor desarrollo de fuerza de que es capaz." (Liceaga, 1930, p.11).

Pediatras e higienistas sostienen que la finalidad de la crianza debe consistir en hacer crecer a los niños sanos y fuertes; de ahí la misión de la puericultura: contribuir en esta formación de una infancia "sana, vigorosa y equilibrada" (Aráoz Alfaro, op. cit. p. xi). El discurso médico sobre la niñez establece así una asociación explícita entre salud y vigor. A diferencia de la idea de salvación del alma, la noción de salud supone la extensión de la vida física, pero encarnada en un cuerpo fuerte, que crece y se desarrolla y que, por eso, también es un cuerpo bello:

"[...] es ley de la humanidad que los seres de esta especie eduquen su cuerpo, lo mantengan en estado de salud, fuerza y belleza, y establezcan entre todos sus órganos, miembros y sentidos una recíproca relación, conservándose sanos, y dignos del objeto para el que fueron creados. A este fin tiende la higiene.” (Guía Maternal, 1900, p.95).

Desde esta concepción de salud, por oposición, se delinean las imágenes que los médicos construyen como símbolo de la enfermedad infantil: el niño raquítico, el niño enclenque, el "niño débil" en todos sus aspectos.

La libertad y posibilidad de movimientos a los que, como hemos visto, apuntan las indicaciones médicas sobre la vestimenta y cuidados generales del niño, 
se vinculan a esa finalidad de lograr la fortaleza física y, por lo tanto, la salud. ${ }^{129}$ No obstante, como hemos visto, ello se combina con la prescripción de un método que ordene en el tiempo las acciones de cuidado del niño, de modo de evitar los excesos e instalar una regularidad en las conductas y también en las emociones infantiles. Y es que el vigor asociado a la salud, tal como lo plantea Barrán (1995), no se refiere sólo a la fuerza corporal, sino también a la dimensión moral de control de las pasiones y el placer. $^{130}$

Se considera que la salud física es soporte de y se entrelaza con la salud intelectual y la salud moral del niño, las que también, de alguna manera, constituyen objeto de preocupación de la pediatría y la puericultura, puesto que "[...] el ser humano no es un ser puramente físico, pues hay que admitir en él algo que no se rige por las leyes generales de la materia, y ahí entra actuar la parte abstracta de la higiene privada: la moral é intelectual." (Guía Maternal, 1900, p. 96). Si la salud intelectual implica un adecuado desarrollo de la inteligencia infantil, la salud moral alude a los sentimientos e inclinaciones que forman su temperamento, su voluntad y su carácter, a la formación del "alma" infantil. ${ }^{131}$

La salud física es valorada como "base de todas las disposiciones felices", que debe anteponerse al crecimiento intelectual. Así, Aráoz Alfaro (1929) recomienda que "no se esfuercen, pues, los padres por instruir a sus hijos muy temprano; dedíquense a hacerles crecer sanos y fuertes; después se instruirán mejor y más pronto" (p. 268). Retomando planteos similares de Rousseau, el cuidado del cuerpo es considerado la base para "el cultivo de la inteligencia y la moral", que suelen ocupar los últimos capítulos de los manuales de puericultura. Desde esta perspectiva se critica tanto la enseñanza precoz de la lecto-escritura y de conocimientos teóricos, ya que produce un debilitamiento físico y un temprano

\footnotetext{
${ }^{129}$ De acuerdo a los modelos de educación corporal planteados y analizados por Vigarello (op. cit.), se pondría de manifiesto en estos discursos el paso de las "urbanidades" al "vigor", modelo caracterizado por la valoración del movimiento para lograr una postura recta, asociada a la robustez.

${ }^{130}$ Barrán analiza la relación entre medicina y sociedad, considerando específicamente la construcción de nuevas sensibilidades, en el Uruguay de comienzos del siglo XX.

${ }^{131}$ Feinmann (1915), por ejemplo, incluye los aspectos intelectuales y morales del niño como parte de la "psico-fisiología infantill: "La psico-fisiología infantil comprende, por un lado, los fenómenos de la sensorialidad orgánica ya estudiada, y por el otro, la sensibilidad afectiva, que comprende las manifestaciones elementales del miedo, de la cólera, de los celos, de la simpatía y de la antipatía humanas. El alma de los niños contiene, desde su primera edad, el germen de todos estos sentimientos que mueven sus inclinaciones y forman su temperamento, su voluntad y su carácter. La educación moral de los niños, debe comenzar por eso, según enseña muy bien Bernard Pérez, desde la cuna, para evitar las desviaciones que sufre la conciencia, cuando se abandona a una eflorescencia espontánea." (p.134).
} 
desgaste intelectual - el personaje del niño débil y nervioso, caracterizado por su fragilidad emocional-, como los ejercicios físicos demasiado intensos, que generan un consumo excesivo y temprano de las fuerzas infantiles - el niño que crece demasiado pronto, cuyo vigor se agota antes de la adolescencia.

En el prólogo redactado para el manual de Liceaga sobre La crianza del niño, el médico Alfredo Casaubon (1930) afirma que "Para ser un hombre sano y fuerte es necesario haber sido un niño en iguales condiciones, y es la puericultura la que da las reglas para que esto último se realice en la medida que las circunstancias lo permitan (p.7). Vemos así, que salud y fortaleza son también los atributos que conectan al niño del presente con el hombre del futuro, un adulto genérico pensando como integrante de la población de la nación. De esta manera, el "vigor físico y moral" no sólo es tomado como el factor clave de "la salud" del individuo, sino también de la población, dado que, como lo explica un médico a comienzos del siglo XX: "La fuerza de un país reside, en gran parte por lo menos, en la robustez de sus hijos y en el crecimiento mayor de la población, basado en el aumento de la natalidad y en la disminución de la mortalidad." (Bordot, 1917, p.652).

Cabe señalar que esta tendencia de la medicina infantil a definir su quehacer en términos del logro de la salud del niño se inscribe en una perspectiva que trasciende la ciencia médica y que hace de "la salud" un valor social, un valor casi absoluto en los términos del análisis de Barrán (op. cit.), en tanto es definida de un modo cada vez más amplio, hasta abarcar prácticamente todos los aspectos de la vida. Asimismo, siguiendo a este autor, podemos pensar que el valor que adquiere la salud posibilita y a la vez es alimentado por la medicalización de la sociedad.

Desde la perspectiva médica de la época considerada para este estudio, salud y fortaleza son, a su vez, los atributos de un cuerpo que sigue en su desarrollo los parámetros brindados por la naturaleza. "La naturaleza" aparece, de una u otra manera, como el parámetro de referencia para una crianza racional:

"El mecanismo del niño es fácil, pero frágil. Su misma sencillez, mal entendida, lo expone al peligro de cualquier imprudencia. La regularidad de su funcionamiento se halla asegurado por la naturaleza, que es también la mejor consejera al respecto. La ciencia del niño, no consiste como podría creerse, en inventar leyes nuevas para aplicarlas a su estudio, sino en conocer las fuerzas naturales que rigen su organismo." (Feinmann, 1915, p. 39). 
Aquí reencontramos, ahora en relación a las finalidades de la crianza, pero con similares tensiones y ambigüedades, las representaciones sobre la naturaleza que fueran presentadas en el capítulo 2 respecto de la denominada "naturaleza infantil". La tensión entre naturaleza y civilización, naturaleza y educación, atraviesa las explicaciones e indicaciones médicas sobre el modo de criar a los niños. Es para trascender su estado natural -en el sentido de instintivo, irracional, pre-social- que se los debe criar, pero también es la naturaleza la que proporciona la guía de una crianza racional y permite formar niños sanos -como lo explica Feinmann-, desde una perspectiva que recupera de Rousseau la noción de la naturaleza como regeneradora de los desvíos de la sociedad.

Una y otra vez los autores de los manuales de puericultura, retomando explícitamente ideas de Rousseau, aconsejan "que la crianza del niño se haga conforme a los preceptos de la naturaleza" (Aráoz Alfaro, 1929, p.72), señalando al mismo tiempo la necesidad de su educación, de su moldeamiento (por lo tanto, de la transformación de sus características naturales), para que llegue a ser tal como la sociedad lo necesita. Los "dictados de la naturaleza" deben guiar la alimentación, casi haciendo irremplazable el pecho materno, y también la vestimenta, que debe ser holgada y cómoda para permitir el desarrollo de una postura y movimientos naturales. Como hemos visto antes, se trata de asegurar protección pero sin impedir el desarrollo natural del cuerpo y de la inteligencia infantiles, garantizando, a su vez, una libertad que no se adelante a las etapas naturales de este desarrollo. Tal como lo observa Joaquim (1997) en su análisis de los tratados de educación infantil portugueses de los siglos XVII y XVIII, en las ideas rousseaunianas la naturaleza es vista como el lugar de la regeneración de aquello que la sociedad ha corrompido. Desde esta perspectiva, el trabajo que el médico debe realizar es de conocimiento y copia de la naturaleza, estableciendo en los cuerpos el "régimen natural" que la sociedad mutiló o tornó decadente justamente por haberse apartado de las "leyes naturales". Sin embargo, a su vez, se trata de una naturaleza que posee un orden que permite establecer leyes y regularidades, sometida al orden de la razón, de una "razón natural", pues para garantizar su salud, "al niño no se lo puede abandonar a las brutalidades del instinto" (Moll Weiss, 1905, p.19). ${ }^{132}$

${ }^{132}$ Es necesario no perder de vista, si bien no es objeto de esta tesis, el carácter polisémico del concepto de "naturaleza", según las diferentes corrientes del pensamiento occidental en las que se inscribe, y las múltiples relaciones con otros conceptos que de allí se derivan y que se combinan en el discurso médico aquí analizado. Así por ejemplo, si el positivismo la escinde de los humano y la 


\subsection{Los resultados de la medicalización: transformaciones y resistencias.}

En este capítulo hemos visto el trabajo médico tendiente a imponer la puericultura -y, a través de ella, la pediatría- como modo legítimo de abordar la crianza de un niño, en tanto basado en un saber científico, considerado objetivo y comprobable. Sin embargo, para que entre 1890 y 1930 la implantación de esta creencia y sus correspondientes prácticas fuera en parte posible, tuvo que disputar la legitimidad de los saberes familiares, tradicionales y religiosos, hasta entonces considerados eficaces para el cuidado infantil.

Entendido, en un sentido amplio, como la incorporación como parte de los saberes y prácticas de la biomedicina, de aspectos y ámbitos de la vida humana que anteriormente no eran de su incumbencia, el proceso de medicalización de la crianza infantil aquí estudiado debe situarse en el marco y como parte de esa disputa. Pensado en estos términos y tal como lo propone Menéndez (1990), es decir como parte de un proceso constante, nunca del todo concluido, de construcción de hegemonía por parte de la biomedicina, surge el interrogante acerca cuál ha sido el alcance de la medicalización de la crianza en el periodo histórico aquí considerado. Para ello, puede resultar útil considerar los tres niveles en que Barrán (op. cit.) encuentra expresado el proceso de medicalización en la sociedad uruguaya entre 1900 y 1930; tres niveles que no tuvieron la misma profundidad ni ocurrieron con el mismo ritmo histórico: el nivel de atención médica en el tratamiento de la enfermedad, el nivel de la conversión de la salud en uno de los valores supremos de la sociedad (cambio en la mentalidad colectiva que en parte antecedió a la medicalización) y el nivel de la asunción por la sociedad de conductas cotidianas, valores colectivos e imágenes derivados de la propagación del saber médicos.

Realizar un balance de los resultados de este proceso en el caso aquí estudiado implica intentar considerar las prácticas y representaciones de los diferentes actores sociales involucrados, en este caso particular no sólo de los médicos, sino también de las familias, las mujeres y los niños de la época analizada. Si bien el tipo de fuentes utilizadas dificulta el acceso a las percepciones y acciones maternas e infantiles, los informes periódicos sobre el funcionamiento de los dispensarios de lactantes e institutos de puericultura ofrecen datos sobre el uso que

razón, para poder construirla en un "otro" cosificado, un objeto a analizar (Luz, op. cit.), otras corrientes de pensamiento más ligadas al romanticismo la abordan desde la idea de totalidad y continuidad de la vida. 
de estos servicios hacía la población. Además, las quejas reiteradas de los médicos sobre las actitudes de las madres ante sus consejos y prescripciones, también brindan un medio fructífero para acceder indirectamente a las prácticas de aquellas, como también lo muestran Nari (2004) y Billorou (2007) en sus estudios.

En los mencionados informes periódicos, generalmente presentados a las autoridades de la Municipalidad o la Asistencia Pública, los pediatras refieren un descenso de la mortalidad infantil, vinculado a la acción de los nuevos establecimientos sanitarios dedicados a la primera infancia. Por ejemplo, Oliva (1917) registra que en Buenos Aires, la cifra de muerte por cada mil niños nacidos pasó de 116 en 1907 a 92,8 en 1916. Dado que este descenso se dio en las cifras de muertes por enfermedades del aparato digestivo, hacia cuya prevención apuntaban dispensarios de lactantes e institutos de puericultura, los datos "[...] autorizan a referirla a la acción educativa y protectora que desarrollan las referidas instituciones, conjuntamente con la sociedad de Beneficencia, por intermedio de la Casa de Expósitos y del Hospital de Niños." (1917, p. 633). El autor compara estas estadísticas con las de grandes ciudades de otros países y señala que Buenos Aires sólo es aventajada por Paris (90 por 1000) y seguida por Nueva York (102 por1000).

Desde esta visión optimista, algunos médicos señalan que el número de pacientes que asisten a los dispensarios aumenta progresivamente, viendo en ello una muestra de la incorporación por parte de las madres de la necesidad de la guía de la medicina para la crianza de sus hijos:

"Después del periodo dificultoso del principio, en que las madres no llevaban a sus hijos y se retraían, con la desconfianza propia de nuestro pueblo, que rechaza todo lo nuevo, ha venido el segundo, en que, con la inteligencia propia también de ese pueblo desconfiado, ha comprendido el inmenso beneficio que las madres pueden sacar de las instituciones de esta especie, y he tenido el placer de ver aquellas que primero acudieron como acto de desesperación a la Gota de Leche, volver con sus nuevos hijos, recién nacidos, a solicitar los consejos de la ciencia para impedir que llegaran a enfermarse, como sucedió con los anteriores." (Foster, 1906, p.275).

Sin embargo, desde una perspectiva más pesimista, otros o los mismos autores también dan cuenta de las dificultades y obstáculos que se presentan en ese proceso de medicalización. 
Por un lado, al analizar las políticas públicas destinadas a la salud infantil, los médicos celebran la cantidad de establecimientos de atención existentes pero, por lo menos hasta la década de 1920, también plantean que su número continúa siendo insuficiente en relación con el de la población pobre y obrera. Además, perciben que el desarrollo de establecimientos de ese tipo existente en la ciudad de Buenos Aires no se replica de la misma manera en el interior del país (Billorou, 2008).

Por otro lado, más allá de su aumento, la concurrencia es irregular y dista mucho de ser masiva entre los sectores populares. Así, se plantea que sigue habiendo algunas madres que "[...] ya sea por la distancia a que viven, o por negligencia, traen a sus hijos más de tarde en tarde, habiendo que reclamárselo con insistencia." (Foster, 1906, p.277). Los datos estadísticos recopilados y sistematizados en la actualidad por Nari (op. cit) muestran que el porcentaje de niños atendidos en el Dispensario Municipal de Lactantes corresponde en 1908 sólo al 0,29 \% del total de niños menores de dos años. En 1915, el porcentaje asciende a 6,65\%; en 1920, a 14\% y en 1930 , a $24.6 \%$.

Las quejas reiteradas de los médicos apuntan a que las madres llevan a sus bebés a los dispensarios sólo cuando están enfermos, abandonando los controles periódicos cuando el niño mejora. También acusan a las mujeres de concurrir a esos establecimientos interesadamente, sólo para obtener los alimentos preparados que brindan a los niños. ${ }^{133}$ Además, la reiteración continua de ciertas indicaciones, como las de no envolver al niño con fajas, no darle otros alimentos que no sean la leche materna, ni permitir el uso de chupetes, considerados una fuente de transmisión de enfermedades, muestra indirectamente que son prácticas que siguen siendo realizadas más allá de los consejos médicos.

Vemos, entonces, que la clientela que los pediatras de los servicios públicos de salud logran atraer, está compuesta mayormente por madres con hijos que padecen algún problema de salud o que, por no poder ser amamantados, requieren de una asistencia alimentaria. Mucho más difícil parece ser lograr que se sometan a la guía del médico las madres de niños sanos, a las que posiblemente su grupo familiar provea de los conocimientos necesarios para llevar a cabo la crianza. Para lograrlo, los médicos ponen en práctica distintas estrategias de persuasión, entre las que se

\footnotetext{
${ }^{133}$ Esta acusación también puede escucharse en boca de los actuales responsables de los consultorios pediátricos de hospitales y centros de atención primaria de la salud: "lo traen al control sólo para llevarse la leche".
} 
destacan la acción de inspectoras y visitadoras de higiene, que visitan a las familias en su domicilio. También la entrega de leches y harinas ya preparadas para quienes no pueden amamantar funcionaría como un incentivo para acercar a las madres a los servicios de salud.

Así, en la época analizada, la medicalización parece haber sido más intensa con respecto a la enfermedad infantil que al cuidado cotidiano del niño sano. La medicina se mostró eficaz en la reducción de la mortalidad infantil, pero a la hora de criar a sus hijos, las mujeres y las familias no aceptaron ni pasiva ni rápidamente las nuevas prácticas e ideas de la puericultura. Posiblemente debido a la distancia social y cultural que existía entre las familias de sectores populares y los médicos y visitadoras, pero también porque aquellas ya contaban con un cuerpo de saberes sobre la crianza infantil, que hasta entonces se había considerado eficaz y legítimo (Billorou, 2007). En otros términos, cabe suponer que esas familias pudieron beneficiarse en parte de los medios provistos por la medicina para reducir la enfermedad y la muerte de sus niños, pero oponiendo ciertas resistencias a la intromisión que esto conllevaba en sus vidas cotidianas. Más que aceptar en su totalidad los consejos médicos sobre la crianza, parecen haberlos inscripto como parte de un conjunto más amplio de saberes y estrategias de cuidado y formación infantil. La asistencia a dispensarios e institutos de puericultura posiblemente haya formado parte de itinerarios terapéuticos que también incluían a los curadores populares y a los tan criticados "consejos de viejas y vecinas".

Estos procesos, no obstante, no fueron los mismos a lo largo de todo el periodo analizado, ni en todos los sectores sociales, cuya heterogeneidad fuera señalada en el apartado 3.2.2 de este capítulo. La medicalización de la crianza comenzó a mostrarse más amplia y eficaz hacia 1920, con la consolidación del sistema de instituciones de atención médica, el apoyo de las visitadoras de higiene, la ampliación de la escolarización femenina, la extensión de la enseñanza de la puericultura en las escuelas y la conformación de incipientes sectores medios, en los que sintonizaba con las representaciones de la familia nuclear, el rol doméstico asignado a la mujer y una concepción de niñez que enfatizaba su lugar como objeto de protección y formación.

A lo largo de este proceso complejo, más allá de las resistencias de, o mejor dicho, en las disputas con otros saberes y prácticas, la pediatría logró legitimarse en el campo científico y social más amplio como saber experto en la crianza infantil, 
instalando una distinción, permanentemente redefinida, con esos otros saberes considerados legos. Sin embargo, la construcción -nunca del todo concluida- de esa legitimidad, no implicó que dejaran de existir otros modos de realizar el cuidado de los niños, pero sí que estas prácticas y representaciones "otras" fueran subalternizadas y que las madres y familias que las utilizaban pasaran a ser culpabilizadas de gran parte de los problemas de salud que pudieran acontecerles a sus hijos. ${ }^{134}$

\footnotetext{
${ }^{134}$ Recupero aquí especialmente los aportes de Menéndez (op. cit.), acerca de las relaciones de
} hegemonía-subalternidad que se establecen entre modelos médicos. 


\section{Conclusiones}

A lo largo de esta investigación, algunas ideas se fueron delineando a modo de síntesis y de conclusiones provisorias que, más que cerrar las discusiones emprendidas, abren nuevas preguntas y caminos de indagación a ser recorridos.

Comencé este trabajo a partir de una serie de interrogantes sobre el papel de la medicina en la crianza infantil contemporánea, los cuales me llevaron a identificar y analizar el periodo histórico y el modo en que el cuidado infantil ha pasado a ser considerado un proceso crucial que requiere de la guía y control de médicos especializados. A partir de allí, construí mi objeto de investigación en términos del proceso de medicalización de la crianza infantil en la Argentina y delimité para su abordaje el periodo extendido entre 1890 y 1930, por ser el momento en que el niño, su formación y su cuidado se constituyeron en el foco de múltiples y disputados conocimientos e intervenciones, ligados a su definición en términos de "problema social".

El recorrido partió de un análisis de la constitución e institucionalización de una especialidad médica: la pediatría y, vinculada con ella desde un estatus ambiguo, la puericultura. Desde sus comienzos ambas buscaron aprehender no solamente el cuerpo enfermo del niño sino sus condiciones saludables, haciendo de la crianza un eje de sus intervenciones, en el marco de las preocupaciones demográficas que acompañaron el proceso de construcción de la nación a partir de fines del siglo XIX. Este primer tramo implicó visualizar las condiciones sociales que hicieron posibles los procesos de producción de conocimiento experto sobre la niñez (entre ellos, la pediatría y la puericultura, pero también el derecho, la pedagogía, la psicología), pero mostrando que, al mismo tiempo, estos mismos saberes contribuyeron a la construcción de problemas sociales, categorías para nombrarlos, clasificaciones, etc.

En el caso específico del saber médico, puede afirmarse que la constitución de la pediatría como especialidad sólo fue posible a partir de transformaciones en el estatus social de los niños y su papel en la sociedad moderna pero, a su vez, la 
"medicina del niño" contribuyó a definir y naturalizar ese lugar social de la niñez. A modo de síntesis, entonces, considero que existe una relación mutuamente constitutiva entre la estructuración de una especialización profesional (pediatría) y la producción de una categoría social (la infancia), que ofrece interesante proyecciones para pensar investigaciones sobre las transformaciones de la niñez contemporánea en relación con los saberes expertos que la construyen y buscan explicarla.

Retomando lo anterior, pude comprender que la medicalización de la crianza no consistiría sólo en pautar prácticas de cuidado infantil, sino también en instalar cierta idea de niñez que hace de la crianza un proceso necesario y trascendente en términos individuales y sociales. Esto me condujo a analizar las representaciones de la pediatría y la puericultura en términos de una teoría "nativa" sobre la niñez, buscando profundizar el extrañamiento sobre una de las nociones quizás más naturalizadas por el sentido común y por las teorías científicas.

Esa indagación me mostró que el niño fue definido por la medicina de la época estudiada a partir de los procesos de crecimiento y desarrollo, considerados como una manifestación de la "naturaleza infantil". Esto llevó a que, hasta hoy en día, sea abordado por la práctica y la teoría pediátricas como un ser maleable y en transformación, marcado por su vulnerabilidad y definido por su dependencia con respecto de los adultos (los padres, el médico, pero también el maestro, en otro ámbito de construcción de niñez). Tal concepción, que conlleva una noción de temporalidad, de persona, de lazos intergeneracionales, ha sido la base para la percepción de la niñez como una secuencia de etapas sucesivas y progresivas, la primera de las cuales, la "primera infancia", concentró las preocupaciones de la medicina especializada.

El análisis del modo en que la pediatría y la puericultura construyeron su objeto de estudio genera algunas hipótesis a seguir explorando para dar cuenta de la especificidad del abordaje médico de la niñez. En primer lugar, y tal como también lo observa Castellanos (op. cit) el cuerpo que estudia y trata la pediatría es un “cuerpo en formación", además de un posible "cuerpo enfermo". Esta preeminencia de la noción de un cuerpo que crece y se desarrolla, que debe cambiar como condición de normalidad, por sobre la del cuerpo enfermo -o, en todo caso, a la que también se remite el cuerpo enfermo- estaría marcando una diferencia singular de la pediatría al interior de las ciencias médicas. Como concepción de un cuerpo que aumenta continuamente de tamaño y complejiza diferencialmente sus funciones, 
ofrece también interesantes aristas a ser analizadas con mayor profundidad por un abordaje que recupere los desarrollos teóricos de la antropología del cuerpo. A su vez, la idea de desarrollo como devenir complejo hacia la adultez, hace que la pediatría tome al niño en sus aspectos físicos u orgánicos (anatómicos y fisiológicos), pero en su necesaria vinculación con los aspectos psíquicos (el "desarrollo físico, mental y moral" en los términos de los pediatras de comienzos de siglo XX), lo cual también marcaría una diferencia, desde su comienzos, con gran parte de las otras especialidades médicas.

Sin embargo, a la vez que busqué resaltar singularidades del abordaje médico del niño y la crianza, intenté no perder de vista el modo en que sus conceptualizaciones son tributarias de una concepción más general de la niñez, que se perfila en las sociedades europeas a partir del siglo XVIII (Ariès, op. cit; Perrot, op. cit.; Gélis, op. cit.) que trascienden ampliamente el campo médico. En efecto, el concepto de infancia que construye la modernidad implica pensar al niño como un ser aún incompleto, en "estado de naturaleza", un individuo a hacerse, al que la sociedad debe formar, "civilizar", es decir, "socializar". De allí las enormes implicaciones acerca de la definición de las formas socialmente correctas de cuidar y criar a un niño. El lenguaje sobre el cuidado infantil, sobre su socialización corporal, que pone en juego la medicina -pero no sólo ella- debe ser pensado como un lenguaje de la moral y de las emociones, que se torna central para la conformación de la sociedad. Desde esta perspectiva, abordé las múltiples estrategias de divulgación y la prescripción de un "método para criar" -o "formas de aconsejamiento", retomando términos de Vianna (op. cit.) y de Lugones (op.cit.), como parte de un proyecto pedagógico que busca transformar las prácticas de crianza hasta entonces orientadas por saberes familiares, populares, religiosos. Ello iluminó una constante en los abordajes médicos de la niñez, una intención que recorre sus prácticas y que, siguiendo a Castellanos (op. cit.), podemos denominar "gesto pedagógico", del que son destinatarios el niño, pero sobre todo, su familia. Pero, si ese gesto pedagógico debe ser continuamente actualizado en las prácticas pediátricas, es porque el proceso de medicalización nunca termina de completarse. En efecto, la exploración de las obras de puericultura y de pediatría de fines del siglo XIX y comienzos del XX permite entrever otros saberes sobre la niñez y la crianza (saberes tradicionales, familiares, religiosos), con los cuales los médicos de la época discutían implícita o explícitamente. Esto hace de la crianza infantil una arena de disputas, más que un 
territorio definitivamente conquistado por la medicina, y de la medicalización un proceso difícil, complejo, nunca del todo concluido.

No obstante, a través de sus disputas con otros saberes y otros actores que se ocupan de los niños, la pediatría va estableciendo límites específicos entre el papel del médico como cuidador "especializado" y los cuidadores "legos" de los niños, construyendo su legitimidad a partir de distinguirse como un saber experto, autorizado por su carácter científico. Esto hace necesario profundizar brevemente en el modo en que la medicalización de la crianza -pero no sólo de ella- puede ser situada en el marco de relaciones de poder.

La constitución de la pediatría y la puericultura en relación con los problemas que formaron parte de la "cuestión social", hacia fines del siglo XIX y comienzos del XX, permiten pensar, recuperando planteos de De L' Estoile, Neiburg y Sigaud (op. cit.), en la vinculación de estas prácticas de diferenciación al interior de la ciencia y la consiguiente construcción de un discurso experto, con prácticas de poder, en el sentido de políticas de gestión de las poblaciones, vinculadas al Estado. En este sentido, las categorías y prácticas pedagógicas de la medicina del niño pueden ser consideradas como parte de las tecnologías de gobierno (Foucault, 2006), en tanto implican la construcción de modos de intervención sobre niños y familias (Villalta, 2010) que participan en los procesos de regulación de la población. Sin embargo, como lo muestran algunos elementos expuestos en esta tesis, dichos procesos no pueden ser considerados monolíticos, unidireccionales ni definitivos, sino intrínsecamente conflictivos, diversos, atravesados por negociaciones, resignificaciones, tensiones, entre los actores sociales que ellos participan desde posiciones asimétricas (Villalta, op. cit.; Lionetti y Míguez, 2010, Bohoslavsky y Di Liscia, op. cit). Desconocer esta dinámica compleja implicaría dejar de lado la capacidad - no absoluta, sino desigualmente situada- de resistencia, de contestación y presión de las madres, familias, niños, que estuvieron lejos de aceptar pasivamente las nociones y conductas que prescribía la medicina. Considero importante, en este sentido, insistir en el abordaje de la crianza infantil como una arena de disputas, puesto que, como lo señalan Bohoslavsky y Di Liscia (op. cit.), esto "permite ver que los participantes no necesariamente ponen en tela de juicio las normas e ideas que regulan el juego [...], pero sí que tratan de alterar los significados originales, posponer la aplicación de una decisión y obtener espacios más amplios para negociar" (p.11). 
A modo de síntesis provisoria, hemos podido ver que el recurso al médico pediatra como la única voz realmente autorizada para opinar sobre la crianza de los niños puede considerarse resultado de procesos históricos relativamente recientes; procesos que no han concluido ni se han dado de la misma manera en todos los grupos sociales. A lo largo de los mismos, los médicos han disputado y continúan disputando la legitimidad de su saber "experto" sobre el cuidado infantil, con otro tipo de saberes, especialmente con aquellos que, basados en la experiencia, "se transmiten por tradición de madres a hijas" (Martínez de Zuviría, 1915). En estas disputas, junto con la definición de una crianza "correcta", es decir, del tipo cuidados, de alimentación, de educación, que requiere "todo niño sano", se ponen en juego diferentes concepciones de niñez, pero también de la relación entre niños y adultos.

Llegados a este punto, considero importante reflexionar acerca del modo en que las nociones involucradas en el proceso de "criar" se vinculan a un modo particular de entender el lugar del niño en la sociedad y su relación con los adultos.

Esta vinculación es iluminada por las teorías de la socialización, a través de las cuales las sociedades occidentales han construido y naturalizado sus explicaciones del tránsito social del niño en relación con el mundo adulto; explicaciones que se formulan en términos de adquisición, por parte del niño, de repertorios culturales y papeles sociales específicos de la sociedad (adulta) (Jenks, 1996; Cohn, 2005). En otros términos, Rabello de Castro (2001) señala que en el proyecto de la modernidad la infancia fue racionalizada como periodo de socialización, que significó un tiempo de espera y su lenta preparación para la "vida productiva".

La socialización ha sido el eje de gran parte de las elaboraciones teóricas y prácticas que sobre la niñez han producido los saberes científicos modernos, como la psicología del desarrollo, la pedagogía, la sociología y también la antropología, que ha utilizado la noción de "enculturación", más ligado a la adquisición de cultura y competencias para desempeñarse en su marco. Tal como lo señala Cohn (op. cit.), estas nociones de socialización o enculturación se fundan en determinados modos de entender los conceptos de sociedad y cultura, que las propias ciencias sociales ponen actualmente en cuestión: la cultura concebida como un cuerpo acabado, estable y 
coherente de normas, valores y creencias, y la sociedad como una totalidad articulada de relaciones a ser reproducida. ${ }^{135}$

Las teorías de la socialización y del desarrollo infantil, como explicaciones "expertas" de la niñez, han tenido un gran impacto en las concepciones del sentido común sobre el niño. Desde una concepción lineal, etapista y progresiva del proceso de vida, expresada a través de los conceptos de crecimiento y desarrollo, como se vio en el capítulo 2, esas teorías se fundan en y contribuyen a consolidar la idea de que el mundo adulto es completo, racional, estable y también deseable, y que, por lo tanto, se deben generar los mecanismos para permitir a los niños llegar gradualmente a él.

Así, las teorías de la socialización parten de un modelo dado de conducta y de sociedad humanas y buscan explicar la niñez en base a una relación teleológica con este fin pre-establecido: “[...] presentan la estructura normativa del mundo adulto/padre, como su variable independiente. El niño es juzgado con respecto a ese patrón de estructura social consensuado, como más o menos competente." (Jenks, op. cit., pp.9-10, traducción propia). Esto permite a O’Neill (citado en Jenks, op. cit.) afirmar que toda teoría de la socialización infantil es implícitamente una teoría de la realidad social, si no de un orden histórico-social particular.

Esto implica un tipo de relaciones entre niños y adultos formuladas y practicadas en términos de "necesidad" y "cuidado"; cuidado que se asocia también a relaciones de provisión y de instrucción, tal como se sintetizan en el concepto de "crianza". Cabe advertir que en estos vínculos entre adultos y niños se ponen en juego relaciones de poder que pueden caracterizarse en términos de "dependencia". Esta dependencia sitúa al niño en un lugar más de objeto que de sujeto activo, es decir, como receptor de las acciones de otros, que puede tener un signo "positivo": objeto de cuidado o de protección, o "negativo": objeto de maltrato, abuso, abandono (Szulc, 2006). En el mismo sentido, Rabello de Castro (op. cit.) considera que desde el punto de vista de los niños y adolescentes, su apartamiento de las actividades socialmente significativas en la sociedad moderna y su limitación a prácticas de "preparación" para el futuro, significó la institucionalización de su dependencia y su encuadramiento socioinstitucional como "menores" y relativamente incapaces. En el

\footnotetext{
${ }^{135}$ En términos muy generales, puede decirse que la antropología contemporánea aborda la cultura como un sistema simbólico accionado y conformado por los actores a cada momento, continuamente producido y no sólo reproducido; mientras que la sociedad es considerada en términos de una producción continua de las relaciones que la conforman, proceso en el que los actores sociales tiene un papel activo.
} 
ámbito específico de la medicina, en su estudio de la pediatría contemporánea, Castellanos (op.cit.) señala que, tal como hemos visto para el periodo constitutivo de la disciplina, en la medida en que el niño es tomado por la práctica clínica como un ser en desarrollo, marcado por su vulnerabilidad, también el pediatra tiende a considerarlo siempre a partir de su dependencia en relación al adulto (familiar, pediatra) que incorpora el papel de su "cuidador" privilegiado.

Este modo de definir las necesidades infantiles y la "ideología del cuidado" que aparece como contraparte (Jenks, op. cit.), como hemos visto, deben ser situados en contextos sociohistóricos y culturales particulares, vinculados al surgimiento de la infancia y la familia modernas. Así, los procesos de crianza y de socialización en general, tal como lo teorizan y prescriben los saberes expertos de la época analizada (pediatría, pero también pedagogía, psicología), se inscriben en un proceso mucho más amplio, de larga duración histórica, que es el de constitución del individuo moderno en las sociedades occidentales y, más específicamente, el de individualización del niño. Es decir, en un proceso que dio lugar a un modo particular de construcción de la persona, que Norbert Elias (2009) definió como "homo clausus". 136

En este sentido, cabe pensar que si la idea de una "crianza correcta" continúa siendo poderosa en el discurso sobre la infancia y la sociedad en general, motivando constantes y arduos debates entre especialistas, es porque a través de las operaciones más cotidianas de cuidado del niño, de la prescripción de horarios, vestimentas, actividades, hábitos de sueño o de alimentación, se está participando en la construcción de un imaginario sobre el cuerpo infantil, pero también sobre la persona, el tiempo, los vínculos entre generaciones y los lazos sociales en general.

\footnotetext{
${ }^{136}$ El individuo moderno es conceptualizado por Elias en términos de "homo clausus", que implica una determinada relación entre individuo y sociedad, individuo y cuerpo o yo. "Homo clausus" remite a la imagen moderna del ser humano aislado, el hombre como ego, como un ser completamente libre e independiente, como una "personalidad cerrada", un mundo cerrado en sí mismo, que depende de sí mismo en su "interior" y que está separado de los demás individuos, que conforman "la sociedad". Constituye tanto la autoexperiencia del ser humano en la modernidad, como las imágenes sobre el individuo desde las cuales se elaboran las teorías sociológicas, del conocimiento.
} 


\section{BIBLIOGRAFÍA FUENTE}

\section{I) OBRAS ERUDITAS}

\section{a) Revistas científicas/ Artículos publicados en revistas científicas}

Archivos Latinoamericanos de Pediatría

La Semana Médica

Revista de Instrucción Primaria

ACUÑA, Mamerto. 1903. "Protección a la infancia. Los establecimientos llamados 'Goutte de Lait'. Su necesidad en Buenos Aires. Sus ventajas para la clase obrera." La Semana Médica, Año X, Nº41.

AVILA MENDEZ, Marco. 1919. "Protección de la primera infancia por los Institutos de Puericultura y dispensarios de lactantes. Su desarrollo, organización y funcionamiento." Archivos Latinoamericanos de Pediatría, $2^{\mathrm{a}}$ Serie, Tomo XIII, N ${ }^{\circ}$ 6, noviembre-diciembre.

BORDOT, Enrique. 1917. "Desarrollo de la protección de la $1^{\mathrm{a}}$ infancia en Buenos Aires". Archivos Latinoamericanos de Pediatría, $2^{\text {a }}$ Serie, Año VII, Tomo XI, pp. 646-658.

CONI, Emilio R. 1920. "Demografía nacional- Mortalidad infantil en la Argentina, durante el sexenio 1911-1916". Archivos Latinoamericanos de Pediatría, Tomo XIV, $\mathrm{N}^{\circ} 6$.

FORGIONE, José D. 1924. "La puericultura e higiene infantil, como ramos de la enseñanza primaria". La Puericultura. Encuesta sobre la necesidad de su implantación. Revista de Instrucción Primaria, La Plata,

FOSTER, Enrique. 1906. "Memoria sobre el funcionamiento de la 'Gota de leche'. Presentada a la Intendencia municipal." Archivos Latinoamericanos de Pediatría, Año II, No7.

FOSTER, Enrique. 1907. "Memoria sobre el funcionamiento del dispensario de lactantes "La gota de leche". Archivos Latinoamericanos de Pediatría, Año III, $\mathrm{N}^{\circ} 3$, marzo.

FOSTER, Enrique. 1911. "Protección y asistencia de la infancia. Memoria presentada a la Dirección de la Asistencia Pública y correspondiente al año 1910", 
Archivos Latinoamericanos de Pediatría, $2^{\mathrm{a}}$ serie, Año I, tomo V, №1, enero-febrero.

GUILLEN de REZZANO, Clotilde. 1924. “¿Debe enseñarse la puericultura en la escuela primaria?"La Puericultura. Encuesta sobre la necesidad de su implantación en las escuelas primarias del país, Revista de Instrucción Primaria, La Plata.

"Homenaje al Profesor Centeno". 1919. Archivos Latinoamericanos de Pediatría, $2^{\mathrm{a}}$ Serie, Tomo XIII, No 1 .

MALHARRO, Victorina. 1924. "Puericultura en la escuela primaria". La Puericultura. Encuesta sobre la necesidad de su implantación en las escuelas primarias del país, Revista de Instrucción Primaria, La Plata.

MORQUIO, Luis. 1906. "La Pediatría moderna en sus relaciones con la vida profesional (Lección de fin de curso)". Archivos Latinoamericanos de Pediatría, Año II, №11.

MORQUIO, Luis. 1906. "La Pediatría moderna en sus relaciones con la vida profesional (Lección de fin de curso-Segunda parte)". Archivos Latinoamericanos de Pediatría, Año II, Nº12.

MUNIAGURRIA, Camilo. 1924. "Puericultura". La Puericultura. Encuesta sobre la necesidad de su implantación en las escuelas primarias del país, Revista de Instrucción Primaria, La Plata.

OLIVA, Silvestre. 1917. "La protección de la $1^{\text {a }}$ infancia en Buenos Aires. Su organización y resultados." Archivos Latinoamericanos de Pediatría, $2^{\mathrm{a}}$ Serie, Año VII, Tomo XI.

OLIVA, Silvestre. 1918. "Protección de la primera infancia. Memoria y estadística correspondiente al año 1917. Archivos Latinoamericanos de Pediatría, $2^{\mathrm{a}}$ Serie, Año VIII, Tomo XII, No 2.

PENTEADO, Ugolino. 1906. "Do valor da Puerimetria", Archivos Latinoamericanos de Pediatría, Año II, No3.

RODRIGUEZ de CANO, Elvira. 1924. "Breves consideraciones sobre puericultura". La Puericultura. Encuesta sobre la necesidad de su implantación en las escuelas primarias del país, Revista de Instrucción Primaria, La Plata.

SCHLOSSMANN, Arthur. 1913. "La crianza del niño en los dos primeros años de su vida". Revista de Derecho, Historia y Letras, Año 16, Tomo 46.

\section{b) Actas y trabajos presentados en Congresos}

ARÁOZ ALFARO, Gregorio. 1931. "Principales factores de la mortalidad infantil." Jornadas Médicas Argentinas, Buenos Aires. 
FOSTER, Enrique. 1910. "Rol de los dispensarios de lactantes en la protección de la primera infancia”. Trabajos presentados al Congreso Internacional Americano de Medicina e Higiene de 1910. Buenos Aires, E. Spinelli.

LIGA PARA LOS DERECHOS DE LA MUJER Y EL NIÑO. 1913. Cuarto Boletín del Primer Congreso Nacional del Niño y de la Exposición Nacional Anexa. Buenos Aires.

LIGA PARA LOS DERECHOS DE LA MUJER Y EL NIÑO. 1913. Primer Congreso Nacional del Niño. Programa de las Sesiones. Buenos Aires, Escoffier, Caracciolo y Cía.

Primer Congreso Nacional del Niño. 1913. Trabajos Presentados (Conclusiones). Buenos Aires, Escoffier, Caracciolo y Cía.

SUNICO, Francisco P. 1917. "La higiene cultural del niño". $1^{\circ}$ Congreso Americano del Niño.

c) Tesis

BERUTI, Josué A. 1878. Medicina láctea. Tesis. Colección Candioti, Medicina, $\mathrm{T}^{\mathrm{o}} 21$, año 1878, Buenos Aires, Imp. Pablo Coni.

BERUTI, Nicolás. 1877. Lactancia. Tesis. Colección Candioti, Medicina, Tº19. Buenos Aires, Imp. José Peuser.

CERVERA, Joaquín. 1897. Alimentación de la primera infancia. Lactancia materna y artificial. Tesis. Colección Candioti, Medicina, Tº 105 , Buenos Aires, Imp. Prima.

DAVEL, D.F. 1885. Higiene de la alimentación infantil. Tesis. Colección Candioti, Medicina, $\mathrm{T}^{\mathrm{o}} 45$. Buenos Aires, Imp. de la Universidad.

DEMARIA, Enrique B. 1896. Consideraciones higiénicas sobre la leche y la lactancia. Tesis. Colección Candioti, Medicina, T ${ }^{\circ} 98$, Buenos Aires, Imp. Prima.

DORREGO, Pedro Insúa. 1894. Consideraciones higiénicas sobre el recién nacido. Tesis. Colección Candioti, Medicina, Tº88, Buenos Aires, Imp. Argos.

FERNÁNDEZ VILLANUEVA, Julio. 1885. Lactancia y destete. Tesis. Colección Candioti, Medicina, Tº 46 , Buenos Aires, Imp. J.H. Kidd.

FOSTER, Enrique. 1902. El niño. Tesis. Colección Candioti, Medicina, Tơ142, Buenos Aires, Imp. Etchepareborda.

HEUDTLASS, Adolfo P. 1919. Higiene de la Primera Infancia. Tesis. Colección Candioti, Medicina, ${ }^{\circ}$ XIV, Buenos Aires. 
ITHURRALDE, Juan. 1905. Consideración al estudio de la alimentación de la primera infancia. Tesis. Colección Candioti, Medicina, $\mathrm{T}^{\mathbf{0}} 176$, Buenos Aires, Imp. Sudamericana.

KAMINSKY, Esther. 1914. Puericultura. Tesis. Colección Candioti, Medicina, $\mathrm{T}^{\mathrm{o}} 372$, Buenos Aires, Imp. Spinelli.

LEMA, Maciel. 1895. Algunas consideraciones sobre la lactancia artificial. Tesis. Colección Candioti, Medicina, T²95, Buenos Aires, Imp. Coni.

LÓPEZ, Antenor. 1907. El recién nacido y los cuidados a darle. Tesis. Colección Candioti, Medicina, $\mathrm{T}^{\mathbf{0}} 189$, Buenos Aires, Imp. Mena.

MAGLIANO, Hernando. 1914. Consideraciones sobre lactancia y el destete. Tesis. Colección Candioti, Medicina, $T^{\mathbf{0}} 375$, Buenos Aires, Imp. Spinelli.

MUNIAGURRIA, Carlos. 1897. Higiene infantil. Tesis. Colección Candioti, Medicina, $\mathrm{T}^{\mathbf{o}} 108$, Buenos Aires, Imp. San Jorge.

PETRY, Bartolomé. 1894. Contribución al estudio de la lactancia artificial. Tesis. Colección Candioti, Medicina, Tº9, Buenos Aires, Imp. Argos.

SMITH, Edmundo S. 1894. Consideraciones sobre el destete. Tesis. Colección Candioti, Medicina, Tº91, Buenos Aires, Imp. Argos.

SUSINI, Telémaco. 1879. Contribución al estudio de El Empacho. Tesis. Colección Candioti, Medicina, T²7, Buenos Aires, Imp. Pablo Coni.

TIERNEY, Conall J. 1901. Higiene y alimentación infantil. Tesis. Colección Candioti, Medicina, T¹39, año 1901, Buenos Aires, Imp. Boullosa.

TORINO, Martín. 1890. Emociones, depresiones en la infancia. Tesis. Colección Candioti, Medicina, $\mathrm{T}^{\mathrm{o}} 72$, Buenos Aires, Imp. M. Moreno.

TRONGÉ, Faustino C. 1878. Higiene de la primera infancia. Tesis. Colección Candioti, Medicina, $\mathrm{T}^{\mathrm{o}} 23$, Buenos Aires, Imp Luis Maunier.

VACAREZZA, Juan F. 1900. Higiene de la alimentación infantil. Tesis. Colección Candioti, Medicina, $\mathrm{T}^{\mathbf{0}} 133$, Buenos Aires, Imp. Tenorio.

\section{d) Libros y folletos científicos}

CONI, Emilio. 1920. Protección a la madre y al hijo. Puericultura práctica argentina (intra y extrauterina), Imp. y Casa Editora "Coni”, Buenos Aires.

PODESTÁ. 1888. Niños. Estudio Médico-Social, Imprenta de la Patria Italiana, Buenos Aires. 


\section{II- OBRAS DE DIVULGACIÓN}

\section{a) Manuales con formato de libro}

AGOTE, Luis. 1901. La salud de mi hijo. Buenos Aires, Lajouane.

AMUCHÁSTEGUI, Tomás. 1910. La salud del nene. Guía práctica de las madres. Buenos Aires, Arnoldo Moen Hno.

ARÁOZ ALFARO, Gregorio. 1929. El libro de las madres. Manual práctico de higiene del niño, con indicaciones sobre el embarazo, parto y tratamiento de accidentes. Buenos Aires, Cabaut \& Cia. (Primera edición: 1899).

BAS DE MELBHECQ, Señora de. 1864. Amor maternal. Consejos a las madres e higiene de los niños. ( $6^{\mathrm{a}}$ ed.). Paris. (Folleto).

CARREÑO, Carlos y Ricardo Schwarcz. 1927. El niño (su higiene, sus cuidados). Buenos Aires.

CORBAN, F., L.A. Hausen y Q. H. Heald. 1928. La guía de la madre. En casos de enfermedad y emergencia. Florida, Buenos Aires.

DONNÉ, Alfred. 1875. Conseils aux mères sur la manière d'élever les enfants nouveau-nés. $5^{\text {a }}$ édition revue, corrigée et augmentée. Paris, J. Baillière.

DONNÉ, H. 1847. De la educación física de los niños o consejos a las madres sobre el amamantamiento y la manera de criar a sus hijos. Traducción libre de Carlos de Algarra. Paris, Libr. de Rosa.

FEINMANN, Enrique. 1915. La ciencia del niño. Nociones de puricultura e higiene infantil. Cabaut y Cia., Buenos Aires.

FISCHER, Luis. 1930. Manual y guía de alimentación del niño, para uso de médicos, madres y nodrizas. (Salud y cuidado del niño). Buenos Aires.

KUHNE, Luis. 1909. Educación y crianza de los niños. Consejos a los padres, preceptores y educacionistas. Traducción de Manuel J. San Román, de la $11^{\mathrm{a}}$ ed. alemana, completamente revisada y mejorada. Buenos Aires, B. Fueyo.

LAMARQUE, Carlos. 1929. Manual de Puericultura. Para uso de las escuelas normales e institutos especiales. Buenos Aires.

LICEAGA, Félix J. 1930. La crianza del niño. Buenos Aires.

MARTÍNEZ ZUVIRÍA, E. 1918. El niño sano y su alimentación. Buenos Aires.

NAVARRO, Juan Carlos. 1918. La salud del niño; su alimentación. Buenos Aires. 
PINARD, A. 1924. La puericultura de la primera edad. Alimentación. Vestimenta. Higiene. Trad. del francés por Justo y Cohello. París, Bouret. [1904].

VALETA, Antonio. 1917. La salud de los niños (Higiene física y moral). La salud y la vida de los niños depende de la lactancia. Biblioteca del Centro Naturista "Higiene y Salud", Imp. Latina, Montevideo.

\section{b) Cartillas, folletos, textos de conferencias.}

AGUILAR, Doctor Delio. 1919. La cartilla de las madres. Universidad Popular de la Boca, $2^{\mathrm{a}}$ ed., Buenos Aires. (Folleto).

ARÁOZ ALFARO, Gregorio. 1924. Los niños que sufren. Conferencia dada el 19 de setiembre, en Instituto Popular de Conferencias, Buenos Aires.

ARRAGA, Antonio. 1910. Modelo de conferencia sobre Puericultura para darse en los colegios. Buenos Aires, Adolfo Gran.

CIUDAD DE BUENOS AIRES. Municipalidad. 1928. Higiene del embarazo. ¿Qué deben hacer las madres para impedir la muerte de sus hijos de pecho? Museo Municipal de higiene Pública, No¹, Buenos Aires, Mazzuco.

CORBELLINI, Enrique. 1919. Cartilla maternal dedicada al 'Club de Madres' en ocasión de la $3^{a}$ semana del nene. Montevideo, Saint Hnos.

MADRID PÁEZ, Samuel. 1928. La asistencia médica preventiva de la Infancia. Conferencia dada el 5 de agosto, en Instituto Popular de conferencias, 1927, Buenos Aires.

MARCEL LABRE, M. 1925. Educación alimenticia del niño, en Anales del Instituto Popular de Conferencias. $7^{\mathrm{o}}$ ciclo, T.7.

MUNICIPALIDAD DE BUENOS AIRES. 1914. Administración Sanitaria y Asistencia Pública. Alimentación del niño de pecho. Consejos a las madres. (Por E. F. Beláustegui y S. Oliva). Buenos Aires, A. de Martino.

ONELLI, Clemente. 1922. Conversación familiar a las madres. Diez niños nacen, diez niños mueren. Con leche pura sola, puede evitarse. Conferencia, Parroquia San Cristóbal Sud, Buenos Aires.

\section{c) Revistas}

Madre y niño. Revista de higiene y de educación de la primera infancia. . 


\section{d) Textos escolares.}

BERTELLI, Rita P. de. 1924. Por la salud del niño. (Guía práctica de puericultura dedicada a las niñas de todas las clases sociales por la 'Liga Sanitaria del Norte Argentino'). Universidad Nacional de Tucumán, Boletín de Extensión Popular N 52 , Buenos Aires.

COMETO, Carlos S. 1913. Lecturas para niñas sobre higiene infantil. Buenos Aires, Cabaut y Cia.

ETCHEGARAY, Mariano. 1915. Higiene y puericultura. Para uso de las escuelas normales y colegios nacionales. Buenos Aires.

MUNIAGURRIA, Camilo. Muniagurria, Camilo. 1923. La flor humana. Texto de puericultura elemental para uso de las escuelas primarias de niñas de la República. Librería de Antonio García Santos, Buenos Aires. 


\section{BIBLIOGRAFÍA CONSULTADA}

ALONSO, Martín. 1958. Enciclopedia del idioma. Diccionario histórico y moderno de la lengua española (siglos XII al XX). Madrid, Aguilar.

ARIÈS, Philippe. 1981. História social da criança e da família. Rio de Janeiro, Editora Guanabara. (Primera edición en francés: 1973).

ARMUS, Diego (comp.). 2005. Avatares de la medicalización en América Latina, 1870-1970. Buenos Aires, Lugar Editorial.

AMSTRONG, David. 1986. "The invention of infant mortality". Sociology of health \& illness: a Journal of Medical Sociology, V. 8, nº 3.

BADINTER, Elisabeth. 1985. Um amor conquistado. O mito do amor materno. Rio de Janeiro, Nova Fronteira (Primera edición en francés: 1980).

BALANDIER, Georges. 1975. Antropo-lógicas. Barcelona, Ediciones Península. (Primera edición en francés: 1974).

BALLESTER AÑÓN, Rosa y Enrique Perdiguero Gil. 2003. "Ciencia e ideología en los estudios sobre crecimiento humanos en Francia y en España (19001950)". Dynamis. Acta Hispanica ad Medicinae Scientiarumque Historiam Illustrandam. $\mathrm{N}^{\mathrm{o}} 23$, Granada.

BARRÁN, José Pedro. 1995. Medicina y sociedad en el Uruguay del novecientos. Tomo 1: El poder de curar. Montevideo, Ediciones de la Banda Oriental.

BARRANCOS, Dora. 1991. Educación, cultura y trabajadores (1890-1930), Buenos Aires, Centro Editor de América Latina.

BELMARTINO, Susana. 2005. La atención médica argentina en el siglo XX. Instituciones y procesos. Buenos Aires, Siglo XXI.

BIERNAT, Carolina y Karina Ramacciotti. 2008. "La tutela estatal de la madre y el niño: estructuras administrativas, legislación y cuadros técnicos (19361955)". História, Ciências Sociais, Saúde-Manguinhos, Vol. 15, №2, Rio de Janeiro.

BILlOROU, María José. 2007. "Madres y médicos en torno a la cuna. Ideas y prácticas sobre el cuidado infantil (Buenos Aires, 1930-1945)". La Aljaba, Segunda época, Vol. XI.

BILLOROU, María José. 2008. “"La protección maternal e infantil debe ser colocada en primer plano en un país como el nuestro'. Las políticas de protección a la infancia en la Argentina de principios del siglo XX". Trabajo presentado en la 
Jornada Historia de la infancia en Argentina, 1880-1960. Enfoques, problemas y perspectivas. Universidad Nacional de General SarmientoUniversidad de San Andrés. Actas en CD.

BLANQUEZ FRAILE, Agustín. 1946. Diccionario latino-español. Barcelona, Editorial Ramón Sopena.

BOLTANSKI, Luc. 1969. Prime éducation et morale de classe. Paris, Éditions Mouton.

BONET, Octavio A. R. 2003. Os médicos da pessoa. Um estudo comparativo sobre a construçao de uma identidade profissional. Tesis de doctorado en Antropologia Social. Río de Janeiro, Museu Nacional, Universidade Federal do Rio de Janeiro.

BONNET, Doris et Laurence Pourchez. 2010. Du soin au rite dans l'enfance. Toulouse- Paris, Éditions Érès -IRD.

BOURDIEU, Pierre. 1983. “A ‘juventude’ é apenas uma palavra”. Em: Questões de sociologia, Rio de Janeiro, Editora Marco Zero.

BOURDIEU, Pierre. 1990. "Algunas propiedades de los campos". En: Sociología y cultura, México, Editorial Grijalbo.

BOURDIEU, Pierre. 1991. El sentido práctico. Madrid, Taurus Humanidades.

BOURDIEU, Pierre. 1995. "La práctica de la antropología reflexiva (Introducción al seminario de la Escuela de Estudios Superiores en Ciencias Sociales, Paris, octubre de 1987)". En: Bourdieu y Wacquant, Respuestas. Por una antropología reflexiva. México, Editorial Grijalbo.

CANGUILHEM, Georges. 1971. Lo normal y lo patológico. Buenos Aires, Siglo XXI (primera edición en francés: 1966).

CARLI, Sandra. 2002. Niñez, pedagogía y política. Transformaciones de los discursos acerca de la infancia en la historia de la educación argentina entre 1880 y 1955. Buenos Aires, Miño y Dávila.

CARLI, Sandra. 2011. "El campo de los estudios sobre la infancia en las fronteras de las disciplinas. Notas para su caracterización e hipótesis sobre sus desafíos". En: Cosse, Isabella, Valeria Llobet, Carla Villalta y María Carolina Zapiola (eds.), Infancias: políticas y saberes en Argentina y Brasil. Buenos Aires, Teseo.

CASTEL, Robert. 1997. La metamorfosis de la cuestión social. Una crónica del salariado. Buenos Aires-Barcelona-México, Paidós.

CASTELlANOS, Marcelo E. P. 2003. A pediatria e a construção social da Infância: uma análise do discurso Médico-pediátrico. Dissertação de 
Mestrado, Campinas, Pós-Graduação da Faculdade de Ciências Médicas da Universidade Estadual de Campinas.

CASTRO, Edgardo. 2004. El vocabulario de Michel Foucault. Bernal, Prometeo/Editorial de la Universidad Nacional de Quilmes

CHAVES, Mariana. 2005. Los espacios urbanos de jóvenes en la ciudad de La Plata. Tesis de Doctorado, La Plata, Facultad de Ciencias Naturales y Museo, UNLP.

CHAZAN, Lilian Krakowski. 2000. Fetos, máquinas e subjetividade : um estudo sobre a construção social do feto como pessoa através da tecnologia de imagem. Dissertaçao de Mestrado, Rio de Janeiro, Instituto de Medicina Social, Universidade do Estado do Rio de Janeiro.

CHOMBART de LAUWE, Marie J. 1991. Um outro mundo: a infância. Sao Paulo, Parspectiva- Editora da Universidade de Sao Paulo. (Primera edición en francés: 1971).

COHN, Bernard S. 1980. "History and Anthropology: the state of play". Comparative studies in society and history, vol. 22, N.2.

COHN, Clarice. 2002. "A experiência da infância e o aprendizado entre os Xikrin". Em: Lopes da Silva A., Macedo A.V.L.S. \& Nunes A. (eds.), Crianças indígenas: ensaios antropológicos. São Paulo, Global.

COHN, Clarice. 2005. Antropología da criança. Rio de Janeiro, Jorge Zahar Editor.

COLANGELO, María Adelaida. 1996. "Pautas de crianza en diferentes sectores socioculturales de la ciudad de La Plata". Buenos Aires, Comisión de Investigaciones Científicas de la Provincia de Buenos Aires, Informe inédito.

COLANGELO, María Adelaida. 2008. "La constitución de la niñez como objeto de estudio e intervención médicos en la Argentina de comienzos del siglo XX". IX Congreso Argentino de Antropología Social, Posadas. Actas en CD.

COLANGELO, María Adelaida. 2009. "La salud infantil en contextos de diversidad sociocultural". En: Tamagno, Liliana (comp.), Pueblos indígenas: interculturalidad, colonialidad, política. Buenos Aires, Biblos.

COLANGELO, María Adelaida. 2011. "El saber médico y la definición de una 'naturaleza infantil' entre fines del siglo XIX y comienzos del siglo XX en la Argentina." En: Cosse, Isabella, Valeria Llobet, Carla Villalta y María Carolina Zapiola (eds.), Infancias: políticas y saberes en Argentina y Brasil. Buenos Aires, Teseo.

CONRAD, P. 1982 "Sobre la medicalización de la anormalidad y el control social". En: Ingleby, D. (ed.), Psiquiatría crítica. Barcelona, Editorial Crítica. 
COROMINAS, Juan. 1973. Breve Diccionario Etimológico de la Lengua Castellana, Madrid, Editorial Gredos.

COWEN M. P. 2000. "Nacimientos, partos y problemas de la primera infancia. Fines del siglo XVIII, primeras décadas del siglo XIX”. En: J. L. Moreno (ed.), La política social antes de la política social. Buenos Aires, Prometeo.

DAS CHENE, Mary. 1997. "Locating the past", en: Gupta, A. and J. Ferguson (eds.), Anthropological locations. Boundaries and grounds of a field science. Berkeley, Los Angeles and London, University of California Press.

DEL CASTILLO TRONCOSO, Alberto. 2001. "Moral médica y secularización: el cuerpo infantil en el discurso médicos del porfiriato". Política y Cultura, №16. DF, México, Universidad Autónoma Metropolitana- Xochimilco,.

DEL PRIORE, Mary. 1995. Ao sul do corpo. Condição feminina, maternidades e mentalidades no Brasil Colônia, Rio de Janeiro, José Olympio Editora.

DI LISCIA, María Silvia. 2004. "En pos de la regeneración nacional. Instituciones y biotipología en Argentina (1900-1940)". Varia Historia, nº 32.

DI LISCIA, María Silvia. 2005. "Dentro y fuera del hogar. Mujeres, familias y medicalización en Argentina, 1870-1940". Signos históricos, No13. DF, México, Universidad Autónoma Metropolitana- Iztapalapa.

DONZELOT, Jacques. 1990. La policía de las familias. España, Editorial PreTextos, (primera edición en francés: 1977).

DUMONT, Louis. 1993. O individualismo. Uma perspectiva antropológica da ideologia moderna. Río de Janeiro, Editora Rocco.

ELIAS, Norbert. 1998 "La civilización de los padres" [artículo original publicado en 1980]. En: La civilización de los padres y otros ensayos. Santa Fe de Bogotá, Editorial Norma.

ELIAS, Norbert. 2009. El proceso de la civilización. Investigaciones sociogenéticas y psicogenéticas. México, Fondo de Cultura Económica, (primera edición en alemán: 1977 tomo I y 1979 tomo II).

ENRIZ Noelia. 2011. "Un abordaje de la cotidianidad de los niños y niñas mbyá". En: Gabriela Novaro (ed.), Educación y escolaridad en contextos interculturales: temas de investigación, políticas educativas y demandas sociales.. Buenos Aires, Editorial Biblos.

FAY- SALLOIS, Fanny. 1997. Les nourrices à Paris au XIXème. siècle. Paris, Editions Payot.

FLANDRIN, Jean-Louis. 1991. Famílias. Parentesco, casa e sexualidade na sociedade antiga. Liboa, Estampa. (Primera edición en francés: 1984). 
FONSECA, Claudia y Patrice Schuch (orgs.). 2009. Políticas de proteçao à infância: um olhar antropológico. Porto Alegre, Editora da UFRGS.

FOUCAULT, Michel. 1993. "Historia de la 'medicalización"”. Em: La vida de los hombres infames. Buenos Aires/Montevideo, Editorial Altamira/Nordan Comunidad.

FOUCAULT, Michel. 1999. Los anormales. Buenos Aires, Fondo de Cultura Económica.

FOUCAULT, Michel. 2006. Seguridad, territorio, población. Buenos Aires, Fondo de Cultura Económica.

GÉLIS, Jacques. 1990. "La individualización del niño”. En: Ariès, Philippe y Duby, Georges, Historia de la vida privada, Tomo 4. Madrid, Taurus.

GIBERTI, Eva. 1997. "La niñez y el hacer política. En: Giberti, Eva (comp.), Políticas y niñez, Buenos Aires, Losada.

GONZÁLEZ, Ricardo. 1990. "Lo propio y lo ajeno. Actividades culturales y fomentismo en una asociación vecinal, Barrio Nazca (1925- 1930)". En: Armus, Diego (comp.), Mundo urbano y cultura popular. Estudios de Historia Social Argentina. Buenos Aires, Editorial Sudamericana.

GONZÁLEZ LEANDRI, Ricardo. 1996. "La profesión médica en buenos Aires, 1852-1870”. En: Lobato, Mirta Z. (ed.): Política, médicos y enfermedades. Lecturas de historia de la salud en Argentina. Buenos Aires, Editorial BiblosUniversidad Nacional de Mar del Plata.

GONZÁLEZ LEANDRI, Ricardo. 2000. "Miradas médicas sobre la cuestión social. Buenos Aires a fines del siglo XIX y principios del XX". Revista de Indias, vol. LX, No 219.

GONZÁLEZ LEANDRI, Ricardo. 2006. "La consolidación de una inteligentzia médico profesional en Argentina: 1880-19000". Diálogos, Revista electrónica de Historia, año/vol.7, Nº 1 , Costa Rica.

GOTTLIEB, Alma. 2000. "Where have all the babies gone? Toward an anthropology of infants and their caretakers)." Anthropological Quaterly. 73(3).

GUPTA, Akhil and James Ferguson. 1997. "Discipline and practice: 'the fiel'as site, mehod, and location in anthropology". En: Gupta, A. and J. Ferguson (eds.), Anthropological locations. Boundaries and grounds of a field science. Berkeley, Los Angeles and London, University of California Press.

GUY, Donna J. 1998a. "Madres vivas y muertas. Los múltiples conceptos de la maternidad en Buenos Aires". En: Balderston, D. y D. J. Guy (comps.), Sexo y sexualidades en América Latina. Editorial Paidós, Buenos Aires. 
GUY, Donna J. 1998b. "The Pan American Child Congresses, 1916-1942. Pan Americanism, Child reform and Welfare State in Latin America". Journal of Family History 23(3): 272-291.

HECHT, Ana Carolina. 2004. "Hacia una revisión de la categoría 'niño' y ‘cultura wichí' a través de la escuela en el departamento Ramón Lista (Formosa)". Córdoba, VII Congreso Argentino de Antropología Social, Actas en CD.

HOFFMANN, J.M. 1992. "El área de la primera infancia”. En: Psicodiagnosticar, Vol.2, año 2.

JAMES, Allison, Chris Jenks \& Alan Prout. 1998. Theorizing children. Cambridge, Polity Press.

JENKS, Chris. 1996. Childhood. London and New York, Routledge.

JOAQUIM, Teresa. 1997. Menina e moça: a construção social da feminilidade, séculos XVII-XIX. Lisboa, Editora Fim de Século.

KNIBIEHLER, Ivonne. 2001. Historia de las madres y de la maternidad en Occidente, Buenos Aires, Nueva Visión, Bueno Aires. (Primera edición en francés: 2000).

LE BRETON, Davis. 1990. Anthropologie du corps et modernité. Paris, Presses Universitaries de France.

L'ESTOILE, Benoît, Federico Neiburg et Lygia Sigaud. 2000. "Savoirs anthropologiques, administration des populations et constructions de l'État". Revue de Synthèse, Tome 121, N³-4.

LIONETTI, Lucía. 2011a. "Discursos, representaciones y prácticas educativas sobre el cuerpo de los escolares. Argentina en las primeras décadas del siglo XX". Cuadernos de historia $N^{o} 34$, Universidad de Chile, pp.: 31-52.

LIONETTI, Lucía. 2011b. "Infancia y educación en diálogo: un campo de posibilidades para la reflexión teórica y renovadas perspectivas de análisis". En: Cosse, Isabella, Valeria Llobet, Carla Villalta y María Carolina Zapiola (eds.), Infancias: políticas y saberes en Argentina y Brasil. Buenos Aires, Teseo.

LIONETTI, Lucía y Daniel Míguez. 2010. Las infancias en la historia argentina. Intersecciones entre prácticas, discursos e instituciones (1890-1960) compilado por. - 1a ed. - Rosario: Prohistoria Ediciones,

LLOBET, Valeria. 2011. "Un mapeo preliminar de investigaciones sobre infancia y adolescencia en las ciencias sociales en Argentina desde mediados de la década de 1990". Kairos. Revista de Temas Sociales, San Luis, Año 15, №28. 
LOBATO, Mirta Z. (ed.). 1996. Política, médicos y enfermedades. Lecturas de historia de la salud en Argentina. Buenos Aires, Editorial BiblosUniversidad Nacional de Mar del Plata.

LUGONES, María Gabriela. 2009. Obrando en autos, obrando en vidas: formas e fórmulas de Proteçao Judicial dos tribunais prevencionais de Menores de córdoba, Argentina, nos começps do século XXI. Tesis de doctorado, Universidade Federal do Rio de Janeiro.

LOPES DA SILVA A., Macedo A.V.L.S. \& Nunes A. (eds.). 2002. Crianças indígenas: ensaios antropológicos. São Paulo, Global.

LUZ, Madel T. 1997. Natural, racional, social. Razón médica y racionalidad científica moderna. Buenos Aires, Lugar Editorial.

MAZZEO, Victoria. 1988. Mortalidad infantil en la ciudad de Buenos Aires (18561986). Buenos Aires, Centro Editor de América Latina.

MEAD, Margaret. 1962. Educación y Cultura. Barcelona, Paidós.

MEAD, Margaret. 1990. Sexo y Temperamento en tres sociedades primitivas. México, Paidós Studio, Mexico.

MEAD, Margaret. 1993. Adolescencia, sexo y cultura en Samoa. Barcelona, Planeta Agostini.

MENÉNDEZ, Eduardo. 1990. Morir de alcohol. Saber y hegemonía médica. México, Alianza Editorial Mexicana.

MERONI, Ricardo. 1980. "Historia de la pediatría clínica". Actas del Primer Congreso Hispanoamericano de Historia de la Medicina. Buenos Aires, Sociedad Argentina de Historia de la Medicina.

MEYER, Philippe. 1977. L'enfant et la raison d'État. Paris, Editions du Seuil.

MÍGUEZ, Eduardo J. 1999. "Familias de clase media: la formación de un modelo". En: Devoto, Fernando y Marta Madero, Historia de la vida privada en Argentina, Tomo 2: La Argentina plural: 1870-1930. Buenos Aires, Taurus.

NARI, Marcela. 1996. "Las prácticas anticonceptivas, la disminución de la natalidad y el debate médico, 1890-1940”. En: Lobato, Mirta Z. (ed.), Política, médicos y enfermedades. Lecturas de historia de la salud en Argentina. Buenos Aires, Editorial Biblos- Universidad Nacional de Mar del Plata.

NARI, Marcela. 2004. Políticas de maternidad y maternalismo político. Buenos Aires, Editorial Biblos.

NUNES A. (1999). A sociedade das crianças auwe-xavante: por uma antropologia da criança. Lisboa, Ministério da Educação/Instituto de Inovação Educacional. 
OLIVA, Andrea. 2007. Trabajo social y lucha de clases. Análisis histórico de las modalidades de intervención en Argentina. Buenos Aires, Imago Mundi.

OTERO, Hernán. 2007. "El concepto de población en el sistema estadístico nacional". En: Torrado, Susana (comp.), Población y bienestar en la Argentina del primero al segundo centenario, Tomo I. Buenos Aires, Edhasa.

PEREIRA, Júnia Sales. 2006. História de Pediatria no Brasil: de final do século XIX a meados do século XX. Tesis de doctorado inédita, Universidade Federal de minas Gerais. Brasil.

PASSARO, Joanne. 1997. "'You can't take the subway to the field!': 'Village' epistemologies in the Global Village.”. En: Gupta, A. and J. Ferguson (eds.), Anthropological locations. Boundaries and grounds of a field science. Berkeley, Los angeles and London, University of California Press.

PERROT, Michelle. 1989. "Figuras y funciones". En: P. Ariès y G. Duby, Historia de la vida privada, Tomo 4. Madrid, Editorial Taurus.

PUGA, Teodoro F. s/f. "Reseña histórica de la pediatría latinoamericana". (Basado en la Quinta Edición del Libro Pediatría - Meneghello-1997Editorial Médica Panamericana). En: http://www.alape.org/pediatria_latinoamericana.php_Asociación Latinoamericana de Pediatría.

RABELLO DE CASTRO, Lucia. 2001. "Una teoría de la infancia en la contemporaneidad". En: Rabello de Castro, L. (org.), Infancia y adolescencia en la cultura del consumo. Buenos Aires- México, Editorial LumenHumanitas, (primera edición en portugués: 1999).

RECALDE, Héctor. 1988. La higiene y el trabajo (1870-1930), volumen 1y volumen 2. Buenos Aires, Centro Editor de América Latina.

RECALDE, Héctor. 1997. La salud de los trabajadores en Buenos Aires (18701910) a través de las fuentes médicas. Buenos Aires, Grupo Editor Universitario.

REMORINI, Carolina. 2009. Aporte a la caracterización etnográfica de los procesos de salud-enfermedad en las primeras etapas del ciclo vital, en comunidades mbya-guaraní de Misiones, República Argentina. Tesis de doctorado, La Plata, Facultad de Ciencias Naturales y Museo, Universidad Nacional de La Plata. .

RÍOS, Julio César y Ana María Talak. 1999. "La niñez en los espacios urbanos”. En: Devoto y Madero (dirs.). Historia de la vida privada en Argentina. Tomo 2. Buenos Aires, Editorial Taurus.

RIVORÊDO, Carlos Roberto Soares Freire. 1998. "Pediatria; medicina para crianças?". 
Saúde e Sociedade, №2.

RODRÍGUEZ JIMÉNEZ, Pablo. 2007. "La Pediatría en Colombia. 1880- 1960. Crónica de una alegría”. En: Rodríguez Jiménez, Pablo y Emma Manarelli (coords.), Historia de la infancia en América Latina, Bogotá, Universidad Externado de Colombia.

RODRÍGUEZ OCAÑA, Esteban. 2003. "Child health, a paradigmatic issue in modern history". Dynamis. Acta Hispanica ad Medicinae Scientiarumque Historiam Illustrandam. ํ23, Granada.

ROHDEN F. 2009. Uma ciência da diferença: sexo e gênero na medicina da mulher. Rio de Janeiro, Fiocruz.

ROMERO, Luis Alberto. 1990. "Buenos Aires en la entreguerra: libros baratos y cultura de los sectores populares". En: Armus, Diego (comp.). Mundo urbano y cultura popular. Estudios de Historia Social Argentina. Buenos Aires, Editorial Sudamericana.

ROMERO, Luis Alberto. 1995. “Introducción”. En: Romero, Luis A. y Leandro H. Gutiérrez. Sectores populares, cultura y política. Buenos Aires en la entreguerra. Buenos Aires, Editorial Sudamericana.

ROUSSEAU, Emile. 1969. Emilio o la educación. (Selección). Buenos Aires, Centro Editor de América Latina.

SANTILLÁN, Laura. 2011. "El cuidado infantil, la vida familiar y las formas en que se territorializan las intervenciones sociales: un estudio en barrios populares del Gran Buenos Aires.”. En: Cosse, Isabella, Valeria Llobet, Carla Villalta y María Carolina Zapiola (eds.). Infancias: políticas y saberes en Argentina y Brasil. Buenos Aires, Teseo.

SERRE, Delphine. 1997. "L'Etat et les familles: les pratiques d'imposition symbolique des professionnel(le)s de la petite enfance". (Mimeo) Colloque Ciências sociais, Estado e Sociedade. Rio de Janeiro.

SHORTER, Edward. 1977. Naissance de la famille moderne. XVIII ${ }^{o}$-XX $X^{o}$ siècle. Éditions du Seuil, Paris, (primera edición en inglés: 1975).

SOTO, Claudia y Rosa Violante. 2008. Pedagogía de la crianza. Buenos Aires, Paidós.

SPENCER, Paul (ed.), 1990. Anthropology and the riddle of Sphinx. Paradoxes of change in the life course. ASA Monographs No28, London-New York, Routledge.

STOCKING Jr., George. 1983. "The ethnographer's magic: fieldwork in British Anthropology from Tylor to Malinowski”. En: Stocking Jr., George (ed.), Observers observed: essays on ethnographic fieldwork. History of Anthropology. Vol.1, Madison, The University of Wisconsin Press. 
STOCKING Jr., George. 1991. "Maclay, Kubari, Malinowski: archetypes from the dreamtime of anthropology.”. En: Stocking Jr., George (ed.), Colonial situations. Essays on the contextualization of ethnographic knowledge. History of Anthropology. Vol. 7, Madison, The University of Wisconsin Press.

SZULC, Andrea. 2006. "Antropología y Niñez: de la omisión a las 'culturas infantiles"'. En: Wilde, G. y P. Schamber (Eds.), Cultura, comunidades y procesos contemporáneos. Buenos Aires, Editorial SB, Colección "Paradigma indicial".

SZULC, Andrea. 2007. Encrucijadas identitarias: representaciones de y sobre niños mapuche de Neuquén. Tesis de doctorado, Buenos Aires, Facultad de Filosofía y Letras, Universidad de Buenos Aires.

SZULC, Andrea y Clarice Cohn. 2012. "Anthropology and Childhood in South America: Perspectives from Brazil and Argentina”. AnthropoChildren, $\mathrm{N}^{\circ} 1$.

TENTI FANFANI, Emilio. 1990. Estado y pobreza. Estrategias típicas de intervención. Buenos Aires, Centro Editor de América Latina.

TERÁN, Oscar. 2000. "Vida intelectual en el Buenos Aires fin-de siglo (18801910)". En: Derivas de la 'cultura científica'. Buenos Aires, Fondo de Cultura Económica.

THORNE, Barrie. 2004. "Editorial: thorizing age and other differences". Childhood, $11(4)$.

TORRADO, Susana. 2007. “Introducción”. En: Torrado, Susana (comp.), Población y bienestar en la Argentina del primero al segundo centenario, Tomo I. Buenos Aires, Edhasa.

VIANNA, Adriana de Rezende Barreto. 2002. Limites de menoridade: tutela, família $e$ autoridade em julgamento. Tese de Doutorado, Rio de Janeiro, Museu Nacional, Universidade Federal do Rio de Janeiro.

VIGARELLO, George. 2005. Corregir el cuerpo. Historia de un poder pedagógico. Buenos Aires, Nueva Visión. (Primera edición en francés: 2001).

VILLALTA, Carla. 2010. "Introducción”. En Villalta (comp.). Infancia, justicia y derechos humanos. Bernal, Universidad Nacional de Quilmes.

YUTZIS, Daniela. 2008. La administración del cuerpo infantil en el siglo XVIII: una lectura sobre el inicio de la ortopedia infantil. Tesis de Maestría en Educación Corporal, La Plata, Facultad de Humanidades y Ciencias de la Educación, Universidad Nacional de La Plata.

ZIMMERMAN, Eduardo. 1994. Los liberales reformistas. La Cuestión Social en Argentina, 1880-1916. Buenos Aires, Sudamericana 
ANEXOS 


\section{CUADRO $\mathbf{N}^{0} 1$}

Estadísticas de mortalidad infantil en la Argentina entre los años 1911 y 1916.

\begin{tabular}{|c|c|c|c|c|c|c|c|c|c|c|c|c|}
\hline & & De & iones & nti & le 1 d & a 10 & $s-A$ กิ & os 1911 & 916 & 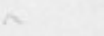 & & * \\
\hline & \multirow{2}{*}{$\begin{array}{l}\text { Capital Federal } \\
\text { Pravineias } \\
y \text { Territorioa }\end{array}$} & \multirow{2}{*}{$\begin{array}{l}1 \text { a } 80 \\
\text { dias }\end{array}$} & \multirow{2}{*}{$\begin{array}{l}1 \text { iो } 6 \\
\text { moses }\end{array}$} & \multirow{2}{*}{$\begin{array}{l}\text { 6 a } 12 \\
\text { meses }\end{array}$} & \multirow[b]{2}{*}{ 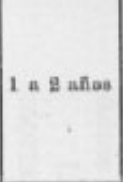 } & \multicolumn{2}{|c|}{$\begin{array}{l}\text { Total de la primera } \\
\text { Infaneia }\end{array}$} & \multirow[b]{2}{*}{2 a 5 afos } & \multirow{2}{*}{$\begin{array}{c}6 \text { a } 10 \\
\text { aftos }\end{array}$} & \multicolumn{2}{|c|}{$\begin{array}{l}\text { Total } \\
\text { de at a } 10 \text { ahtos }\end{array}$} & \multirow[b]{2}{*}{. } \\
\hline & & & & & & Buman & $\begin{array}{c}\text { Promedio } \\
\% \\
\text { defuncion. } \\
\text { gonerales }\end{array}$ & & & Buma & $\begin{array}{c}\text { Pomedio } \\
\% \\
\text { defuasios. } \\
\text { generales }\end{array}$ & \\
\hline & $\begin{array}{c}\text { Capital Federal.. } \\
\text { (Provincias) }\end{array}$ & 6.804 & 11.671 & 9.117 & 9.428 & 37.020 & $26: 4$ & 7.919 & 8.783 & 11.102 & 7.9 & \\
\hline 1 & Tueuman ......... & 6.483 & 6.006 & 4.815 & 6.879 & 29.689 & 46.5 & 2.724 & 1.537 & 4.279 & 8.8 & (5) \\
\hline 2 & San Jaan........ & 2.726 & 1.786 & 1.428 & 1.640 & 7.575 & 46.8 & 806 & 408 & 1.914 & 7.4 & $(12)$ \\
\hline$\overline{3}$ & Mendoza......... & 4.045 & 4.946 & 8.980 & 4.778 & 17.689 & 45.4 & 2.444 & 1.290 & 3.734 & 9.5 & $(3)^{\prime}$ \\
\hline 4 & Cordoba.......... & 9.877 & 10.269 & 9620 & 4.867 & 34.683 & 48.5 & 4.232 & $2.5 \times 3$ & 6.815 & 8.0 & (7) \\
\hline 5 & Bantu Fe....... & 10.476 & 9.146 & 7.683 & 6.892 & 31.127 & 41.1 & 4.152 & 2.576 & 6.728 & 8.0 & (8) \\
\hline 6 & San Luis........ & 1.536 & 1.446 & 1.007 & 855 & 4.814 & 89.9 & 566 & 407 & 973 & 8.0 & (9) \\
\hline 7 & Bgo. del Estero... & 2.893 & 1.926 & 1.755 & 1.489 & 8.003 & 38.9 & 1.045 & 793 & 1.778 & 8.6 & (14) \\
\hline 8 & Balta.......... & 3.399 & 3,642 & 1.627 & 1.181 & 7.799 & 38.5 & 988 & 661 & 1.649 & 8.1 & (6) \\
\hline 9 & Jujuy............... & 1.145 & 1.590 & 919 & 1.186 & 4.790 & 96.4 & 9213 & 505 & 1.428 & 10.9 & (i) \\
\hline 10 & Entre Rios.... .. & 4.762 & 4.202 & 3.096 & 2.592 & 14.653 & 35.4 & 1.949 & 1.257 & 3.206 & 7.7 & (10) \\
\hline 11 & Buenos Aires... & 14.897 & 17.100 & 1.2 .937 & 10.554 & 55.488 & 84.8 & 7.051 & 4.926 & 11.977 & 7.5 & (11) \\
\hline 12 & La Rioja........ & 597 & 610 & 425 & 442 & 9.074 & 39.7 & 260 & 154 & 410 & 6.6 & (13) \\
\hline 13 & Catamarca....... & 708 & 862 & 503 & 500 & 2.573 & 93.3 & 883 & 261 & 584 & 7.4 & (14) \\
\hline 14 & (Territorios) & 2.611 & 3.526 & 2389 & 1.530 & 9.026 & 31.8 & 1.480 & 1.131 & 2.611 & 9.0 & (8) \\
\hline 1 & Andes........... & 67 & B8 & 21 & 18 & 144 & 47.4 & 16 & 21 & 37 & 121 & (2) \\
\hline 2 & Pampa.......... & 1.394 & 1.084 & 777 & 558 & 8.748 & 45.2 & 486 & 311 & 747 & 8.8 & (5) \\
\hline 3 & Formosa.......... & 207 & 109 & 91 & 89 & 496 & 44,0 & 48 & 45 & 88 & 7.7 & (6). \\
\hline 4 & Misiones......... & 708 & 599 & 478 & 399 & 2.064 & 88.0 & 399 & 219 & 558 & 10.3 & (4) \\
\hline 5 & Neuquen......... & 446 & 299 & 194 & 228 & 1.167 & 87.8 & 215 & 176 & 391 & 12.4 & (1) \\
\hline 3 & Chaco ........... & 391 & 326 & B11 & 228 & 1.196 & 87.0 & 141 & 71 & 212 & 6.5 & (8) \\
\hline 7 & Rio Negro....... & 311 & บe2 & 221 & 184 & 1.088 & 81.9 & 182 & 172 & 354 & 10.8 & (v) \\
\hline 8 & Chubat.......... & 264 & 256 & 141 & 163 & 824 & 31.4 & 125 & 77 & 202 & 7.6 & (7) \\
\hline 9 & Santa Cruz ...... & 57 & 61 & 42 & 42 & 202 & 27.4 & 84 & 10 & 44. & 6.3 & (9) \\
\hline \multirow[t]{2}{*}{10} & Tierra del Fuego & 2 & 5 & 1 & 6 & 14 & 8.2 & 6 & 3 & 9 & 5.7 & \multirow[t]{2}{*}{ (10) } \\
\hline & Totales. & 75.616 & 79.767 & 68.458 & 55.998 & 274.864 & 36.7 & 97.817 & 28.818 & 61.190 & 8. 4 & \\
\hline
\end{tabular}

CONI, Emilio R. 1920. "Demografía nacional- Mortalidad infantil en la Argentina, durante el sexenio 1911-1916". Archivos Latinoamericanos de Pediatría, Tomo XIV, $\mathrm{N}^{\mathrm{o}} 6$. 


\section{CUADRO $\mathbf{N}^{\circ} 2$}

Estadística de niños asistidos por los establecimientos de la Asistencia Pública de Buenos Aires entre 1908 y 1917.

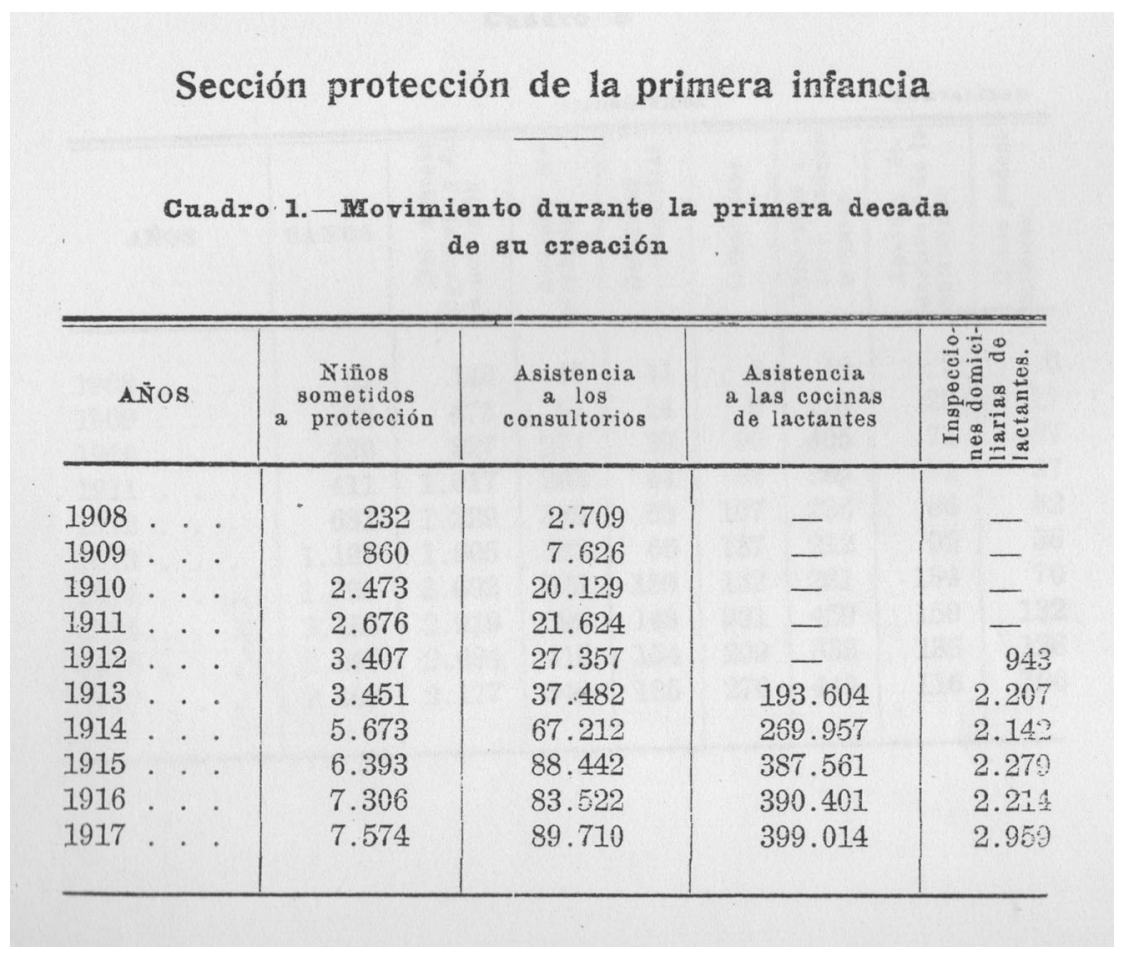

OLIVA, Silvestre. 1918. "Protección de la primera infancia. Memoria y estadística correspondiente al año 1917." Archivos Latinoamericanos de Pediatría, $2^{\mathrm{a}}$ Serie, Tomo XII, №2, 167. 


\section{FIGURA N $\mathbf{N}^{\mathbf{1}} 1$}

"Modo correcto de tomar al niño"

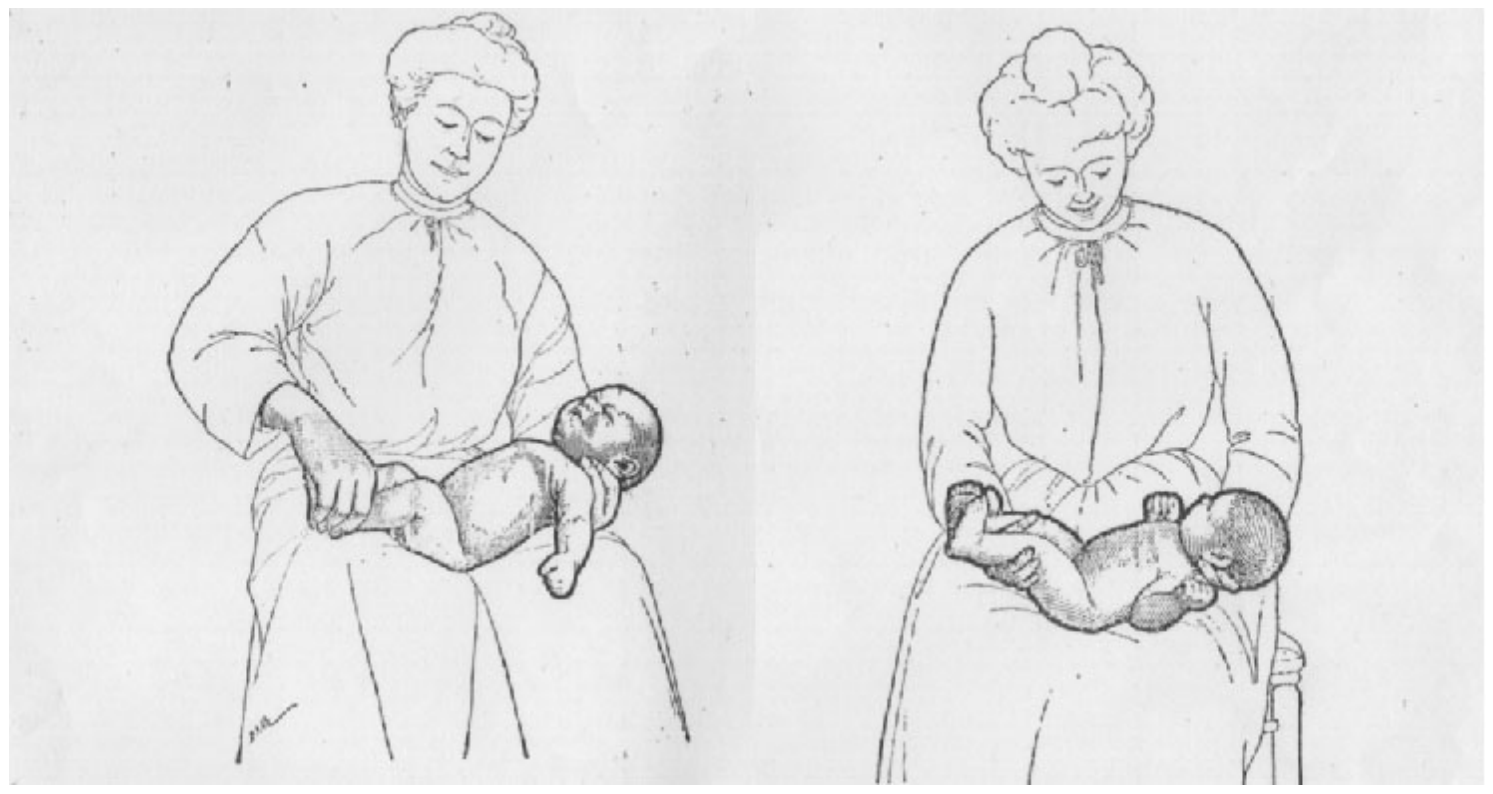

PINARD, A. 1924. La puericultura de la primera edad. Alimentación. Vestimenta. Higiene, pp. 10-11. 


\section{FIGURA No 2}

"Modo incorrecto de tomar al niño"

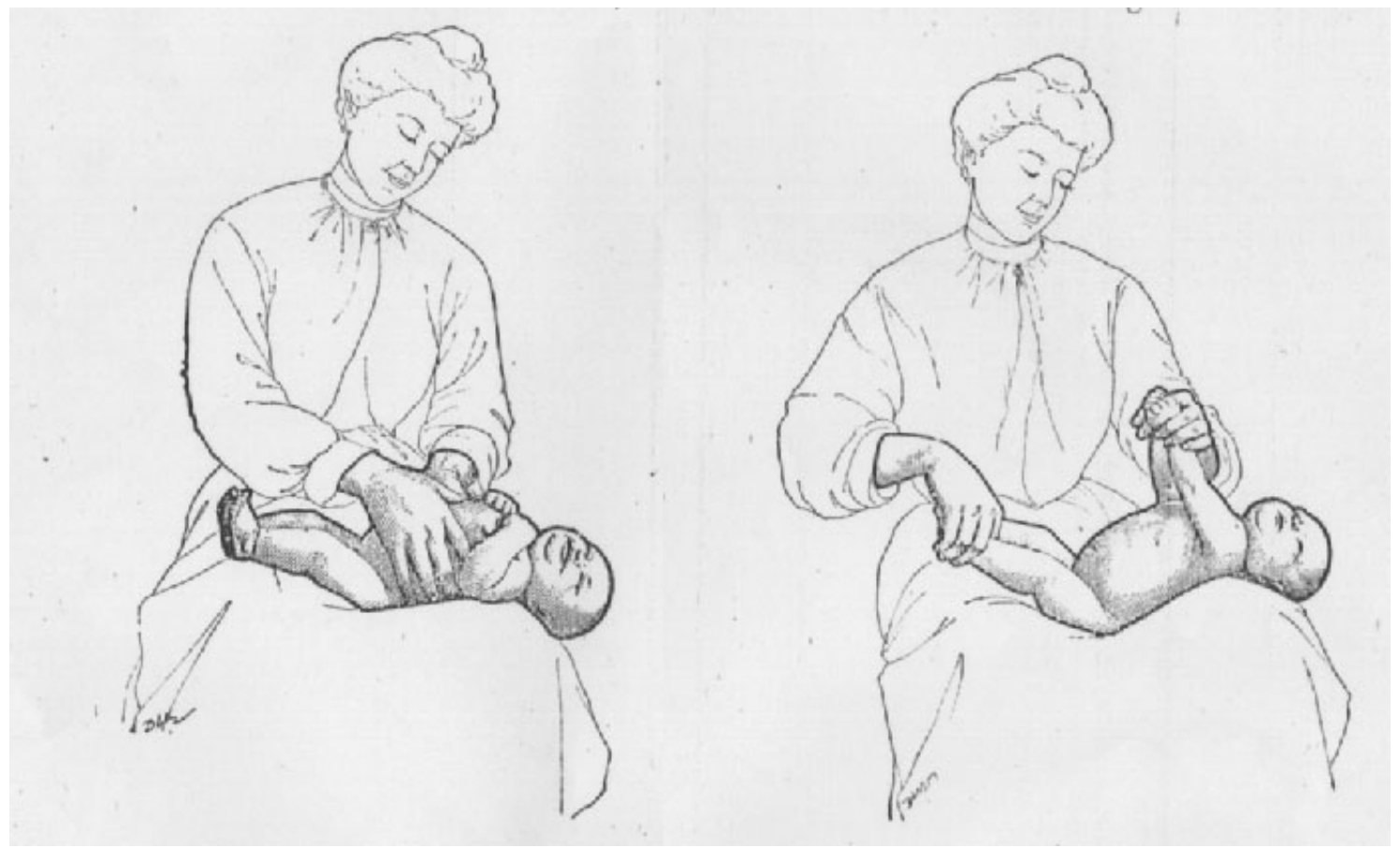

PINARD, A. 1924. La puericultura de la primera edad. Alimentación. Vestimenta. Higiene, pp. 12-12. 


\section{FIGURA N 3}

"Modo de vestir al niño"

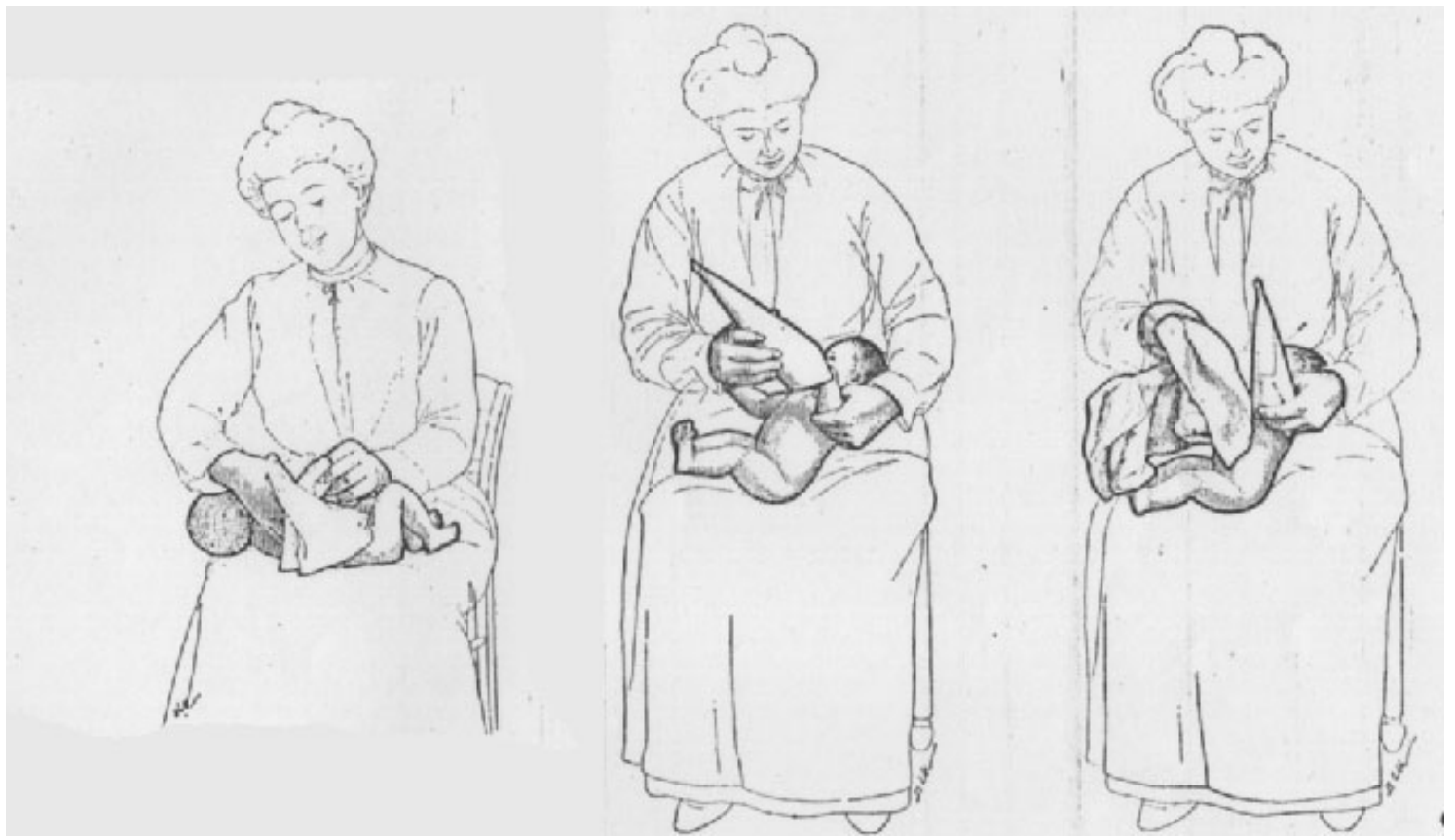

PINARD, A. 1924. La puericultura de la primera edad. Alimentación. Vestimenta. Higiene, pp. 30-31. 


\section{FIGURA N $\mathbf{N}^{\circ} 4$}

"Modo de vestir al niño" (continuación)
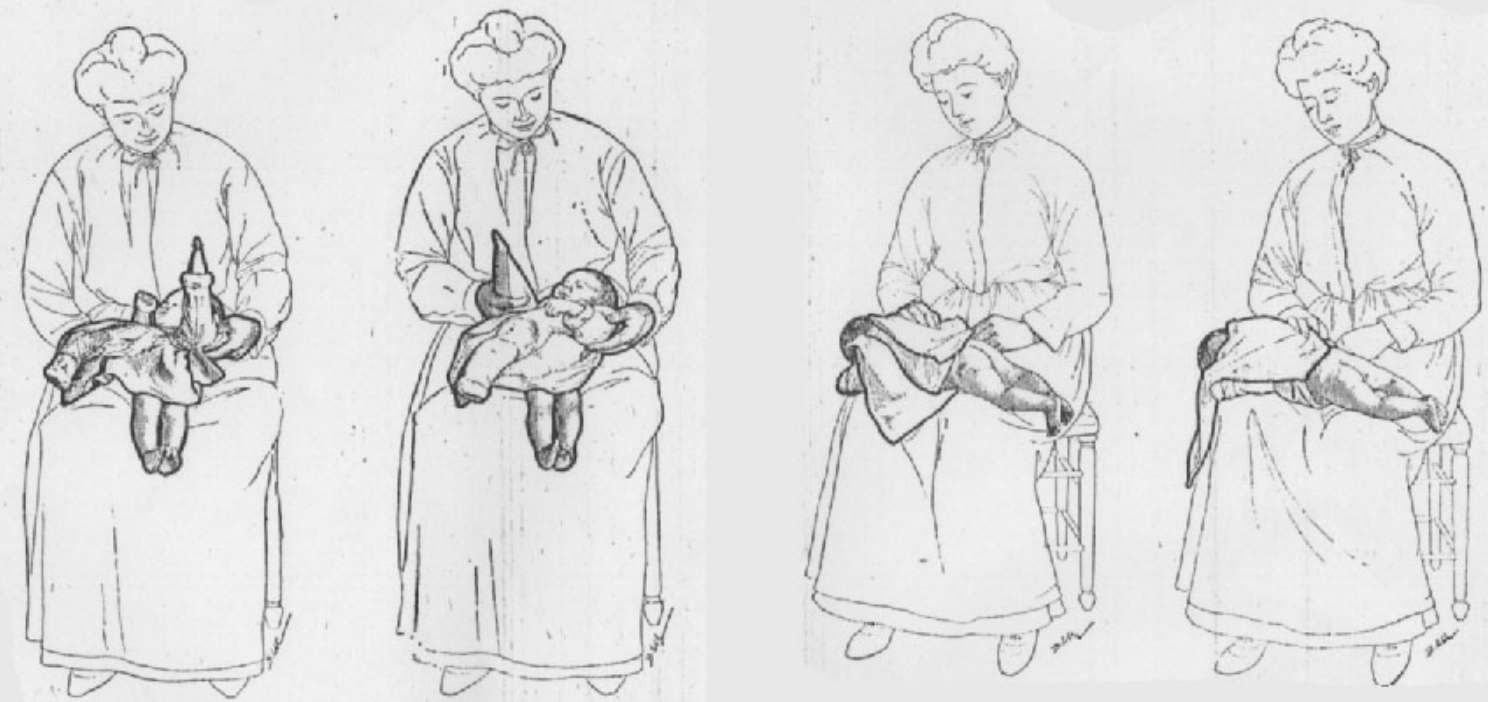

PINARD, A. 1924. La puericultura de la primera edad. Alimentación. Vestimenta. Higiene, pp. 32-33. 


\section{FIGURA N $\mathbf{N}^{0}$}

"Modo de vestir al niño" (continuación)
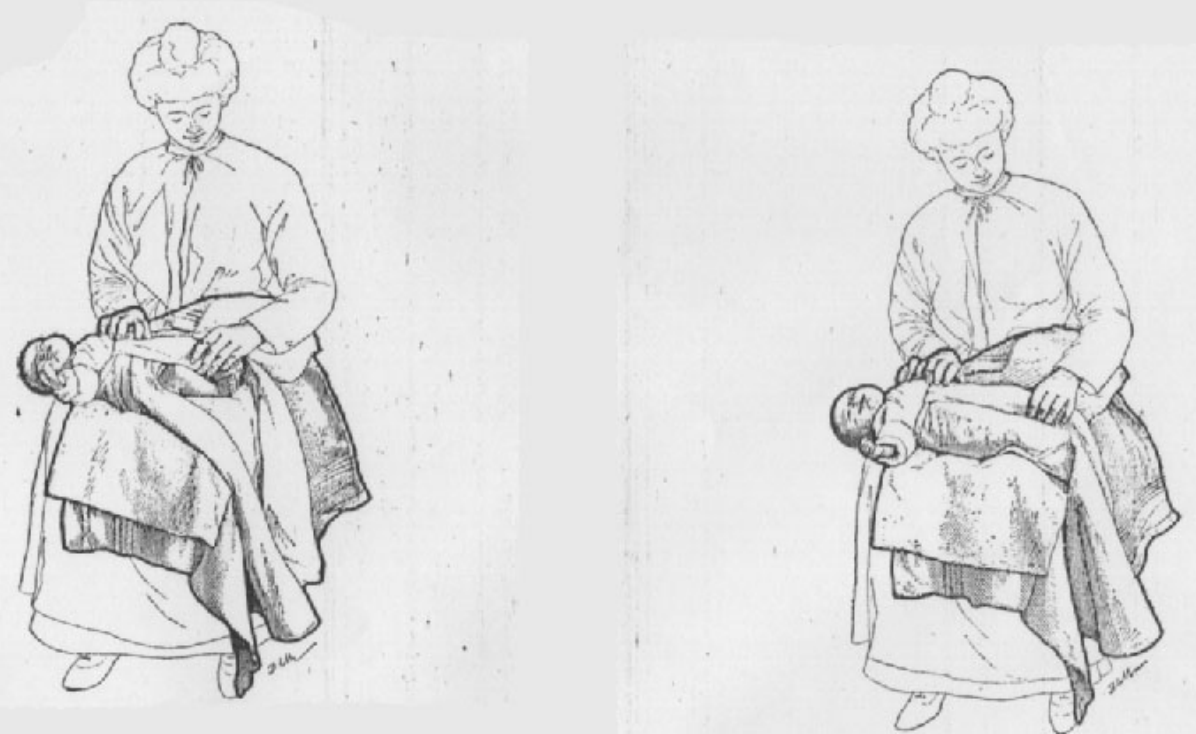

PINARD, A. 1924. La puericultura de la primera edad. Alimentación. Vestimenta. Higiene, pp. 36-37 


\section{FIGURA Nº}

"Modo de vestir al niño" (continuación)

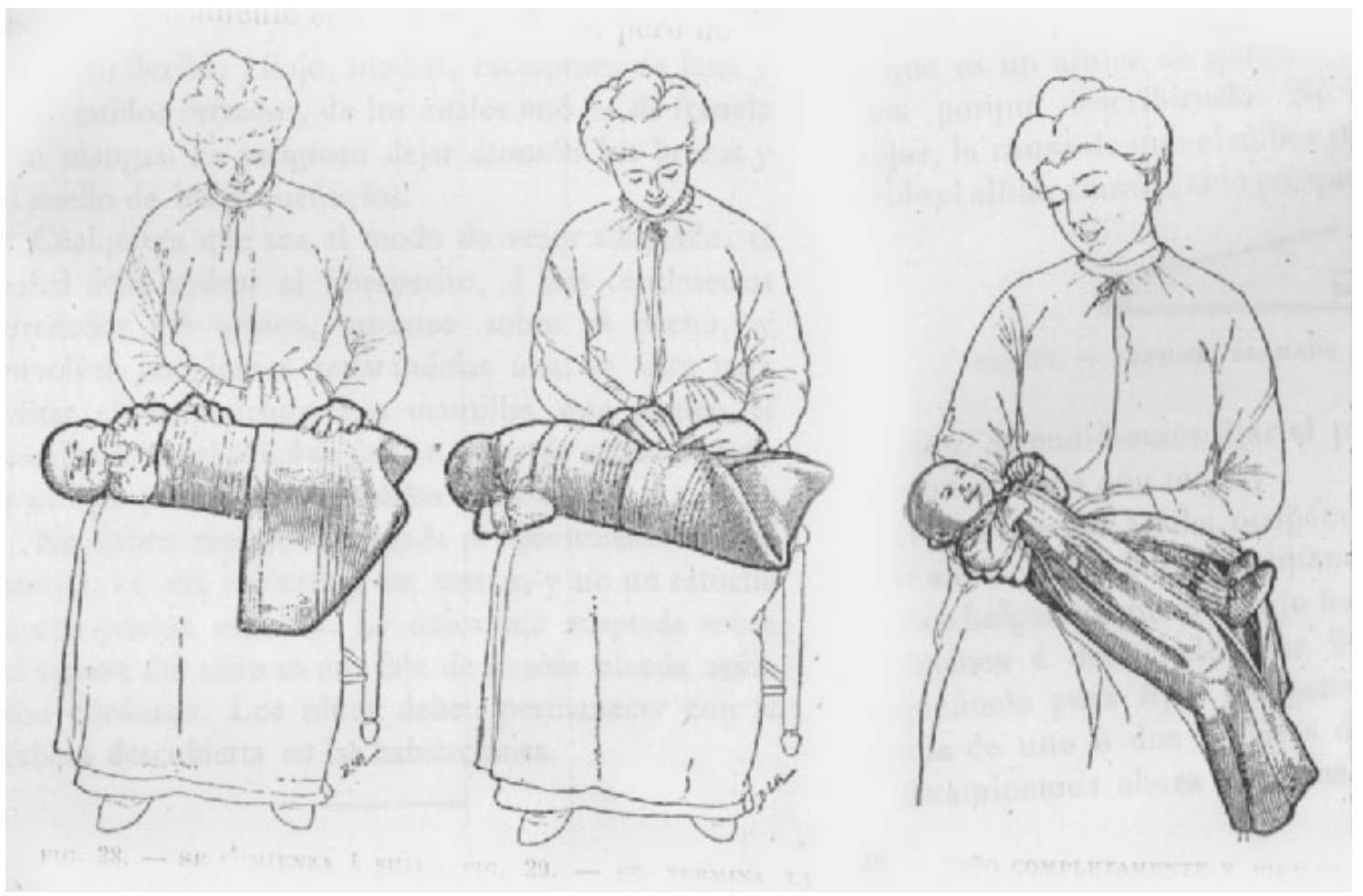

PINARD, A. 1924. La puericultura de la primera edad. Alimentación. Vestimenta. Higiene, pp. 39 y 46. 


\section{FIGURA N $\mathbf{N}^{\mathbf{0}}$}

"Método francés" (izquierda) y “método inglés” (derecha) para vestir al niño.
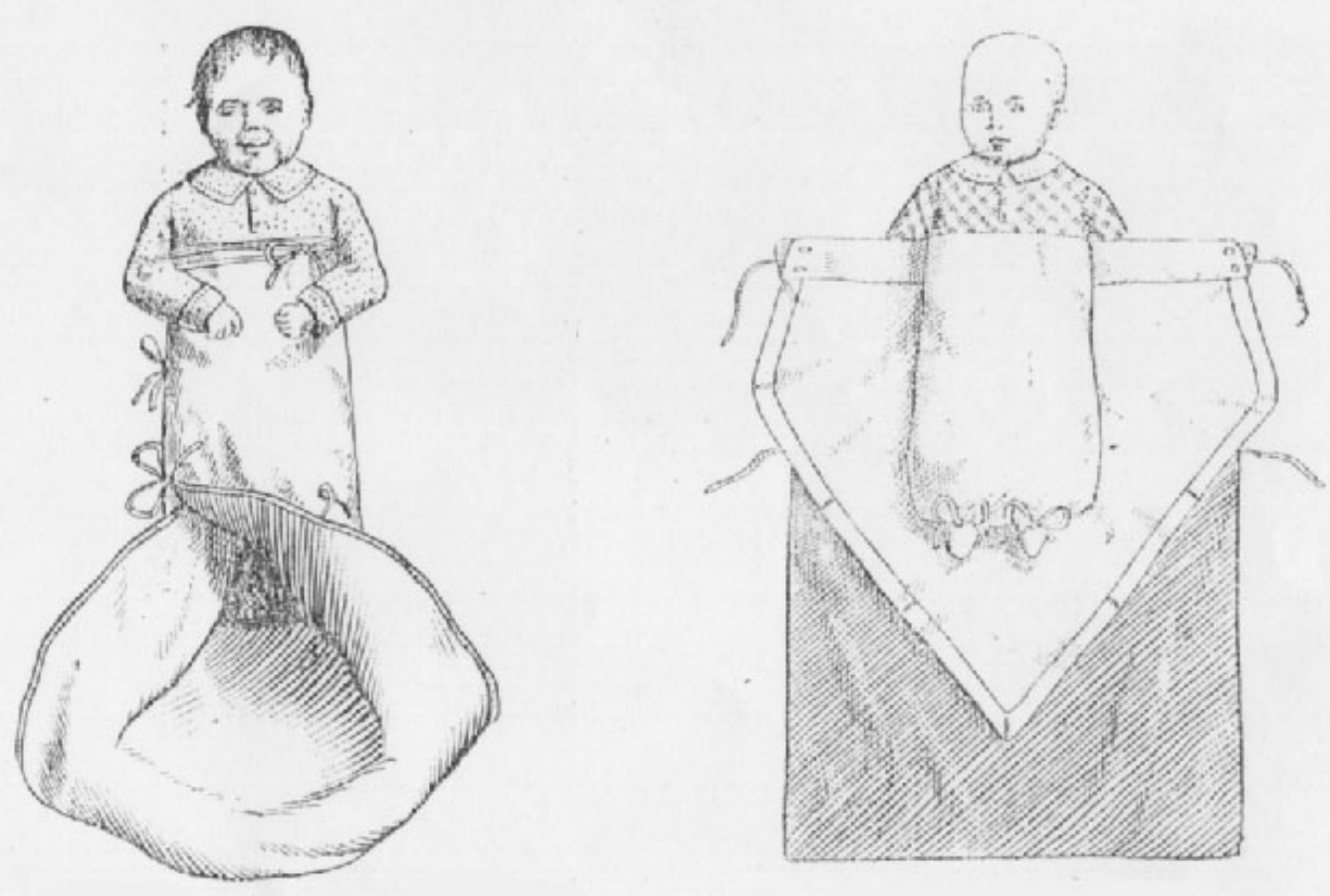

ARÁOZ ALFARO, Gregorio. 1929. El libro de las madres. Manual práctico de higiene del niño, con indicaciones sobre el embarazo, parto y tratamiento, pp.50-51. 